\title{
Sistema de visão artificial para identificação do estado nutricional de plantas
}

\author{
Alvaro Manuel Gómez Zúñiga
}





\title{
Sistema de visão artificial para identificação do estado nutiriconal de plantas
}

\author{
Alvaro Manuel Gómez Zúñiga \\ Orientador: Prof. Dr. Odemir Martinez Bruno \\ Dissertação apresentada ao Instituto de Ciências \\ Matemáticas e de Computação - ICMC-USP, como parte \\ dos requisitos para obtenção do título de Mestre em \\ Ciências - Ciências de Computação e Matemática \\ Computacional. VERSÃO REVISADA
}

USP - São Carlos

Maio de 2012 
Ficha catalográfica elaborada pela Biblioteca Prof. Achille Bassi e Seção Técnica de Informática, ICMC/USP, com os dados fornecidos pelo(a) autor(a)

Gómez Zúñiga, Alvaro Manuel

Sistema de visão artificial para identificação do estado nutricional de plantas / Alvaro Manuel Gómez zúñiga; orientador Odemir Martinez Bruno. -- São Carlos, 2012

$142 \mathrm{p}$.

Dissertação (Mestrado - Programa de Pós-Graduação en Ciências de Computação e Matemática Computacional) -Instituto de Ciências Matemáticas e de Computação, Universidade de São Paulo, 2012.

1. Visão computacional. 2. Processamento de imagens. 3. Deficiências nutricionais. 4. Dimensão fractal. I. Martinez Bruno, Odemir, orient. II. Título. 


\section{Agradecimentos}

A Deus, pela oportunidade e pela força permitindo a realização de um sonho.

Aos meus pais que, mesmo a distância, me incentivaram a correr atrás dos meus ideais.

Ao meu orientador prof. Odemir Martinez Bruno, pela orientação, ajuda e amizade, indispensáveis na elaboração deste trabalho.

Aos amigos de pós-graduação pelos momentos de alegria vividos.

Aos professores e funcionários do ICMC - USP e a todos que, direta ou indiretamente, colaboraram comigo.

À FAPESP pelo apoio financeiro. 



\section{Resumo}

A avaliação do estado nutricional das plantas de milho usualmente é feita através de análises químicas ou pela diagnose visual das folhas da planta, esta última, sujeita a erros de interpretação já que a ausência de algum nutriente na planta gera um padrão de mudança específico na superfície da folha que depende do nível de ausência do nutriente. As dificuldades que apresentam neste processo e sua importância na agricultura, criam a necessidade de pesquisar sistemas automáticos para a avaliação do estado nutricional de plantas. Desta forma, este mestrado teve como objetivo principal o desenvolvimento de um sistema de visão artificial para verificar a possibilidade de identificação de níveis dos macronutrientes Cálcio, Enxofre, Magnésio, Nitrogênio e Potássio em plantas de milho através da análise da superfície das folhas usando métodos de visão computacional. Este projeto realiza uma revisão bibliográfica do estado da arte dos métodos de extração de características de cor, textura em escala de cinza e textura colorida utilizadas em processamento de imagens. A alta similaridade entre os sintomas produzidos pelas deficiências e a pouca similaridade entre amostras de uma mesma deficiência motivou o desenvolvimento de novos métodos de extração de características que pudessem fornecer dados necessários para uma correta separação entre as classes. Os resultados obtidos demonstraram que o sistema desenvolvido possibilita a predição de deficiências nutricionais em estágios iniciais do crescimento da planta usando unicamente a textura da superfície da folha como fonte de informação.

Palavras-chave: Visão Computacional; Extração de características; Reconhecimento de textura; Deficiências nutricionais; Dimensão fractal; 



\section{Abstract}

The evaluation of the nutritional status of corn plants is usually done through chemical analysis or by visual diagnosis of the plant leaves. Visual diagnosis is subject to misinterpretation as the lack of some nutrient in the plant generates a specific pattern of change in the leaf surface that depends on the degree on which the nutrient is absent on the plant. The difficulties present in this process and its importance in agriculture creates the necessity to search automated systems for the assessment of nutritional status of plants. Thus, this dissertation had as main objective the development of an artificial vision system to verify the possibility of identifying levels of macronutrients calcium, sulfur, magnesium, potassium and nitrogen in corn plants by analyzing the surface of the leaves using computer vision methods. This project performs a review of the literature of the state of the art methods for feature extraction of color, grayscale and colored texture used in image processing. The high similarity between the symptoms caused by deficiencies and low similarity between samples of the same deficiency motivated the development of new methods for extracting features that could provide the data needed for a correct separation between classes. The results showed that the system enables the prediction of nutritional deficiencies in an initial stage of plant growth using only texture of the leaf surface as a source of information.

Keywords : Computer vision; Feature extraction; Texture recognition; $\mathrm{Nu}$ tritional deficiencies; Fractal dimension 



\section{Sumário}

Resumo ............................... ii

Abstract ...................... . .

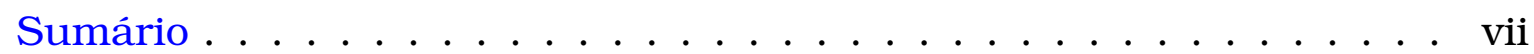

Lista de Figuras . . . . . . . . . . . . . . . . . . . xi

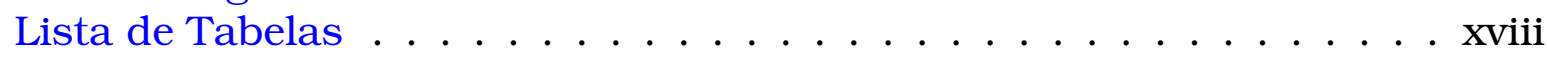

1 Introdução 1

1.1 Justificativa e Motivação . . . . . . . . . . . . . . . . 1

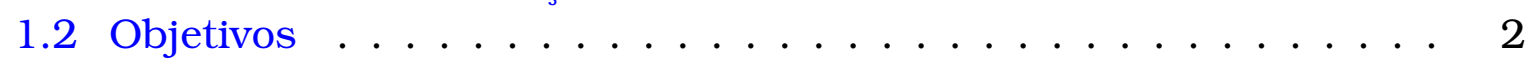

1.3 Organização do Texto . . . . . . . . . . . . . . . 3

2 O milho e a avaliação nutricional 5

2.1 Importância do milho e sua nutrição . . . . . . . . . . . . 5

2.2 Avaliação do estado nutricional . . . . . . . . . . . . 6

2.3 Nutrientes essenciais . . . . . . . . . . . . . . 7

2.4 Sintomas de deficiência identificáveis em plantas de milho . . . 8

2.4.1 Nitrogênio . . . . . . . . . . . . . . 8

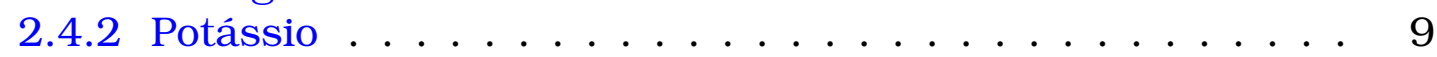

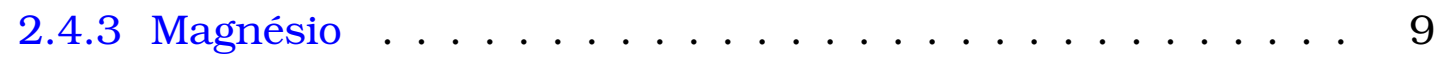

2.4 .4 Cálcio ..................... 11

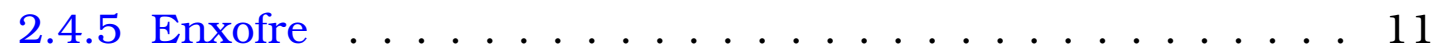

3 Métodos de visão artificial 13

3.1 Introdução ao Análise de imagens . . . . . . . . . . . . . . 13

3.2 Sistemas de visão artificial . . . . . . . . . . . . . . . . 14

3.3 Projeto TreeVis . . . . . . . . . . . . . . . . . . . 16

3.4 Segmentação de imagens . . . . . . . . . . . . . . . 17

3.4.1 Método de Otsu . . . . . . . . . . . . . 18

3.4 .2 Fuzzy C-Means ...................... 18

3.4.3 Avaliação da segmentação . . . . . . . . . . . . . . 19

3.5 Extração de características em imagens . . . . . . . . . . . 20 
3.5 .1 Cor ................... 20

3.5.1.1 Histogramas coloridos . . . . . . . . . . 21

3.5.1.2 Border/Interior classification . . . . . . . . . . 22

3.5.1.3 Momentos invariantes de cor . . . . . . . . . . . 23

3.5.1.4 Momentos de cromaticidade . . . . . . . . . . . 24

3.5 .2 Textura . . . . . . . . . . . . . . . . 26

3.5.3 Matriz de co-ocorrência . . . . . . . . . . . . . . 28

3.5.4 Wavelets de Gabor . . . . . . . . . . . . . . . . 30

3.5.5 Wavelets de Gabor e outros extratores . . . . . . . . . 31

3.5 .6 Fractais . . . . . . . . . . . . . . . . 33

3.5.6.1 Método Boulingand-Minkowsky . . . . . . . . . 33

3.5.6.2 Dimensão Fractal Multiescala . . . . . . . . . . . 34

3.5.6.3 Dimensão Fractal Volumetrica . . . . . . . . . . . 36

3.5.7 Wavelets de Gabor e Fractais . . . . . . . . . . . . . . 38

3.5.8 Padrões locais binários . . . . . . . . . . . . . . 40

3.5.9 Textura Colorida . . . . . . . . . . . . . . . . . 41

3.5.9.1 Dimensão Fractal Volumétrica Multiespectral . . . 41

3.5.9.2 Wavelets de Gabor multiespectrais e fractais . . . . 42

4 Sistema de visão para identificação do estado nutricional $\quad 47$

4.1 Aquisição das amostras . . . . . . . . . . . . . . . . . 47

4.2 Pré-processamento . . . . . . . . . . . . . . 50 50

4.2.1 Segmentação e divisão das folhas . . . . . . . . . . . 50 50

4.2 .2 extração de janelas texturais . . . . . . . . . . . . 52

4.2 .3 Reorientação das janelas texturais . . . . . . . . . 53

4.2.4 Descarte e seleção de janelas . . . . . . . . . . . . . . . 54

4.3 Extração de características . . . . . . . . . . . . . . . 56

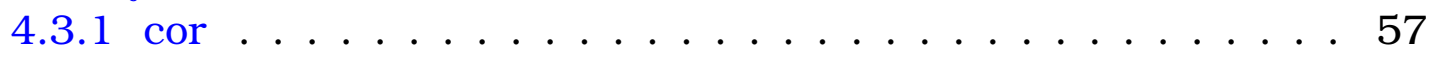

4.3.1.1 Histogramas coloridos . . . . . . . . . . . . 57

4.3.1.2 Border Interior classification . . . . . . . . . . . 59

4.3.1.3 Momentos invariantes de cor . . . . . . . . . . 59

4.3.1.4 Momentos de cromaticidade . . . . . . . . . 60

4.3 .2 textura . . . . . . . . . . . . . . . . 6 61

4.3.2.1 Matrizes de co-ocorrência . . . . . . . . . . 61

4.3.2.2 Wavelets de Gabor . . . . . . . . . . . . . . 62

4.3.2.3 Gabor wavelets e outros extratores . . . . . . . 63

4.3.2.4 Dimensão Fractal Volumetrica . . . . . . . . . . . 65

4.3.2.5 Wavelets de Gabor e Fractais . . . . . . . . . . 65

4.3.2.6 Padrões locais binarios . . . . . . . . . . . . 66

4.3.2.7 Padrões locais binários invariantes . . . . . . . . 66

4.3 .3 textura colorida . . . . . . . . . . . . . . . 68

4.3.3.1 Dimensão Fractal Volumétrica Multiespectral . . . 68 
4.3.3.2 Gabor wavelets multiespectral e fractais . . . . . 68

5 Metodologia Biológica $\quad 71$

5.1 Local do experimento . . . . . . . . . . . . . . 71

5.2 Caracterização do híbrido de milho usado . . . . . . . . . . . 71

5.3 Instalação do experimento . . . . . . . . . . . . . . . . 72

5.4 Validação de amostras biológicas . . . . . . . . . . . . . 75

5.5 Experimentos Biológicos realizados . . . . . . . . . . . . 75

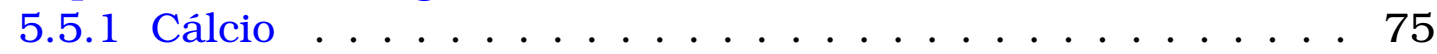

5.5 .2 Magnésio . . . . . . . . . . . . . . 76

5.5 .3 Enxofre . . . . . . . . . . . . . . . 77

5.5 .4 Nitrogênio . . . . . . . . . . . . . . . . . 77

5.5 .5 Potássio . . . . . . . . . . . . . . . 77

6 Classificação $\quad 81$

6.0.6 Estratégia de classificação adotada . . . . . . . . . . . 8 81

6.0.7 Métodos de classificação . . . . . . . . . . . . . . . . 84

6.0.7.1 K-vizinhos mas próximos . . . . . . . . . . 85

6.0 .7 .2 Naive Bayes . . . . . . . . . . . . . . . 85

6.0.7.3 Máquinas de suporte de vetores . . . . . . . . . 86

6.0.7.4 Detalhes do uso dos classificadores nos experimentos . . . . . . . . . . . . 87

7 Experimentos e Resultados $\quad 89$

7.1 Base de Imagens . . . . . . . . . . . . . . . . . . . . . . . . . 89

7.2 Avaliação dos métodos de extração de características . . . . . . . 91

7.2.1 Síntese dos resultados . . . . . . . . . . . . . . 128

8 Conclusões 131

8.0.2 Principais contribuições . . . . . . . . . . . . . 133

8.0 .3 Trabalhos Futuros . . . . . . . . . . . . . . . . 134

$\begin{array}{lr}\text { Referências Bibliográficas } & 142\end{array}$ 



\section{Lista de Figuras}

2.1 Folha de milho com deficiência de nitrogênio . . . . . . . . . . 9

2.2 Folha de milho com deficiência de fósforo . . . . . . . . . . . 10

2.3 Folha de milho com deficiência de Magnésio . . . . . . . . . . 10

2.4 Folha de milho com deficiência de Cálcio . . . . . . . . . . . . . 11

2.5 Folha de milho com deficiência de Enxofre . . . . . . . . . . . . 12

3.1 Ambiente de trabalho do TreeVis mostrando alguns modulos em execução . . . . . . . . . . . . . . . . . 17

3.2 Redução de cor numa imagem RGB, (a) imagem original, (b) imagem quantizada em 256 cores, (c) imagem quantizada em 128 cores . . . . . . . . . . . . . . . . . . 22

3.3 Processamento pelo método BIC (a) imagem original, (b) imagem classificada onde os pixels com os cores originais são os pixels da borda e os pixels brancos são o interior (adaptado de (Stehling et al., 2002)) . . . . . . . . . . . . . . . . 23

3.4 Exemplo de cromaticidades $(\mathrm{x}, \mathrm{y})$ onde (a) é o traço bi-dimensional (T) e (b) a distribuição bi-dimensional (D) (Paschos, 2000) . . . . 26

3.5 Imagens de distintas texturas extraídas do álbum brodatz. . . . . 27

3.6 Processo de extração de características (adaptado de (Zuniga e Bruno, 2010). . . . . . . . . . . . . . . . . . 32

3.7 Dilatação de uma curva com um disco. (Backes, 2006) . . . . . . 33

3.8 a imagem (a) é a curva log-log, a imagem (b) a curva derivada . . 34

3.9 Os pontos em vermelho não são considerados para o método . . . 36

3.10 esquema de reflexão da sinal para evitar o fenômeno de Gibbs, o cor preto e a sinal original . . . . . . . . . . . . . 36

3.11 Assinaturas de 3 letras A,P,R com diferentes níveis de ruido . . . 37

3.12 Geração da superfície, (a) é a imagem original, (b)a superfície $S$. 37

3.13 Cálculo de assinaturas fractais no processo de Gabor. . . . . . . . 39

3.14 Cálculo das assinaturas no processo de Gabor e fractais, de cada assinatura é extraido $N$ descritores Fourier. . . . . . . . . . . . 39 
3.15Processo de extração de características do operador LBP, o novo valor e montado desde o vizinho esquerdo central. . . . . . . . . . 41

3.16 diferença entre as superfícies geradas (Backes e Bruno, 2008) . . 42

3.17 Processo de extração de características do Gabor usando infor mação de cor. . . . . . . . . . . . . . . . . . 43

4.1 Esquema de digitalização das amostras . . . . . . . . . . . . . 48

4.2 Processo de segmentação da imagem, (a) Imagem Original, (b) Imagem obtida da mistura das mascaras geradas pelo método de otsu e FCM (c) mascara de segmentação final, (d) uma das folhas segmentadas ..................... 51

4.3 Divisão das folhas em 3 partes iguais . . . . . . . . . . . . . 52

4.4 Extração de janelas texturais . . . . . . . . . . . . . 53

4.5 Transformada de Radon (a) imagem original, (b) acumulador da transformada mostrando que a orientação mais provável é 79 . 54

4.6 Extração de caracteristicas do histograma colorido . . . . . . . . 58

4.7 Extração de características usando BIC . . . . . . . . . . . . 59

4.8 Extração de características usando Momentos invariantes de cor 60

4.9 Extração de características usando Momentos de cromaticidade . 61

4.10 Extração de características usando Matrizes de co-ocorrência 62

4.11 Extração de características usando wavelets de Gabor . . . . . . . 63

4.12 Extração de características usando Matrizes de co-ocorrência 65

4.13 Geração do mapa LBP de uma imagem . . . . . . . . . . . . . . . 66

5.1 Casa de vegetação usada para os experimentos biológicos. . . . . 72

5.2 Instalação do experimento nos vasos. (a) e (b) processo de fixação da planta na espuma, (c) planta logo após o transplantio, (d) conjunto de vasos usados . . . . . . . . . . . . 73

5.3 Sistema de injeção de ar. (a) compressor de ar usado, (b) sistema de transporte do ar, (c) introdução do ar nos vasos, (d) borbulhas do ar na solução nutritiva . . . . . . . . . . . . . . . . 74

5.4 Montagem do experimento de Nitrogênio . . . . . . . . . . . . 78

5.5 Vista dos vasos individuais e o sistema radicular das plantas . . . 79

5.6 Montagem de baterias de experimentos, na frente plantas num estádio inicial de crescimento, no fundo plantas no estado V8 . . 80

6.1 Estratégia de classificação . . . . . . . . . . . . . . 82

7.1 Bases de Imagens usadas nos experimentos . . . . . . . . . . . 92

7.2 Folhas usadas na geração da base de imagens . . . . . . . . . . 93

7.3 Folhas usadas na geração da base de imagens . . . . . . . . . . . 94

7.4 Cinco exemplos de janelas texturais da classe Coleta 1 Bases2 T1 do Cálcio . . . . . . . . . . . . . . . . . 95 
7.5 Cinco exemplos de janelas texturais da classe Coletal Bases2 T1 do enxofre . . . . . . . . . . . . . . . . 95

7.6 Cinco exemplos de janelas texturais da classe Coleta 1 Bases2 T1 do magnésio . . . . . . . . . . . . . . . . . 95

7.7 Cinco exemplos de janelas texturais da classe Coleta1 Bases2 T1 do nitrogênio . . . . . . . . . . . . . . . . . 95

7.8 Cinco exemplos de janelas texturais da classe Coleta1 Bases2 T1

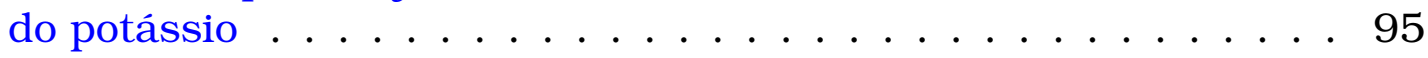

7.9 Cinco exemplos de janelas texturais da classe Coleta1 Bases2 T4 95

7.10Acerto de Histograma Colorido para cada número de cores na coleta 1........................ 97

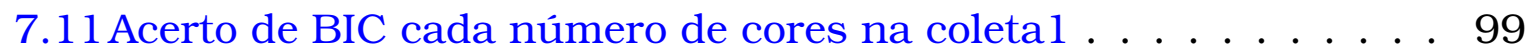

7.12 Acerto de BIC cada número de cores na coleta 1 . . . . . . . . . . 102

7.13Acerto de Matrizes de Coocorrência para cada número de cores na coleta $1 . \ldots \ldots 107$

7.14 Acerto de wavelets de Gabor para cada combinação de escalas x orientações . . . . . . . . . . . . . . . 109

7.15Acerto de dimensão fractal volumétrica para cada raio de expansão 112 7.16Acerto de wavelets de Gabor e fractais para distinto número de raios de expansão . . . . . . . . . . . . . . . . . . . . . 114

7.17 Acerto de Padrões locais binarios invariantes para cada número experimento . . . . . . . . . . . . . . 117

7.18Acerto de wavelets de Gabor para cada combinação de escalas $x$ orientações . . . . . . . . . . . . . . . . . . 124

7.19Acerto de wavelets de Gabor multiespectrais e fractais para distinto número de variáveis canônicas . . . . . . . . . . . . . . . . . 126 



\section{Lista de Tabelas}

7.1 Sumário da classificação usando o método de histogramas coloridos para a Coleta 1 usando KNN para classificar os dados, O melhor resultado foi obtido com 128 cores. . . . . . . . . . . . . 96

7.2 Sumário da classificação usando o método de histogramas coloridos para a Coleta 2 usando $\mathrm{KNN}$ para classificar os dados, O melhor resultado foi obtido com 128 cores. . . . . . . . . . . . . . 96

7.3 Sumário da classificação usando o método de histogramas coloridos para a Coleta 3 usando KNN para classificar os dados, O melhor resultado foi obtido com 128 cores. . . . . . . . . . . . 96

7.4 Sumário da classificação usando o método BIC para a Coleta 1 usando KNN para classificar os dados, O melhor resultado foi obtido com 8 cores. . . . . . . . . . . . . . . . . 98

7.5 Sumário da classificação usando o método BIC para a Coleta 2 usando KNN para classificar os dados, O melhor resultado foi obtido com 8 cores. . . . . . . . . . . . . . . . . . 98

7.6 Sumário da classificação usando o método BIC para a Coleta 3 usando KNN para classificar os dados, O melhor resultado foi obtido com 8 cores. . . . . . . . . . . . . . . . 98

7.7 Sumário da classificação usando o método momentos invariantes para a Coleta 1 usando SVM para classificar os dados. . . . . . . 100

7.8 Sumário da classificação usando o método momentos invariantes para a Coleta 2 usando KNN para classificar os dados. . . . . . . 100

7.9 Sumário da classificação usando o método momentos invariantes para a Coleta 3 usando KNN para classificar os dados. . . . . . . 100

7.10Sumário da classificação usando o método momentos cromaticidade para a Coleta 1 usando KNN para classificar os dados. . . . 101

7.11 Sumário da classificação usando o método momentos cromaticidade para a Coleta 2 usando KNN para classificar os dados. . . . 101

7.12 Sumário da classificação usando o método momentos cromaticidade para a Coleta 3 usando KNN para classificar os dados. . . . 101 
7.13 Matriz de confusão para a coleta 1 com o método momentos invariantes. . . . . . . . . . . . . . . . . . . . . . 103

7.14 Matriz de confusão para a coleta 2 com o método histograma colorido. . . . . . . . . . . . . . . . . . . . 103

7.15Matriz de confusão para a coleta 3 com o método histograma colorido. . . . . . . . . . . . . . . . . . . . . . . . . 104

7.16 Sumário da classificação usando o método matrizes de coocorrência para a Coleta 1 usando SVM para classificar os dados. . . 105

7.17 Sumário da classificação usando o método matrizes de coocorrência para a Coleta 2 usando SVM para classificar os dados. . . 105

7.18Sumário da classificação usando o método matrizes de coocorrência para a Coleta 3 usando SVM para classificar os dados. . . 106

7.19Sumário da classificação usando o método wavelets de Gabor para a Coleta 1 usando SVM para classificar os dados. . . . . . . 107

7.20 Sumário da classificação usando o método wavelets de Gabor para a Coleta 2 usando SVM para classificar os dados. . . . . . . 108

7.21 Sumário da classificação usando o método wavelets de Gabor para a Coleta 3 usando SVM para classificar os dados. . . . . . . 108

7.22 Sumário da classificação usando o método wavelets de Gabor e LBP para a Coleta 1 usando SVM para classificar os dados. . . . . 109

7.23 Sumário da classificação usando o método wavelets de Gabor e LBP para a Coleta 2 usando SVM para classificar os dados. . . . . 110

7.24 Sumário da classificação usando o método wavelets de Gabor e LBP para a Coleta 3 usando SVM para classificar os dados. . . . . 110

7.25Sumário da classificação usando o método dimensão fractal volumétrica para a Coleta 1 usando SVM para classificar os dados.

7.26 Sumário da classificação usando o método dimensão fractal volumétrica para a Coleta 2 usando SVM para classificar os dados.

7.27 Sumário da classificação usando o método dimensão fractal volumétrica para a Coleta 3 usando SVM para classificar os dados.

7.28 Sumário da classificação usando o método wavelets de Gabor e fractais para a Coleta 1 usando SVM para classificar os dados. . 113

7.29Sumário da classificação usando o método wavelets de Gabor e fractais para a Coleta 2 usando SVM para classificar os dados. . 113

7.30Sumário da classificação usando o método wavelets de Gabor e fractais para a Coleta 1 usando SVM para classificar os dados. . 113

7.31 Sumário da classificação usando o método padrões locais binarios para a Coleta 1 usando SVM para classificar os dados. . . . . 115

7.32 Sumário da classificação usando o método padrões locais binarios para a Coleta 2 usando SVM para classificar os dados. . . . . 115

7.33 Sumário da classificação usando o método padrões locais binarios para a Coleta 3 usando SVM para classificar os dados. . . . . 115 
7.34 Sumário da classificação usando o método padrões locais binários invariantes para a Coleta 1 usando SVM para classificar os

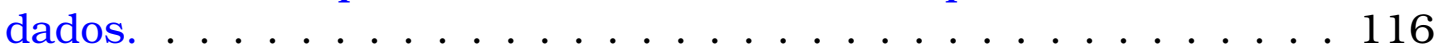

7.35Sumário da classificação usando o método padrões locais binários invariantes para a Coleta 1 usando SVM para classificar os dados.

7.36 Sumário da classificação usando o método padrões locais binários invariantes para a Coleta 1 usando SVM para classificar os dados. ..................... 116

7.37 Matriz de confusão para a coleta 1 com o método wavelets de Gabor e fractais

7.38 Matriz de confusão para a coleta 2 com o método wavelets de Gabor e fractais . . . . . . . . . . . . . . . . 118

7.39 Matriz de confusão para a coleta 3 com o método Dimensão fractal volumétrica . . . . . . . . . . . . . . . . . . . 118

7.40 Sumário da classificação usando o método Dimensão fractal volumétrica multiespectral para a Coleta 1 usando SVM para classificar os dados.

7.41 Sumário da classificação usando o método Dimensão fractal volumétrica multiespectral para a Coleta 2 usando SVM para classificar os dados.

7.42 Sumário da classificação usando o método Dimensão fractal volumétrica multiespectral para a Coleta 3 usando SVM para classificar os dados.

7.43 Sumário da classificação usando o método Dimensão fractal volumétrica multiespectral usando análise canônica para a Coleta 1 usando SVM para classificar os dados. . . . . . . . . . .

7.44 Sumário da classificação usando o método Dimensão fractal volumétrica multiespectral usando análise canônica para a Coleta 2 usando SVM para classificar os dados. . . . . . . . . . . . . .

7.45Sumário da classificação usando o método Dimensão fractal volumétrica multiespectral usando análise canônica para a Coleta 3 usando SVM para classificar os dados. . . . . . . . . . .

7.46Sumário da classificação usando o wavelets de Gabor multiespectral para a Coleta 1 usando SVM para classificar os dados. . . 122

7.47 Sumário da classificação usando o wavelets de Gabor multiespectral para a Coleta 2 usando SVM para classificar os dados. . . 123

7.48Sumário da classificação usando o wavelets de Gabor multiespectral para a Coleta 3 usando SVM para classificar os dados. . . 123

7.49Sumário da classificação usando o método wavelets de Gabor multiespectral e fractais para a Coleta 1 usando SVM para classificar os dados. 
7.50Sumário da classificação usando o método wavelets de Gabor multiespectral e fractais para a Coleta 2 usando SVM para classificar os dados. . . . . . . . . . . . . . . . . . . 125

7.51 Sumário da classificação usando o método wavelets de Gabor multiespectral e fractais para a Coleta 3 usando SVM para classificar os dados. . . . . . . . . . . . . . . . . . . 125

7.52 Matriz de confusão para a coleta 1 com o método wavelets de Gabor multiespectrais e fractais . . . . . . . . . . . . . . . 125

7.53 Matriz de confusão para a coleta 2 com o método wavelets de Gabor multiespectrais e fractais . . . . . . . . . . . . . . 126

7.54 Matriz de confusão para a coleta 3 com o método wavelets de Gabor multiespectrais e fractais . . . . . . . . . . . . . . 127 


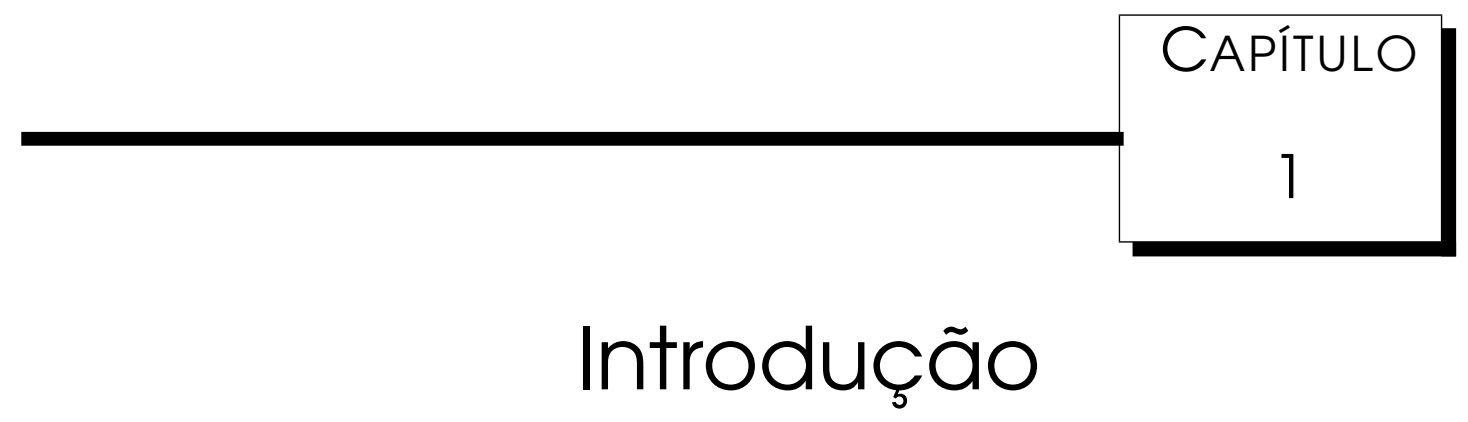

\subsection{Justificativa e Motivação}

As plantas são organismos autotróficos que retiram do solo água e sais minerais para se desenvolver normalmente. Os sais minerais contém nutrientes essenciais para o desenvolvimento da planta, a ausência destes promove alterações no seu metabolismo gerando sintomas visíveis de deficiência sendo a maioria destes apresentados na superfície das folhas (clorose, necrose, etc.), cada nutriente gera um ou mais sintomas característicos dependendo da severidade da deficiência (Malavolta, 2006). Porém, é essencial conhecer o nível nutricional das plantas numa área cultivada, pois a ausência destes pode comprometer a produtividade da cultura. Neste contexto, o milho (Zea mays L.) destaca-se como a segunda principal cultura fornecedora de insumos para o agronegócio e a alimentação humana sendo utilizado no preparo de mais de 500 derivados no Brasil (Nogueira-Júnior et al., 1987).

A avaliação do estado nutricional das plantas de milho é feita através de análises químicas ou pelo diagnóstico visual. A análise química é feita num estágio de desenvolvimento avançado da planta que torna impossível realizar adubação corretiva antes que a produção da safra esteja comprometida. Por outro lado, a análise visual é feita por uma pessoa com conhecimento na 
área sendo sujeita a erros de interpretação e impossibilitando uma avaliação adequada quando existem deficiências simultâneas na planta. Desta forma, a necessidade de melhora na eficiência dos métodos de análise tem levado a busca de novas tecnologias que possam ser usadas como ferramentas de precisão para obter dados quantitativos dos niveis de deficiência num estágio de crescimento inicial. Assim, a visão computacional torna-se uma alternativa ideal para o desenvolvimento de métodos específicos de reconhecimento e extração de informações de forma automatizada que contribuam a uma tecnificação agrícola aumentando a produtividade da produção e reduzindo os custos da adubação excessiva.

Em contrapartida, os distintos atributos visuais que apresentam cada uma das deficiências nutricionais associado com a mudança destes padrões pelo grau de deficiência apresentado é um problema complexo que precisa do aprimoramento de métodos específicos de visão computacional e a adaptação de modelos matemáticos para gerar uma metodologia confiável que consiga identificar e diferenciar as deficiências tanto na presença como na intensidade.

\subsection{Objetivos}

Este trabalho de mestrado teve como objetivo geral estudar e avaliar a possibilidade de identificar deficiências nutricionais de plantas de milho usando unicamente a superficie da folha digitalizada numa imagem como fonte de informação e aplicando algoritmos de visão computacional e reconhecimento de padrões. Especificamente os objetivos deste trabalho foram:

- Verificar a possibilidade de identificação de níveis de deficiência nutricional dos macronutrientes N, P , K Mg, e S (Nitrogênio, Fósforo, Potássio, Magnésio e Enxofre) em plantas de milho através da análise da superfície das folhas.

- Projetar e implementar um sistema de visão computacional que realize a segmentação e classificação automática das deficiências nutricionais.

- Verificar a possibilidade de identificar as deficiências nutricionais num estádio inicial de crescimento. 
- Estudar algoritmos e métodos para a segmentação, análise e extração de características das imagens das folhas e seu potencial para resolver o problema.

- Divulgar os resultados da pesquisa mediante a apresentação de artigos e trabalhos e patentes em nível nacional e internacional.

Além dos objetivos mencionados acima teve-se por objetivo também estudar e aprimorar métodos de extração de textura em imagens já que no momento da proposta do projeto a textura amostrou-se a mais promissória para a resolução do problema. Porém, o foco da pesquisa computacional é conduzido na área de extração de características avaliando distintas aproximações e comparando os resultados com o estado da arte na área.

\subsection{Organização do Texto}

Esta dissertação está dividida em seis capítulos, o capítulo 2 apresenta uma visão geral da importância do milho no Brasil, como é feito o diagnóstico visual das deficiências nutricionais e os sintomas visuais que as folhas apresentam.

No capítulo 4 é realizada uma revisão bibliográfica das técnicas de análise e processamento de imagens estudadas para cada parte do sistema. Os principais tópicos abordados são referentes à segmentação e análise cor, textura e textura colorida.

O capitulo 5 apresenta as etapas envolvidas no sistema de identificação de deficiências nutricionais, bem como as técnicas e configurações especificas adotadas para cada uma delas.

O capítulo 6 descreve a metodologia biológica adotada para a geração, aquisição e validação das amostras vegetais e a parceria realizada com a FZEAUSP.

O capítulo 7 apresenta uma breve descrição dos métodos de aprendizado de maquina usados e os indicadores estatísticos usados para avaliar o desempenho das técnicas nos experimentos.

O capítulo 8 apresenta os experimentos computacionais realizados avaliando a qualidade dos métodos de extração de características e o grau de 
diferenciação obtido assim como o desempenho dos classificadores para cada uma das técnicas.

Finalmente no capítulo 9 são discutidas as principais conclusões, as contribuições geradas pelo trabalho e os novos projetos que poderiam ser desenvolvidos em continuidade a este trabalho. 


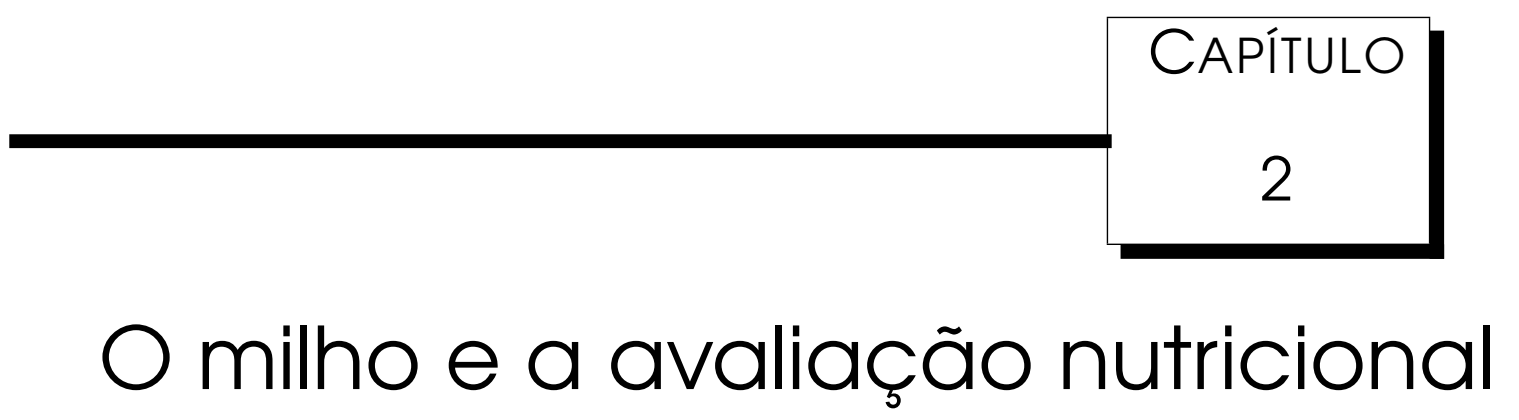

Neste capítulo são introduzidos os conceitos técnicos e biológicos que fundamentam o projeto, sendo o foco principal a avaliação nutricional do milho, sintomas apresentados e outras informações relevantes para o desenvolvimento do projeto.

\subsection{Importância do milho e sua nutrição}

O Brasil é o terceiro produtor mundial de milho com uma produção estimada de 52.723,3 milhões de toneladas (Conab, 2010). O milho é um dos principais fornecedores de derivados para alimentação humana e animal com mais de 500 derivados usados em muitas áreas para diversas aplicações, segundo (Nogueira-Júnior et al., 1987) entre algumas das principais temos:

- Alimentícia e química: Óleo, fermento, sorvetes, cerveja, refrigerantes, etc.

- Fermentação: Acetonas, butanol, isopropanol, metanol, glicerina, etc.

- Mecânica: Fundição de metais, explosivos, plásticos, cola, cosméticos, sabões, etc. 
- Rações: Grão moído, farelo, matéria seca, etc.

Embora o nível tecnológico alcançado pelos produtores de milho Brasil é considerado aceitável, a baixa produtividade média e os custos associados (adubação, transporte, etc) tem sido o motivo principal da busca de novas tecnologias para a melhora da produtividade e redução dos custos das safras (Emprapa, 2006). Alguns dos fatores limitantes da produção é o número de plantas por área cultivada e disponibilidade de nutrientes nessa área, o milho requer que suas exigências nutricionais sejam plenamente atendidas para expressar todo seu potencial produtivo (Amaral Filho et al., 2005).

Na atualidade o custo de adubação do milho representam entre $40 \%$ e $45 \%$ o custo total da produção (Coelho e Alves, 2004), o monitoramento da disponibilidade de nutrientes no solo é um fator importante no processo produtivo. A maior quantidade de plantas por área cultivada gera a necessidade de monitorar o nível adequado de nutrientes para diagnosticar sua necessidade de aplicação, o emprego de altas doses além do necessário de algum nutriente em forma de adubo pode afetar o crescimento da planta e contaminar águas superficiais e subterrâneas (Da Silva, 2011).

\subsection{Avaliação do estado nutricional}

Os métodos tradicionais de análise nutricional envolvem a coleta de matéria da planta e a medição dos nutrientes mediante análises químicas num laboratório especializado. Mas, a demora entre a coleta de amostras e os resultados da análise gera desvantagens, sendo a principal o fato de que impossibilita a correção desta deficiência naquele ciclo de produção, isto quer dizer que a produção da cultura já foi comprometida (Wu et al., 2007).

O diagnóstico foliar visual das plantas é uma maneira prática para identificar deficiências numa etapa de crescimento inicial (Argenta et al., 2002) partindo da premissa que é nas folhas que ocorre a maioria de processos fisiológicos e metabólicos (Da Silva, 2011). A anormalidade visível causada pela deficiência é o resultado de uma cadeia de eventos que começam com uma mudança de nível molecular, continua com uma mudança ao nível submolecular, prossegue com modificações ao nível celular e finalmente o tecido é 
afetado podendo ser visualizado por mudanças de cor, forma, tamanho e textura das folhas (Ramos et al., 2009).O diagnóstico visual é realizado por um humano com conhecimento na área, porém, a precisão é sujeita a erros de interpretação associado à impossibilidade de fornecer resultados quantitativos do nível da deficiência na planta.

Outra fonte que pode gerar confusão no diagnóstico visual é a presença de doenças, fungos e outros efeitos influenciados pelos fatores ambientais. Assim, o diagnóstico visual é um método que analisa em períodos definidos de vida da planta suas folhas e são comparadas com uma folha padrão (cultivada num ambiente controlado para ter certeza que apresenta todos os nutrientes num nível adequado) para determinar pelas mudanças e sintomas mostrados o tipo de deficiência que possui.

\subsection{Nutrientes essenciais}

Existem muitos elementos químicos no tecido vegetal de uma planta, entretanto, nem todos são considerados nutrientes da planta. Para que um elemento químico seja definido como fundamental para a planta deve-se atender os critérios de essencialidade direta, indireta ou ambas (Prado, 2008).

- Direto: O elemento participa de algum composto ou reação sem a qual a planta não vive.

- Indireto: A planta pode ser privada do elemento ate certo nível que começa a gerar sintomas da sua deficiência.

Finalmente os nutrientes são divididos em macronutrientes e micronutrientes de acordo com a proporção de absorção e aparição na materia seca das plantas (Prado, 2008):

- Macronutrientes: Nutrientes exigidos pelas plantas em quantidades maiores e com incidência desde o começo ate o final do desenvolvimento: N(nitrogênio), P(fósforo), K(potássio), Ca(cálcio), Mg(magnésio) e S(enxofre).

- Micronutrientes: Absorvidos em menores quantidades é com incidência menor no desenvolvimento da planta: Fe(ferro), Mn(manganês), Zn(zinco), $\mathrm{Cu}$ (cobre), B(boro), Cl(cloro), Mo(Molivdeno). 
Neste trabalho de mestrado foram analisados todos os macronutrientes por exercer uma função fundamental no desenvolvimento das plantas, porém. $\mathrm{O}$ sintoma que gera cada tipo de nutriente depende da severidade da deficiência, da espécie ou variedade e de fatores ambientais (Malavolta, 2006).

\subsection{Sintomas de deficiência identificáveis em plantas de milho}

Existem diversas deformações que acontecem nas plantas em presença de uma deficiência nutricional, a definição teórica dos sintomas fornece informações importantes para o desenvolvimento de métodos de visão computacional. Outro dos fatores importantes é a habilidade das plantas de deslocar nutrientes de folhas velhas para novas ou viceversa dependendo do tipo de nutriente e a função que este cumpre no crescimento da folha, contudo, alguns nutrientes são mais dificilmente transportados que outros sendo sua deficiência notada com maior severidade nas folhas novas, no caso contrário alguns nutrientes são facilmente transportados e a deficiência é notada facilmente nas folhas velhas.

A continuação são explicadas as deficiências identificáveis visualmente que gera cada macronutriente estudado:

\subsubsection{Nitrogênio}

Os sintomas típicos de deficiência de nitrogênio (N) no milho começam com um amarelecimento das folhas da ponta para base em forma de "V"pela diminuição de formação de clorofila nas folhas, dependendo do nível de deficiência as folhas tornam-se verde claro até chegar a amarelo. O nitrogênio é um nutriente móvel na planta, portanto os sintomas aparecem nas folhas velhas e se deslocam ate as folhas mais novas conforme ocorre o desenvolvimento da planta, as pontas das folhas velhas amostram necrose e dilaceramento (Coe1ho, 1995).

Em condições de deficiência de nitrogênio o crescimento da planta é retardado, gera uma redução no comprimento da espiga e o número de espigas por plantas afetando também a produção de grãos (Coelho, 1995). 
A Figura 2.1 mostra uma folha com deficiência de nitrogênio.

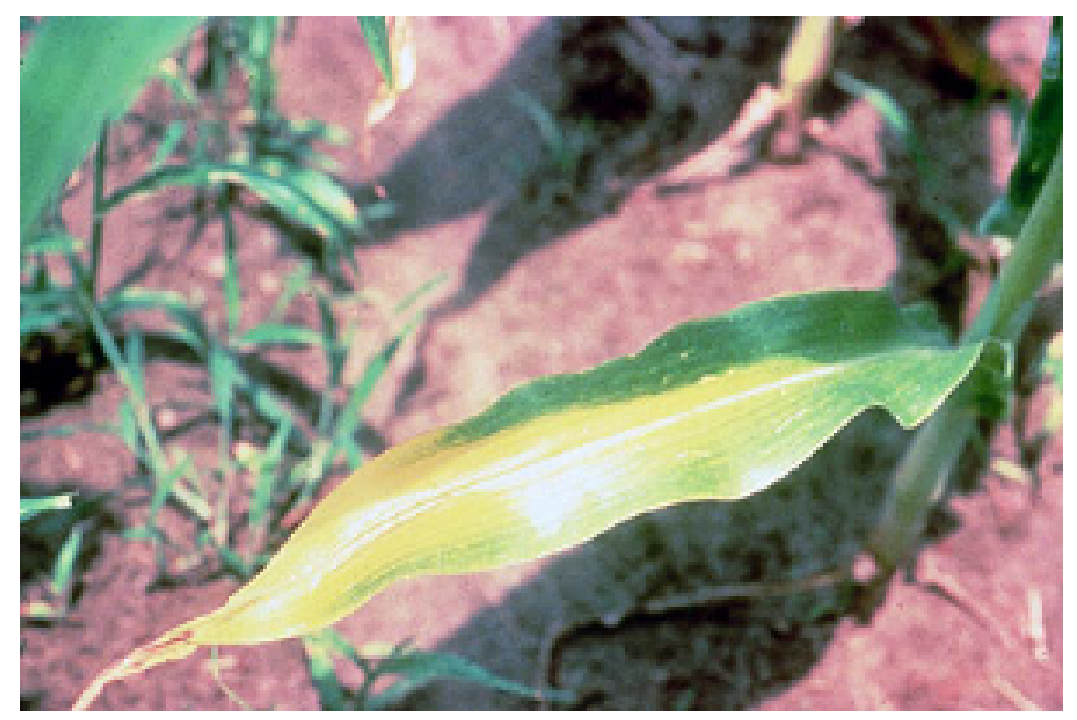

Figura 2.1: Folha de milho com deficiência de nitrogênio (Mosaic, 2010).

\subsubsection{Potássio}

A deficiência de potássio é observada como o amarelecimento e necrose (morte) e dilaceração do tecido da borda das folhas mais velhas. Se a deficiência é constante continuará a mover-se até as folhas mais novas. Outros sintomas amostrados são a aparição de manchas marrom oscuro nos nódulos das folhas. As folhas mais novas podem amostrar clorose internerval (Coelho, 1995) (Malavolta, 2006).

Em presença de deficiência de potássio a planta não amadurece corretamente e afeta o número e tamanho dos grãos produzidos (Malavolta, 2006).

A Figura 2.2 mostra uma folha com deficiência de potássio.

\subsubsection{Magnésio}

Com deficiência de magnésio as folhas velhas ficam com uma cor verde claro nas partes internervurais conforme a deficiência progride estas amarelecem dando o aspecto de estrias podendo ficar de cor roxo ou marrom. As folhas tornam-se grossas, quebradiças e enroladas. Conforme a planta cresce 


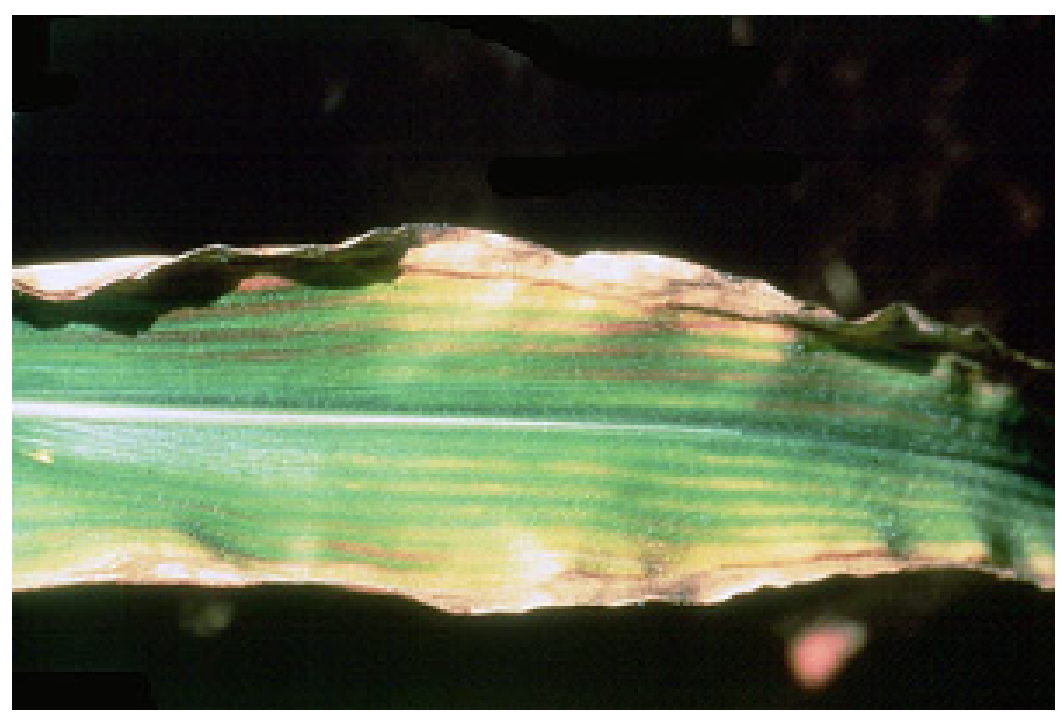

Figura 2.2: Folha de milho com deficiência de fósforo (Mosaic, 2010).

o sintoma pode se transportar para as folhas novas (Coelho, 1995) (Da Silva, 2011).

O magnésio afeta diretamente a fotossíntese da planta, assim a qualidade da matéria vegetal produzida pela planta depende da disponibilidade de magnésio, além disso, o magnésio participa na maioria dos aspectos da planta durante o ciclo de vida desta (Da Silva, 2011).

A Figura 2.3 mostra uma folha com deficiência de magnésio.

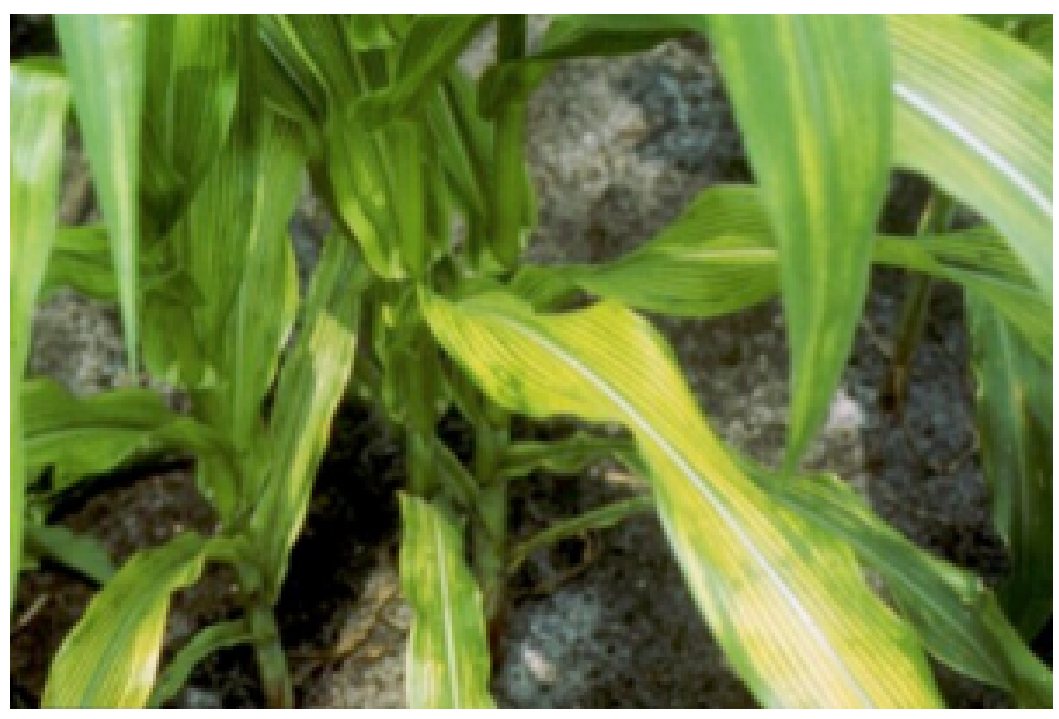

Figura 2.3: Folha de milho com deficiência de Magnésio (Mosaic, 2010). 


\subsubsection{Cálcio}

A deficiência de cálcio produz um retardo no desenvolvimento das folhas novas em alguns casos grudando umas às outras. Nas folhas novas aparece clorose internervural, dilaceração das margens e morte da região de crescimento, a área da folha também é afetada por esta deficiência .

O cálcio é essencial no funcionamento das membranas das plantas e produzem um efeito radicular que reduz a absorção de outros nutrientes e água na planta. O Cálcio é indispensável para a germinação do grão e o crescimento do tubo polínico (Da Silva, 2011).

A Figura 2.4 mostra uma folha com deficiência de cálcio.

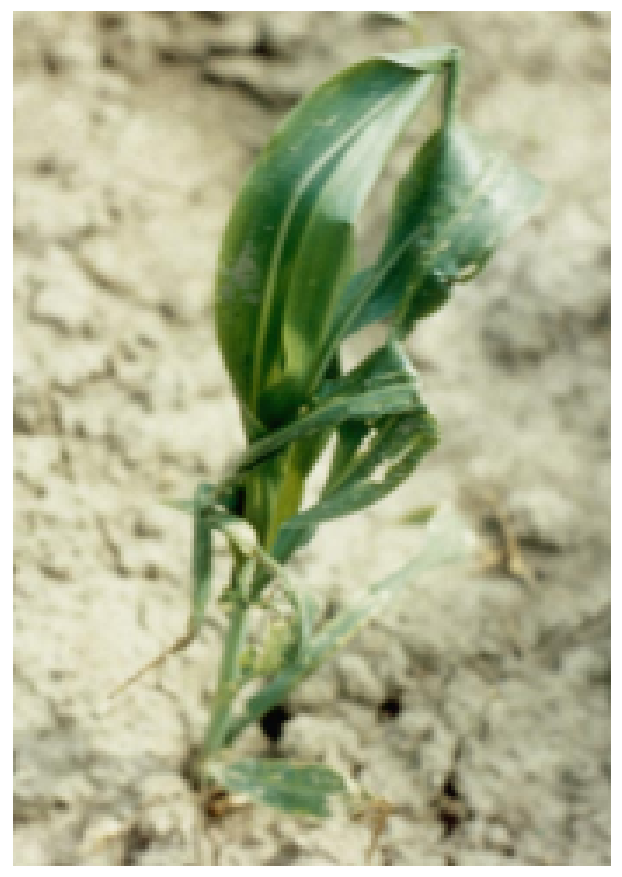

Figura 2.4: Folha de milho com deficiência de Cálcio (Sawyer, 2004).

\subsubsection{Enxofre}

Os sintomas de deficiência do enxofre são muito semelhantes aos de deficiência de nitrogênio, mostrando no começo uma coloração amarela nas folhas com a diferença que a coloração é mais marcada nas folhas novas, clorose internerval ocorre também nas folhas novas (Malavolta, 2006). 
A disponibilidade de enxofre na planta determina diretamente o aumento da produção e a qualidade do produto. O Enxofre é componente fundamental de aminoácidos e proteínas essenciais na planta (Da Silva, 2011).

A Figura 2.5 mostra uma folha com deficiência de Enxofre.

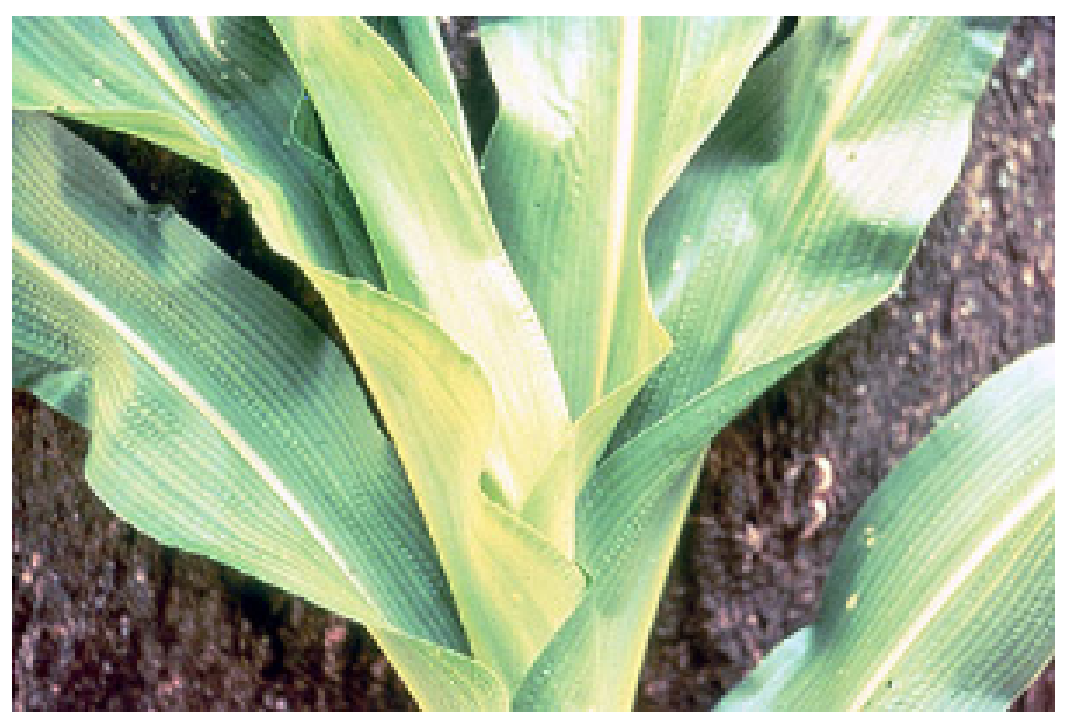

Figura 2.5: Folha de milho com deficiência de Enxofre (Mosaic, 2010). 


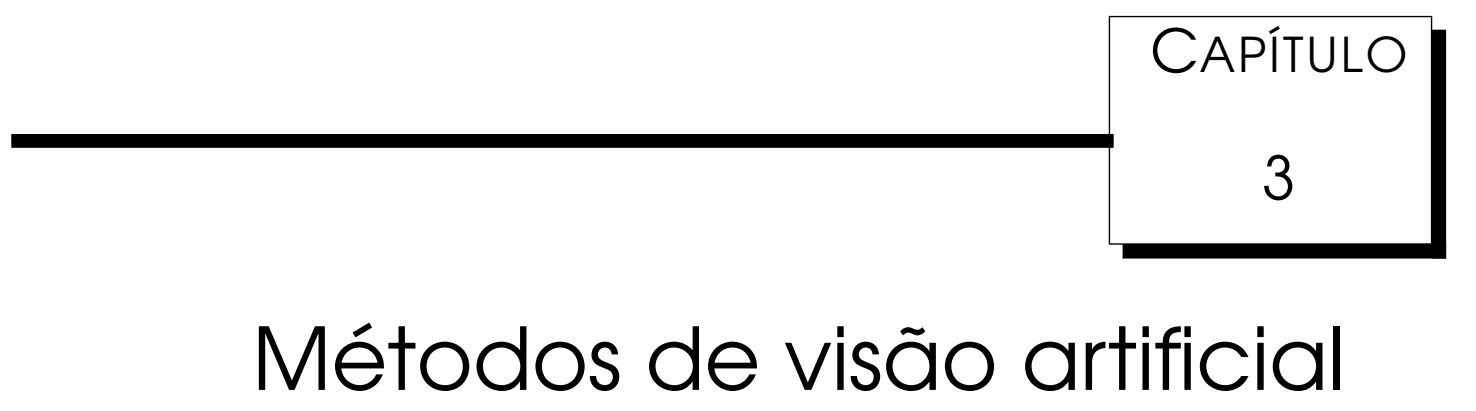

Neste capítulo são introduzidos conceitos fundamentais de visão artificial e análise de imagens necessários para o entendimento do problema. Desta maneira este capítulo procura: (1) definir as partes de um sistema de visão artificial (SVA) baseado em exemplos encontrados na literatura e extrai conclusões das fatores que determinam o sucesso de um SVA. (2) apresentar os conceitos e técnicas básicas de segmentação de imagens. (3) expor os principais métodos achados na literatura de técnicas de extração de características de cor, textura e textura colorida.

\subsection{Introdução ao Análise de imagens}

O processamento digital de imagens é uma das áreas mais desafiantes da computação. Existe um volume importante de pesquisa na área com o intuito de desenvolver algoritmos cada vez mais sofisticados e confiáveis para ser usados em aplicações reais. A visão artificial é uma área aberta e em pleno desenvolvimento (Niblack, 1985), segundo, uma imagem é por natureza de domínio bi-dimensional e pode ser multi-dimensional considerando a informação de cor, isto faz que o desenvolvimento de filtros e algoritmos seja uma tarefa complexa (Gonzalez et al., 2003). 


\subsection{Sistemas de visão artificial}

A organização de um sistema de visão computacional é dependente do tipo e objetivo da aplicação, não é possível criar um sistema que possa ser aplicado a todos os possiveis cenários. Para que um sistema de visão artificial obtenha resultados ideais deve se restringir ao domínio do problema baseado em uma série de heurísticas que possibilitam reduzir o número de objetos indesejados ou ruídos que podem estar presentes na imagem. No entanto, a maioria de sistemas de estas características seguem uma série de passos, os quais são resumidos a continuação:

- Aquisição de imagem: Seja de sensores, câmeras, scanner ou outro tipo de aparelhos para a captura, o resultado pode variar entre uma imagem bi-dimensional, uma tri-dimensional ou ainda uma seqüencia de imagens. Os valores dos pixels geralmente indicam a intensidade da luz em uma ou várias faixas de cor.

- Pré-processamento: Uma imagem geralmente deve ser processada antes de aplicar um método de visão computacional para assegurar que satisfaz algumas condições. Exemplos: redução de ruídos, melhora do contraste, aplicação de filtros, etc.

- Extração de características: É um dos pontos mais importantes em um sistema de visão artificial, pela grande variedade de características que uma imagem pode ter e a complexidade dos métodos criados para extraílhas, atualmente não existe uma técnica que funcione para todo tipo de imagens.

- Classificação: neste ponto a entrada é geralmente um conjunto pequeno de dados (o vetor de características da imagem gerado no processo anterior). A classificação envolve identificar a classe que pertence cada uma das imagens da base de dados.

Existem muitos sistemas de visão computacional aplicados à biologia, um dos projetos feitos pelo grupo de pesquisador é o projeto TreeVis (Tree Vision System), para a identificação de espécies vegetais mediante as características das folhas (cor, contorno, textura, etc). O ponto fundamental explorado 
pelo TreeVis é a obtenção de um vetor de características representativas para a identificação de espécies vegetais, composto de vários tipos de descritores (texturais, estruturais, etc) que melhor diferencie os objetos a serem reconhecidos, atualmente o projeto TreeVis possui aportes dos trabalhos de (Casanova, 2008), (Plotze, 2004), (Sá Junior, 2008).

Além disso, existem muitos trabalhos na literatura de sistemas de visão computacional aplicados à biologia, pode se extrair dos trabalhos feitos por (Timmermans, 1998), (Runtz, 1991), (McCarthy et al., 2008) (Guanghui e Changying, 2003) uma metodologia que parece governar este tipo de sistemas de visão computacional:

- Aquisição de amostras: as amostras são adquiridas geralmente por scanners ou câmeras de alta resolução para tentar capturar o maior detalhe possivel das plantas

- Segmentação: Nesta fase só é necessário separar os objetos importantes de outros que estejam presentes na imagem, a aplicação de filtros ou outro tipo de técnicas de processamento de imagens é muito limitado já que a maioria destes sistemas trabalham com textura ou forma (contorno) e a aplicação destes filtros muda as características das imagens.

- Geração de base de dados: Com as imagens segmentadas é possível gerar uma base de dados com as imagens, é importante ter suficientes amostras para um treinamento e teste efetivos.

- Extração de características: A textura é um das características mais importantes a ser extraídas dos sistemas aplicados a biologia, isto devido a que as texturas e cores das plantas fornecem informação que em muitos casos é suficiente para gerar um vetor de características ideal.

- Redução da dimensionalidade: Uma das características indesejáveis das técnicas de extração de características sofisticadas é o número de descritores por imagem que estas obtêm, e necessário realizar um processamento a os dados para reduzir a dimensionalidade sem perder detalhes importantes.

- Classificação: Neste ponto usam-se técnicas para a identificação de classes por meio do reconhecimento de padrões a partir de uma série de 
variáveis independentes armazenadas no vetor de características, classificadores bayesianos, redes neurais e análise linear descriminante são algumas das técnicas mais usadas.

\subsection{Projeto TreeVis}

O projeto TreeVis (Tree Vision System) vem sendo desenvolvido pelo grupo de computação científica do IFSC há nove anos, o objetivo principal deste projeto é desenvolver um conjunto de métodos e técnicas para a identificação e classificação de espécies vegetais de diferentes ecossistemas brasileiros. O sistema tem como foco principal a classificação de espécies, o resultado deste mestrado foi acrescentar um módulo gerando assim uma nova área aplicando os algoritmos necessários para identificação do estado nutricional de milho e sua possivel futura extensão a outras espécies vegetais.

O Treevis apresenta quatro pilares fundamentais (Casanova, 2008) que foram usados como guia para o desenvolvimento de uma metodologia computacional para a identificação do estado nutricional, são eles:

- Exploração de atributos: A exploração sistemática dos atributos que melhor separam as classes é um problema persistente na visão artificial, no TreeVis são exploradas todas as possibilidades considerando: geometria, cor, textura e complexidade.

- Sinergismo: A combinação dos atributos extraídos pode trazer melhores resultados na classificação do que usar cada atributo por separado. Na contrapartida, o uso excessivo de atributos que não fornecem informação relevante pode gerar um incremento desnecessário do processamento e resultados que não justificam a carga. A combinação ideal é analisada estatisticamente para determinar os atributos importantes e o impacto que cada atributo tem no resultado final.

- Análise estatística: Refere-se a análise de resultados usando um método de classificação estatística para determinar a pertença de cada imagem introduzida a uma classe existente fornecendo também uma serie de parâmetros que indicam a contabilidade do resultado. 
- Validação: Os resultados finais são avaliados por um especialista no domínio para garantir a consistência das informações adquiridas.

O ambiente de trabalho do TreeVis é mostrado na figura 3.1.

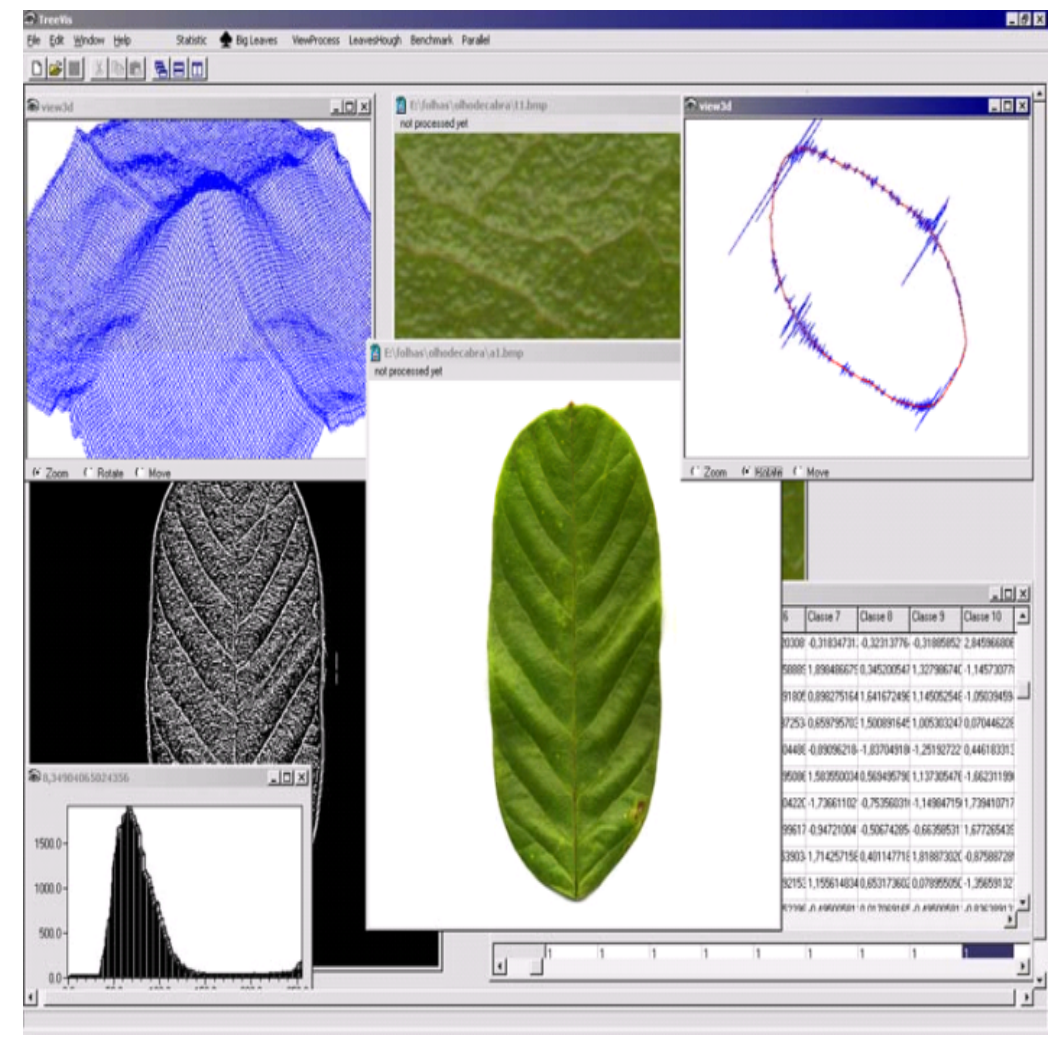

Figura 3.1: Ambiente de trabalho do TreeVis mostrando alguns modulos em execução (Casanova, 2008).

\subsection{Segmentação de imagens}

A segmentação de imagens é o ponto de partida de muitos SVAs. No domínio da visão aplicada à biologia, uma segmentação correta de uma imagem pode ajudar em tarefas de classificação de espécies, identificação de doenças, etc. Em (Pazoti, 2005), (Casanova, 2008), o objetivo da segmentação é dividir a imagem para a extração de segmentos significativos a partir de uma imagem com objetos úteis e informações não relevantes. O nível de subdivisão da imagem depende do problema a tratar. O problema de segmentar objetos 
em imagens é uma das tarefas mais difíceis na área de visão artificial, podem existir um número infinito de dificuldades para segmentar uma imagem sem domínio definido, é por isso que é importante considerar o contexto para criar um algoritmo que se ajuste a cada tipo de problema (Gonzalez e Woods, 2006).

A maioria dos métodos de segmentação de imagens são baseados em duas propriedades dos valores de intensidade da imagem: descontinuidade e similaridade. Na primeira aproximação a segmentação é baseada em mudanças abruptas de intensidade (bordas). Na segunda aproximação as regiões de divisão são decididas por um critério de similaridade adequado as características visuais que os objetos são mais propensos a ter (heurísticas).

Existem diversos métodos para segmentar imagens, são apresentados alguns dos mais relevantes para sua aplicação na presente pesquisa.

\subsubsection{Método de Otsu}

A segmentação baseada em limiarização é um dos métodos mais simples e mais usados na literatura (Padmavathi et al., 2010). O método de limiarização consiste em achar um valor ideal que separe os objetos do fundo da imagem. Isto significa etiquetar os pixels da imagem $f(x, y)$ que pertencem às regiões da imagem que são consideradas como primeiro plano com um valor nominal e os pixels que pertencem ao fundo com outro valor nominal (geralmente é usado os valores 1 e 0 respectivamente, gerando assim uma imagem binária).

Um dos problemas na limiarização é obter um valor ótimo para o corte sem intervenção de um observador, isto é de maneira automática baseado nas características da imagem analisada. O método de otsu tenta resolver este problema maximizando a separação entre conjuntos de pixels analisando o histograma da imagem.

\subsubsection{Fuzzy C-Means}

O método de Fuzzy C-Means (FCM) aplicado ao processamento de imagens consiste na rotulação de pixels pelo valor de magnitude destes gerando agrupamentos baseados em similaridade. O FCM é um algoritmo iterativo que encontra agrupamentos usando o conceito de pertinencia compartilhada (lógica difusa) onde um pixel pode pertencer a um ou mais agrupamentos. Os 
agrupamentos devem ter duas propriedades importantes (Padmavathi et al., 2010):

- Homogeneidade dentro dos agrupamentos: Os pixels que pertencem a um agrupamento devem ser o mais similares possíveis.

- Heterogeneidade entre os agrupamentos: Os pixels que pertencem a agrupamentos diferentes devem ser o mais dissimilares possíveis.

Para o uso deste tipo de método em imagens é necessário estimar o número de agrupamentos inicias. Pode ser usada alguma função prévia que estime o número de possíveis agrupamentos baseado na distribuição dos níveis de intensidade, mas, geralmente é feita uma avaliação visual por um observador humano, tornando a técnica supervisionada. A técnica FCM tenta encontrar agrupamentos maximizando uma função objetivo (Ali et al., 2004):

$$
J=\sum_{i=1}^{N} \sum_{j=1}^{C} v_{i j}^{m}\left|x_{i}-c_{j}\right|^{2},
$$

Onde:

$N=\#$ pixels na imagem

, $C=\#$ de agrupamentos

, $v=$ tabela de distribuição de $\mathrm{NxC}$

, $m=$ valor da função difusa

, $x_{i}=\mathrm{i}$ pixel em $\mathrm{N}$

, $c_{j}=\mathrm{j}$ agrupamento em $\mathrm{C}$

, $\left|x_{i}-c_{j}\right|=$ é a distancia euclidiana entre $x_{i} \mathrm{e} c_{j}$

\subsubsection{Avaliação da segmentação}

A avaliação dos resultados da segmentação de uma imagem são geralmente subjetivos, deixando a um observador humano a tarefa de verificar a efetividade da técnica baseada em se as imagens geradas pelo algoritmos são adequados para o observador. Contudo, existem algumas métricas que podem ser tomadas em consideração (Padmavathi et al., 2010): 
- Sobre-segmentação: Um objeto completo na imagem é representado por dois ou mais segmentos.

- Sub-segmentação: Duas ou mais regiões são representadas por um segmento.

- Localização incorreta de limites: os limites das áreas segmentadas podem conter ruídos ou informação não desejada.

\subsection{Extração de características em imagens}

O desenvolvimento de métodos de extração de características de imagens é um dos pontos mais sensíveis num SVA. As imagens possuem uma descrição matemática baseada em pixels onde cada valor indica uma intensidade ou cor numa posição especifica da imagem. Embora todas as informações encontram-se dentro deste conjunto de pixels, a imagem inteira é grande demais para ser usada diretamente num SVA porque contém muito dado redundante que não é útil na descrição do seu conteúdo. Porem, a imagem precisa de um processamento que a reduza a um conjunto de descritores chamados de vetor de características, este processo é conhecido como extração de características. Uma extração de características ideal deve expressar numericamente a maior quantidade de atributos inerentes dos objetos da imagem na menor quantidade possível de descritores. Na literatura existem muitas aproximações e métodos para extração de características, neste trabalho consideramos cor, textura e textura colorida como 3 elementos que devem ser analisados separadamente para determinar a importância de cada um e a importância da mistura destes no contexto de identificação de deficiências nutricionais. Assim todas os extratores apresentados representam o estado da arte atual dos métodos que após análise resultam aplicáveis para os objetivos deste trabalho.

\subsubsection{Cor}

Cor é um atributo importante em qualquer imagem e representa a característica visual mais usada pelo cérebro humano para diferenciar objetos e coisas (Wu et al., 2002). No contexto deste trabalho cor representa um atri- 
buto forte usado pelos expertos humanos para diferenciar as deficiências nutricionais pelas mudanças que acontecem na superfície da folha. Assim, é necessário avaliar a potencialidade de extratores de cor na diferenciação de deficiências. A continuação são apresentados algumas técnicas de extração de cor de imagens achadas na literatura.

\subsubsection{Histogramas coloridos}

Os histogramas são uma representação compacta de uma imagem sem ter nenhum conhecimento prévio do conteúdo da imagem, porém, são descritores adequados para muitas aplicações (Siggelko, 2002). Um histograma de cor é um dos atributos mais básicos usadas na extração de características principalmente porque não precisa de uma implementação complexa e permite avaliar rapidamente a importância da cor num conjunto de imagens. É uma aproximação usualmente adotada em recuperação de imagens baseada em conteúdo (Sharma et al., 2001).

Num histograma cada pixel é associado a uma cor especifica, cada cor pode ser descrito por três componentes na maioria de espaços de cor usados (por exemplo, vermelho, verde e azul são as componentes do espaço RGB).

Formalmente podemos construir um histograma de cor de uma imagem em RGB definida pela função $f(x, y) \operatorname{com} x=0,1, \ldots, N-1$ e $y=0,1, \ldots, M-1$ possuindo valores discretos $i=0,1, \ldots, G-1$, onde $\mathrm{G}$ é o valor possível de intensidade, $N, M$ são as dimensões em $x$ e $y$ da imagem. Em cada canal de cor na imagem considera-se uma função $f_{c}(x, y)$ onde $c$ indica o canal de cor. O histograma é uma função mostrando o número de pixels da imagem que possuem um determinado cor, dado por:

$$
h(r, g, b)=\sum_{x=0}^{N-1} \sum_{y=0}^{M-1} \delta\left(f_{c}(x, y), i\right),
$$

Onde:

$$
\delta(j, i)= \begin{cases}1, & \text { se } j=i \\ 0, & \text { caso contrário }\end{cases}
$$

Uma imagem quantizada perde informação de cor dependendo do número 
de cores da quantização, a figura 3.2 mostra o processo para 256 e 128 cores. A perda de informação relevante é mínima.

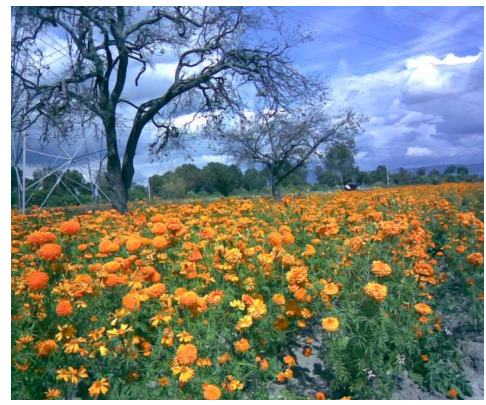

(a)

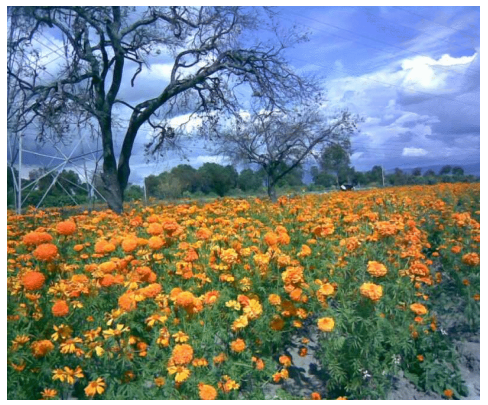

(b)

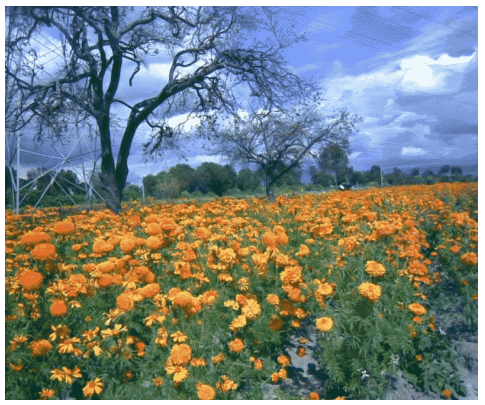

(c)

Figura 3.2: Redução de cor numa imagem RGB, (a) imagem original, (b) imagem quantizada em 256 cores, (c) imagem quantizada em 128 cores

O histograma gerado pode ser usado diretamente como vetor de características, entretanto, podem ser extraídas outras informações estatísticas contidas no histograma.

\subsubsection{Border/Interior classification}

O BIC é um método simples para análise de imagens, é baseado na classificação dos pixels de uma imagem como pertencentes a uma borda de um objeto ou o interior deste. Dois histogramas são gerados a partir dos grupos de pixels de cada agrupamento classificado e são usados como vetores de características da imagem. Existem 4 passos importantes no algoritmo (Stehling et al., 2002):

- Quantização de cor: É importante a redução de cores da imagem usando um algoritmo de quantização (para manter a dimensão dos histogramas gerados num limite aceitável), o algoritmo original de BIC sugere o uso de $4 x 4 x 4$ cores no espaço RGB.

- Classificação: Um pixel é classificado como borda se algum dos 4 vizinhos deste possui uma cor quantizada distinta, um pixel é classificado como interior se todos os 4 vizinhos deste possuem o mesmo cor quantizado.

- Geração dos histogramas: Depois da classificação são gerados dois histogramas um para os pixels da borda e outro para os pixels do interior, 
cada um considera só os pixels classificados como pertencentes a sua classe.

- Concatenação dos histogramas: Finalmente os histogramas são concatenados para gerar o vetor de características final da imagem.

Bic é uma técnica simples mas efetiva para caracterizar cor, a figura 3.3 mostra o resultado de aplicar BIC numa imagem colorida

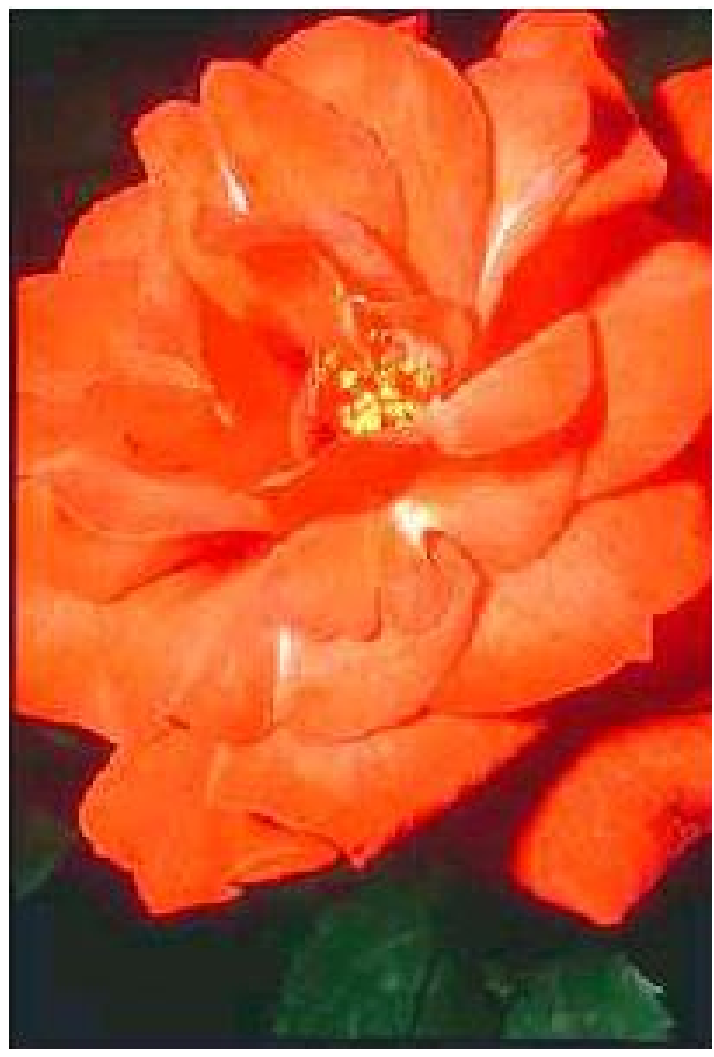

(a)

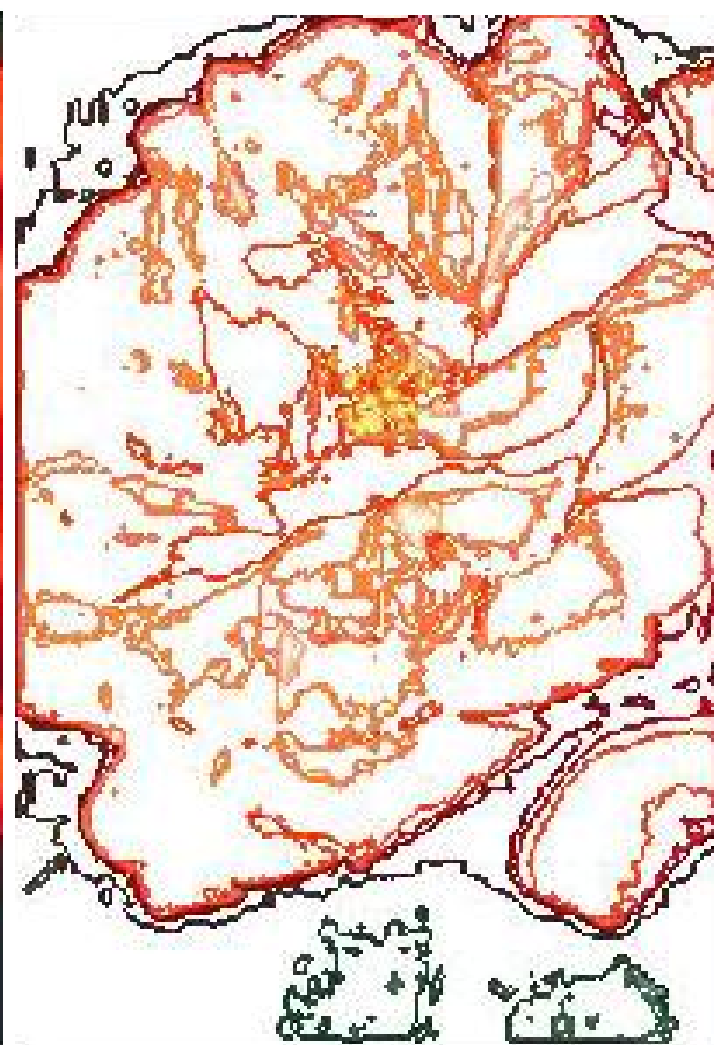

(b)

Figura 3.3: Processamento pelo método BIC (a) imagem original, (b) imagem classificada onde os pixels com os cores originais são os pixels da borda e os pixels brancos são o interior (adaptado de (Stehling et al., 2002))

\subsubsection{Momentos invariantes de cor}

Na literatura existem diversos métodos que utilizam momentos para descrever cor e textura nas imagens. A pesquisa pioneira na área foi feita por (Hu, 
1962) onde foi desenvolvido um conjunto de momentos invariantes a rotação, translação, escalamento entre outros. Considerando a informação de cor esta pode ser representada como uma função que mistura distintas propriedades intrínsecas dos pixels na imagem (uniformidade, variância, etc) (Mindru et al., 2004).

O momento da cor geral pode ser definida como uma função $M_{p q}^{a b c}$ que atribui a cada pixel da imagem $f(x, y)$ o vetor triplo $I(x, y)=(R(x, y), G(x, y), B(x, y))$ contendo os valores RGB para o correspondente pixel, assim temos:

$$
M_{p q}^{a b c}=\iint x^{q} y^{q}[R(x, y)]^{a}[G(x, y)]^{b}[B(x, y)]^{c} d x d y,
$$

Onde $p$ e $q$ a ordem é $a+b+c$ o grau do momento. Usando esta função pode ser gerados um número amplo de momentos com valores pequenos de $p$ e $q$. Um reduzido conjunto de momentos pode conter a maioria de informação relevante da imagem.

Usando a combinação adequada de momentos é possível normalizar as características quando existem mudanças entre distintas imagens (iluminação, rotação, etc), estes são chamados de momentos invariantes, segundo (Mindru et al., 2004) 24 momentos invariantes podem ser calculados.

\subsubsection{Momentos de cromaticidade}

Existem muitas aproximações apresentadas para caracterizar textura em imagens coloridas, a maioria destes métodos são baseados em modelos matemáticos complexos que podem ter um custo computacional muito alto.

Um método simples para extração de características de textura colorida conhecido como momentos de cromaticidade foi apresentado originalmente por (Paschos, 2000). O método é baseado no conceito de cromaticidade definido no espaço de cor CIE XYZ onde cada pixel gera um conjunto $(x, y)$ de valores de cromaticidade obtendo assim um número de pontos $\mathrm{n}$ chamado "diagrama de cromaticidade".

O espaço de cores CIE XYZ é definido pela transformação:

$$
X=0.607 x R+0.174 x G+0.200 x B
$$




$$
\begin{array}{r}
Y=0.299 x R+0.587 x G+0.114 x B \\
Z=0.066 x G+1.111 x B,
\end{array}
$$

Com os valores de $\mathrm{X}, \mathrm{Y}$ e $\mathrm{Z}$ pode-se obter o conjunto de cromaticidades:

$$
\begin{aligned}
& x=X / X+Y+Z \\
& y=Y / X+Y+Z,
\end{aligned}
$$

Em 1931 foi estabelecido pela CIE o espaço XYZ que permite que as cores sejam representados por sua cromaticidade (eixo $X$ e $Y$ e sua luminescência eixo $Z$, o diagrama de cromaticidade é o resultado da transformação matemática para uma imagem $I$ de dimensões $L_{x}$ e $L_{y}$ definido como:

$$
T(x, y)=\left\{\begin{array}{lc}
1 & \text { if } \exists(i, j): I(i, j) \text { produze }(x, y) \\
0 & \text { caso contrario }
\end{array}\right.
$$

onde

$0 \leq i \leq L_{x}-1,0 \leq j \leq L_{y}$

A distribuição bi-dimensional é:

$$
D(x, y)=k \quad \text { onde } \quad K=\text { \#pixels } \quad(x, y)
$$

Estas dois funções podem ser caracterizadas por um conjunto de momentos $(m, l)$ os quais são definidos por:

$$
\begin{aligned}
& M_{T}(m, l)=\sum_{x=0}^{x_{s}-1} \sum_{y=0}^{y_{s}-1} x^{m} y^{l} T(x, y), \\
& M_{D}(m, l)=\sum_{x=0}^{x_{s}-1} \sum_{y=0}^{y_{s}-1} x^{m} y^{l} D(x, y),
\end{aligned}
$$

onde $m, l=0,1,2, \ldots$ e $X_{s}, Y_{s}$ são as dimensões discretas do espaço x-y. A menor quantidade de momentos que possam diferenciar as diferentes texturas é usada como vetor de características para classificação, o resultado do processo e mostrado na Figura 3.4. 


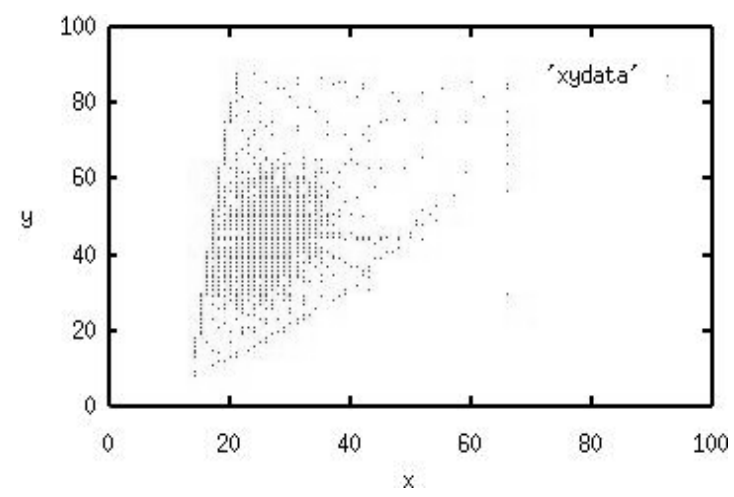

(a)

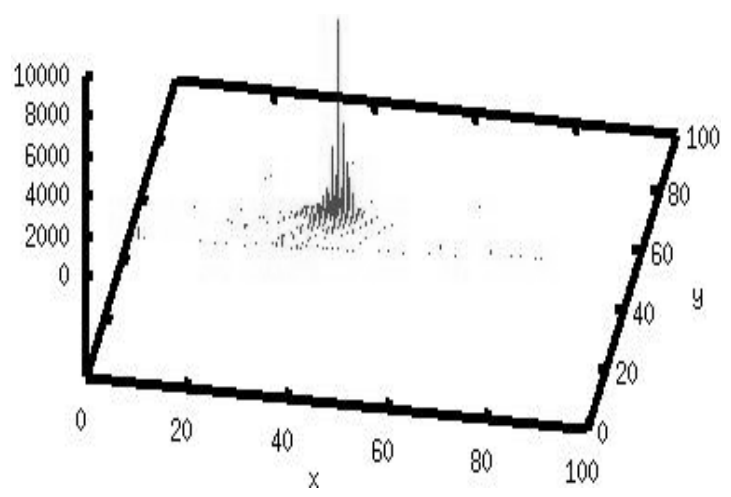

(b)

Figura 3.4: Exemplo de cromaticidades (x,y) onde (a) é o traço bi-dimensional (T) e (b) a distribuição bi-dimensional (D) (Paschos, 2000)

\subsubsection{Textura}

A análise de textura é uma área importante de estudo em visão computacional. A maioria das superfícies naturais oferece texturas únicas que um sistema de visão computacional deve poder interpretar.

A textura reflete as variações das propriedades ópticas em um objeto, diferentes superfícies produzem diferentes texturas. Isto faz com que a textura seja uma importante fonte de informação para muitas tarefas de visão computacional como: classificação, segmentação, etc.

A palavra "textura"em imagens tem muitas definições formuladas dependendo da aplicação específica e com a concepção de que não há consenso geral sobre o tópico. Algumas definições são motivadas pela percepção visual da textura, e outras são completamente orientadas pela aplicação em que a definição será usada. A Figura 3.5 mostra diferentes texturas artificiais.

Como uma função, a textura pode ser definida como a variação espacial das intensidades dos pixels numa imagem (Chen et al., 1998) e a relação entre estes pixels e seus vizinhos.

As abordagens para a análise de textura podem-se dividir em:

- Estrutural

- Estatístico

- Espectral 


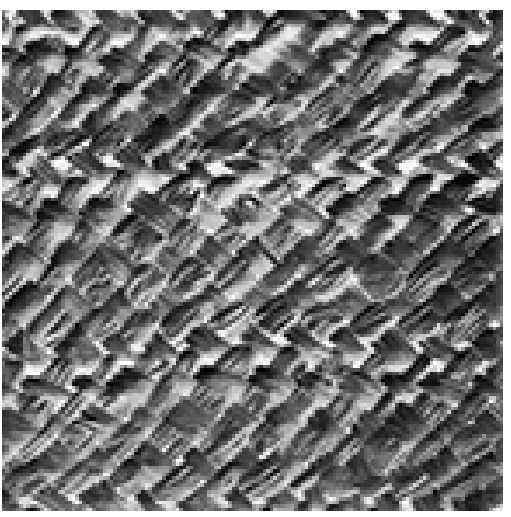

(a)

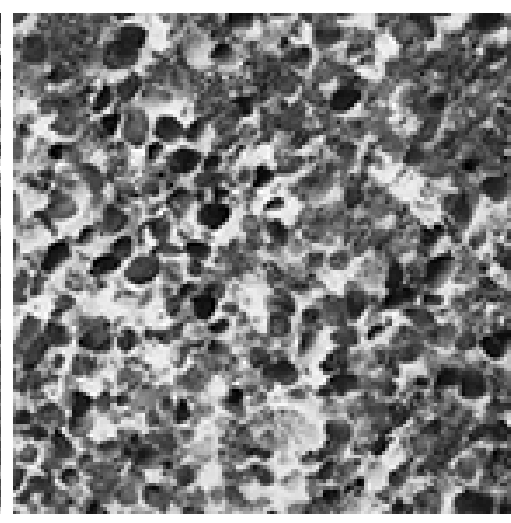

(b)

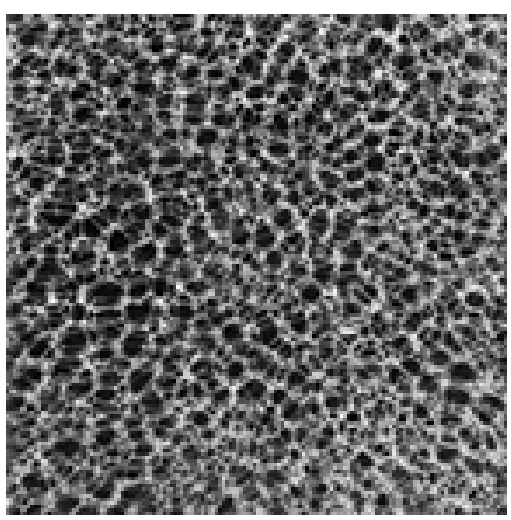

(c)

Figura 3.5: Imagens de distintas texturas extraídas do álbum brodatz.

$\mathrm{Na}$ abordagem estrutural consideram que a textura é composta de um padrão de repetição e descrevem o padrão por regras capazes de gerar este padrão e reproduzi-lo. A percepção de que uma textura é composta pela repetição de uma rega é o fundamento da análise fractal em imagens. Nos métodos fractais mede-se o grau com que uma imagem pode ser representada por uma rega original repetida muitas vezes para gerar a textura, isto é de muita utilidade especialmente em texturas naturais (estruturas biologicas, superficies de plantas, etc).

Por outro lado, os métodos estatísticos descrevem a textura usando regras estatísticas que governam a distribuição e relação espacial dos níveis de cinza na imagem. Eles apresentam um bom desempenho na análise de texturas naturais e texturas com baixa resolução, onde os elementos da textura são difíceis de descrever (Weszka e Rosenfeld, 1976), neste contexto a matriz de co-ocorrência (Haralick, 1979) é a técnica mais popular para análise de textura. As características de segunda ordem acumuladas nesta matriz medem a dependência espacial dos níveis de cinza na imagem, um conjunto de descritores pode ser extraido da matriz e formar o vetor de características da imagem.

O método Espectral baseia-se na transformação da imagem para outro espaço de análise, como é o caso da aplicação da transformada de Fourier (Rosenfeld e Weszka, 1980), Filtros de Gabor (Daugman, 1985) e transformada de wavelet (Mallat, 1989), (Laine e Fan, 1993). Para realizar uma análise 
espectral transforma-se a imagem no espaço cujo sistema de coordenadas tem uma interpretação relacionada às características de uma textura (como freqüência ou tamanho). Este método é usado para caracterizar os padrões periódicos analisando a imagem em forma global.

O maior problema com a transformação de Fourier é que cada componente do espectro de freqüência depende da imagem global. Se a textura tem uma variação espacial do padrão da imagem Fourier obtém resultados pobres por sua falta de localização espacial, a utilização de filtros de Gabor resolve este problema. Com os filtros de Gabor, a análise espectral também considera o espaço de escala e uma determinada orientação. Comparado com Gabor a transformada de wavelet possui algumas vantagens que permite que sejam usadas com muito sucesso em aplicações específicas. Isto faz que a transformada de wavelet seja um dos métodos mais adequados em análise de textura. (Materka e Strzelecki, 1998)

\subsubsection{Matriz de co-ocorrência}

A matriz de co-ocorrência é um dos métodos mais conhecidos para análise de textura, as estatísticas de segunda ordem armazenadas nesta matriz medem a dependência espacial dos níveis de cinza, o uso de matriz de coocorrência para descrição de textura é baseado na ocorrência repetida de alguma relação entre os níveis de cinza da imagem que varia rapidamente com a distância em texturas finas e pausadamente em texturas grossas (Haralick, 1979).

Supondo que parte da textura a ser analisada é uma janela de $M \times N$ a ocorrência de uma relação pode ser descrita por uma matriz de freqüências relativas $p_{d \theta}(i, j)$ que descreve com quanta freqüência 2 pixels com niveis de cinza $a, b$ aparecem na janela separados por uma distância $d$ em direção $\theta$, para uma imagem $f(x, y)$ sua matriz de co-ocorrência é definida como:

$$
f\left(x_{1}, y_{1}\right)=i \quad e \quad f\left(x_{2}, y_{2}\right)=j,
$$

Onde

$$
\left(x_{2}, y_{2}\right)=\left(x_{1}, y_{1}\right)+(d \cos \theta, d \operatorname{sen} \theta),
$$


Isto gera uma matriz de dimensão igual ao número de intensidades na imagem para cada distância $d$ e orientação $\theta$, o valor das distâncias $d$ e os ângulos a ser usadas depende do tipo de textura a ser tratada, valores baixos são usados para texturas finas e valores altos para texturas grossas.

Os valores para caracterizar a textura podem ser gerados pelas seguintes equações:

Energia:

$$
E=\sum_{i=0}^{G-1} \sum_{j=0}^{G-1}[p(i, j)]^{2},
$$

Correlação:

$$
C=\sum_{i=0}^{G-1} \sum_{j=0}^{G-1} \frac{i j p_{d \theta}(i, j)-\mu_{x} m i c r o_{y}}{\sigma_{x} \sigma_{y}},
$$

Contraste:

$$
C o=\sum_{i=0}^{G-1} \sum_{j=0}^{G-1}(i-j)^{2} p(i, j),
$$

Valor absoluto:

$$
V a=\sum_{i=0}^{G-1} \sum_{j=0}^{G-1}|i-j| p(i, j),
$$

Diferença inversa:

$$
D i=\sum_{i=0}^{G-1} \sum_{j=0}^{G-1} \frac{p(i, j)}{1+(i-j)^{2}},
$$

Entropia:

$$
E=-\sum_{i=0}^{G-1} \sum_{j=0}^{G-1} p(i, j) \log _{2}[p(i, j)],
$$

Probabilidade máxima:

$$
P m=\max _{i, j} p(i, j)
$$

Homogeneidade:

$$
H=\sum_{i=0}^{G-1} \sum_{j=0}^{G-1} \frac{p(i, j)}{(1+|r-n|)},
$$

onde:

$$
\begin{aligned}
& \boldsymbol{\mu}_{x}=\sum_{i} i \sum_{j} p_{d \theta}(i, j), \\
& \boldsymbol{\mu}_{y}=\sum_{j} j \sum_{i} p_{d \theta}(i, j),
\end{aligned}
$$




$$
\begin{aligned}
& \theta_{x}=\sum_{i}\left(i-\mu_{x}\right)^{2} \sum_{j} p_{d \theta}(i, j), \\
& \theta_{y}=\sum_{j}\left(j-\mu_{x}\right)^{2} \sum_{i} p_{d \theta}(i, j),
\end{aligned}
$$

\subsubsection{Wavelets de Gabor}

A transformada de Gabor foi criada em 1946 por Denis Gabor (Gabor, 1946) e no contexto atual é uma das técnicas mais usadas em extração de características de imagens e análise de textura por sua relevância biológica e propriedades técnicas, a transformada de Gabor tem forma semelhante aos campos receptivos das células simples do córtex visual primário (Daugman, 1980).

Esta técnica tem sido aplicada com sucesso em biometria, segmentação de imagens reconhecimento de textura, entre muitos outros campos e os resultados mais bem sucedidos são relatados por (Manjunath e Ma, 1996) onde foi mostrado que a transformada de Gabor obtém melhores resultados que outros métodos que trabalham com a transformada de wavelet (PP, TWT, MR-SAR).

A transformada de Gabor bi-dimensional é uma função gaussiana bi-dimensional modulada com uma senóide orientada com uma determinada freqüência $W$ e em uma determinada direção $\theta$, sua forma bi-dimensional no domínio do espaço $g(x, y)$ e da freqüência $G(u, v)$ é dada pelas equações embaixo.

$$
\begin{gathered}
g(x, y)=\left(\frac{1}{2 \pi \sigma_{x} \sigma_{y}}\right) \exp \left[-\frac{1}{2}\left(\frac{x^{2}}{\sigma_{x}^{2}}+\frac{y^{2}}{\sigma_{y}^{2}}\right)+2 \pi j W x\right], \\
G(u, v)=\exp \left\{-\frac{1}{2}\left[\frac{(u-W)^{2}}{\sigma_{u}^{2}}+\frac{v^{2}}{\sigma_{v}^{2}}\right]\right\},
\end{gathered}
$$

A transformada de Gabor pode ser adaptada como wavelet, neste caso estas equações são usadas como wavelet mãe. Em seguida, um dicionário de filtros pode ser obtido por dilatações e rotações de $g z(x, y)$ através da função de geração proposta em (Manjunath e Ma, 1996):

$$
g_{m n}(x, y)=a^{-m} g\left(x^{\prime}, y^{\prime}\right),
$$

Onde $a>1$ e $m, n$ especificam a escala e orientação respectiva, com $m=$ $0,1, \ldots, M-1 e n=0,1, \ldots, N-1 M$ é o número total de escalas e $N$ é o número total de orientações. 


$$
\begin{gathered}
x^{\prime}=a^{-m}(x \cos \theta+y \sin \theta), \\
y^{\prime}=a^{-m}(-x \sin \theta+y \cos \theta),
\end{gathered}
$$

Quando $\theta=\frac{n k}{N}$ o fator de escala $a^{-m}$ é necessário para garantir que a energia é independente de $m$. A escolha dos parâmetros ideais é baseado em modelos matemáticos apresentados em (Manjunath e Ma, 1996).

Este modelo garante uma cobertura máxima no espectro de Fourier com menor redundância de informação. Os valores $U_{l}$ e $U_{h}$ vão denotar os limites inferior e superior do centro de freqüências de interesse. Os sigmas ideais para cada filtro são obtidos pelas seguintes equações:

$$
\begin{gathered}
a=\left(\frac{U_{h}}{U_{l}}\right)^{\frac{1}{M-1}}, \\
\vartheta_{x}=\frac{(a+1) \sqrt{2 \ln 2}}{2 \pi a^{m}(a-1) U_{l}}, \\
\vartheta_{y}=\frac{1}{2 \pi \tan \left(\frac{\pi}{2 N}\right) \sqrt{\frac{U_{h}^{2}}{2 \ln 2}-\left(\frac{1}{2 \pi \vartheta_{x}}\right)^{2}}},
\end{gathered}
$$

Os valores $\vartheta_{x}$ e $\vartheta_{y}$ caracteriza o domínio espacial e extensão de banda do filtro na direção $x$ e $y$ respectivamente

\subsubsection{Wavelets de Gabor e outros extratores}

Um dos pontos fracos do uso de Gabor wavelets é a etapa de extração de características, geralmente é realizado o cálculo de um valor estatístico de cada uma das imagens convoluidas e o vetor de características é obtido pela concatenação dos valores estatísticos gerados. A literatura mostra que existem muitas tentativas de melhorar a etapa de extração de características usando técnicas mais sofisticadas que forneçam informações mais relevantes de cada uma das imagens geradas no processo de convolução. Algumas aproximações usam características de primeira ordem em textura, outras usam algoritmos mais complexos que geram um número maior de atributos por imagem, mas, 
conseguem extrair maior informação significativa.

O resultado de uma convolução de uma imagem $I(x, y)$ e o conjunto de wavelets de Gabor $\varphi f_{u}, m, n$ é definido como:

$$
g i_{m, n}(x, y)=I(x, y) * \varphi f_{u}, m, n,
$$

Onde $\varphi f_{u}, m, n$ é a wavelet de Gabor de freqüência central $f_{u}$, escala $m$ e orientação $n$

A literatura relacionada mostra que os métodos mais efetivos são baseados em estatísticas de primeira e segunda ordem (Bandzi, 2007), (Grigorescu et al., 2002), padrões locais binários (Zhang et al., 2005), (Lei, 2008) e Momentos invariantes de textura (Muneeswaran et al., 2005).

O esquema de implementação do uso de extratores é similar em todos os trabalhos, a figura 3.6 mostra o processo.

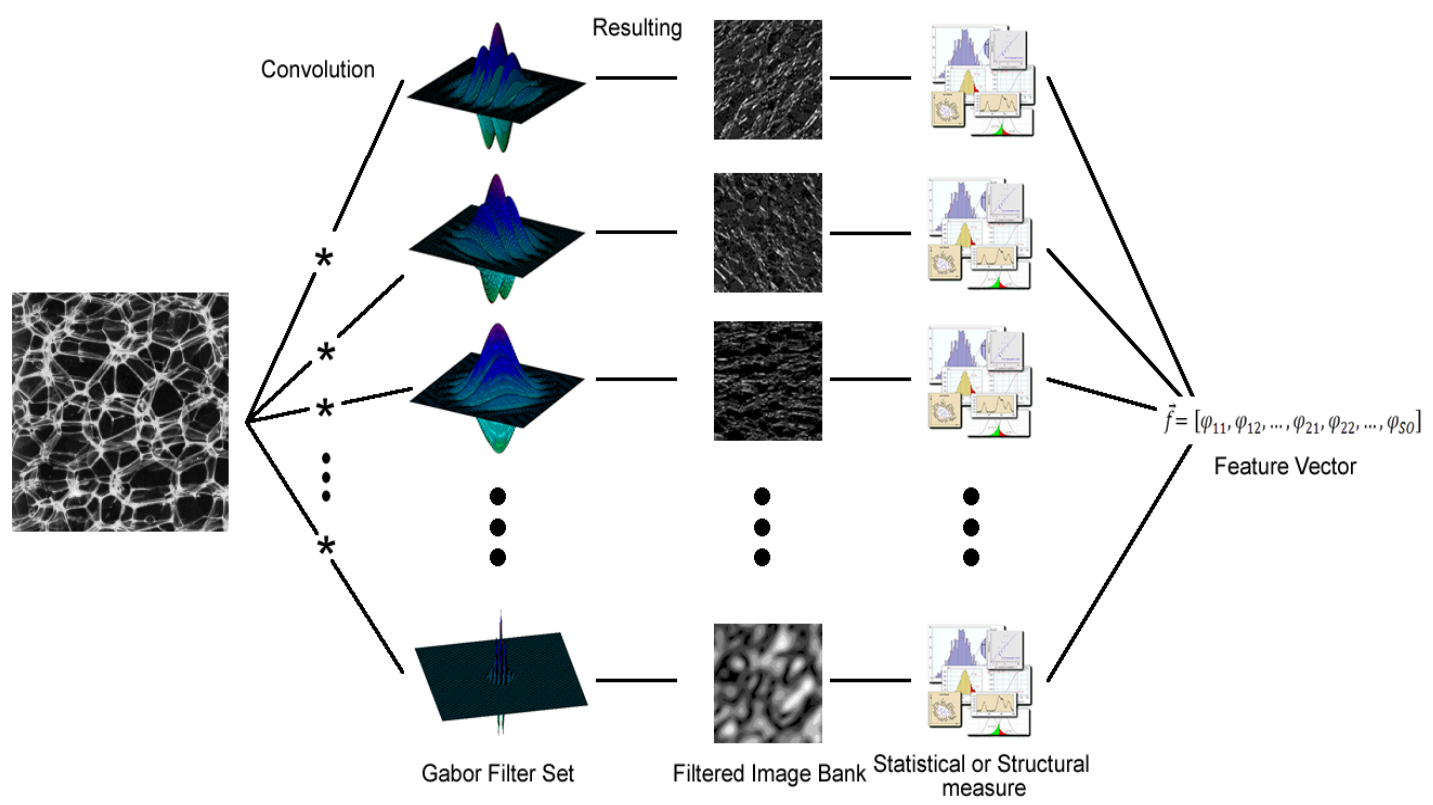

Figura 3.6: Processo de extração de características (adaptado de (Zuniga e Bruno, 2010). 


\subsubsection{Fractais}

\subsubsection{Método Boulingand-Minkowsky}

Boulingand-Minkowksy é um dos métodos mais exatos para o cálculo da dimensão fractal de um objeto, é sensível a pequenas mudanças e pode detectar diferenças pequenas entre dois objetos que seria difícil de encontrar com algoritmos estruturais convencionais (Tricot, 1995).

O método é baseado no estudo da área de influência criada pela dilatação da forma por um disco de raio $r$ na Figura 3.7

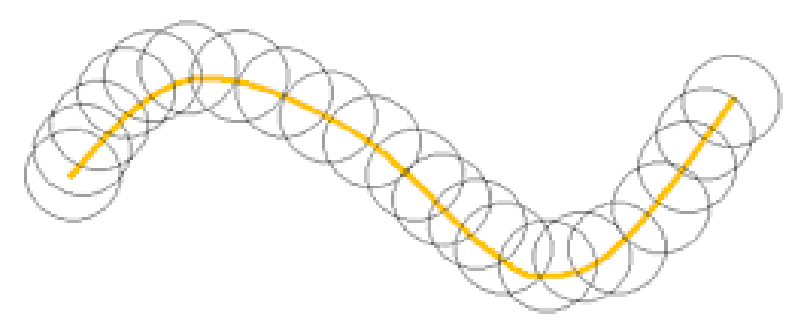

Figura 3.7: Dilatação de uma curva com um disco. (Backes, 2006)

$$
A_{r}=\left\{x \in R^{2}|\exists y \epsilon A:| x-y \mid \leq r\right\},
$$

sendo $B_{r}(x)$ um disco de raio $r$ e $A \in R^{2}$ a forma analisada, definimos a dilatação de $A, A_{r}$, como o conjunto de pontos em $R^{2}$ que se encontram a uma distância de $A$ menor ou igual a $r$ (Backes, 2006):

Para o cálculo da dimensão fractal modifica-se o raio de dilatação $r$ do disco ao longo do contorno do objeto na imagem, os pixels limitados pelo disco são somados (se o pixel encontra-se dentro da área de dilatação seu valor é de 1) para gerar uma área de dilatação A(r), o raio de dilatação é modificado até que as novas áreas não forneçam informações relevantes do objeto, assim o cálculo da dimensão fractal é dado por:

$$
D=2-\lim _{r \rightarrow 0} \frac{\ln (A(r))}{\ln (r)},
$$

onde D é a dimensão fractal da imagem binária.

Depois se traça um gráfico log-log onde o eixo $y$ é o logaritmo da área de influência $A(r)$ e o eixo $x$ o tamanho do raio $r$, neste gráfico obtém-se a 
aproximação de uma reta mediante regressão linear com coeficiente angular $\alpha$ e a dimensão fractal de A é $D=2-\alpha$.

O método Bouligand-Minkowski tem um custo computacional alto, mas a transformada de distância euclidiana (EDT) pode ser usada para melhorar o tempo de processamento do cálculo da área de influência (Fabbri et al., 2008).

\subsubsection{Dimensão Fractal Multiescala}

Uma das características da curva log-log do método Bouligand-Minkowski é a saturação de pontos conforme o raio cresce isto significa que a curva possui riqueza de detalhes que não podem ser expressos em um valor numérico, para isto é necessário usar técnicas de análise de sinais para obter a maior quantidade de informação relevante da curva.

Usando a primeira derivada da curva $u(t)$ é possivel encontrar a função que une as mudanças na dimensão fractal à dilatação do raio $r$ (Backes e Bruno, 2008), esta função é chamada Dimensão Fractal Multiescala (DFM) e é definido como:

$$
D F M=2-\frac{d u(t)}{d t},
$$

Onde $d u(t) / d t$ é a derivada da curva log-log calculada pelo método BouligandMinkowski como é apresentado na Figura 3.8

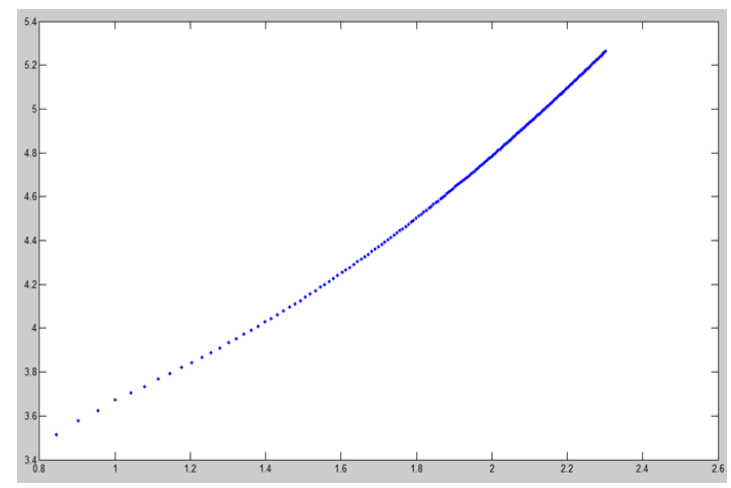

(a)

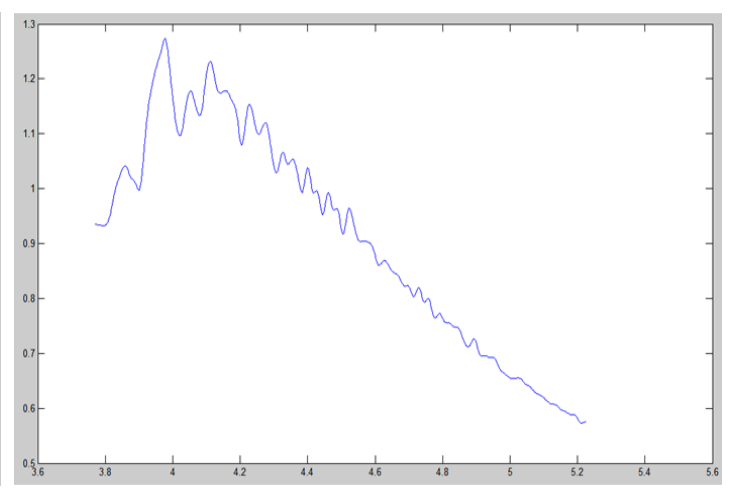

(b)

Figura 3.8: a imagem (a) é a curva log-log, a imagem (b) a curva derivada

Existem métodos para fazer derivação de curvas discretas, mas alguns deles tem um custo computacional muito alto e não obtém bons resultados, para 
ter a maior precisão possível na derivação da curva usa-se a propriedade derivativa da transformada de Fourier, esta propriedade permite fazer o cálculo da derivada no espectro e tem melhor desempenho que outros métodos numéricos já que considera todos os pontos para fazer o cálculo (Backes e Bruno, 2008).

O uso de métodos derivativos traz consigo um problema, uma tendência enfatizar ruídos do sinal especialmente os de alta freqüência, para evitar este problema são usados filtros de suavização (gaussiano). Tomando isto em conta o método de derivação baseado na propriedade derivativa da transformada de Fourier pode ser formulado como:

$$
\frac{d u(t)}{d t}=F^{\{-1\}}\left\{F\{u(t)\} F\left\{g_{\sigma}(t)\right\}(j 2 \pi f)\right\},
$$

sendo

$$
g_{\sigma}(t)=\frac{1}{\sigma \sqrt{2 \pi}}\left(\frac{-t^{2}}{2 \sigma^{2}}\right),
$$

onde $t$ e $u(t)$ são o logaritmo do raio e o logaritmo da área de influência do método, $f$ é a freqüência j é um número imaginário $g_{\sigma}(t)$ é a função gaussiana com desvio padrão $\sigma$.

Alguns aspectos têm que se levar em conta antes de aplicar o método de derivação, o sinal $u(t)$ deve ter amostragem regular, para isto é necessário tirar os primeiros pontos do sinal e interpolar o resto de pontos.

O problema com a transformada de Fourier é que é descontínuo nas extremidades do sinal, então é necessário aplicar um esquema de reflexão da curva como é mostrado na Figura 3.10.

Ao final do método obtém-se a assinatura do objeto conforme ilustra a Figura 3.11 com um exemplo para as letras A,P e R.

Esta assinatura pode ser usada diretamente para classificação do objeto, mas a alta dimensionalidade do sinal é um problema que pode ser solucionado com o uso de descritores Fourier para obter os $N$ descritores mais importantes do sinal (Costa e Cesar, 2000). 


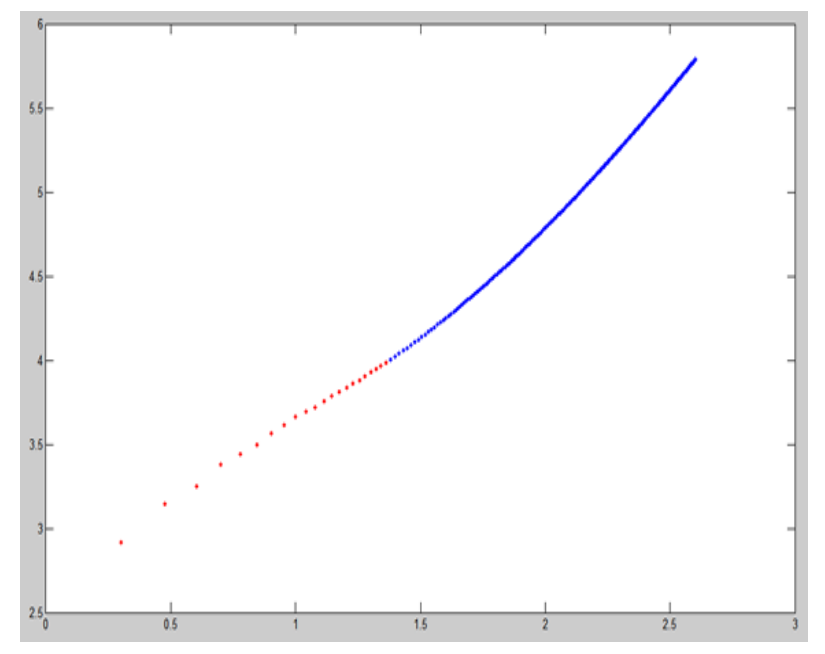

Figura 3.9: Os pontos em vermelho não são considerados para o método

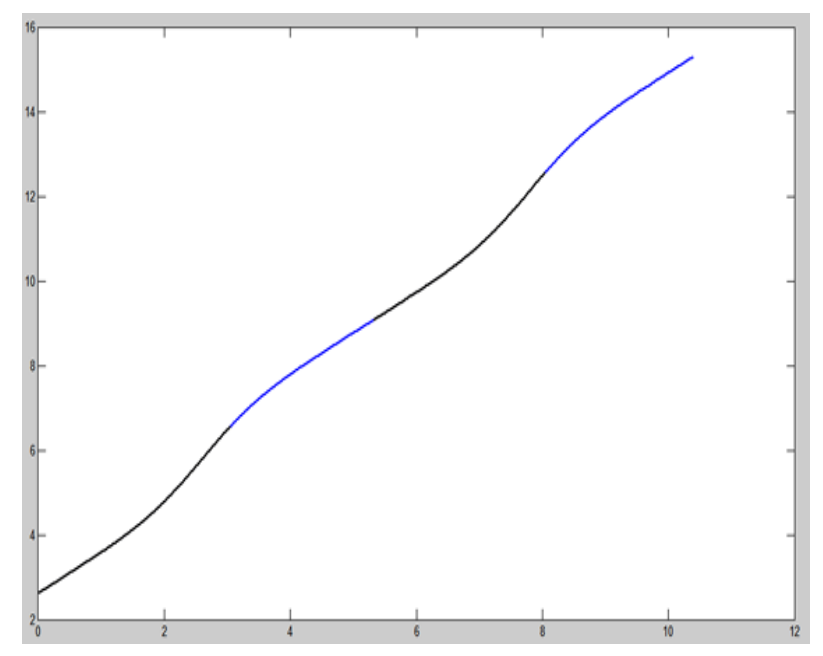

Figura 3.10: esquema de reflexão da sinal para evitar o fenômeno de Gibbs, o cor preto e a sinal original

\subsubsection{Dimensão Fractal Volumetrica}

Os métodos de estimativa de dimensão fractal estudados trabalham com imagens binárias. Entretanto, como este trabalho utiliza texturas, seria interesante adotar dimensão fractal nas imagens de niveis de cinza ou coloridas. O método de cálculo da dimensão fractal foi estendido para trabalhar com estas imagens na proposta de (Backes et al., 2009).

Para isto, a seguinte aproximação é tomada. Dada uma imagem $A \epsilon R^{2}$ a superfície $S \epsilon R^{3}$ é gerada, esta superfície $S$ é gerada transformando cada pixel 


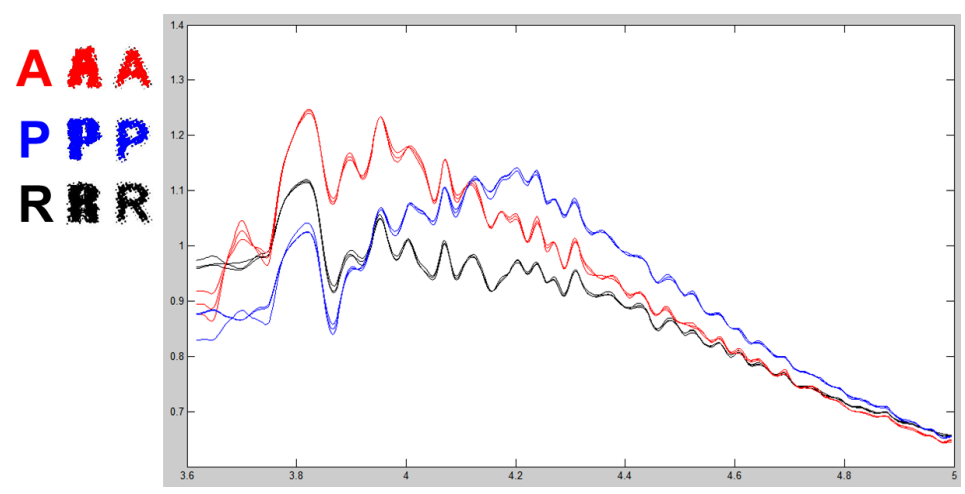

Figura 3.11: Assinaturas de 3 letras A,P,R com diferentes níveis de ruido

da imagem original num ponto $p=(y, x, z), p \epsilon R^{3}, X$ e $Y$ são as coordenadas dos pixels na imagem e $z=A(y, x)$ (Backes et al., 2009).

Depois, a dilatação da superfície $S$ com uma esfera de raio $r$ a DF pode ser estimada

$$
D=3-\lim _{r \rightarrow 0} \frac{\log (V(r))}{\log (r)}
$$

com

$$
V(r)=\left\{p^{\prime} \epsilon R^{3}|\exists p \epsilon S:| p-p^{\prime} \mid \leq r\right\}
$$

Onde $p^{\prime}=\left(x^{\prime}, y^{\prime}, z^{\prime}\right)$ é um ponto em $R^{3}$ que dista de $p=(x, y, z)$ um valor menor ou igual a $r, V(r)$ é o volume calculado, a Figura 3.12 amostra a transformação de uma imagem em escala de cinza ao espaço 3D.

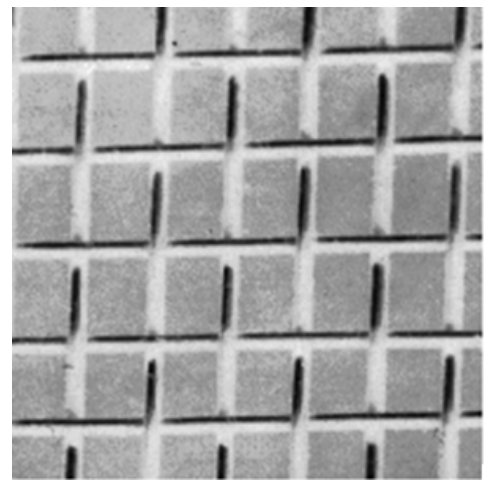

(a)

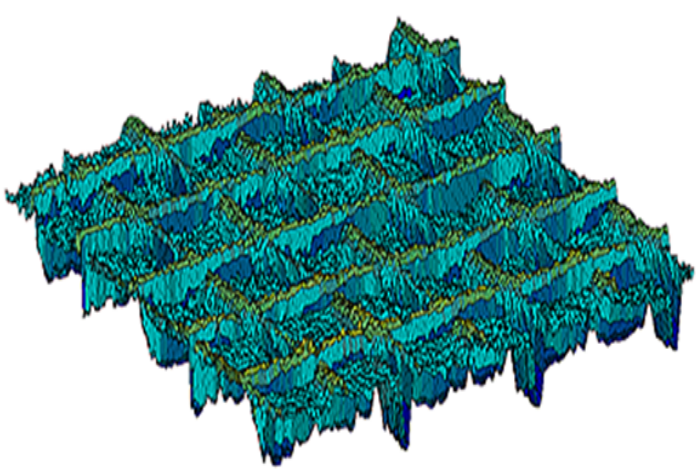

(b)

Figura 3.12: Geração da superfície, (a) é a imagem original, (b)a superfície $S$ 


\subsubsection{Wavelets de Gabor e Fractais}

Um dos métodos propostos pelo pesquisador neste trabalho de mestrado é o uso de fractais como extrator de características das wavelets de Gabor Zuniga e Bruno (2010). As propriedades de extração de características dos métodos fractais mostram-se ideais para gerar uma assinatura fractal de cada uma das imagens convoluidas resultantes do processo de Gabor. A assinatura fractal extraída de cada imagem convoluida fornece informações mais detalhadas da que a maioria de descritores estatísticos poderia fornecer, mas, o processo envolve concatenar estas assinaturas que dependendo do número de escalas e orientações usadas podem geram um vetor de características final de alta dimensionalidade, para resolver isto è necessário técnicas de analise de sinais para reduzir a dimensionalidade das assinaturas mantendo a maior quantidade de informação possível. Para resolver este problema é usada a técnica de descritores fourier para a redução da dimensionalidade de cada assinatura antes da concatenação.

A assinatura fractal representa as relações entre intensidades dos pixels de uma imagem, mesmo pequenas mudanças nos padrões podem produzir mudanças significativas na assinatura. O método proposto usa a dimensão fractal volumétrica para extrair uma assinatura fractal de cada uma das imagens convoluidas no processo de Gabor. Cada assinatura gerada é analisada independentemente para a extração do seus $N$ descritores Fourier mais importantes.

Os descritores Fourier são baseados nas propriedades da transformada de Fourier de sinais, o objetivo de extrair descritores Fourier é reduzir a dimensionalidade de um sinal sem perda significativa de informação, quanto menos descritores são usados maior é perda de informação do sinal original, o processo é explicado na Figura 3.14

Seja $g i_{m, n}(x, y)$ a imagem convoluida resultante da equação 3.27. Seja $e$ o vetor de distâncias euclidianas $e=\left[1, \sqrt{2}, \sqrt{3}, \ldots, \sqrt{r_{\text {max }}}\right]$, a assinatura fractal volumétrica de cada imagem convoluida é definida como:

$$
\omega_{m, n}(z)=\left\{V F D\left(g i_{m, n}(x, y), r\right) \mid \forall r \in e\right\},
$$

onde $r$ é um raio do vetor $e$ e $\omega_{m, n}(z)$ é um vetor que contém as assinatu- 


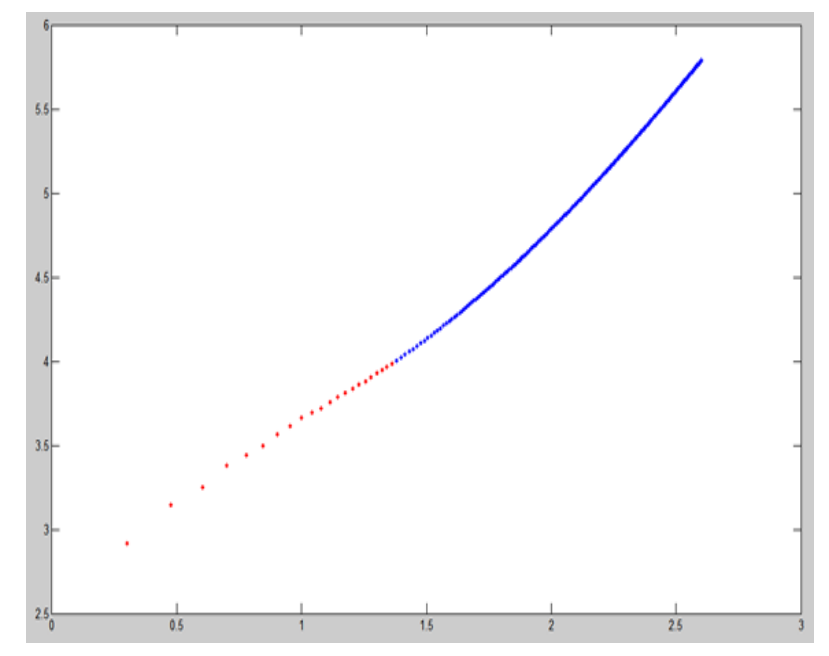

Figura 3.13: Cálculo de assinaturas fractais no processo de Gabor.

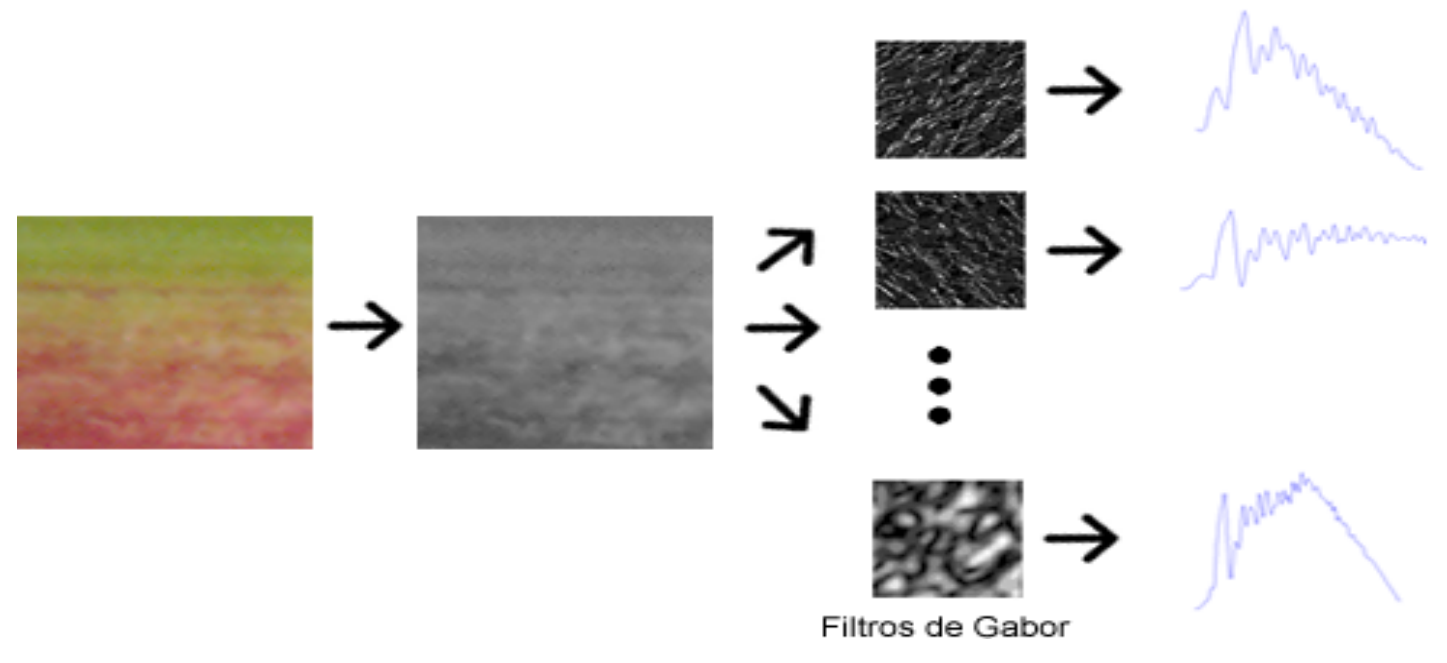

Figura 3. 14: Cálculo das assinaturas no processo de Gabor e fractais, de cada assinatura é extraido $N$ descritores Fourier.

ras fractais para todas as imagens convoluidas $m, n$. Finalmente são usados descritores Fourier para a redução das assinaturas selecionando os $N$ principais componentes de cada assinatura. O cálculo dos descritores Fourier está definido pela equação:

$$
\phi_{m, n}(z)=\left\{\lambda\left(\omega_{m, n}, N\right)\right\}
$$

onde $\left\{\lambda\left(\omega_{m, n}, N\right)\right\}$ são os $N$ descritores Fourier de $\omega_{m, n}$ com orientação $m$ e escala $n$. Os descritores Fourier são baseados na análise de sinais no dimínio 
de freqüência. Neste contexto, a transformada de Fourier pode ser expressa por:

$$
F(u)=\frac{1 / N}{\sum_{x=0}^{N-1} f(x) e^{-2 \pi \mu x j / N}},
$$

sendo $\mu=0,1,2, \ldots N-1$

Neste trabalho os descritores $D(u)$ são obtidos em duas etapas. Na primeira, efetua-se o cálculo da transformada de Fourier e calcula-se a magnitude da transformada obtida por :

$$
\|F(u)\|=\left[R^{2}(u)+I^{2}(u)\right]^{1 / 2},
$$

Os valores de $\|F(u)\|$ correspondendo às menores freqüências são os descritores principais da assinatura. Finalmente é aplicada uma função de normalização para manter a tolerância a ruídos e variações geométricas.

$$
D(u)= \begin{cases}0, & \text { se } f=0 \\ D(0) / D(u), & \text { se } f \neq 0 \\ , & \end{cases}
$$

Finalmente o vetor de característica consiste na concatenação dos principais componentes previamente calculados:

$$
F=\left[\phi_{1,1}(1), \phi_{1,1}(2), \ldots, \phi_{1,1}(z), \phi_{1,2}(1), \phi_{1,2}(2), \ldots, \phi_{1,1}(z), \ldots, \phi_{m, n}(z)\right]
$$

\subsubsection{Padrões locais binários}

O operador de padrão local binário (LBP) originalmente proposto por (Ojala et al., 2002) é definido como uma medida invariante em escala de cinza de textura em imagens, derivada de uma definição geral de microtextura. O operador LBP é uma medida poderosa para extrair características de textura das imagens mostrando excelentes resultados em muitos estudos, o operador LBP é especialmente aplicadas a reconhecimento de rostos. O operador LBP pode ser visto como uma abordagem unificadora para os modelos estatística e estrutural de análise de textura. 
Talvez a propriedade mais importante do operador LBP em aplicações no mundo real é a sua invariância contra as alterações do nível de cinza. Outro igualmente importante é a sua simplicidade computacional, o que torna possivel analisar imagens em ambientes complexos em tempo real. O método de LBP e suas variantes já foram utilizados em um grande número de aplicações especialmente em reconhecimento de faces (Zhao e Pietikainen, 2007), (Ahonen et al., 2004) .

O operador LBP original rotula os pixels de uma imagem limiarizado a vizinhança de $3 \times 3$ de cada pixel $f_{p}(p=0,1, \ldots, 7)$ com o valor central $f_{c}$ e considerando o resultado como um número binário de acordo com:

$$
S\left(f_{p}-f_{c}\right)= \begin{cases}1, & f_{p}=f_{c} \\ 0, & f_{p}<f_{c}\end{cases}
$$

Depois atribuindo um fator binomial $2^{p}$ para cada $S\left(f_{p}-f_{c}\right)$ o valor final e obtido com a equação:

$$
L B P=\sum_{p=0}^{7} S\left(f_{p}-f_{c}\right) 2^{p},
$$

O que caracteriza a estrutura especial da textura na imagem, este processo e feito na imagem inteira mediante uma máscara de convolução e gera o mapa LBP o processo é explicado na Figura 3.15.

\begin{tabular}{|l|l|l|}
\hline 196 & 174 & 198 \\
\hline 178 & 173 & 160 \\
\hline 168 & 172 & 160 \\
\hline
\end{tabular}$\longrightarrow$\begin{tabular}{|l|l|l|}
\hline 1 & 1 & 1 \\
\hline 1 & & 0 \\
\hline 0 & 0 & 0 \\
\hline
\end{tabular}$\longrightarrow(10000111)_{2}=135$

Figura 3.15: Processo de extração de características do operador LBP, o novo valor e montado desde o vizinho esquerdo central.

\subsubsection{Textura Colorida}

\subsubsection{Dimensão Fractal Volumétrica Multiespectral}

Os métodos de estimativa de dimensão fractal explicados anteriormente não consideram informação de cor das imagens, isto faz com que informação 
importante não seja considerada para a análise. Numa tentativa de tornar esta informação útil Backes e Bruno (Backes e Bruno, 2008) propuseram estimar a dimensão fractal da interação dos canais de cor de uma imagem.

Para gerar a superfície 3-dimensional considera-se cada componente da imagem $(R, G, B)$ e gera-se a superfície 3-dimensional onde $x$ e $y$ são as coordenadas da imagem e cada uma das componentes de cor da imagem representa um ponto no espaço $S(x ; y ; z)$ onde $z$ é o valor da intensidade.

Na Figura 3.16 é apresentada uma imagem de textura (a). com sua representação dos níveis de cinza (b) e dos canais cromáticos (c).

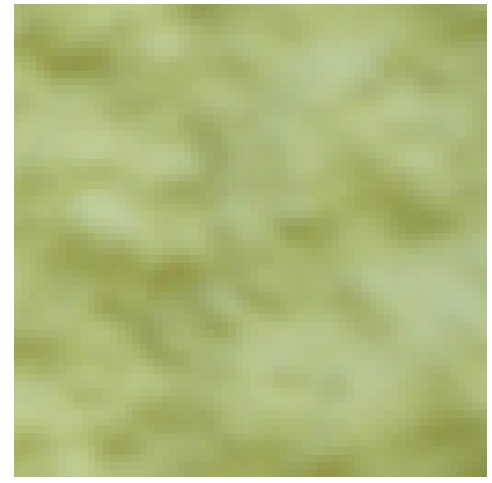

(a) Imagem original

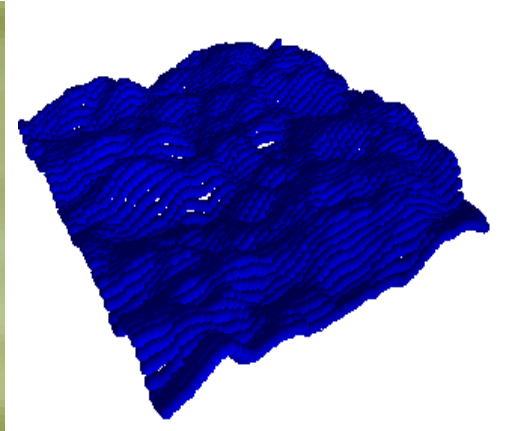

(b) superfície simples

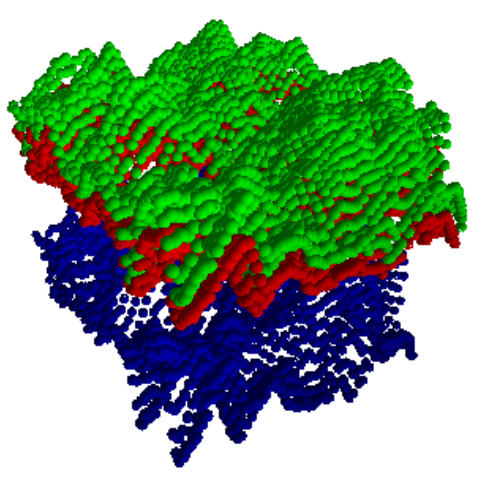

(c) espaço intercores

Figura 3.16: diferença entre as superfícies geradas (Backes e Bruno, 2008)

A equação utilizada para estimar a dimensão fractal é a mesma utilizada para imagens em níveis de cinza, a diferença é que a interação entre os espaços de cores vão gerar mudanças mais facilmente identificáveis, obtendo assim, informação que não seria capturada por métodos que processem imagens em escala de cinza.

\subsubsection{Wavelets de Gabor multiespectrais e fractais}

Esta técnica para o processamento de textura colorida é o resultado da pesquisa neste projeto. Uma imagem colorida pode conter mais de um canal de cor, no espaço RGB os 3 canais de cor contém informações que podem ajudar a diferenciar um objeto de outro. Para adaptar uma imagem colorida ao método de Gabor wavelets toma-se uma aproximação baseada na decomposição dos canais de cor e processamento de cada canal de cor por separado, 
finalmente estes são unidos de novo para formar as imagens convoluidas e é aplicada a técnica de dimensão fractal volumétrica multiespectral para a extração de características, a figura 3.17 mostra o processo

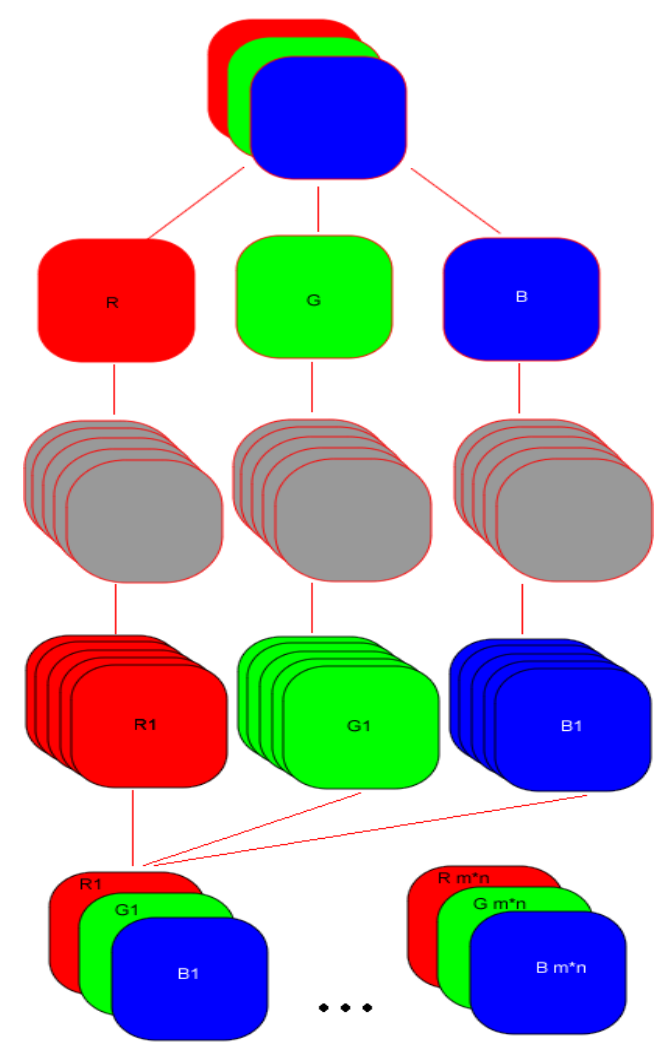

Figura 3.17: Processo de extração de características do Gabor usando informação de cor.

De cada imagem convoluida e reconstruída ao espaço RGB é aplicada DFV para a geração das assinaturas, assim a informação de cor é considerada para o fornecimento de características sem a necessidade de acrescentar a dimensionalidade do vetor de características resultantes.

Este método foi proposto no mestrado e visa expandir a técnica monoespectral apresentada em Zuniga e Bruno (2010) considerando a informação de cor da imagem. Este novo método propõe também o uso de análise canônica para redução da dimensionalidade das assinaturas geradas. A aplicação da técnica de análise canônica é considerada pelo reduzido número de descritores que gera com pouca perda de informação (geralmente os 10 primeiros descritores 
contém o $99 \%$ da informação da assinatura.

A análise canônica discriminante (CDA) é uma técnica de redução de dimensionalidade relacionada à técnica de análise de componentes principais (PCA). O objetivo da CDA é achar uma combinação linear de variáveis quantitativas que forneçam a máxima separação entre classes. Estas combinações lineares possuem o poder de produzir um número reduzido de variáveis independentes (descorrelacionadas) chamadas variáveis canônicas.

A dispersão total entre os vetores de características é dada por:

$$
S=\sum_{i=1}^{N}\left(\varphi_{i}-\vec{M}\right)\left(\varphi_{i}-\vec{M}\right)^{\prime},
$$

onde $\vec{M}$ é o vetor global meio e $\overrightarrow{\varphi_{i}}$ contém as filas de descritores de todos os vetores para uma classe $i$, definido por:

$$
\begin{gathered}
\overrightarrow{\varphi_{i}}=F_{M}\left(x_{\sigma}\right), \\
\vec{M}=\frac{\sum_{x=1}^{N} F_{M}(x)}{N},
\end{gathered}
$$

Sendo que $M$ é o número total de descritores. $\mathrm{N}$ o número total de objetos, a matriz $S_{i}$ que indica a disperção dos objetos dentro de uma mesma classe, é definida como:

$$
S_{i}=\sum_{i \in C_{i}}\left(\overrightarrow{\varphi_{i}}-\overrightarrow{u_{i}}\right)\left(\overrightarrow{\varphi_{i}}-\overrightarrow{u_{i}}\right)^{\prime},
$$

onde $\overrightarrow{u_{i}}$ é o vetor médio das características para os objetos da classe $i$ definida pela equação:

$$
\overrightarrow{u_{i}}=\frac{\sum_{x=1}^{N} \vec{F}_{i}\left(x_{k}\right)}{N_{k}},
$$

A variação dentro de uma classe $S_{\text {intra }}$ indica a dispersão combinada dentro dos objetos de uma mesma classe, é definida por:

$$
S_{\text {intra }}=\sum_{i=1}^{K} S_{i}
$$


e a variação entre as classe $S_{\text {inter }}$ indica a dispersão das classes em termos de seus centróides, é definida por:

$$
S_{\text {inter }}=\sum_{i=1}^{K} N_{i}\left(\overrightarrow{u_{i}}-\vec{M}\right)\left(\overrightarrow{u_{i}}-\vec{M}\right)^{\prime},
$$

onde $K$ é o número de classes e $N$ é o número de objetos da classe $i$, finalmente temos a variação total representada por:

$$
S=S_{\text {intra }}+S_{\text {inter }}
$$

Para obter os componentes principais usamos a aproximação apresentada por Rossatto et al. (2011):

$$
C=S_{\text {inter }} * S_{\text {intra }}^{-1}
$$

A função discriminante canônica para os descritores $i$ é dada por:

$$
Z_{i}=a_{i 1} X_{1}+a_{i 2} X_{2}+,,,+a_{i p} X_{p}
$$

Onde $p$ é o número de descritores, $a_{i j}$ são os valores ordenados de $C$ sendo que $a_{1}$ é o descritor mais significativo. Esta definição leva a $Z_{i}$ descritores não correlacionados, onde $i$ é o número de descritores usados para reduzir a dimensionadidade do conjunto de dados mantendo $i<p$.

Cada assinatura fractal gerada no processo é reduzida ao conjunto de $i$ descritores de $Z_{i}$ e usada como vetor de características. 



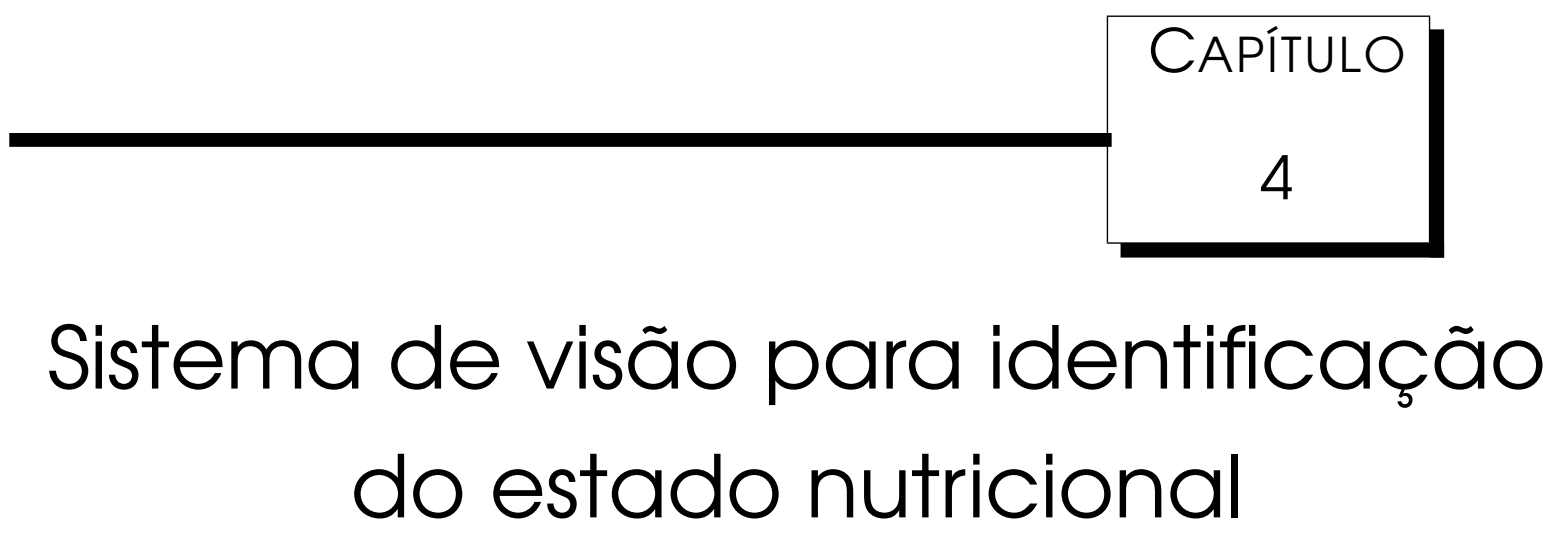

A seguir é apresentado em detalhe os métodos envolvidos em cada etapa do sistema descrevendo detalhadamente o procedimento adotado desde a aquisição das amostras até a classificação.

\subsection{Aquisição das amostras}

A aquisição de imagens é a etapa mais importante num sistema de visão artificial, a qualidade e características da imagem gerada afeta todo o funcionamento do sistema. Todo problema que pode ser solucionado com o uso de um hardware especifico ou alguma técnica para a captura deve ser usada para evitar acrescentar dificuldades extras ao processamento. Assim, foi elegido um procedimento único para as capturas e digitalização das amostras considerando os objetivos principais do trabalho.

As amostras foram coletas de uma casa de vegetação e cada folha foi limpa para remover impurezas e digitalizada usando um escanner comercial a uma resolução padrão de 1200dpi (pontos por polegada) e armazenada num formato sem perda de informação. O número de amostras usadas impossibilita 
impor mais restrições no processo de digitalização e cria a necessidade de ter um sistema o mais automático possível para o processamento de cada imagem. A Figura 4.1 mostra o processo.

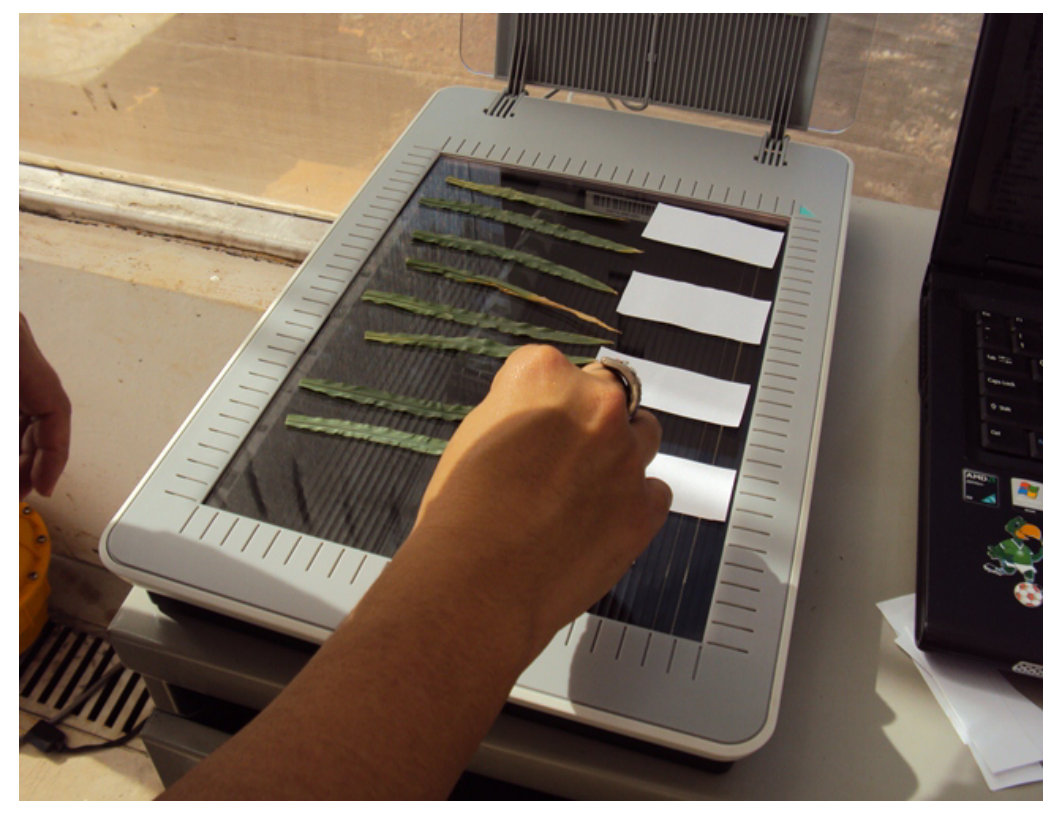

Figura 4.1: Esquema de digitalização das amostras usando um scanner comercial

Para o processo de digitalização foi definido um padrão de construção dos nomes dos arquivos, isto facilita ao sistema conhecer de antemão os conteúdos da imagem e ajuda á segmentação e geração da base de imagens. Antes de expor o padrão de nomes é necessario conhecer alguns conceitos usados na coleta de amostras:

- Dose de adubo: Cada amostra possui a dose ideal de todos os nutrientes menos do nutriente a identificar, para isso foram criadas 4 níveis de adubo na planta representados pela letra $\mathrm{T}$ : $T 1$ representa ausência total do nutriente em questão. T2 representa $1 / 3$ da dose completa, T3 2/3 da dose completa e finalmente $T 4$ é a dose completa do nutriente, considerando que uma dose completa é uma quantidade necessária para o correto desenvolvimento da planta.

- Posição da folha na planta: As folhas das plantas são nomeadas em concordância com sua posição na planta, as folhas velhas encontra-se na 
base da planta e enquanto a planta cresce gera novas folhas que vão se acumulando no topo, estas são conhecidas como folhas novas. É importante conhecer se as folhas analisadas são novas ou velhas pelo fato que alguns nutrientes só apresentam sintomas em uma de estas dependendo da mobilidade do nutriente.

- Repetição: Todas as plantas usadas possuam repetições para obter validade estatística, isto quer dizer que pelo menos 4 plantas são cultivadas em condições iguais.

- Coleta: As amostras são extraídas em distintos estágios de crescimento da planta, isto é necessário para determinar se é possível detetar a deficiência num estágio incial do crescimento para tomar medidas corretivas e até que ponto no desenvolvimento da planta é possível identificar as deficiências.

- Nutriente: Cada planta (e suas repetições) é exposto a uma deficiência de nutriente única, não é considerada mistura de nutrientes para uma mesma planta.

- Partes da folha disponíveis: Para algumas folhas não é possível digitalizada a totalidade desta, para isto é necessário determinar qual parte da folha está sendo digitalizada, para este trabalho consideramos 3 partes: base, meio e ponta.

A nomenclatura dos arquivos ficou definido como TW_FN_rXXXX_lado_coletaY_ntrNutriente_parZZZ.tiff onde $W$ é a dose de adubo usada, $N$ representa se a planta é nova ou velha, $r$ representa o número de repetições contidas na imagem, lado representa se a folha foi digitalizada pelo frente ou pelo verso. $Y$ representa o número de coleta, 1 é a primeira coleta (estágio inicial de crescimento) e 3 é o estágio final (planta madura), Nutriente representa o nutriente usado para criar a deficiência na planta, $Z Z Z$ representa as partes que a folha da imagem possui, 1 representa a ponta, 2 o meio e 3 a base. Por exemplo, a imagem T3_FV_r1234_frente_coleta2_ntrPotassio_par123.tiff representa uma folha com $2 / 3$ da dose do nutriente, é folha velha digitalizada pela frente da coleta 2 do nutriente potássio com a totalidade da folha disponível. Os concei- 
tos relacionados à parte experimental biológica são aprofundados no próximo capítulo.

\subsection{Pré-processamento}

A etapa de pré-processamento permite corrigir defeitos produzidos durante a digitalização das amostras e adequar as imagens para seu processamento. Sendo assim, neste trabalho é adotada uma estratégia de avaliação baseada em janelas da superfície da folha. O uso de janelas permite manter as características da superfície da folha num espaço limitado com a vantagem que permite gerar características consistentes (orientação, tamanho, etc) entre distintas folhas necessário para a classificação destas.

O método de pré-processamento proposto envolve (1) segmentar as folhas do fundo da imagem original e estabelecer os limites de cada folha, (2) dividir as folhas em 3 partes (base, meio e ponta), (3) depois são extraídas janelas de textura de cada uma das folhas, (4) as janelas extraídas são orientadas horizontalmente e finalmente (5) são descartadas as amostras que possuam ruídos ou outras informações não relevantes.

\subsubsection{Segmentação e divisão das folhas}

Usando técnicas de segmentação e morfologia matemática descritas nas seções 3.4.1 e 3.4.2 procura-se separar a região foliar do fundo da imagem.

Primeiro é executada uma limiarização automática com o método de otsu para obter um valor estimado do limiar necessário para separar os objetos do fundo, depois é aplicada a técnica fuzzy C-Means (Padmavathi et al., 2010) usando 2 agrupamentos (pixels do fundo, pixels da folha). A avantajem do uso de fuzzy C-Means para segmentar é que esta técnica considera as mudanças de cor da folha (típico em folhas com deficiência de algum nutriente) como parte da folha ao ter um agrupamento de pixels majoritariamente brancos e outro agrupamento de pixel de cor verde e variações próximas. Finalmente um algoritmo de componentes conectadas é usado para estabelecer as áreas de cada uma das folhas e separando as folhas pelos limites de suas áreas na imagem 
O resultado de cada uma das técnicas usadas é uma mascara que é combinada numa mascara final e aplicada sob a imagem gerando $N$ folhas de cada imagem original. $\mathrm{O}$ resultado pode ser visto na figura 4.2.

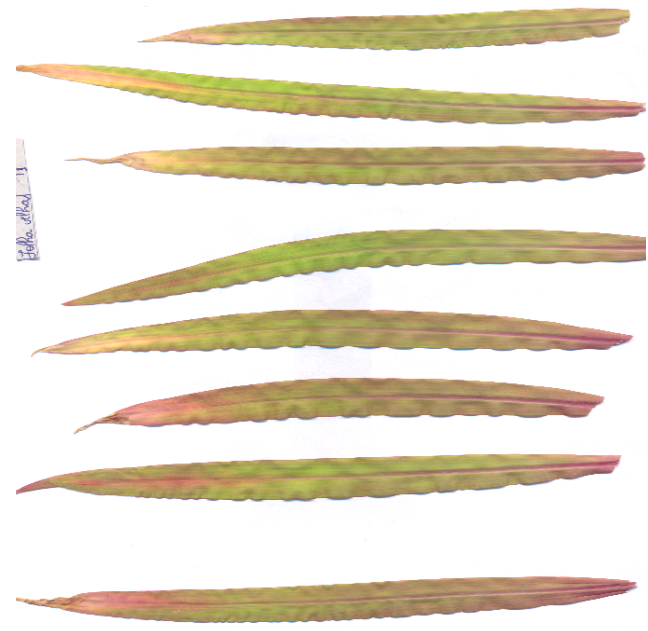

(a)

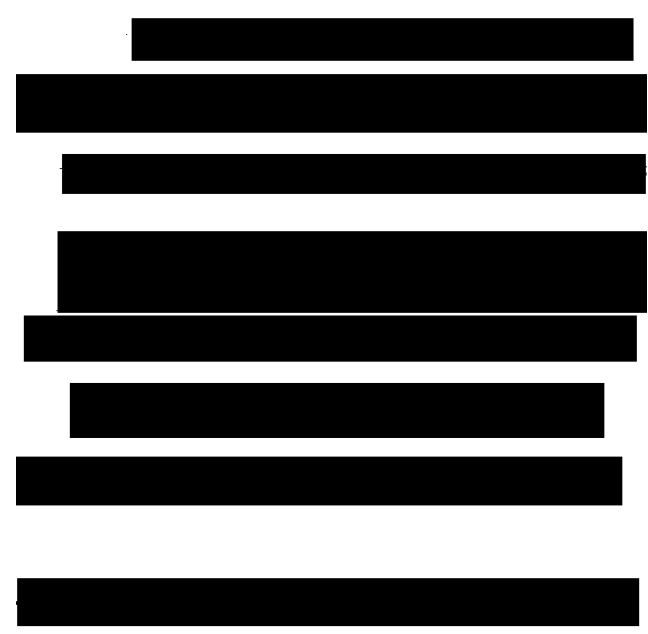

(c)

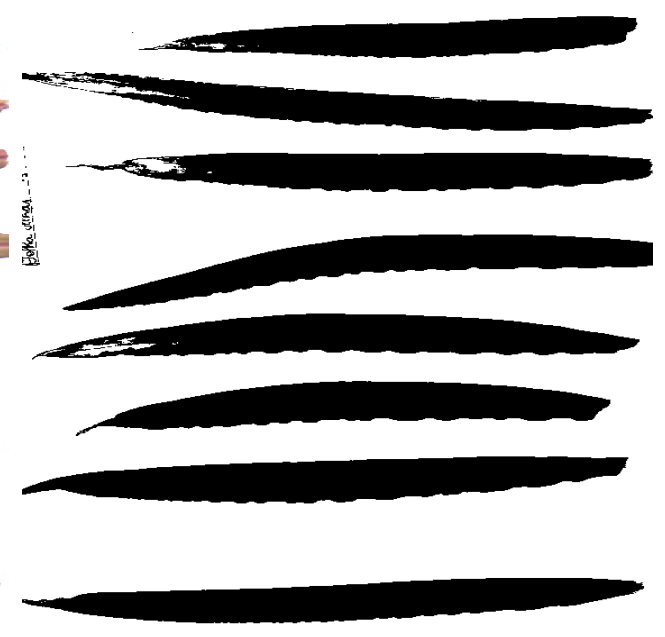

(b)

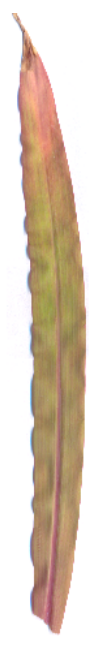

(d)

Figura 4.2: Processo de segmentação da imagem, (a) Imagem Original, (b) Imagem obtida da mistura das mascaras geradas pelo método de otsu e FCM (c) mascara de segmentação final, (d) uma das folhas segmentadas

Finalmente cada uma das folhas é dividida em 3 partes iguais (base, meio e ponta) isto é necessário para determinar a incidência de sintomas na folha da planta dependendo do nutriente usado. A Figura 4.3 mostra o processo. 


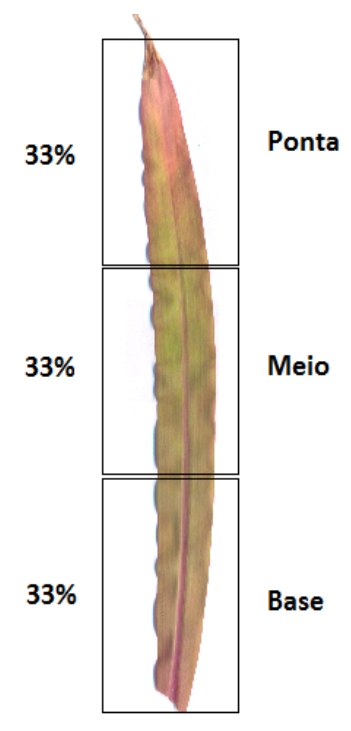

Figura 4.3: Divisão das folhas em 3 partes iguais

\subsection{2 extração de janelas texturais}

A abordagem deste trabalho propõe a análise da textura da folha, por tanto, é necessária a extração de janelas texturais da superfície da folha que abranjam áreas distintas da folha para ter maior representatividade. As janelas texturais possuem a avantajem de conter a textura num espaço limitado padrão evitando assim que outros fatores influenciem a etapa de extração de características. Desta forma, um algoritmo automático realiza a extração de $N$ janelas de cada parte da folha tentando cobrir a maior quantidade de espaço sem sobreposição.

O processo adotado para a extração de janelas é similar ao usado no método de estimativa de dimensão fractal boxcounting numa imagem. Uma grade de tamanho mxn (tamanho desejado para as janelas) é ajustada à imagem e os espaços que contem informação da superfície completa são considerados como válidos. Depois um algoritmo seleciona randomicamente $N$ imagens do total de janelas por classe para gerar as janelas representativas desta classe.

Cada janela foi salva separadamente com um sufixo ${ }_{X} X X$ denotando o número de janela permitindo o algoritmo conhecer depois a posição exata de cada janela na imagem original. O processo pode ser melhor entendido na figura 4.3 . 


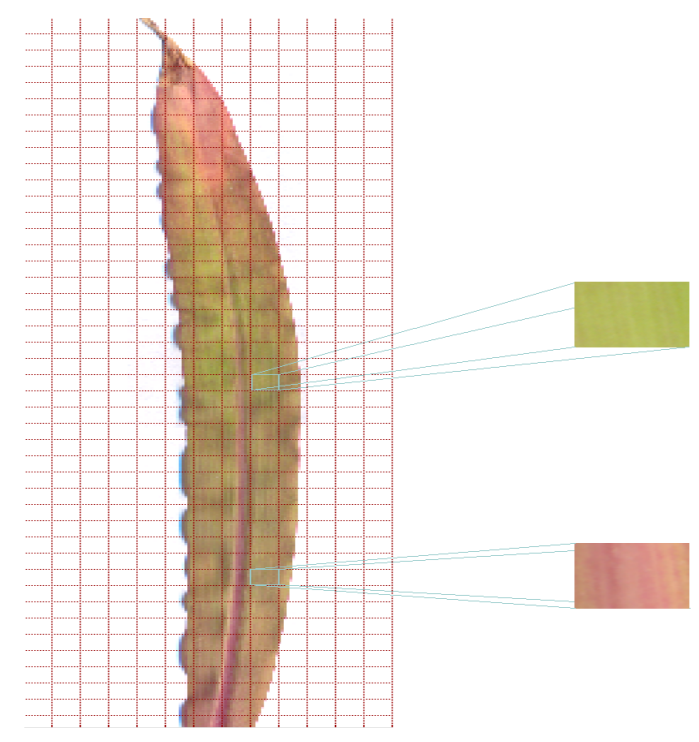

Figura 4.4: Extração de janelas texturais

\subsubsection{Reorientação das janelas texturais}

A orientação das janelas é um fator importante a considerar quando a textura é a característica mais importante. Se uma técnica de extração de características de textura não é preparada para lidar com invariância a rotação de textura produz distintos resultados sem validade estatística. Neste trabalho é recomendado digitalizar todas as folhas em posição horizontal, mas, não é possivel considerar que todas as folhas emcontram-se na posição correta, ainda mais quando uma folha pode ser longa e curva e não ter possibilidades de ficar horizontal em toda sua extensão na imagem. Para ter certeza que todas as janelas encontra-se em posição horizontal é considerado o uso de técnicas que permitam avaliar a orientação da textura e rotacionar a textura no caso esta não esteja corretamente posicionada.

A técnica adotada para a reorientação das janelas é baseada na transformada de Radon. A transformada de Radon calcula as projeções de uma imagem em direções especificadas, é definida pela equação (Hai-peng et al., 2005):

$$
R_{\theta}(p)=\int_{-\infty}^{+\infty} f\left(x^{\prime} \cos \theta-y^{\prime} \sin \theta, x^{\prime} \sin \theta+y^{\prime} \cos \theta\right) d y^{\prime}
$$

Onde 


$$
\left[\begin{array}{l}
x^{\prime} \\
y^{\prime}
\end{array}\right]=\left[\begin{array}{cc}
\cos \theta & \sin \theta \\
-\sin \theta & \cos \theta
\end{array}\right]\left[\begin{array}{l}
x \\
y
\end{array}\right]
$$

O operador mapeia a imagem $f(x, y)$ ao domínio de projeção $(p, \theta)$ onde $\theta$ é o ângulo e $p$ é a distancia ao origem do sistema de coordenadas (Hai-peng et al., 2005). A transformada gera uma assinatura de 180 pontos [0 - 179] baseada na posição espacial de pontos de intersecção no espaço de radon. a detecção da maior acumulação de pontos de intersecção para um determinado ângulo determina a orientação mais provável da textura analisada.

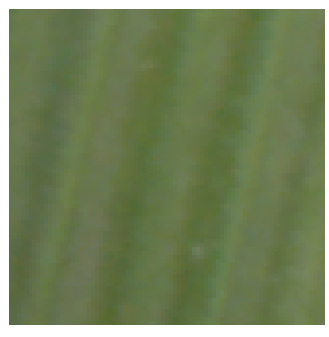

(a)

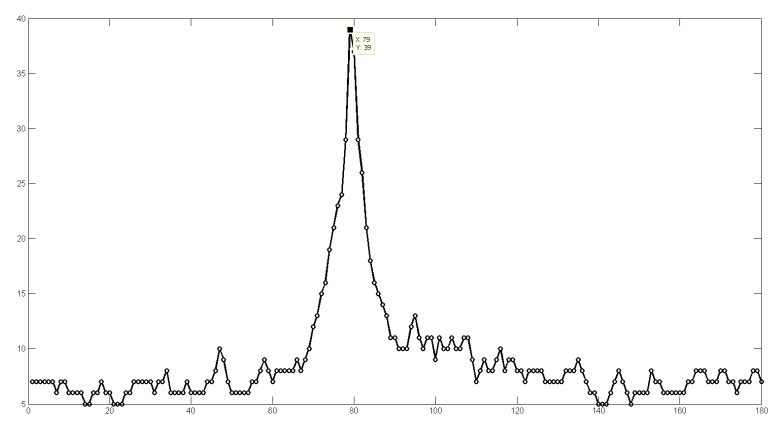

(b)

Figura 4.5: Transformada de Radon (a) imagem original, (b) acumulador da transformada mostrando que a orientação mais provável é 79

Conhecendo o ângulo da inclinação da textura é aplicada um algoritmo de rotação e a imagem é reduzida para considerar os pixels da imagem após a rotação unicamente.

\subsubsection{Descarte e seleção de janelas}

As janelas de uma mesma classe deveriam apresentar um padrão similar, mas, a sintomatologia das deficiencias nas folhas mostra padrões de cores que mudam dependendo da intensidade da deficiencia, idade da folha, etc. Neste trabalho tenta se identificar as deficiencias nutricionais baseado na textura/textura cromática, é por isso que a seleção das janelas representativas da classe é uma das etapas mais importante do processo. 
Em teoria uma deficiência manifiesta-se como uma alteração molecular e ou celular superfície da folha que pode ser descrita como mudança de cor e textura por um observador experiente. Baseado nesta teoria a mudança celular da superfície da folha pode ser identificada pelo sistema de visão, porem, a amostragem das janelas de cada folha pode ser inteiramente aleatório.

A estratégia adotada para a seleção é similar à usada em (Casanova, 2008). Considerando que uma janela de textura é representada pela função $f(x, y)$ com dimensões mxne pode ser definida por unm conjunto de $p$ atributos onde cada atributo representa alguma medida estatística da textura pode-se construir o vetor de características $x=p_{1}, p_{2}, \ldots p_{q}$ que vai determinar a dispersão das janelas num espaço $q$ dimensional.

Não é necessária a informação de cor, assim, as imagens são processadas em escala de cinza onde são extraídas duas medidas estatísticas simples (meia, variância) para determinar a uniformidade e similaridade das janelas texturais. O vetor de características de cada janela é formado por:

$$
X_{i}=\left[\theta_{i}, \vartheta_{i}\right],
$$

onde

$$
\begin{gathered}
\theta_{i}=\frac{1}{m n} \sum_{x=1, y=1}^{m, n} f(x, y) e, \\
\vartheta_{i}=\frac{1}{m n} \sum_{x=1, y=1}^{m, n}\left(f(x, y)-\theta_{i}\right)^{2},
\end{gathered}
$$

Para considerar quais amostras são ruído e quais podem ser usadas para a base de imagens final cria-se uma janela que é a média dos valores de intensidade de todas as outras janelas da classe. Esta janela é considerada como a janela padrão da classe e são escolhidos os $k$-vizinhos mais próximos destas no espaço 3-dimensional gerado com os 3 descritores estatísticos usados, onde $k$ é o número de janelas desejadas para cada classe. Para a segunda hipótese a extração de características é feita nos canais de cor RGB concatenado os resultados num vetor de características definido por:

$$
X C_{i}=\left[\theta_{i r}, \vartheta_{i r}, \theta_{i g}, \vartheta_{i g}, \theta_{i b}, \vartheta_{i b}\right],
$$


onde $r, g$, e $b$ representam os 3 canais de cor de uma imagem colorida. Uma estratégia adotada para a medição de distancia entre dados multivariados é o uso da distancia mahalanobis que é ideal quando se tem dados correlacionados (Casanova, 2008). A distancia mahalanobis é definda pela equação:

$$
R(p ; q)=\sqrt{(p-q)^{T} \sum^{-1}(p-q)},
$$

onde $\sum^{-1}(p-q)$ é a matriz de covariância, $p$ representa o vetor a medir e $q$ o vetor característico de uma janela considerada como saudavel. que chamaremos de janela padrão. Assim, toma-se a janela mais distante da janela padrão e pega-se os k-vizinhos mais próximos a esta. Com esta estratégia garantimos obter no primeiro caso um conjunto de janelas representativas sem uso de informação de cor, e no segundo caso um conjunto de janelas que diferem o máximo possivel a uma janela padrão usando informação de cor.

O número de janelas usadas por cada classe varia com cada experimento e com a disponibilidade de ter o mesmo número de janelas para todas as classes. É importante considerar que é mais difícil obter uma quantidade consistente de janelas da ponta da planta que do meio ou da base.

\subsection{Extração de características}

O objetivo da extração de características é gerar uma representação numérica exata e compacta de um objeto numa imagem. Um vetor de características ideal mostra pouca variação entre os objetos de uma mesma classe e variação entre objetos de classes distintas. As características podem ser definidas como atributos inerentes de um objeto considerando que essas características diferenciam o objeto de outros similares. Os valores de magnitude dos pixels de uma imagem digital poderiam ser usados como características primitivas desta, entretanto, a grande dimensionalidade dos dados e a pouca representatitivide de cada valor analisado separadamente geraria um vetor pouco útil. Os melhores extratores de características achados na literatura mostram o oposto ao exemplo anterior: dimensionalidade reduzida, alta representatividade, isto quer dizer que pode representar as partes mais significativas do objeto num conjunto reduzido de dados. 
Embora existam muitos extratores para diversos tipos de imagens não existe um método que seja a melhor opção para todos os casos. A necessidade de testar diversos métodos para avaliar o melhor é um problema aberto na área de visão computacional.

Nesta seção é apresentada a implementação especifica de todos os métodos de extração de características explicados na seção 3 mantendo o esquema de extração de cor, textura e textura colorida para avaliar a importância destes fatores nas imagens usadas. Só são consideradas definições especificas de implementação para cada método.

\subsection{1 cor}

\subsubsection{Histogramas coloridos}

O histograma não contém informação espacial dos pixels , contudo ainda contém informações importantes que podem ser derivadas, por exemplo, um histograma bimodal pode indicar que a imagem contém um objeto e um fundo que difere muito. Desta forma, algumas propriedades podem ser utilizadas para descrever tais características.

Seja $h(i)$ o histograma colorido de uma imagem RGB e $p(i)$ a função de densidade de probabilidade é dada por:

$$
p(i)=\frac{h(i)}{N M},
$$

onde $i=0,1, G-1$. Sendo $G$ o numero de escalas de cinza usadas, e $N, M$ as dimensões da imagem. As características usadas que melhor descrevem a textura estatisticamente são dados pelas equações:

Media:

$$
\boldsymbol{\mu}=\sum_{i=0}^{G-1} i p(i),
$$

Variância:

$$
\sigma^{2}=\sum_{i=0}^{G-1}(i-\mu)^{2} p(i)
$$

Assimetria:

$$
\boldsymbol{\mu}_{3}=\sigma^{-3} \sum_{i=0}^{G-1}(i-\mu)^{3} p(i),
$$


Kurtose:

$$
\mu_{4}=\sigma^{-4} \sum_{i=0}^{G-1}(i-\mu)^{4} p(i)-3
$$

Entropia:

$$
E=-\sum_{i=0}^{G-1} p(i) \log _{2}[p(i)],
$$

A média mede o nível de intensidade médio da imagem, a variância descreve a variação da intensidade ao redor da média, a assimetria é um valor que mede se o histograma é simétrico em torno da meia, a Kurtose é uma medida de achatamento do histograma, a entropia é uma medida de uniformidade do histograma.

Para redução do histograma inicial é necessaria a redução de cores da imagem. São usados 6 parâmetros para a redução de cor Cores $=4,8,16$, $32,64,128$ O vetor de características é gerado concatenando os valores obtidos num vetor unidimensional:

$$
F=\left[\mu, \sigma^{2}, \mu_{3}, \mu_{4}, E\right]
$$

O processo pode ser melhor entendido na Figura 4.6:

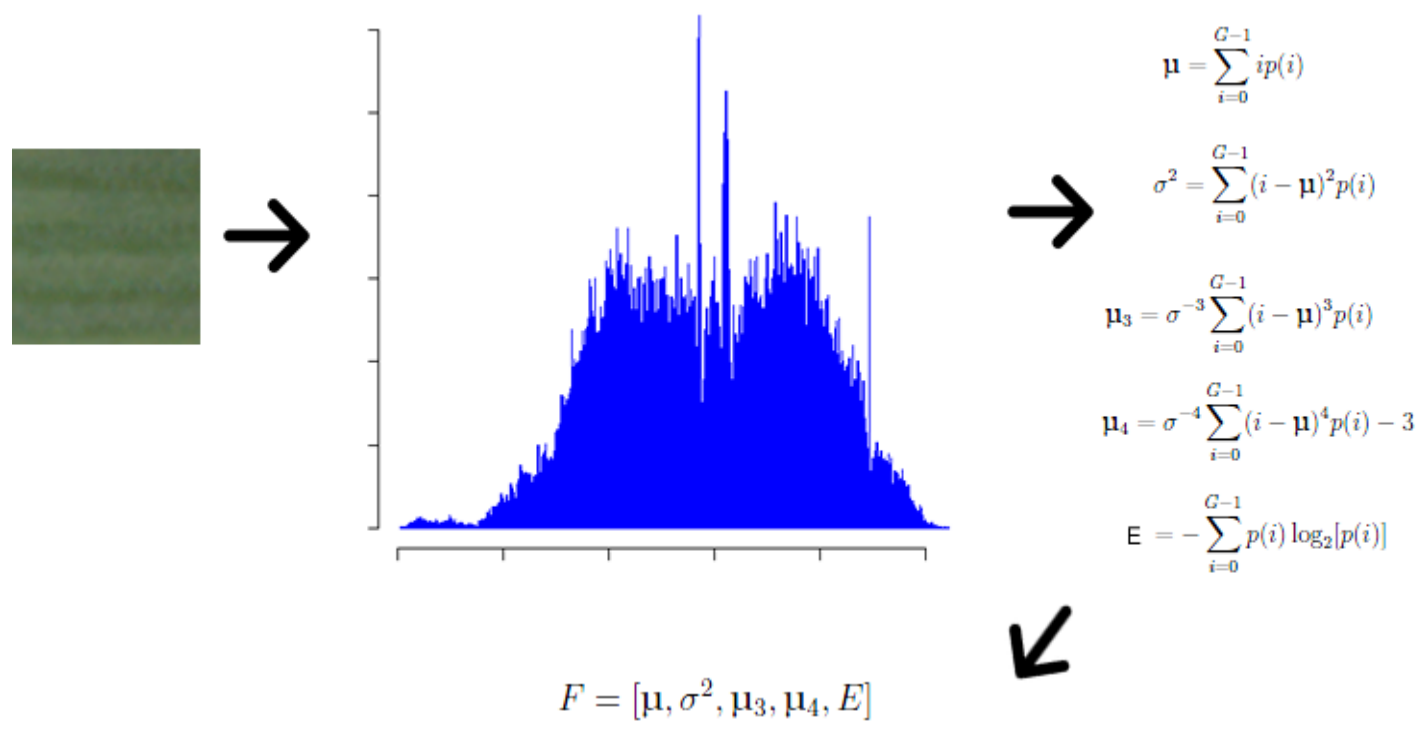

Figura 4.6: Extração de caracteristicas do histograma colorido 


\subsubsection{Border Interior classification}

Um dos fatores importantes no uso de BIC (Border Interior Classification) como extrator de características é a redução de cores na imagem antes de obter os histogramas de borda e interior. A literatura (Stehling et al., 2002) sugere o uso de 64 cores, mas, com o intuito de explorar a resposta em imagens de folhas de plantas que amostram características muito similares experimenta-se com 6 configurações: Cores $=4,8,16,32,64,128$. O número de cores determina o tamanho dos histogramas gerados, assim quanto maior o número de cores maior a dimensionalidade do vetor de características usado. O processo pode ser melhor entendido na figura 4.7:

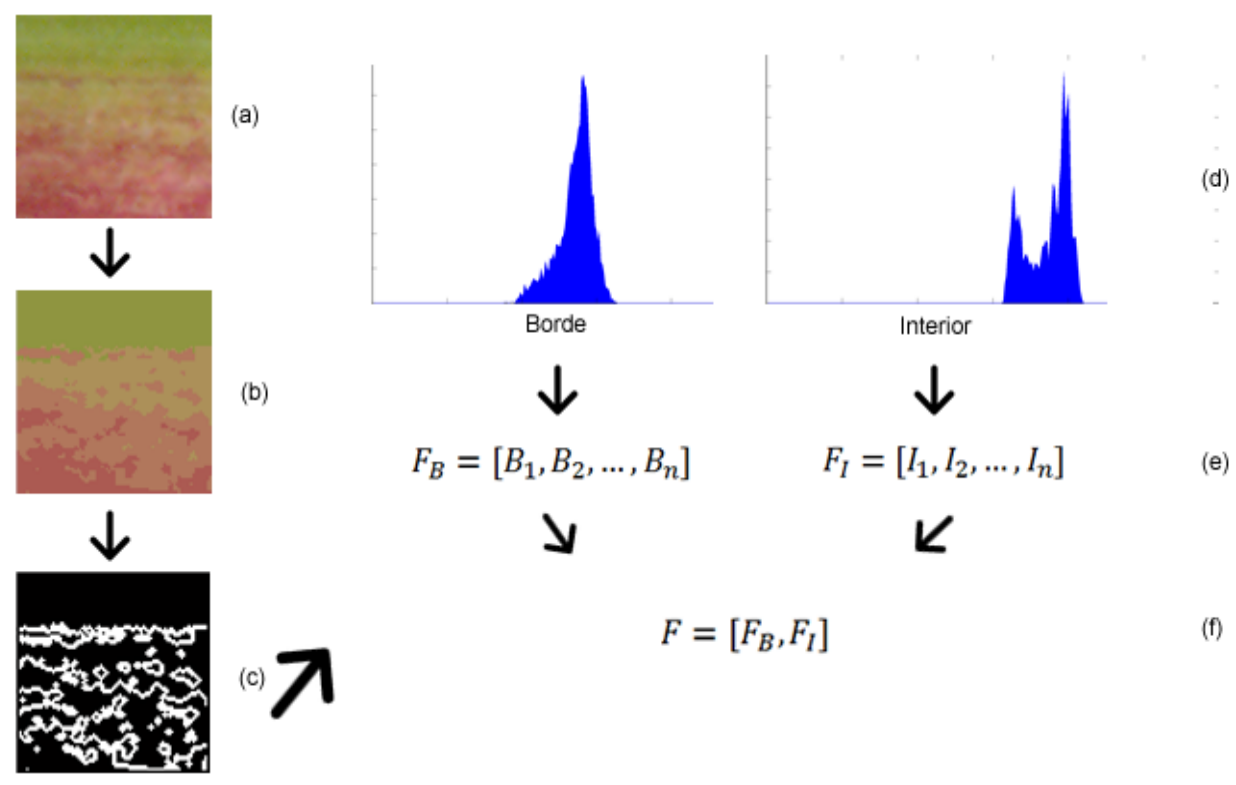

Figura 4.7: Extração de características usando BIC. (a) imagem origina, (b) redução de cores da imagem, (c) determinação de áreas de borda e áreas de interior, (d) obtenção dos histogramas de borde e interior, (e) geração dos vetores de características, (f) concatenação dos vetores para formar o vetor final.

\subsubsection{Momentos invariantes de cor}

Os momentos invariantes de cor são classificados de acordo com 3 parâmetros: ordem, grau e número de cores. Um dos problemas na seleção dos momentos é o número destes que devem ser usados para extrair a maioria de informação significativa da imagem. Para resolver este problema usa-se a 
aproximação sugerida em (Mindru et al., 2004) na qual é usada momentos invariantes gerais.

Os momentos invariantes gerais são obtidos usando a equação 3.4 e os momentos $M_{00}^{a b c}, M_{10}^{a b c}$ e $M_{01}^{a b c}$ onde $(a b c) \in=(0,0,0),(1,0,0),(0,1,0),(0,0,1)(2,0,0),(0,2$ $, 0),(0,0,2),(1,1,0),(1,0,1),(0,1,1)$

A figura 4.12 mostra o processo:

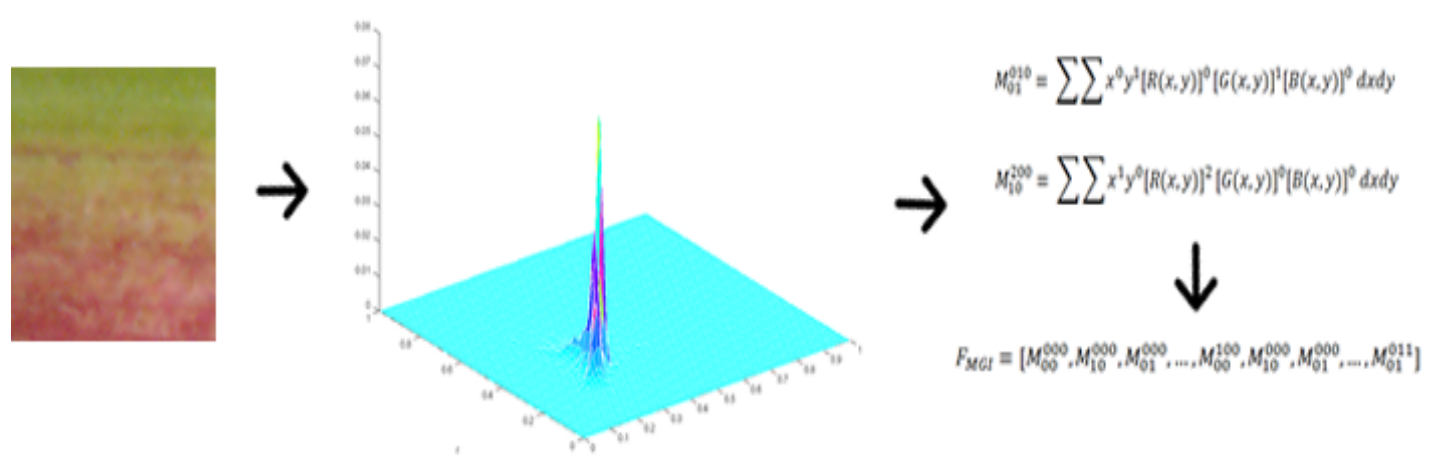

Figura 4.8: Extração de características usando Momentos invariantes de cor.

\subsubsection{Momentos de cromaticidade}

Os momentos calculados são de tipo T (3.9) e D (3.10). Para o cálculo dos valores de $m, l$ usa-se a aproximação baseada nos resultados apresentados por (Hu, 1962): $(p+q) \leq 2$ para os momentos de Tipo $\mathrm{T}$ e $\mathrm{D}$, de acordo com (Paschos, 2000) 5 momentos do tipo T e 5 momentos de tipo D são suficientes para obter resultados ideais. Assim é usada a combinação: $(p, q)=$ $(0,0),(1,0),(0,1),(2,0),(0,2)$

$$
F=\left[M_{T}(0,0), M_{T}(0,1), \ldots, M_{T}(0,2), M_{D}(0,0), M_{D}(0,1), \ldots, M_{D}(0,2)\right]
$$

A Figura 4.9 mostra o processo: 


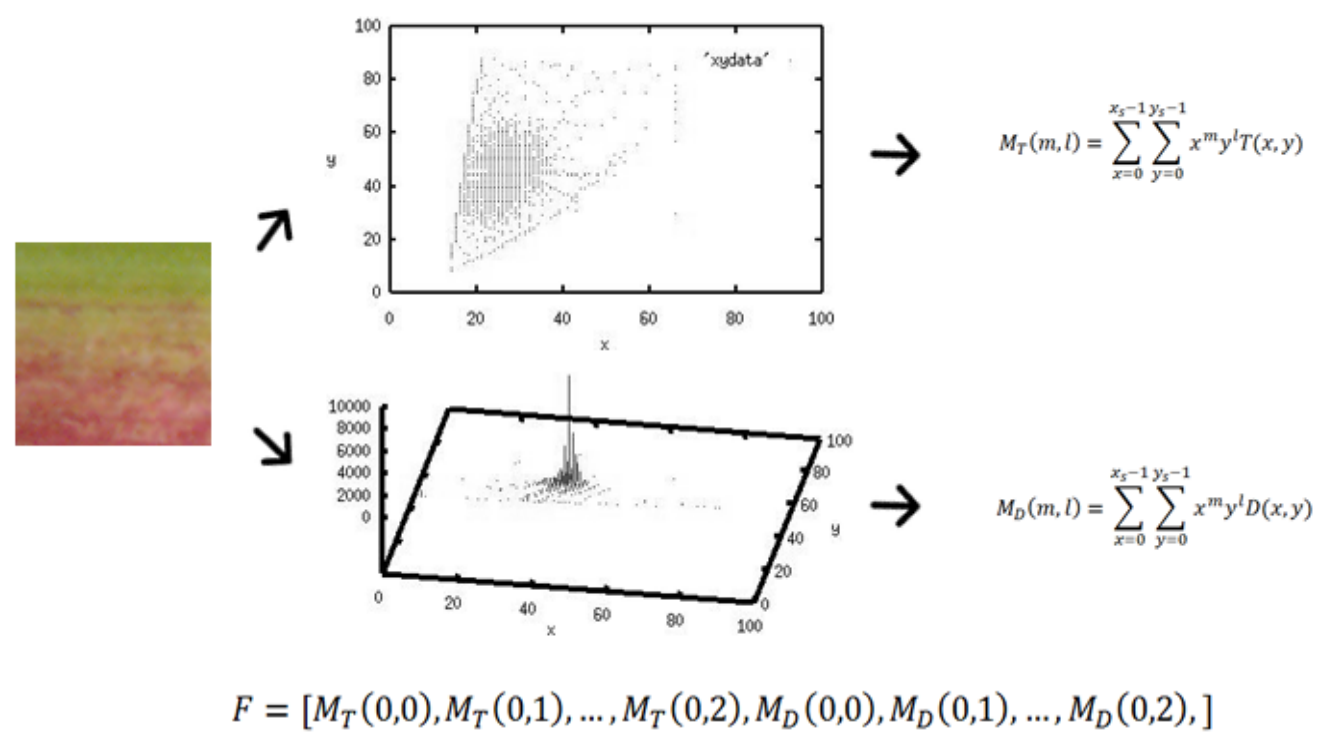

Figura 4.9: Extração de características usando Momentos de cromaticidade, o espaço superior é o momento T e o espaço inferior é o momento D.

\subsection{2 textura}

\subsubsection{Matrizes de co-ocorrência}

A matriz de co-ocorrência descreve estatísticas de segundo ordem e funciona muito bem para uma grande variedade de texturas (Materka e Strzelecki, 1998), algumas das propriedades mais importantes deste método são a invariância a transformações monotônicas em escala de cinza e a descrição da distribuição espacial dos pixels. Por outro lado o método não considera texturas baseadas em primitivas e o custo de processamento é alto. Um algoritmo para o cálculo rápido das matrizes de co-ocorrência foi proposto por (Argenti et al., 1990).

Com o objetivo de diminuir o custo computacional e obter a maior quantidade de informações relevantes da imagem usa-se as aproximações adotadas em (Haralick, 1979) e (Clausi e Deng, 2005). Foram geradas 3 experimentos com a técnica sendo que a proposta original do autor é o uso de 16 cores para evitar acrescentar o custo computacional da técnica. A imagem original é reduzida de 256 a 8,16 e 32 níveis de cinza e são usadas duas distâncias entre os pixels $(\delta=1, \delta=2)$ e quatro orientações $\left(0^{0}, 45^{0}, 90^{\circ}, 135^{\circ}\right)$ totalizando 
assim 8 matrizes. Um total de 3 descritores de segunda ordem são extraídos: Entropia, contraste e correlação denotadas pelas Equações 3.16, 3.13 e 3.12 respectivamente. O vetor de características final está formado por 24 atributos ( 8 matrizes, 3 características por matriz). A Figura 4.10 mostra o processo.

$$
F=\left[E\left(p_{1,0^{0}}\right), C o\left(p_{1,0^{0}}\right), C\left(p_{1,0^{0}}\right), E\left(p_{1,45^{0}}\right), \ldots, C\left(p_{1,135^{0}}\right), E\left(p_{2,0^{0}}\right), \ldots, C\left(p_{2,135^{0}}\right)\right]
$$

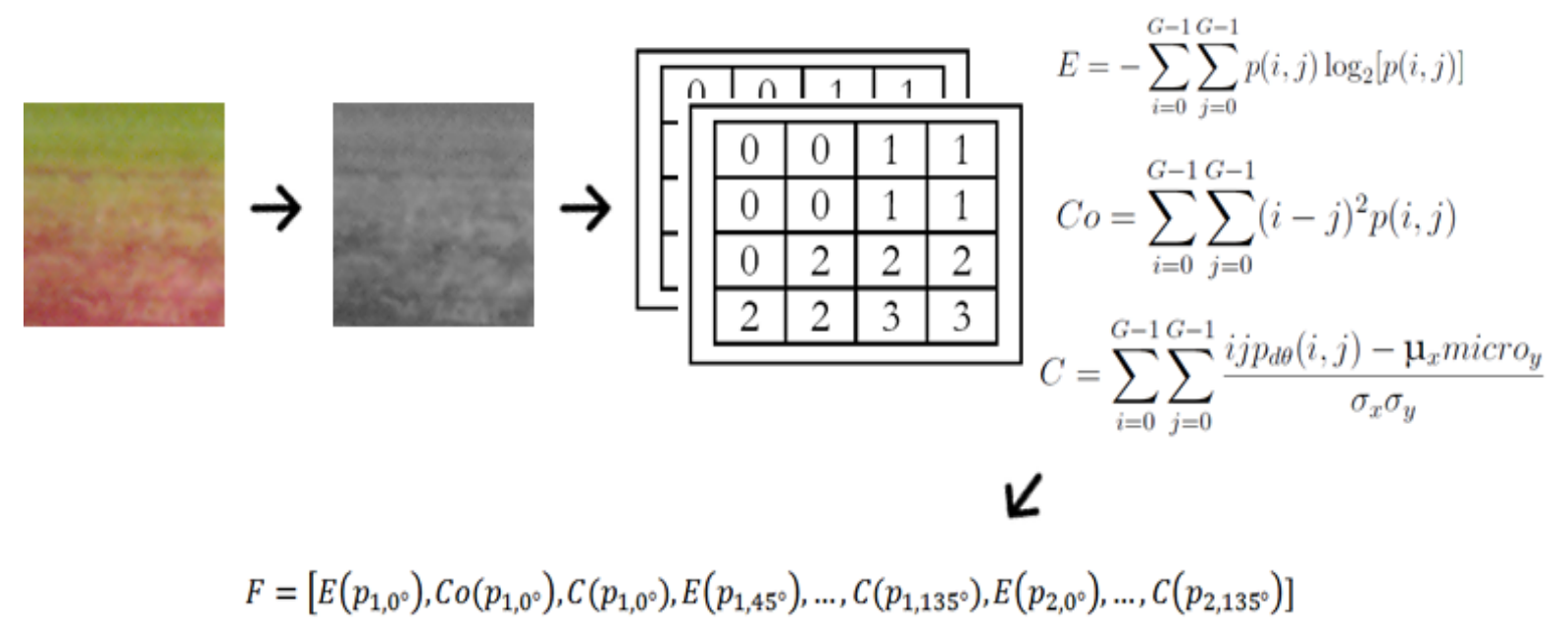

Figura 4.10: Extração de características usando Matrizes de co-ocorrência

\subsubsection{Wavelets de Gabor}

A partir de um número de escalas $S$, rotações $K$ e intervalos de frequencia $U_{h}$ e $U_{l}$ cria-se um conjunto de filtros de Gabor para a convolução com uma imagem. Sendo $f(x, y)$ a imagem e $g_{m n}(x, y)$ o filtro de Gabor com escala $m$ e rotação $n$ são obtidas imagens convoluidas conforme mostra a equação:

$$
r_{m, n}(x, y)=f(x, y) * g_{m n}(x, y),
$$

onde $r_{m, n}$ é a imagem convoluida pelo filtro de escala $m$ e orientação $n$. O descritor $E_{m n}$ da imagem é obtido pelo cálculo da energia da imagem filtrada, defindo por: 


$$
E_{m n}=\sum_{x, y}\left[r_{m n}(x, y)\right]^{2}
$$

O vetor de características é construído pela concatenação das energias de cada uma das imagens convoluidas sendo $K$ e $S$ os valores que determinam o número de descritores do vetor, a Figura 4.11 mostra o processo.

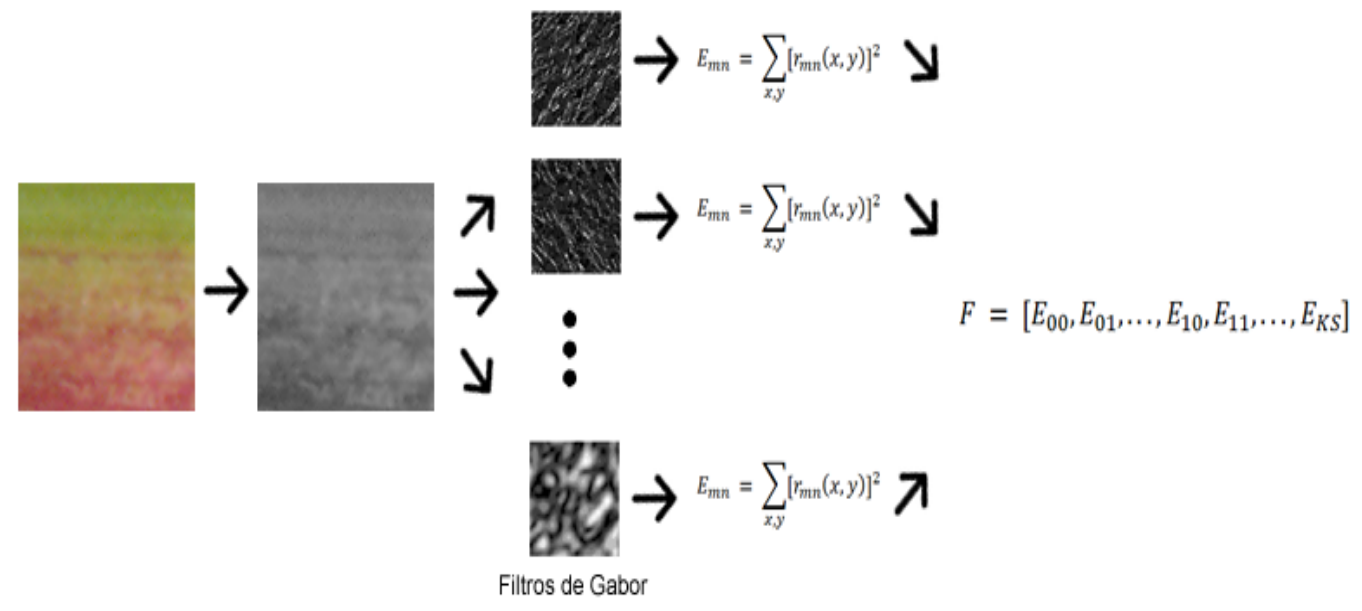

Figura 4.11: Extração de características usando wavelets de Gabor

O vetor de características final é definido por:

$$
F=\left[E_{00}, E_{01}, \ldots, E_{10}, E_{11}, \ldots, E_{K S}\right]
$$

\subsubsection{Gabor wavelets e outros extratores}

O uso de extratores de características sob as imagens convoluidas das wavelets de Gabor é uma área de pesquisa que visa obter a maior quantidade de informação relevante das imagens geradas pelo processo com a menor dimensionalidade possível. Neste trabalho foram implementadas 4 aproximações mais conhecidas da na literatura, estatísticas de primeira ordem, padrões locais binários, momentos invariantes e co-variância. O esquema geral usado para a aplicação dos extratores de características pode ser melhor entendido na figura 3.6.

- Gabor e estatísticas de primeira ordem: Um dos métodos mais simples e com melhores resultados é a aplicação de estatísticas de primeira ordem. 
São extraídas de cada uma das imagens convoluidas: Energia, variancia, percentil75 de acordo com a implementação de (Bandzi, 2007)

$$
\begin{gathered}
E=\sum_{i=0}^{G-1}[p(i)]^{2}, \\
V=\sum_{i=0}^{G-1}(i-u)^{2} p(i), \\
P_{75}=p_{\text {ord }}(\lceil 0.75(G-1)\rceil),
\end{gathered}
$$

Onde $p_{\text {ord }}$ é o vetor ordenado de p e $u=\sum_{i=0}^{G-1} i p(i)$.

- Gabor e Co-variância: A combinação de matrizes de co-variância e wavelets de Gabor é apresentado em (Tou et al., 2007).

- Gabor e padrões locais binarios: O padrão local binário é aplicado nas imagens de Gabor de acordo com a implementação de Zhang et al. (2005). Para reduzir o tamanho do histograma final é usada uma vizinhança de 4. Desde que a 4-vizinhança permite um máximo de 16 valores possíveis no mapa gerado. O vetor final é composto pela concatenação destes valores para cada uma das imagens convoluidas

$$
H=\left[h_{1,1}, h_{1,2}, \ldots, h_{2,1}, h_{2,2}, \ldots, h_{m, n}\right],
$$

Onde $m, n$ é o número de escalas e orientações usadas no processo e $h$ é:

$$
h_{1,1, i}=\sum_{x, y \in R}\left(f G_{g l b p}(x, y, u, v)=i\right),
$$

- Gabor e momentos invariantes de textura: Os momentos invariantes tem a propriedade de ser independentes de escalamento, rotação e translação, o momento de uma imagem em escala de cinza é calculado usando a equação:

$$
m_{p q}=\sum \sum x_{x}^{p} y_{y}^{q} f(x, y),
$$


são extraidos 6 momentos de cada uma das imagens com os valores de $(p, q)=[(0,0),(0,1),(1,0),(2,0),(0,2),(1,1)]$

\subsubsection{Dimensão Fractal Volumetrica}

A assinatura da imagem e calculada para todos os valores de $r \in E$ onde $E$ é o conjunto de distâncias euclidianas para um raio máximo $r_{\max }$ (Backes et al., 2009). Os experimentos com esta tecnica são apresentados variando o raio desde um raio de expansão de 1 até 20

$$
\begin{gathered}
E=1, \sqrt{2}, \sqrt{3}, \ldots, r_{\max }, \\
\psi\left(r_{\max }\right)=\left[\log V(1), \log V(\sqrt{2}), \log V(\sqrt{3}), \ldots, \log V\left(r_{\max }\right)\right],
\end{gathered}
$$

A Figura 4.12 mostra o processo
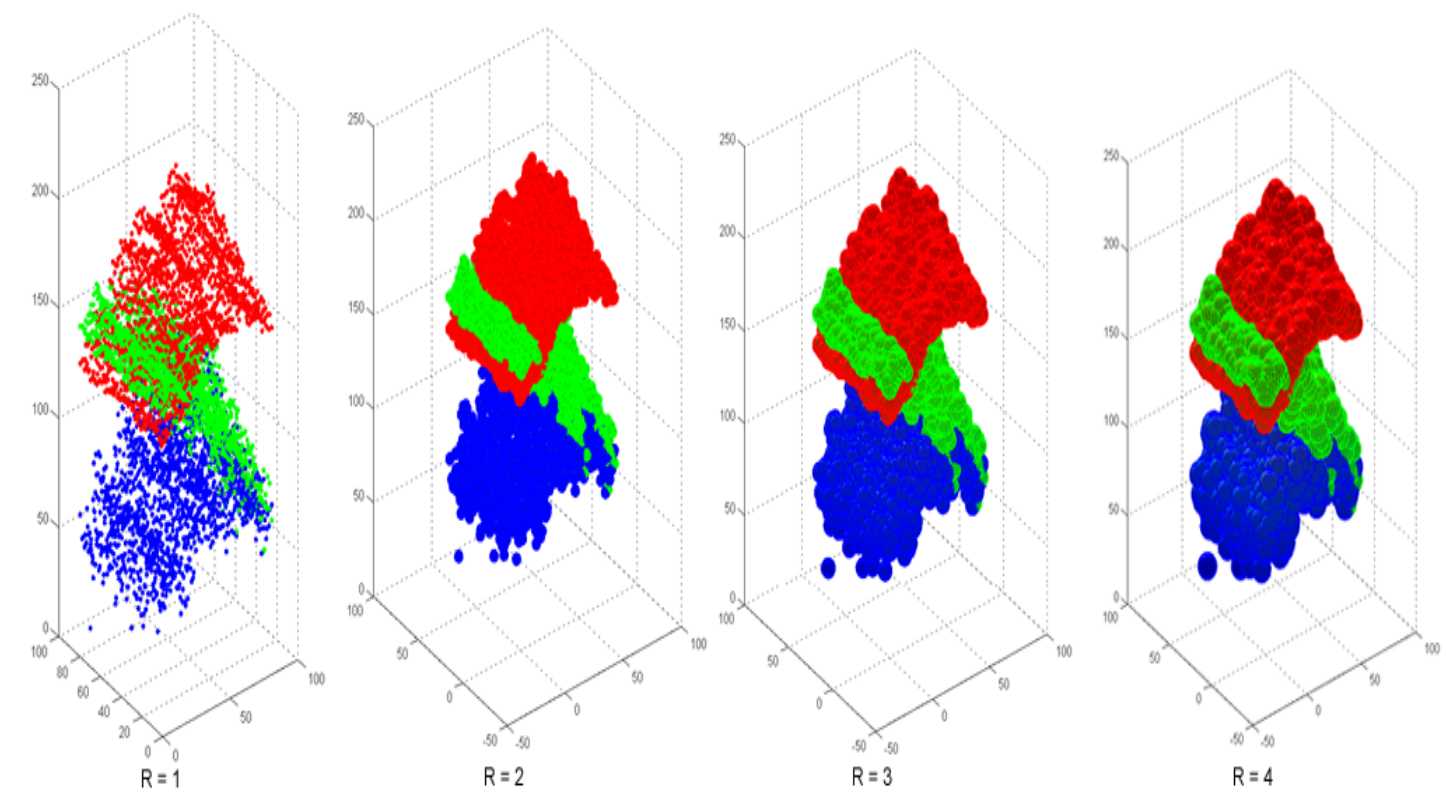

Figura 4.12: Extração de características usando Matrizes de co-ocorrência

\subsubsection{Wavelets de Gabor e Fractais}

O método de wavelets e fractais é sensivel à dimensionalidade final dos vetores de características gerados, porem, deve-se usar a melhor configuração 
para a base de imagens usadas com o método de wavelets de Gabor tradicional (escalas x orientações), neste caso usa-se a configuração que obteve os melhores resultados do método de Gabor waveles com energia e o melhor raio possível extraido dos resultados do método de dimensão fractal volumétrica. Assim o método garante a melhor combinação possível.

\subsubsection{Padrões locais binarios}

O operador original é uma fonte consistente de informação de micro e macro textura numa imagem. A vizinhança usada no processo determina o tamanho do vetor de características final. A implementação original sugere o uso de vizinhança de 8 , nos experimentos é usada uma aproximação de vizinhos de 4 e vizinhos de 8 considerando que na primeira o vetor de características é composto por 16 atributos e na segunda por 256 atributos. A figura mostra o processo:

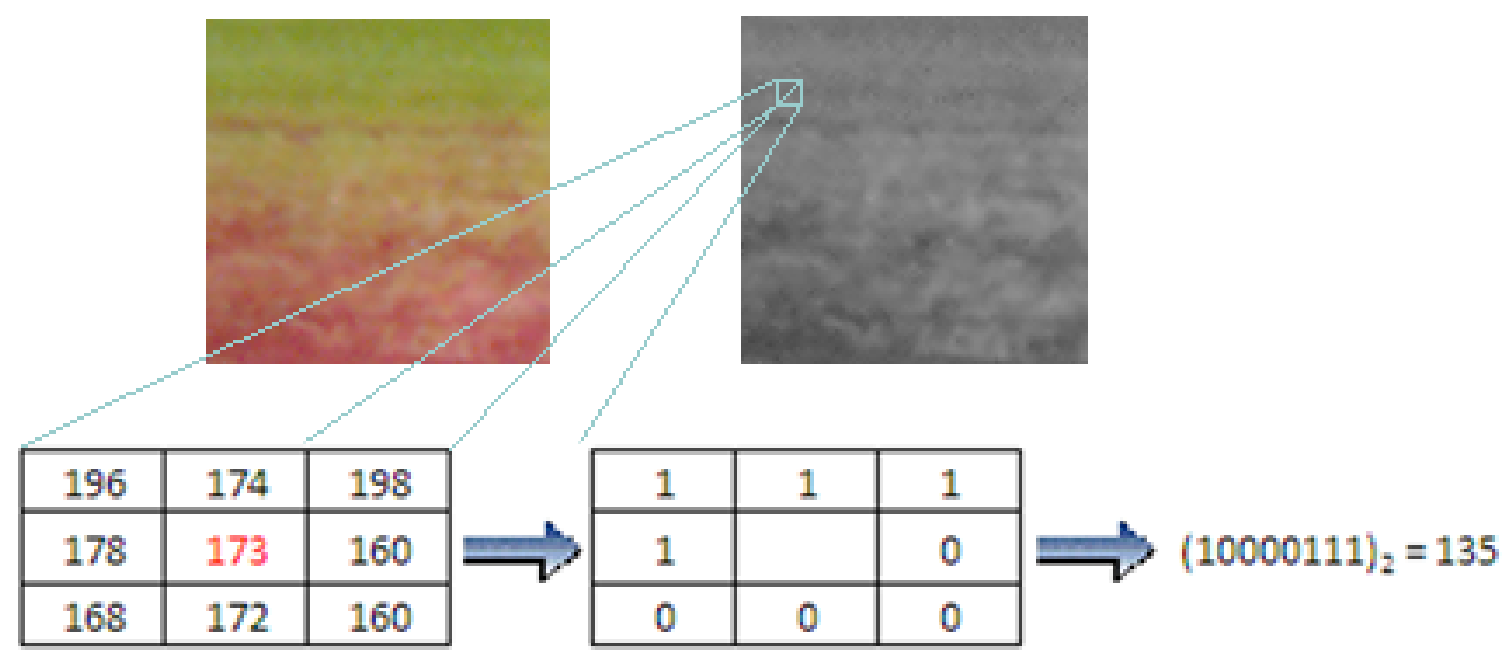

Figura 4.13: Geração do mapa LBP de uma imagem

O processo converte todos os pixels da imagem numa representação chamada mapa LBP, o histograma da imagem gerada representa o vetor de características da imagem.

\subsubsection{Padrões locais binários invariantes}

O padrão local binário invariante a rotação pode ser definido pela equação: 


$$
L B P_{P, R}^{r i}= \begin{cases}\sum_{p=0}^{P-1} s\left(g_{p}-g_{c}\right), & \text { se } U\left(L B P_{P, R}^{r i}\right) \leq 2 \\ P+1, & \text { caso contrario }\end{cases}
$$

onde

$$
L B P_{P, R}^{r i}=\left|s\left(g_{P-1}-g_{c}\right)-s\left(g_{0}-g_{c}\right)\right|+\sum_{p=1}^{P-1}\left|s\left(g_{p}-g_{c}\right)-s\left(g_{p-1}-g_{c}\right)\right|,
$$

$L B P_{P, R}^{r i}$ representa o padrão local binário invariante obtido depois de rotacionar a vizinhança de $P$ pixels onde $P$ é a vizinhança usada e $R$ a distancia radial do pixel ate seus vizinhos.

O LBP uniforme invariante a rotação é igualmente invariante a transformações da escala de cinza. Esta representação não captura, contudo, a informação de contraste da imagem. É necessária uma medida $V A R_{P, R}$ do contraste local obtida de modo similar pela equação Ojala et al. (2002):

$$
V A R_{P, R}=\frac{1}{P} \sum_{p=0} P-1\left(g_{p}-\mu\right)^{2}
$$

Onde

$$
\mu=\frac{1}{P} \sum_{p=0} P-1 g_{p}
$$

$L B P^{r i u}$ e $V A R_{P, R}$ são complementárias sua combinação num vetor de características gera uma representação invariante da imagem muito útil para classificação de texturas. Os parâmetros usados para os experimentos são selecionados de acordo com os resultados apresentados por Z. Guo e Zhang (2010), os valores de $(P, R)$ são: $(8,1),(16,2),(24,3)$, usando os descritores obtidos pelo histograma de $L B P^{r i u}$ e $V A R_{P, R}$ por separado e finalmente concatenando os histogramas para gerar uma representação $L B P^{\text {riu }} / V A R_{P, R}$. 


\subsection{3 textura colorida}

\subsubsection{Dimensão Fractal Volumétrica Multiespectral}

Uma imagem colorida codificada em RGB possui 3 canais de cor que oferecem informação relevante da imagem, a análise desses canais por separado pode significar perdas de informação importante da relação entre canais de um mesmo pixel, assim é necessária uma análise num mesmo esquema dos pixels dos 3 canais. Cada canal de cor é projetado em 3 dimensões no mesmo espaço $(x, y)$ e expandido para analisar não apenas as relações entre pixels de um mesmo canal mas também a relação entre pixels de diferentes canais.

Do jeito similar ao apresentado na Seção 4.3.2.4 a assinatura da imagem é calculada para todos os valores de $r \epsilon E$ onde $E$ é o conjunto de distâncias euclidianas para um raio máximo $r_{\max }$ (Backes et al., 2009).

$$
\begin{gathered}
E=1, \sqrt{2}, \sqrt{3}, \ldots, r_{\max }, \\
\psi\left(r_{\max }\right)=\left[\log V(1), \log V(\sqrt{2}), \log V(\sqrt{3}), \ldots, \log V\left(r_{\max }\right)\right],
\end{gathered}
$$

\subsubsection{Gabor wavelets multiespectral e fractais}

Seja uma imagem colorida $f(x, y)$ composta por 3 canais de cor RGBG $f(x, y)=[R(x, y), G(x, y), B(x, y)]$ o resultado da convolução de cada banda de cor com o filtro de Gabor $g_{m n}(x, y)$ de escala $m$ e orientação $n$ é dado pelas equações:

$$
r_{m, n}^{R}(x, y)=R(x, y) * g_{m n}(x, y),
$$

é dado por:

$$
r_{m, n}^{G}(x, y)=G(x, y) * g_{m n}(x, y),
$$

é dado por:

$$
r_{m, n}^{B}(x, y)=B(x, y) * g_{m n}(x, y),
$$

é dado por: 
Seja $e$ o vetor de distâncias euclidianas $e=\left[1, \sqrt{2}, \sqrt{3}, \ldots, \sqrt{r_{\text {max }}}\right]$ a projeção dos canais de cor num espaço 3-dimensional gera a superfície $R^{3}$ usando cada pixel da imagem original como num ponto $p_{R}=(y, x, z), p \in R^{3}, p_{G}=(y, x, z), p \in R^{3}$, $p_{B}=(y, x, z), p \in R^{3}$, no espaço $X$ e $Y$ são as coordenadas espaciais dos pixels na imagem e a terceira dimensão é o valor de intensidade do pixel $z=R(y, x)$, $z=G(y, x), z=B(y, x)$ respectivamente.

Uma vez gerada a superficie o processo é exatamente o mesmo que para dimensão fractal volumétrica, uma assinatura é calculada para cada canal de cor usando as equações 4.25 e 4.26 a assinatura fractal volumétrica de cada imagem convoluida é definida como:

$$
\omega_{m, n}^{R G B}(i, z)=\left\{V F D\left(r_{m, n}^{R G B}(x, y), r\right) \mid \forall r \in e\right\},
$$

Onde $r$ é um raio do vetor $e$ e $\omega_{m, n}^{R G B}(i, z)$ é uma matriz que contém as assinaturas fractais para todas as imagens convoluidas $m, n$ onde $i$ identifica o número do objeto processado (imagem processada). Finalmente é aplicada análise canônica na matriz de vetores de características de uma mesma escala e orientação para todos os objetos analisados (após o processamento de todas as imagens). Por exemplo, todas as assinaturas da escala 1 e orientação 1 de todas as imagens processadas São submetidas a análise canônica para determinar os $N$ principais descritores de cada uma destas assinaturas são armazenadas na matriz $\phi_{m, n}(i, z)$ de acordo com:

$$
\phi_{m, n}(i, z)=\left\{\lambda\left(\omega_{m, n}^{R G B}, N\right)\right\},
$$

Cada uma das filas de $\phi_{m, n}(i, z)$ representa o vetor de características do objeto $i$ 



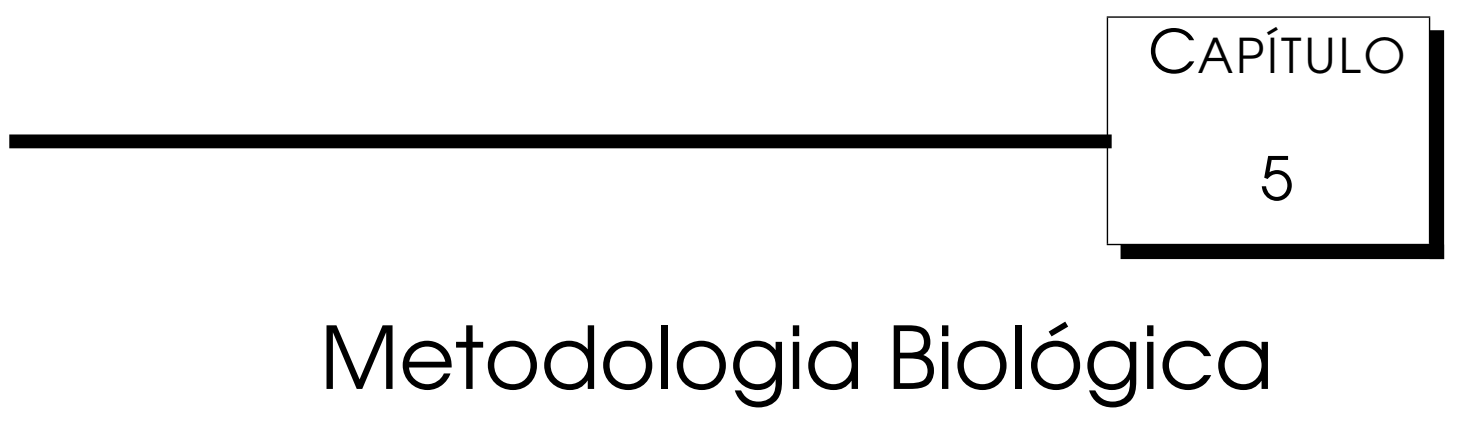

Neste capítulo são apresentados os métodos e técnicas usadas para a geração das amostras biológicas usadas no sistema de visão computacional.

\subsection{Local do experimento}

O trabalho experimental biológico foi conduzido em cinco experimentos independentes, o primeiro sendo enxofre, o segundo magnésio, o terceiro cálcio, o quarto nitrogênio e o quinto potássio. Todos os experimentos foram conduzidos em casa de vegetação localizada na Faculdade de Zootecnia e Engenharia de Alimentos FZEA-USP em Pirassununga, estado de São Paulo, Brasil. O uso de casa de vegetação garante o controle exato de nutrientes e evita a aparição de pragas e doenças que possam afetar a superfície das plantas. A Figura 5.1 mostra imagens da casa de vegetação usada.

\subsection{Caracterização do híbrido de milho usado}

O estudo é centrado na cultura de milho (Zea mays L.) sob cultivo hidropônico em vasos com solução nutritiva. O nome do híbrido usado é o DBK 499 de ciclo precoce, utilizado para grãos e adaptado para as regiões do Oeste do 


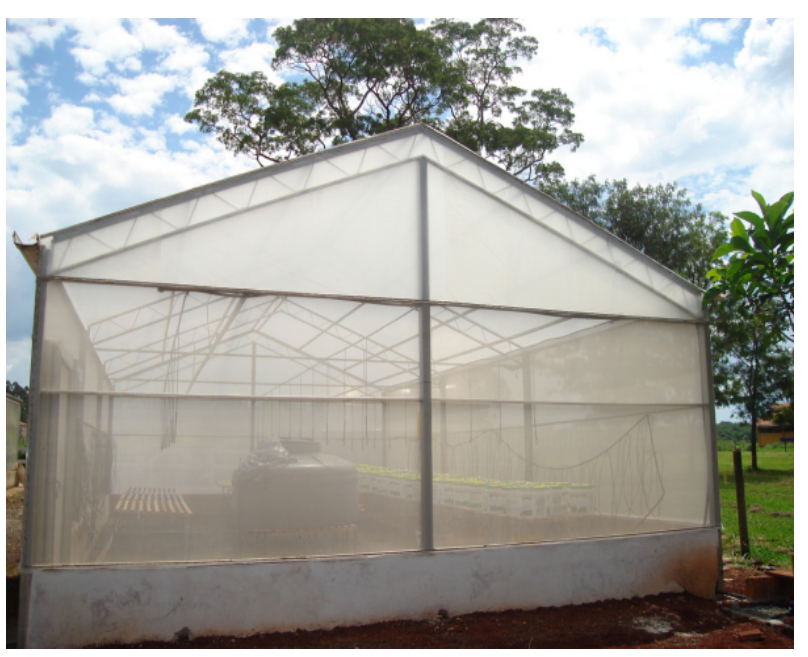

(a)

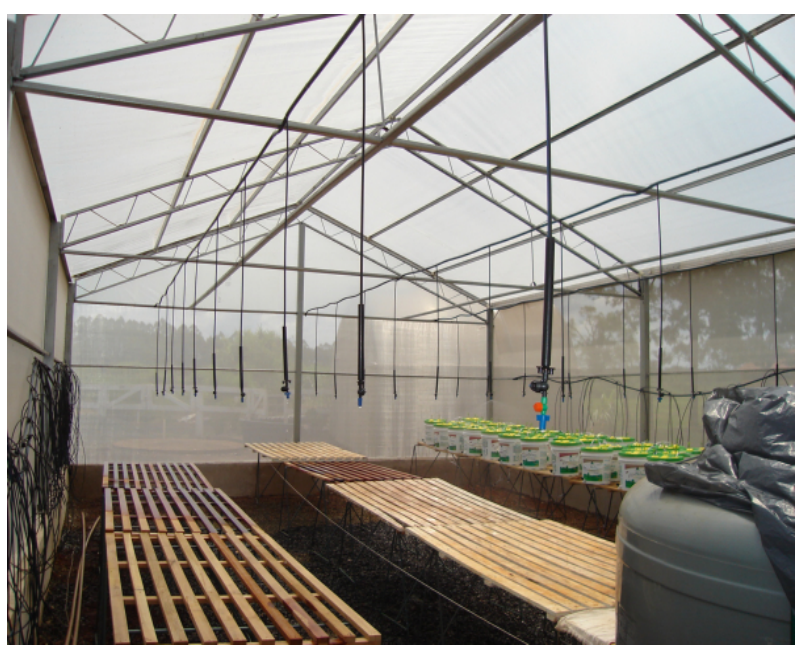

(b)

Figura 5.1: Casa de vegetação usada para os experimentos biológicos.

paraná, sudeste, Centro-Oeste e Nordeste do pais (Da Silva, 2011).

\subsection{Instalação do experimento}

A semeadura foi feita em bandejas plásticas com areia lavada e as plantas foram mantidas por duas semanas antes de ser passadas a os vasos. Após o período de semeadura as plantas são transferidas aos vasos para seu crescimento até sua etapa final. Um vaso contém quatro plantas homogêneas fixadas à tampa por uma espuma na altura do colo da planta permitindo as 
raízes ficarem imersas dentro da solução nutritiva. A Figura 5.2 mostra os vasos usados na instalação dos experimentos

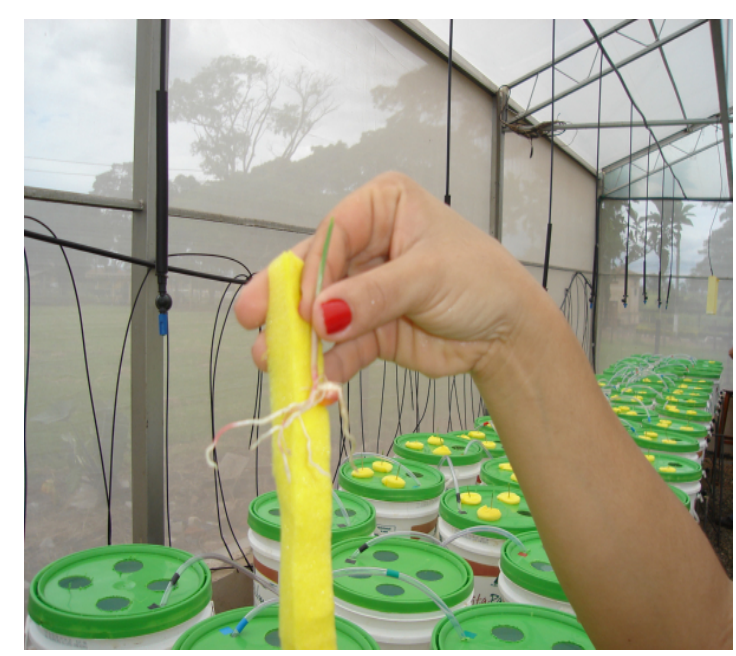

(a)

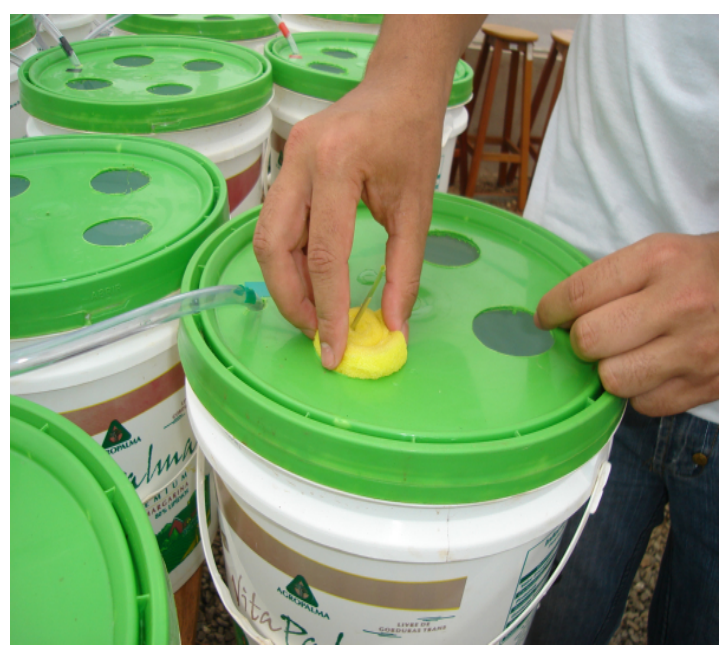

(c)

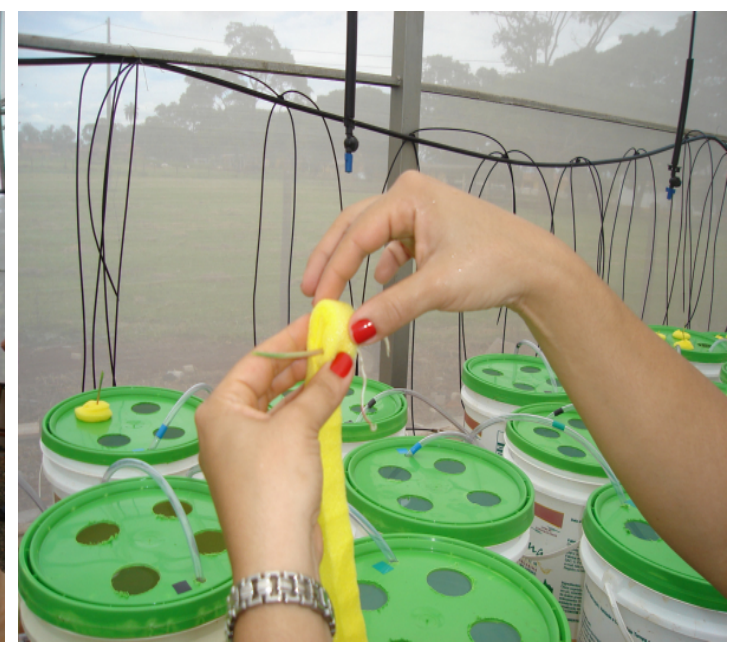

(b)

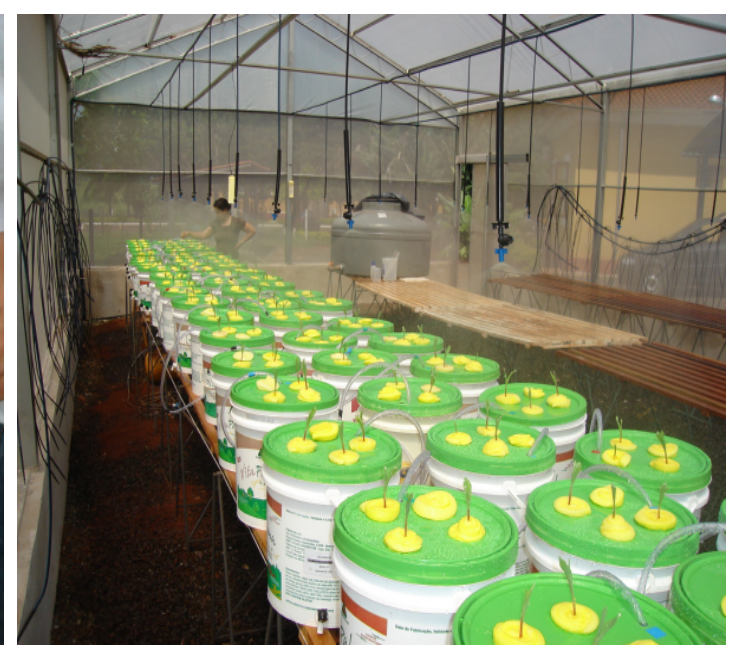

(d)

Figura 5.2: Instalação do experimento nos vasos. (a) e (b) processo de fixação da planta na espuma, (c) planta logo após o transplantio, (d) conjunto de vasos usados

Cada vaso de polietileno comportava 3.6 litros de solução nutritiva e recebiam ar comprimido e borbulhado durante 10 segundos cada 1 minuto. Além disso, um sistema de pulverização de agua foi instalado para manter a umidade dentro da casa de vegetação. A Figura 5.3 mostra o sistema de ar usado.

Todas as plantas foram cultivadas até o estado de desenvolvimento com oito 


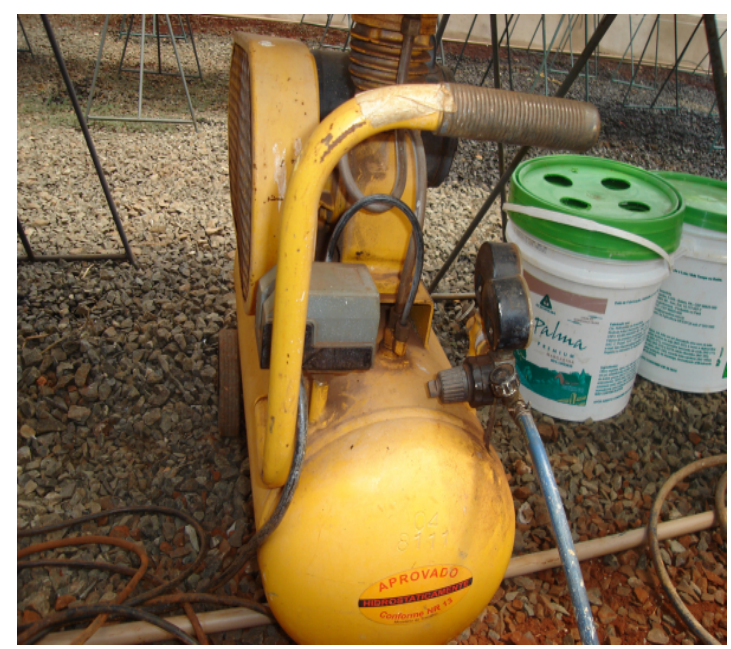

(a)

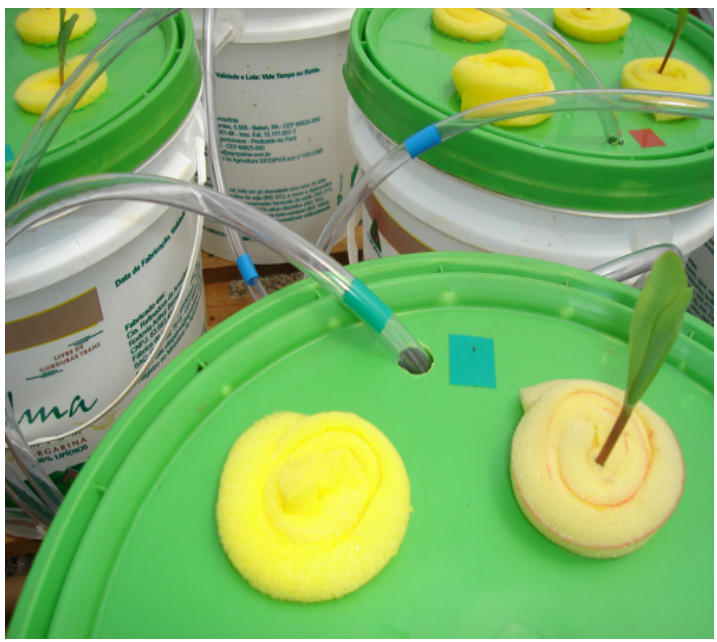

(c)

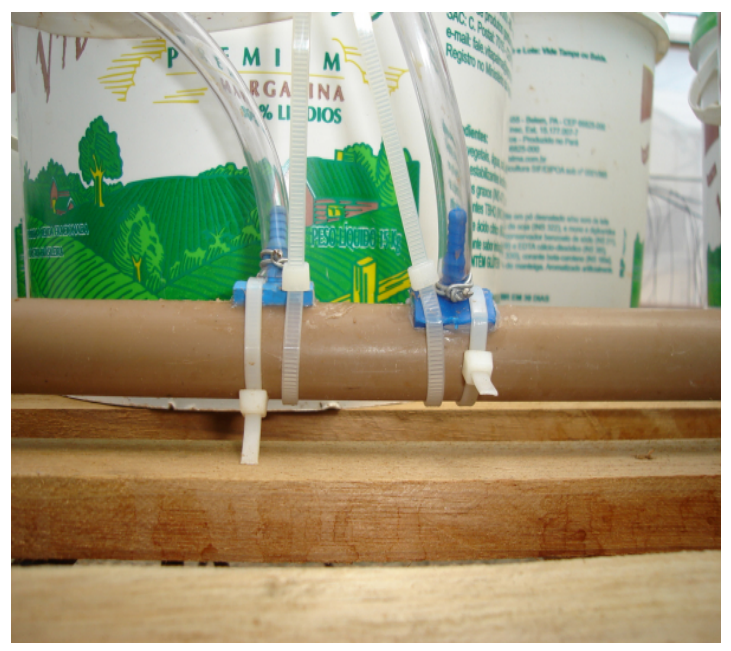

(b)

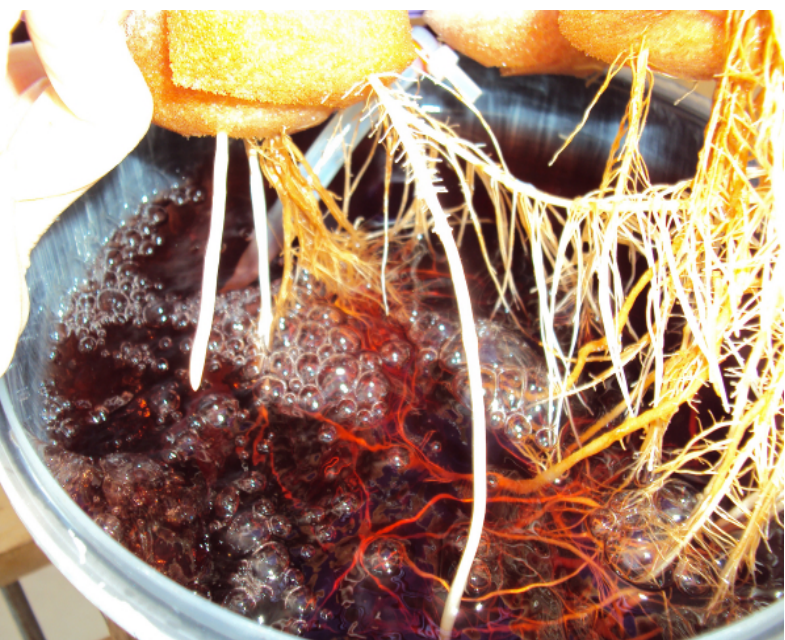

(d)

Figura 5.3: Sistema de injeção de ar. (a) compressor de ar usado, (b) sistema de transporte do ar, (c) introdução do ar nos vasos, (d) borbulhas do ar na solução nutritiva

folhas completamente desenvolvidas (V8) (Da Silva, 2011). O delineamento experimental foi feito num esquema de $4 \times 3$ (quatro níveis de nutriente e 3 épocas de coleta de dados sendo cada época um estádio do desenvolvimento da planta) com quatro repetições resultando em 48 vasos por experimento. No total foram conduzidos 5 experimentos, um para cada nutriente. Com motivo de validação dos resultados biológicos foi feita uma análise química por cada coleta. A análise química requer destruição do tecido vegetal da 
planta, porem, foram retirados 4 vasos em cada coleta (uma repetição de cada nível de nutriente), reduzindo o número de vasos utilizáveis para 36.

\subsection{Validação de amostras biológicas}

O uso de plantas com deficiências requer uma validação que possa determinar se as plantas contém a quantidade exata dos nutrientes necessários para criar a deficiência. O único processo que fornece resultados exatos é a análise química. O processo de análise química das plantas envolve a destruição do tecido vegetal com ácido sulfúrico para a determinação do nitrogênio e com ácido nítrico para a determinação de fósforo, potássio, magnésio, enxofre e cálcio. Os resultados são tabelas de teores de nutrientes que logo após os experimentos computacionais são correlacionadas para obter informação adicional dos resultados.

A análise química foi feita no laboratório de Ciências Agrárias na Faculdade de Zootecnia e Engenharia de Alimentos da Universidade de São Paulo, campus de Pirassununga - SP segundo métodos descritos por (BATAGLIA, 1983).

\subsection{Experimentos Biológicos realizados}

Cada nutriente possui uma movilidade distinta, isto quer dizer que a deficiência pode ser apresentada nas folhas novas da planta se a deficiência for móvel (pouca movilidade do nutriente pelo floema da planta) ou nas folhas velhas (alta movilidade) assim, foram extraídas a folha nova e a folha velha de todas as coletas. O conjunto de nutrientes analisados representa a totalidade de macronutrientes necessários par ao crescimento da planta.

\subsubsection{Cálcio}

Foram utilizadas quatro doses de cálcio correspondentes a $0 \mathrm{mg} / \mathrm{L}$ (dose zero - T1), $66 \mathrm{mg} / \mathrm{L}$ (dose 1/3 - T2), $133 \mathrm{mg} / \mathrm{L}$ (dose 2/3 - T3) e $200 \mathrm{mg} / \mathrm{L}$ (dose completa - T4). O experimento foi cultivado no período 29 de junho de 2010 a 25 de agosto de 2010 (Da Silva, 2011). 
Aos 29 dias quando a planta estava no estado V4 de desenvolvimento (quatro folhas totalmente desenvolvidas) realizou-se a primeira coleta de amostras (coleta 1). É neste estado de desenvolvimento da cultura que ocorre o inicio da definição do potencial produtivo sendo este estado a ultima oportunidade de realizar adubação corretiva na cultura sem afetar sua produção final (FANCELLI, 1986). Nenhum dos métodos tradicionais consegue obter uma descrição nutricional adequada neste estado para determinar exatamente a deficiência (em caso exista) e a severidade desta. Foram digitalizadas a folha 4 (velha) e folha nova para o estudo pelo sistema de visão artificial.

Aos 20 dias após a primeira coleta quando a planta estava no estádio V6 de desenvolvimento (seis folhas totalmente desenvolvidas) realizou-se a segunda coleta de amostras (coleta 2). Neste estádio não é possível a aplicação de adubação corretiva no caso de existir alguma deficiência nutricional, segundo (FANCELLI, 1986) é neste estádio que ocorre a definição de número de espigas. Foram digitalizadas a folha 6 (velha) e folha nova para o estudo pelo sistema de visão artificial.

Finalmente, aos 10 dias após a segunda coleta quando a planta estava no estádio V8 de desenvolvimento (oito folhas totalmente desenvolvidas) realizouse a terceira coleta de amostras (coleta 3), segundo (FANCELLI, 1986) é neste estádio que ocorre a definição do número e tamanho da espiga. Foram digitalizadas a folha 8 (velha) e folha nova para o estudo pelo sistema de visão artificial

\subsubsection{Magnésio}

Foram utilizadas quatro doses de magnésio correspondentes a 0 (doze zero - T1), $16 \mathrm{mg} / \mathrm{L}$ (dose $1 / 3$ - T2), $32 \mathrm{mg} / \mathrm{L}$ (dose 2/3 - T3) e $48 \mathrm{mg} / \mathrm{L}$ (dose completa - T4). O experimento foi cultivado no período 23 de junho a 24 de agosto de 2010.

Aos 28 dias quando a planta estava no estado V4 foi realizada a primeira coleta, a segunda coleta foi realizada aos 20 dias após a primeira coleta no estado V6 e a terceira coleta ocorreu 14 dias após a segunda coleta no estádio V8 de desenvolvimento da planta. Os critérios adotados foram os mesmos que no experimento de Cálcio. Foram digitalizadas a folha 4 (nova) e folha velha na coleta 1 , folha 6 (nova) e folha velha na coleta 2 e folha 8 (nova) e folha 
velha na coleta 3 .

\subsubsection{Enxofre}

Foram utilizadas quatro doses de Enxofre correspondentes a 0 (doze zero - T1), 23,3 mg/L (dose 1/3 - T2), 46,7 mg/L (dose $2 / 3$ - T3) e $70 \mathrm{mg} / \mathrm{L}$ (dose completa - T4). O experimento foi cultivado no período 28 de maio a 27 de julho de 2010.

Aos 26 dias quando a planta estava no estádio V4 foi realizada a primeira coleta, a segunda coleta foi realizada aos 19 dias após a primeira coleta no estádio V6 e a terceira coleta ocorreu 14 dias após a segunda coleta no estádio V8 de desenvolvimento da planta. Os criterios adotados foram os mesmos que no experimento de Cálcio. Foram digitalizadas a folha 4 (velha) e folha nova na coleta 1 , folha 6 (velha) e folha nova na coleta 2 e folha 8 (velha) e folha nova na coleta 3 .

\subsubsection{Nitrogênio}

Foram utilizadas quatro doses de Nitrogênio correspondentes a 0 (doze zero - T1), $42 \mathrm{mg} / \mathrm{L}$ (dose $1 / 5$ - T2), $84 \mathrm{mg} / \mathrm{L}$ (dose $2 / 5$ - T3) e $210 \mathrm{mg} / \mathrm{L}$ (dose completa - T4). Neste experimento, cultivou-se o milho nos vasos no período de 09 dezembro de 2010 até 01 de fevereiro de 2011.

Aos 30 dias quando a planta estava no estado V4 foi realizada a primeira coleta, a segunda coleta foi realizada aos 20 dias após a primeira coleta no estádio V6 e a terceira coleta ocorreu 10 dias após a segunda coleta no estádio V8 de desenvolvimento da planta. Os criterios adotados foram os mesmos que no experimento de Cálcio. Foram digitalizadas a folha 4 (velha) e folha nova na coleta 1 , folha 6 (velha) e folha nova na coleta 2 e folha 8 (velha) e folha nova na coleta 3 .

\subsubsection{Potássio}

Foram utilizadas quatro doses de potássio correspondentes a 0 (doze zero - T1), $47 \mathrm{mg} / \mathrm{L}$ (dose 1/5 - T2), $94 \mathrm{mg} / \mathrm{L}$ (dose 2/5 - T3) e $235 \mathrm{mg} / \mathrm{L}$ (dose completa - T4). Neste experimento, cultivou-se o milho nos vasos no período de 04 de abril de 2011 até 13 de julho de 2011. 
Aos 30 dias quando a planta estava no estado V4 foi realizada a primeira coleta, a segunda coleta foi realizada aos 20 dias após a primeira coleta no estádio V6 e a terceira coleta ocorreu 10 dias após a segunda coleta no estádio V8 de desenvolvimento da planta. Os criterios adotados foram os mesmos que no experimento de Cálcio. Foram digitalizadas a folha 4 (velha) e folha nova na coleta 1, folha 6 (velha) e folha nova na coleta 2 e folha 8 (velha) e folha nova na coleta 3. A figura 5.4 mostra a montagem do experimento, a figura 5.4 mostra o sistema radicular das plantas e a figura 5.6 mostra algumas plantas em estádio inicial de crescimento e outras no estádio final.

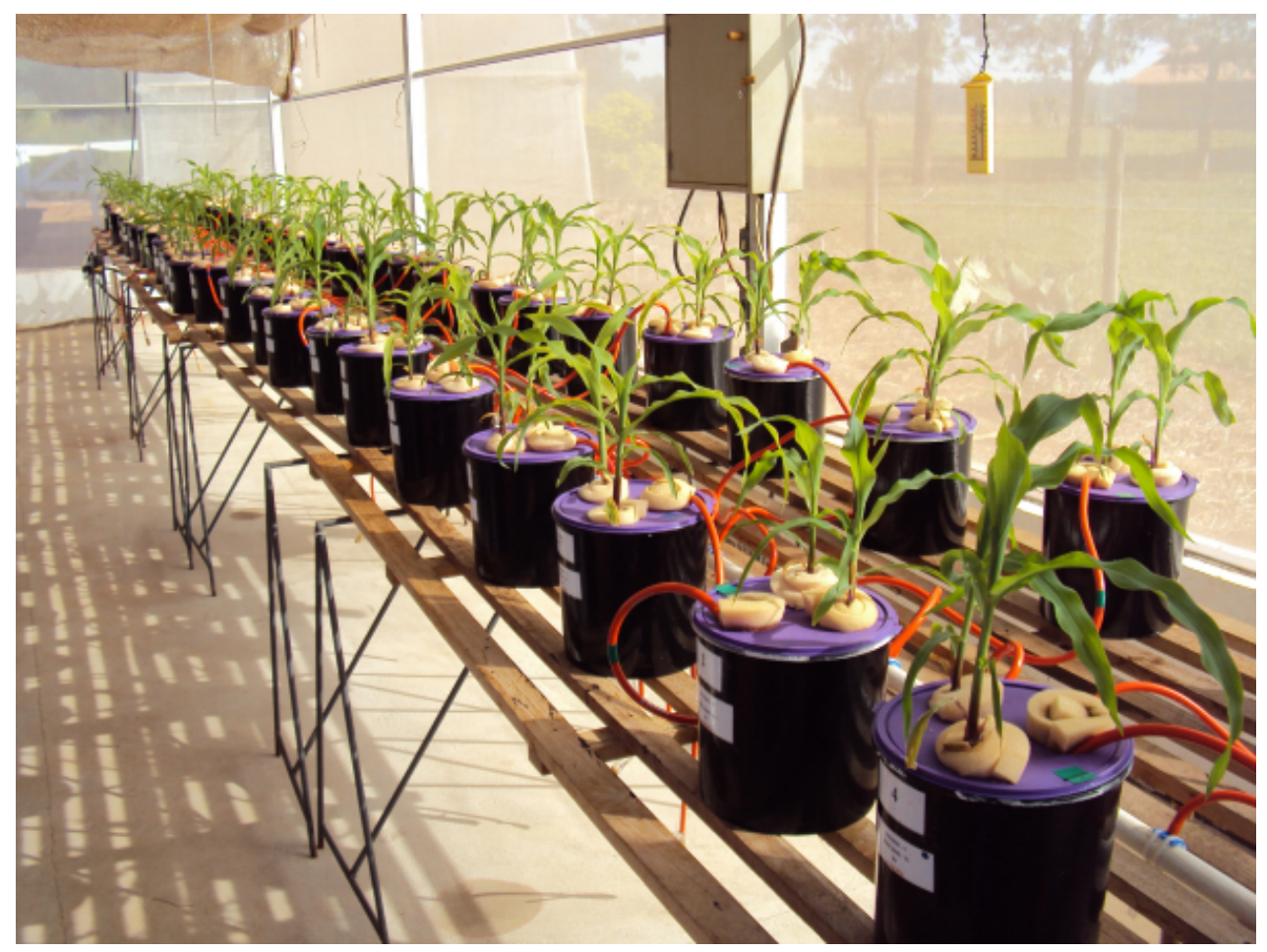

Figura 5.4: Montagem do experimento de Nitrogênio 


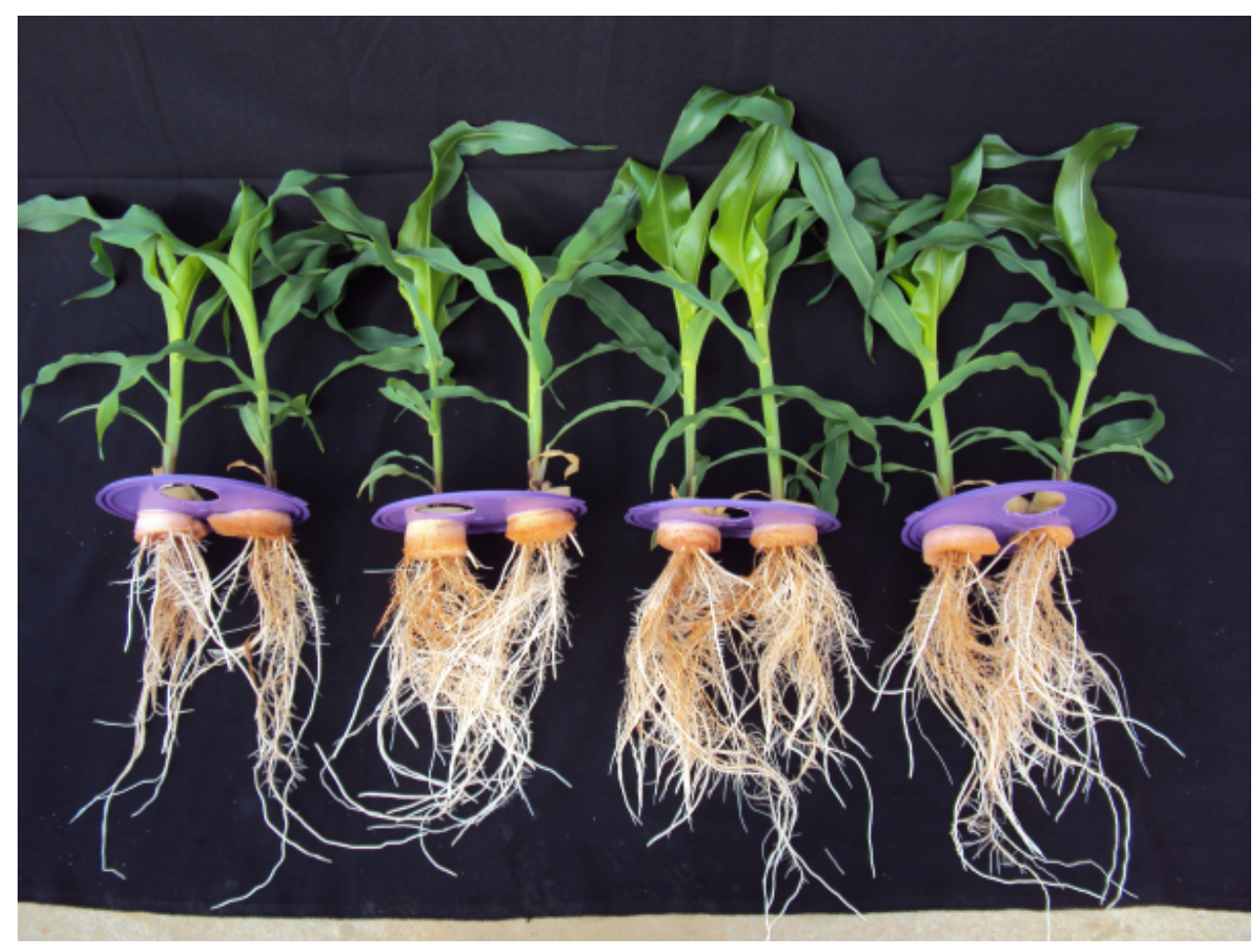

Figura 5.5: Vista dos vasos individuais e o sistema radicular das plantas 


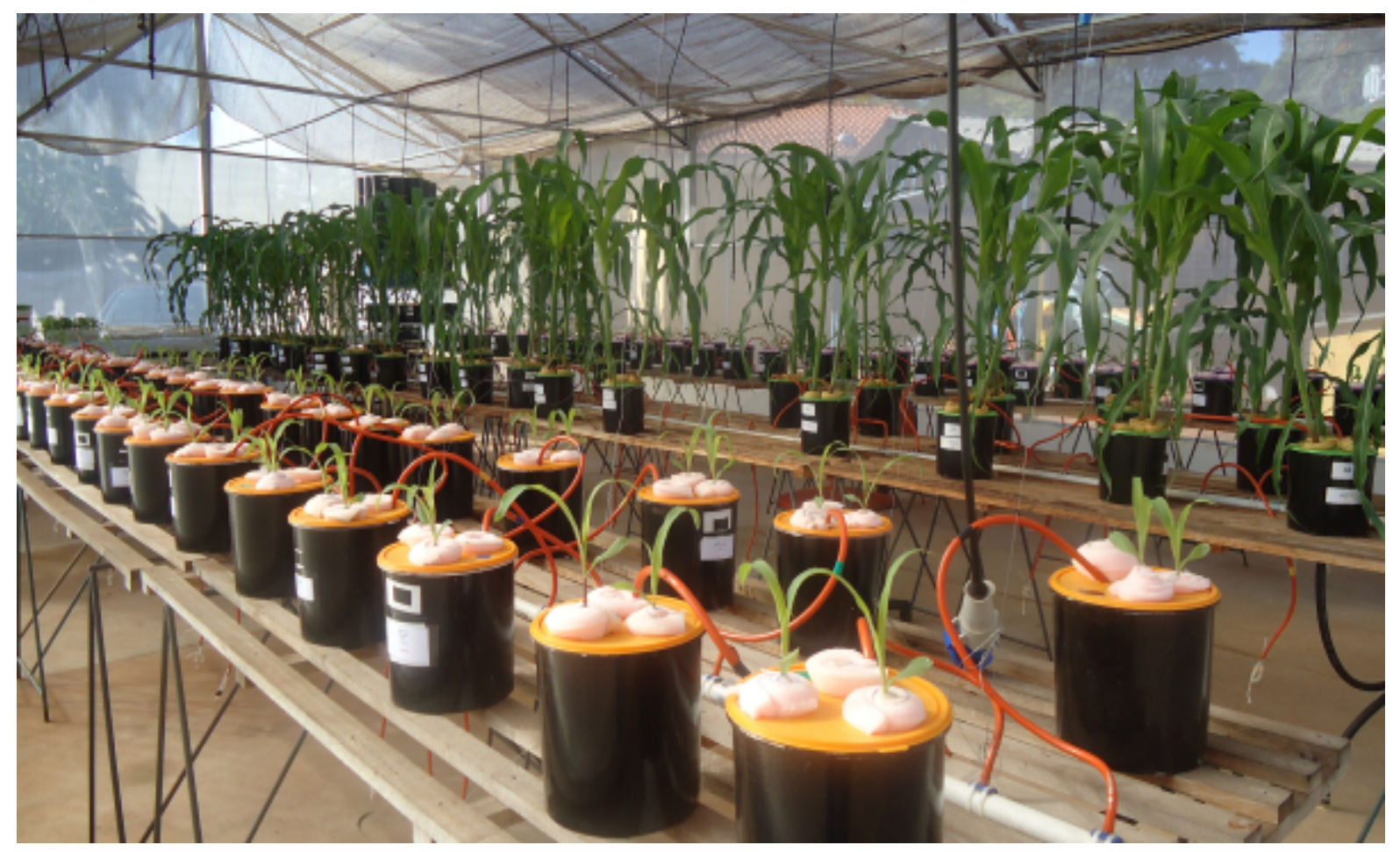

Figura 5.6: Montagem de baterias de experimentos, na frente plantas num estádio inicial de crescimento, no fundo plantas no estado V8 


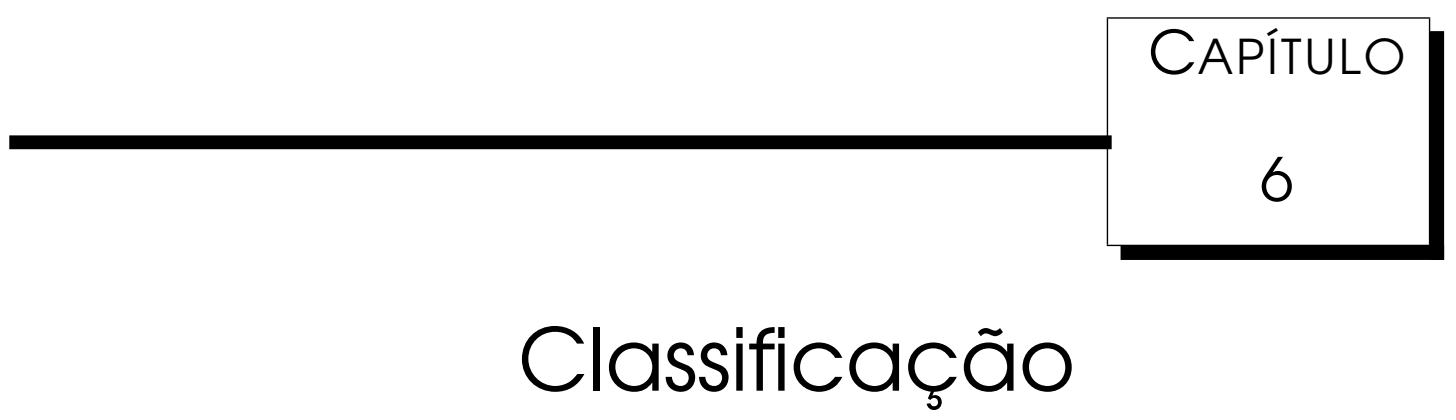

\subsubsection{Estratégia de classificação adotada}

Após a obtenção dos vetores de características é necessário avaliar a capacidade de cada um destes vetores de diferenciar deficiências nutricionais baseado em características intrínsecas do vetor (importância dos atributos extraídos). Também é necessário avaliar qual classificador é o mais adequado para cada tipo de vetor gerado. Assim temos uma estratégia de experimentação que pode ser explicada na figura 6.1.

Pela grande quantidade de tabelas que foram geradas para todos os experimentos apresenta-se neste trabalho só as tabelas mais importantes por cada método seguindo a seguinte estratégia:

1. Avaliação comparativa dos vetores de características gerados por cada método: Após determinar o melhor classificador para cada vetor especifico é apresentada a tabela do melhor classificador.

2. Para os métodos que possuam variações nos parametros de geração do vetor apresenta-se unicamente a tabela com a variação que gerou melhores resultados e os resultados das outras variações são apresentadas num gráfico de evolução do acerto global para o melhor classificador. 


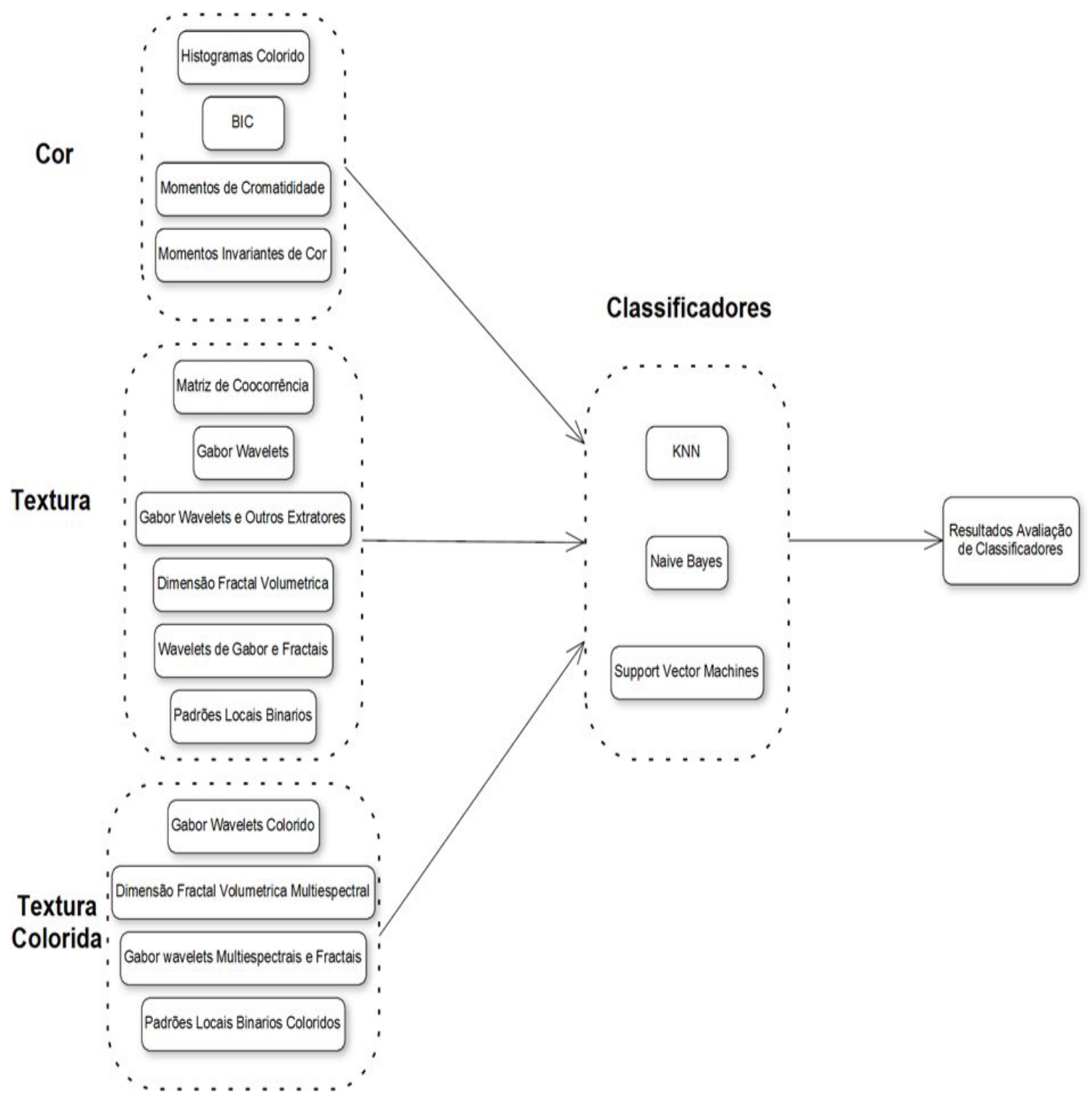

Figura 6.1: Estratégia de classificação

3. Para reduzir o número de tabelas e resultados unicamente são apresentados detalhes como a matriz de confusão dos melhores métodos para cor, textura e textura colorida.

Para todas as etapas e para os diversos classificadores empregados utilizouse o método de validação cruzada com 10 folds como procedimento padrão para estimar o acerto global, usando seleção randômica dos conjuntos de treinamento e teste para cada corrida e mantendo a consistência entre as classes 
(mesmo número de amostras para todas as classes). As tabelas de resultados apresentadas mostram uma serie de indicadores estatísticos da classificação que indicam o sucesso da classificação desde distintos pontos de vista. A continuação explicam-se todas estas estatisticas usadas:

- Número de descritores: Todas as tabelas começam sua descrição de resultados apresentando o número de descritores (variáveis no vetor de características). É importante conhecer o número de descritores gerado por cada técnica de extração de características ja que pode influênciar a determinação das melhores técnicas, prefere-se técnicas com um grau de acerto global alto e um número reduzido de descritores.

- Acerto Global: A probabilidade de acerto global mede o desempenho da classificação da totalidade das classes e o valor indica a porcentagem de imagens para as quais sua etiqueta de classe e sua predição de classe (gerada pelo classificador) é a mesma. É o parâmetro estatístico mais importante è dado pela divisão da soma os valores da diagonal principal da matriz de confusão pela quantidade total de janelas usadas.

- Indice Kappa: O indice kappa foi desenvolvido por (Cohen, 1960) e indica a concordância entre o acerto global e a verdade tomando em consideração que uma parte do acerto global gerado pelo classificador pode ser unicamente obtido pelo azar. O índice Kappa é dado por:

$$
K=\frac{\theta_{1}-\theta_{2}}{1-\theta_{2}},
$$

onde

$$
\theta_{1}=\sum_{i=1}^{r} \frac{m_{i i}}{n},
$$

e

$$
\theta_{2}=\sum_{i=1}^{r} \frac{m_{i}+m+i}{n^{2}},
$$


Os valores gerados pelo índice kappa vão até 1, é considerada a seguinte tabela para avaliar o valor gerado:

- $<0:$ pobre

- $0-0.20$ : não confiável

- $0.21-0.40$ : baixo

- $0.41-0.60$ : moderado

- $0.61-0.80$ : confiável

- $0.81-1.0$ : quase perfeito

- Desvio padrão do acerto: O uso de validação cruzada com seleção randômica dos conjuntos de treinamento e teste permite obter distintos valores de acerto global para cada corrida, assim mostra-se o desvio padrão entre estes valores para obter uma validade estatística do acerto.

- Confiança do Acerto: A medida de confiança indica o grau com que o classificador acerta a resposta gerada. Para obter esse valor é analisada a distribuição de probabilidade de uma amostra para todas as classes, por cada classe uma amostra analisada gera um valor de correspondência e o classificador toma como predição a classe que obtém o maior valor de correspondência. Todos os valores de correspondência para as amostras corretamente classificadas são somados e divididos entre o número total de amostras corretamente classificadas para gerar o nivel de confiança.

\subsubsection{Métodos de classificação}

Foram escolhidos 3 métodos de classificação para avaliar os vetores de características, estes são: K-vizinhos mais proximos (KNN), Naive Bayes e Maquinas de vetores de suporte (SVM). A escolha foi decida pela grande variabilidade dos vetores de características gerados pelos métodos de extração de características. É importante conhecer a diferença de classificação entre classificadores simples como KNN e Naive Bayes com classificadores mais sofisticados como SVM. 


\subsubsection{K-vizinhos mas próximos}

O método mais básico usado foi o classificador KNN. Este classificador é baseado na idéia que a predição de pertinência de um objeto deve ser a mesma que os objetos mais similares (distância N-dimensional) a ele de um conjunto de objetos num dataset de treinamento.

KNN é baseado na medida de distância entre objetos, a distância mais comummente usada é a distancia euclidiana (Duda, 2000). Seja o ponto no espaço $\mathrm{N}$-dimensional $P=\left(p_{1}, p_{2}, \ldots, p_{n}\right)$ e $Q=\left(p_{1}, q_{2}, \ldots, q_{n}\right)$ a distancia euclidiana $\mathrm{N}$-dimensional se define como:

$$
E u c=\sqrt{\left(p_{1}-q_{1}\right)^{2}+\left(p_{2}-q_{2}\right)^{2}+\ldots+\left(p_{n}-q_{n}\right)^{2}}=\sqrt{\sum n i=1\left(p_{i}-q_{i}\right)^{2}},
$$

Os dois fatores mais importantes que afetam o desempenho do classificador é a seleção do valor de K (número de vizinhos a procurar para determinar o objeto ou conjunto de objetos mais próximos) e o método de busca usado. Se K é muito pequeno pode ser sensível a ruídos, se é muito grande o resultado é afetado por vizinhos q não pertencem à classe. O método de busca afeta unicamente o tempo de classificação sendo que este algoritmo realizará as comparações entre o objeto a classificar e os objetos no conjunto de treinamento.

\subsubsection{Naive Bayes}

Classificadores bayesianos são baseados na idéia que os objetos de uma classe podem ser modelados por processos estatísticos. O processo que gera os objetos de uma classe também gera uma probabilidade desse objeto pertencer à classe da qual nasceu, isto também é chamado de probabilidade a priori (Duda, 2000). Para determinar a classe a qual um objeto desconhecido poderia pertencer é necessário calcular sua probabilidade a posteriori. A rega de classificação do Naive Bayes pode ser entendida como a rotulação do objeto desconhecido com a etiqueta de classe do grupo com a maior probabilidade condicional, ou seja o grupo que tem mais probabilidade dele pertencer. Para isto é usado o teorema de Bayes. A rega de Bayes indica que um objeto pode pertencer a um grupo i quando: 


$$
P(i \mid x)>P(j \mid x),
$$

Onde

$$
P(i \mid x)=\frac{P(i) \prod_{k=1}^{n} P\left(X_{k} \mid i\right)}{\prod_{k=1}^{n} P\left(X_{k}\right)},
$$

$\mathrm{e}$

$$
P\left(X_{k} \mid i\right)=\frac{1}{\sqrt{2 \pi \sigma_{i k}^{2}} e^{\frac{\left(x_{i}-\mu_{i k}\right)^{2}}{2 \sigma_{i k}^{2}}}},
$$

$P(x \mid i)$ é a probabilidade de obter um conjunto de características $\mathrm{x}$ sendo que o objeto pertence ao grupo i, $P(i)$ é a probabilidade a priori. O método de Naive bayes assume a independencia dos atributos dentro de um mesmo vetor de caracterizas, mas apresenta bom funcionamento ainda quando as características estejam fortemente correlacionadas (Rossatto et al., 2011).

\subsubsection{Máquinas de suporte de vetores}

As maquinas de vetores de suporte (SVM) foram introduzidas em 1995 para classificação de vetores de características. SVMs geram uma separação linear com um hiperplano no espaço dos objetos, o hiperplano deve fornecer o maior nível de generalização e evitar limitar o espaço separado o mais possível (overfitting). Para determinar a posição exata do hiperplano é usada uma otimização dual que é resolvida com algoritmos seqüenciais de otimização até atingir um ponto definido por algum limiar.

O problema de separação linear é que num sempre um hiperplano pode separar todos os objetos no treinamento, para resolver este problema foram introduzidas duas melhoras nos SVMs, a primeira refere-se à possibilidade de permitir erros mas penalizar esses erros no cálculo da posição final do hiperplano. A segunda melhora foi a introdução das funções kernel, muitos dos dados do mundo real não são linearmente separáveis, para resolver isto é necessário projetar os dados em dimensões maiores com atributos gerados a partir dos atributos originais, assim pode-se encontrar um hiperplano ndimensional que separe efetivamente as classes. 
6.0.7.4 Detalhes do uso dos classificadores nos experimentos

a continuação são apresentadas alguns detalhes específicos dos classificadores usados nos experimentos:

- KNN: Para KNN foi usada um número $\mathrm{K}=1$. Foi elegido esse valor para manter a simplicidade do método, o método de busca escolhido foi busca linear.

- Naive Bayes: Para o uso de Naive bayes não é usado nenhum procedimento de normalização dos dados nem de decorrelação ao menos que seja explicitamente usado no método de extração de características.

- SVM: Para SVM foi usado um kernel polinomial de grau 2 com parâmetro de tolerância 0.001 e um $\epsilon=1.0 \times 10^{-12}$ e um processo de normalização dos dados prévio à classificação. 



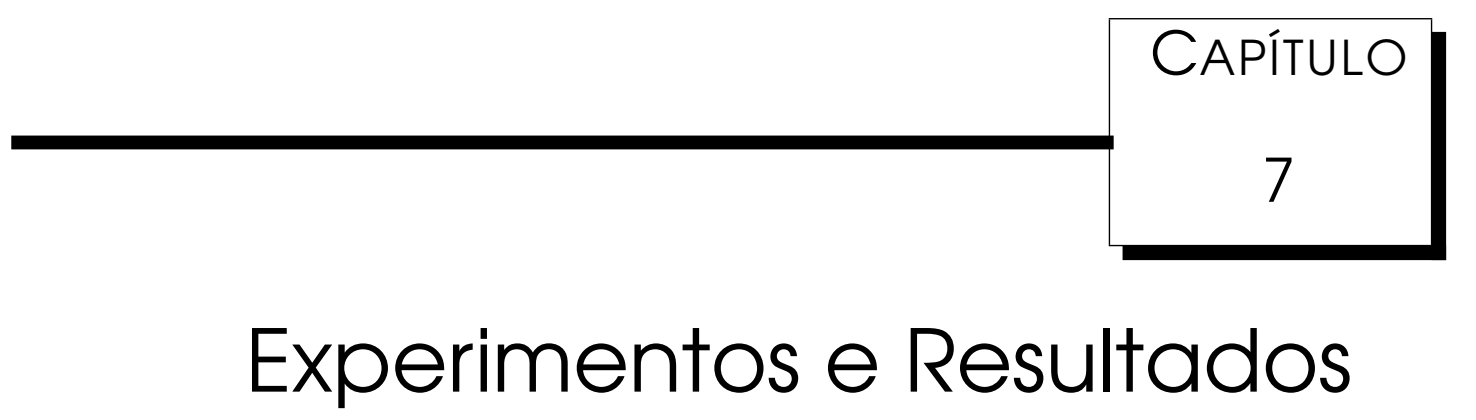

Neste capítulo são apresentados os experimentos realizados para a identificação de deficiências nutricionais em plantas de milho. O capítulo está dividido em três partes: (1) Geração da base de imagens. (2) comparação dos métodos de extração de características usados. (3) Discussão dos resultados.

\subsection{Base de Imagens}

As imagens de folhas de milho utilizadas foram coletadas dos herbários descritos na seção 5. No total foram analisadas 5 deficiências nutricionais (Cálcio, Magnésio, Enxofre, Nitrogênio e Potássio) em 4 níveis de deficiência T1 (ausência total do nutriente), T2 (1/3 da dose normal), T3 (2/3 da dose normal) e T4 (dose completa). Foram coletadas folhas em 3 épocas de crescimento que denominaremos coletas, cada coleta representa um estágio de crescimento sendo a Coleta 1 o estágio inicial e Coleta 3 o estágio final. Todas as folhas coletadas foram divididas em 3 partes seguindo o procedimento apresentado na seção 4.2.1. Os processos biológicos explicados no capítulo anterior sugerem que as deficiências podem ser apresentadas na folha nova ou na folha velha da planta, assim, foram coletadas tanto a folha nova como a folha velha de cada coleta para todos os experimentos. Para referências futu- 
ras a folha nova sera conhecida como folha2 e a folha velha como folha4. No total foram coletadas 8 folhas ( 2 folhas por cada repetição) gerando um total de 960 folhas coletadas e digitalizadas divididas em 240 classes. Foram extraídas um total de 100 janelas por cada classe, totalizando 28800 janelas. O tamanho usado para as janelas foi $80 x 80 p x$ tamanhos maiores não permitiam a extração do mesmo número de janelas para todas as classes devido a que algumas folhas tinham um tamanho muito reduzido.

O objetivo é conhecer quais são as deficiências nutricionais das amostras obtidas, concretamente, a deficiência (se houver alguma) que a folha possui e o nível de deficiência (T1,T2 ou T3). Outros dados das folhas conhecidos a priori são a coleta e o tipo de folha (folha nova ou velha) porém usa-se essa informação para reduzir o espaço de classificação das amostras dividindo-as em 18 bases de imagens, cada uma com 16 classes. Com o intuito de fornecer informações significativas foram geradas também duas classes por cada base de imagens que usam a informação das folhas inteira (sem cortes) essa base é gerada misturando as janelas obtidas da base o meio e a ponta, gerando no final 24 bases de imagens.

Em resumo as bases usadas são:

- Bases2: 1600 imagens, 80x80 pixels, RGB. As imagens desta classe pertencem ao terço inferior da folha.

- Bases4: 1600 imagens, 80x80 pixels, RGB. As imagens desta classe pertencem ao terço inferior da folha.

- Médios2: 1600 imagens, 80x80 pixels, RGB. As imagens desta classe pertencem ao terço médio da folha.

- Médios4: 1600 imagens, 80x80 pixels, RGB. As imagens desta classe pertencem ao terço médio da folha.

- Pontas2: 1600 imagens, 80x80 pixels, RGB. As imagens desta classe pertencem ao terço superior da folha.

- Pontas4: 1600 imagens, 80x80 pixels, RGB. As imagens desta classe pertencem ao terço superior da folha. 
- Todo2: 4800 imagens, 80x80 pixels, RGB. As imagens desta classe são a mistura de todas as imagens de Bases2, Médios2 e Pontas2.

- Todo4: 4800 imagens, 80x80 pixels, RGB. As imagens desta classe são a mistura de todas as imagens de Bases4, Médios4 e Pontas4.

A figura 7.1 mostra as bases de imagens e as classes por cada uma das bases.

As figuras 7.2 e 7.3 mostram as folhas usadas na geração da base de imagens. enquanto as figuras $7.4,7.5,7.6,7.7,7.8$ e 7.9 mostra janelas de algumas classes usadas nos experimentos.

\subsection{Avaliação dos métodos de extração de caracte- rísticas}

A seguir apresenta-se os resultados obtidos por todos os métodos de extração de características usados. Para todos os resultados é apresentada a porcentagem de imagens corretamente classificadas, número de descritores usados, indice kappa, o desvio padrão do acerto e a confiança do acerto.

- Histograma colorido

Os resultados da tabela 7.1, 7.2 e 7.3 mostram que o uso de histogramas coloridos para análise de cor de folhas de milho não é adequado principalmente à uniformidade das cores das janelas texturais e o fato que para ser computacionalmente viável o método precisa reduzir o número de cores da imagem tornando-as mais difícil de processar. O método apresento uma taxa de acerto global de $61.688 \%$ na classe Médios2 para a Coleta1, $57.250 \%$ na base de imagens Pontas2 para a Coleta2 e $57.813 \%$ na base de imagens Pontas2 para a Coleta3. O índice kappa mostra que a maioria dos resultados encontra-se num tipo de concordância aceitável. A confiança do acerto é moderada em todos os resultados mostrando uma clara ambigüidade das características para diferenciar cada classe. O método foi testado o método com 4,8,16,32,64,128 cores sendo que o melhor resultado obtido foi com 128 cores para coleta 1 , coleta 2 e coleta 


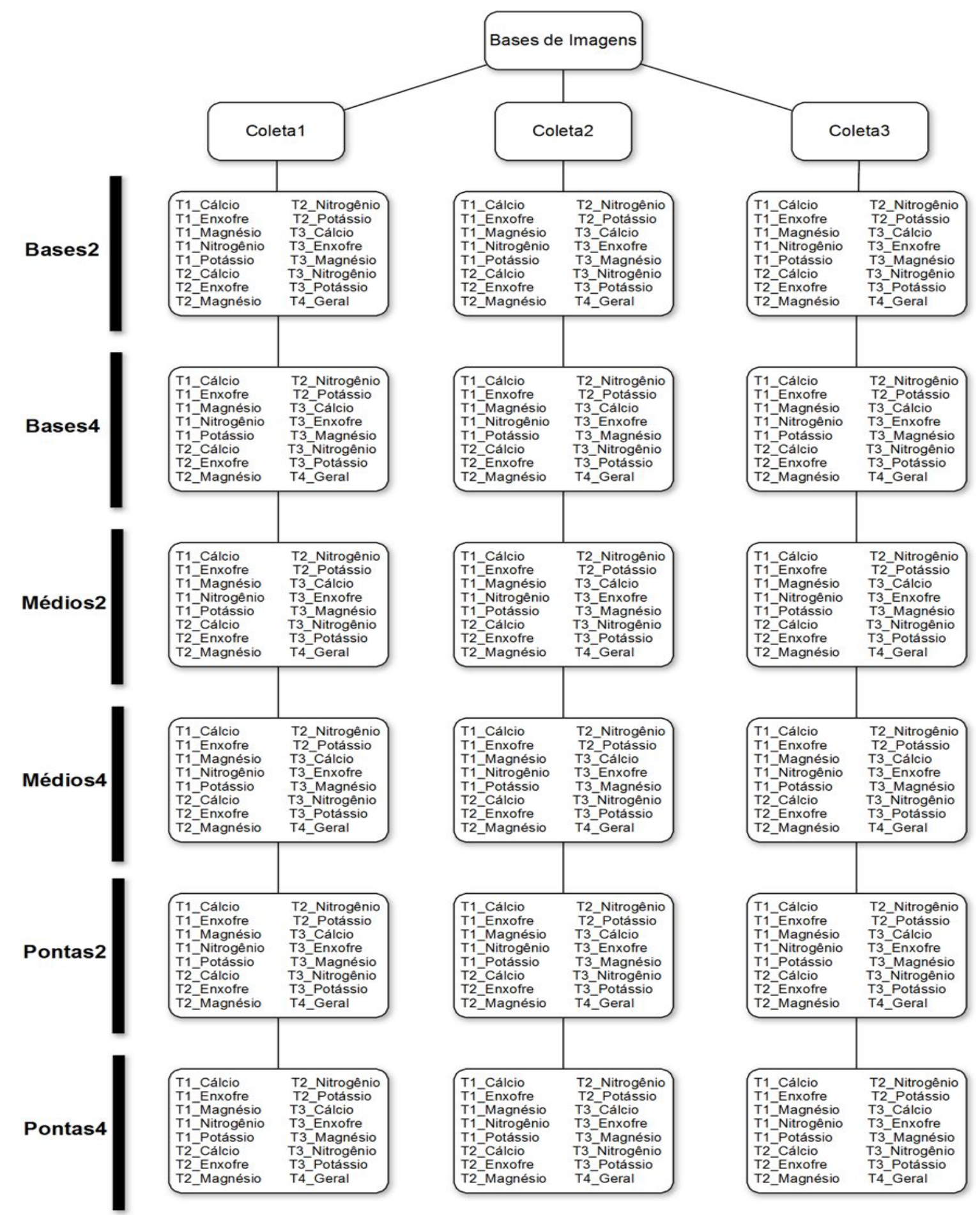

Figura 7.1: Bases de Imagens usadas nos experimentos 


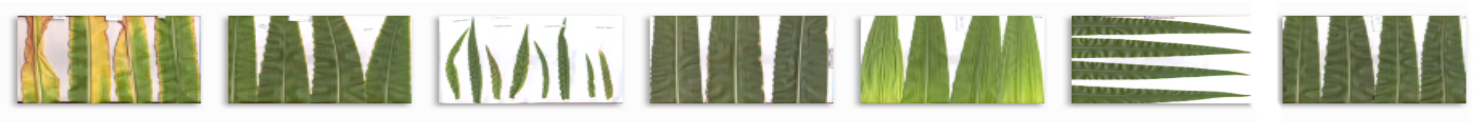

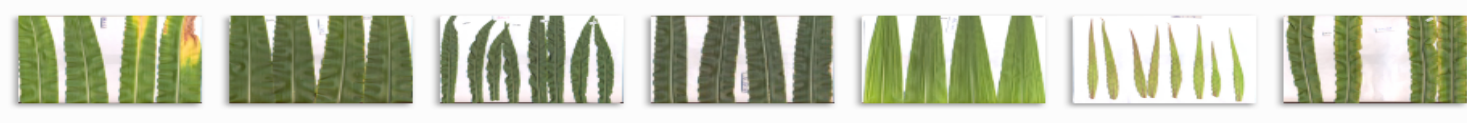

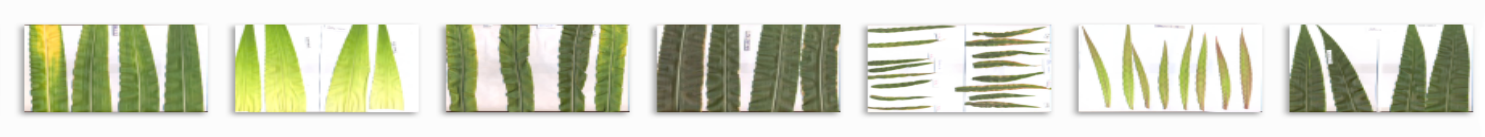
Liim UMM MM

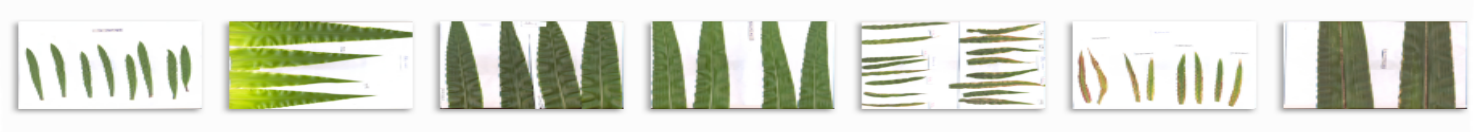

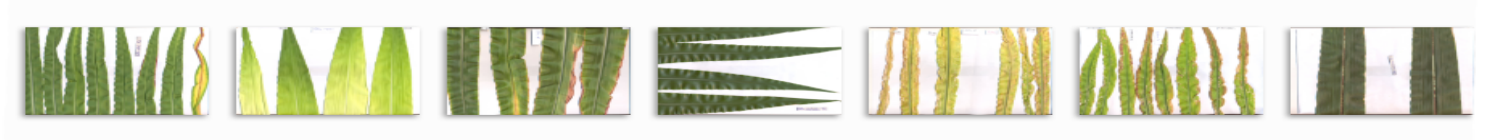

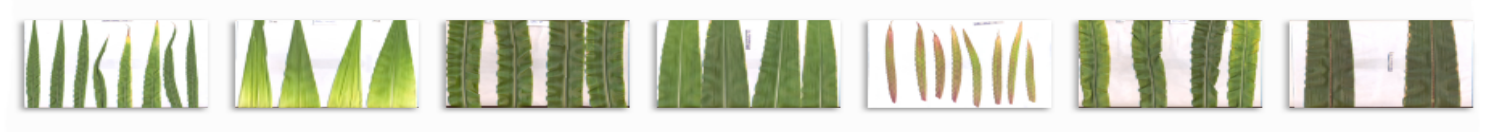

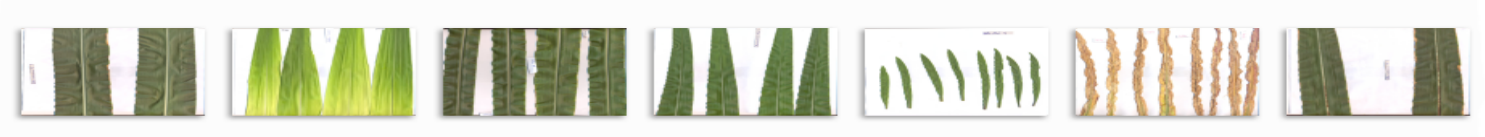
애 $\equiv$ III

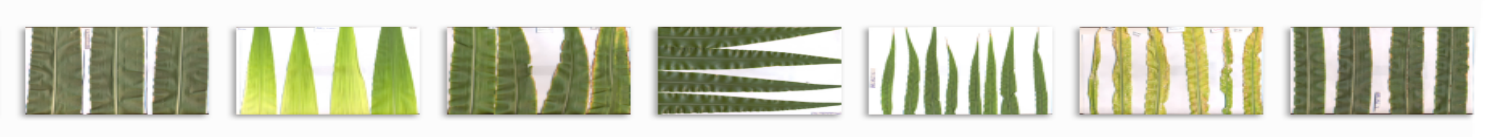

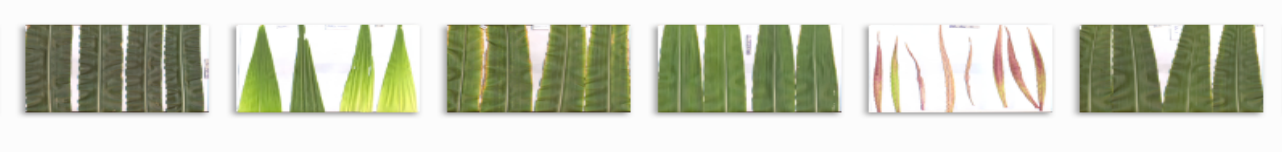

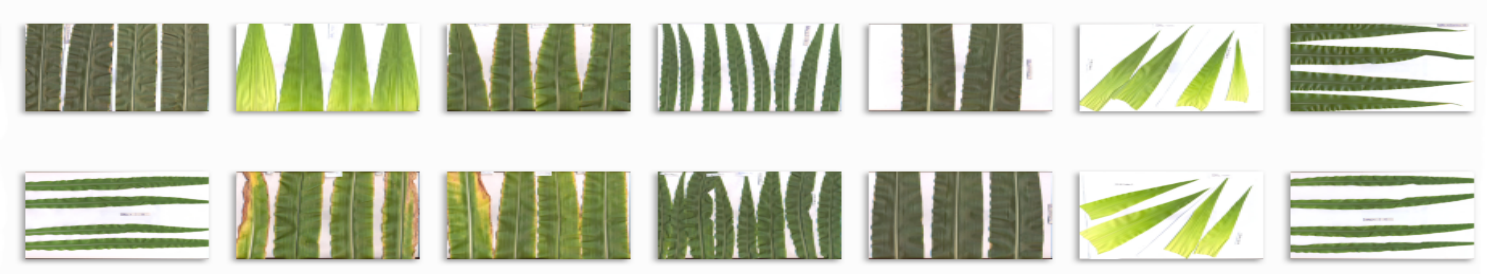

Figura 7.2: Folhas usadas na geração da base de imagens 


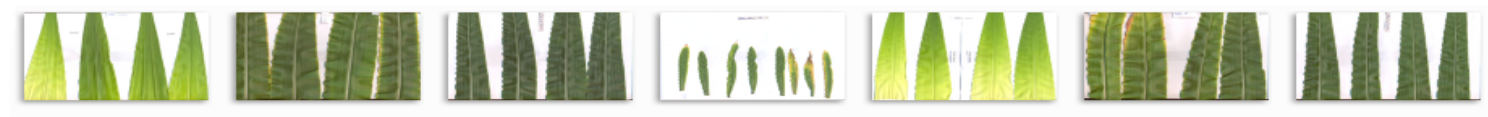

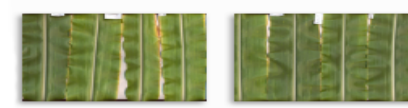
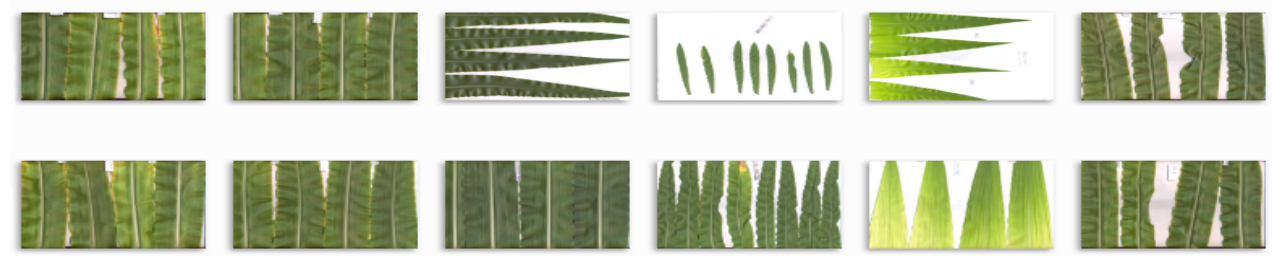 MIIIIII
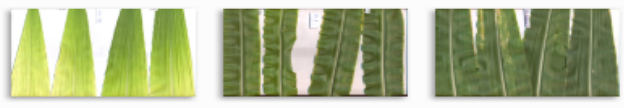
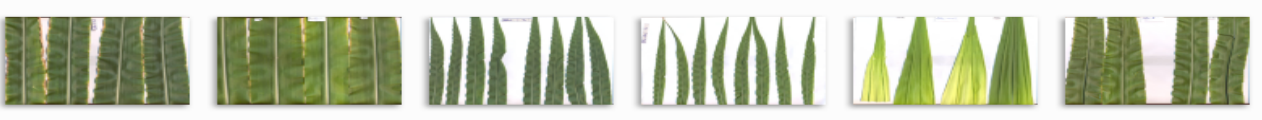

111.

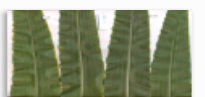

|(I)/ill
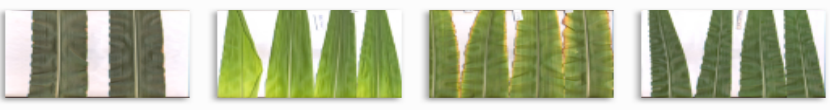

11111

MAN

IIIIIII
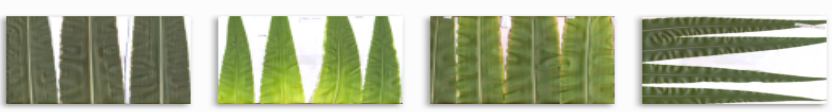

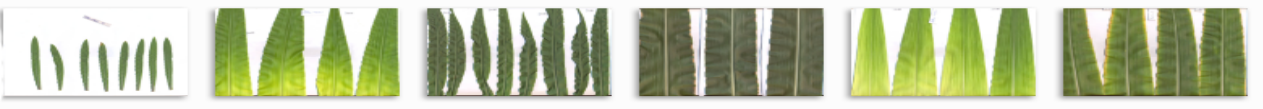

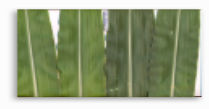

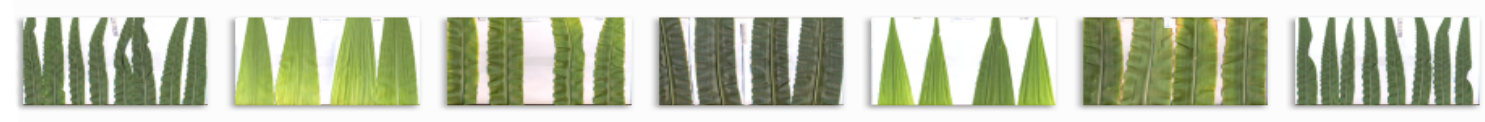

Hiilili LMM IIII

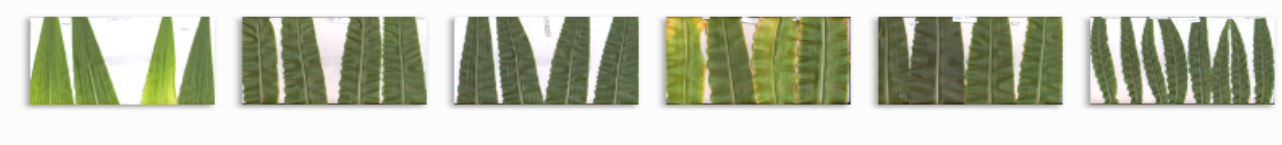
MMII HIII E

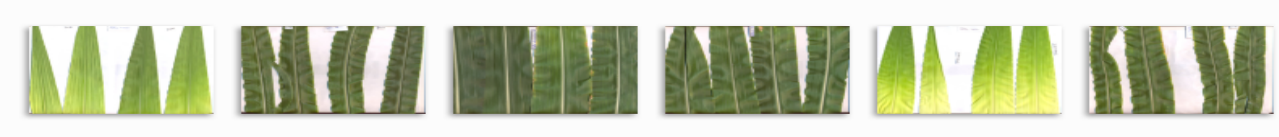
MM Hi|l| =

Figura 7.3: Folhas usadas na geração da base de imagens 


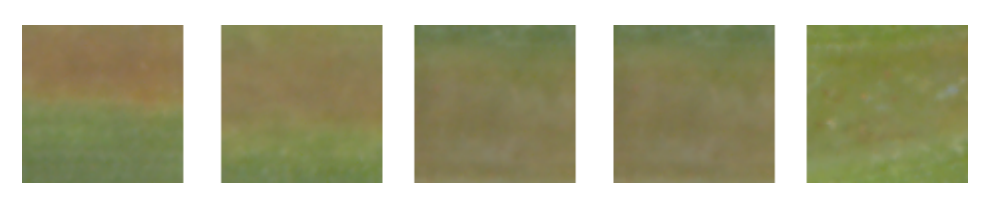

Figura 7.4: Cinco exemplos de janelas texturais da classe Coleta1 Bases2 T1 do Cálcio
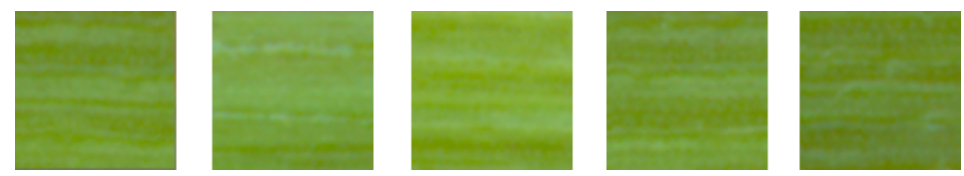

Figura 7.5: Cinco exemplos de janelas texturais da classe Coleta1 Bases2 T1 do enxofre
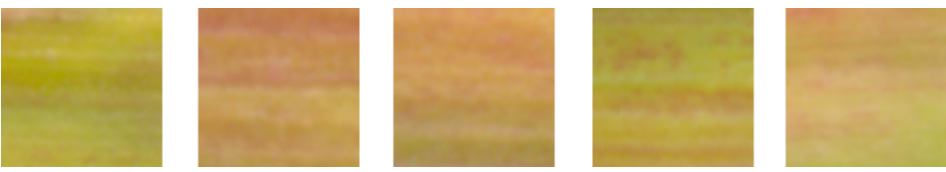

Figura 7.6: Cinco exemplos de janelas texturais da classe Coleta1 Bases2 T1 do magnésio
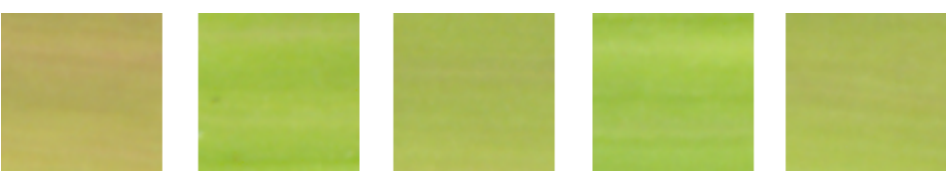

Figura 7.7: Cinco exemplos de janelas texturais da classe Coleta1 Bases2 T1 do nitrogênio
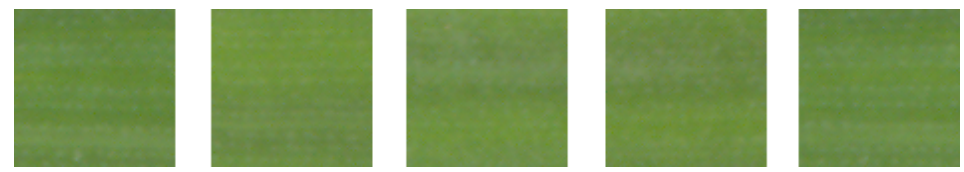

Figura 7.8: Cinco exemplos de janelas texturais da classe Coleta1 Bases2 T1 do potássio
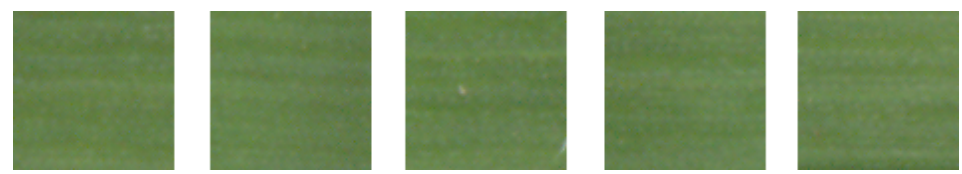

Figura 7.9: Cinco exemplos de janelas texturais da classe Coleta1 Bases2 T4

3. O gráfico 7.10, mostra a evolução do acerto global para as 3 coletas com a melhor técnica de classificação. 


\begin{tabular}{|c|c|c|c|c|c|c|}
\hline Base de Imagens & $\begin{array}{c}\text { Nro. de } \\
\text { Descritores }\end{array}$ & $\begin{array}{l}\text { Nro. de Imagens } \\
\text { Corretamente } \\
\text { Classificadas }\end{array}$ & $\begin{array}{l}\text { Probabilidade de } \\
\text { Acerto Global (\%) }\end{array}$ & Kappa & $\begin{array}{l}\text { Desvio padrão } \\
\text { do acerto (\%) }\end{array}$ & $\begin{array}{c}\text { Confiança } \\
\text { Acertos }\end{array}$ \\
\hline Bases2 & 5 & 828 & 51.750 & 0.485 & 1.066 & 98.209 \\
\hline Bases4 & 5 & 822 & 51.375 & 0.481 & 1.037 & 98.228 \\
\hline Médios2 & 5 & 987 & 61.688 & 0.591 & 0.943 & 98.222 \\
\hline Médios4 & 5 & 936 & 58.500 & 0.557 & 1.012 & 98.227 \\
\hline Pontas2 & 5 & 937 & 58.563 & 0.558 & 1.009 & 98.213 \\
\hline Pontas4 & 5 & 818 & 51.125 & 0.479 & 1.087 & 98.226 \\
\hline Todo2 & 5 & 2469 & 51.438 & 0.482 & 1.077 & 99.403 \\
\hline Todo4 & 5 & 2316 & 48.250 & 0.448 & 1.102 & 99.404 \\
\hline
\end{tabular}

Tabela 7.1: Sumário da classificação usando o método de histogramas coloridos para a Coleta 1 usando KNN para classificar os dados, O melhor resultado foi obtido com 128 cores.

\begin{tabular}{cccccc}
\hline Base de Imagens & $\begin{array}{c}\text { Nro. de } \\
\text { Descritores }\end{array}$ & $\begin{array}{c}\text { Nro. de Imagens } \\
\text { Corretamente } \\
\text { Classificadas }\end{array}$ & $\begin{array}{c}\text { Probabilidade de } \\
\text { Acerto Global (\%) }\end{array}$ & Kappa & $\begin{array}{c}\text { Desvio padrão } \\
\text { do acerto (\%) }\end{array}$ \\
\hline Bases2 & 5 & 697 & 43.563 & 0.398 & 1.228 \\
Confiança \\
Acertos
\end{tabular}

Tabela 7.2: Sumário da classificação usando o método de histogramas coloridos para a Coleta 2 usando KNN para classificar os dados, O melhor resultado foi obtido com 128 cores.

\begin{tabular}{cccccc}
\hline Base de Imagens & $\begin{array}{c}\text { Nro. de } \\
\text { Descritores }\end{array}$ & $\begin{array}{c}\text { Nro. de Imagens } \\
\text { Corretamente } \\
\text { Classificadas }\end{array}$ & $\begin{array}{c}\text { Probabilidade de } \\
\text { Acerto Global (\%) }\end{array}$ & $\begin{array}{c}\text { Kappa } \\
\text { Desvio padrão } \\
\text { do acerto (\%) }\end{array}$ \\
\hline Bases2 & 5 & 851 & 53.188 & 0.501 & 1.021 \\
Bases4 & 5 & 720 & 45.000 & 0.413 & 1.157 \\
Médios2 & 5 & 788 & 49.250 & 0.459 & 1.083 \\
Médios4 & 5 & 676 & 57.850 & 0.384 & 0.13 \\
Acertos
\end{tabular}

Tabela 7.3: Sumário da classificação usando o método de histogramas coloridos para a Coleta 3 usando KNN para classificar os dados, O melhor resultado foi obtido com 128 cores.

Os resultados obtidos com outros classificadores não amostram uma melhora no resultado, os descritores gerados simplesmente não fornecem uma informação que possa ser melhor classificada por uma técnica de aprendizado de máquina sofisticada. O uso de máquina de suporte de vetores e naive Bayes sob os vetores de características extraídos fornecem 


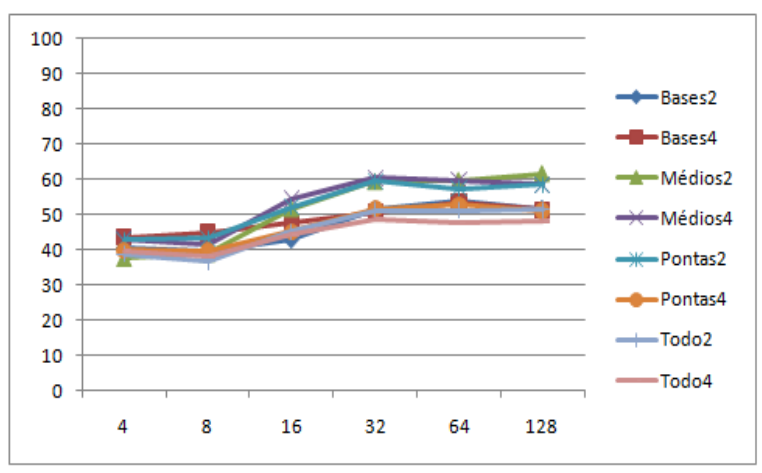

(a)

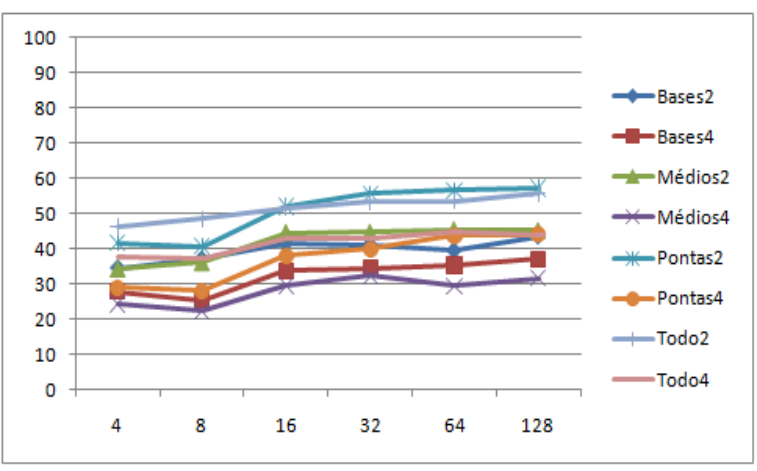

(b)

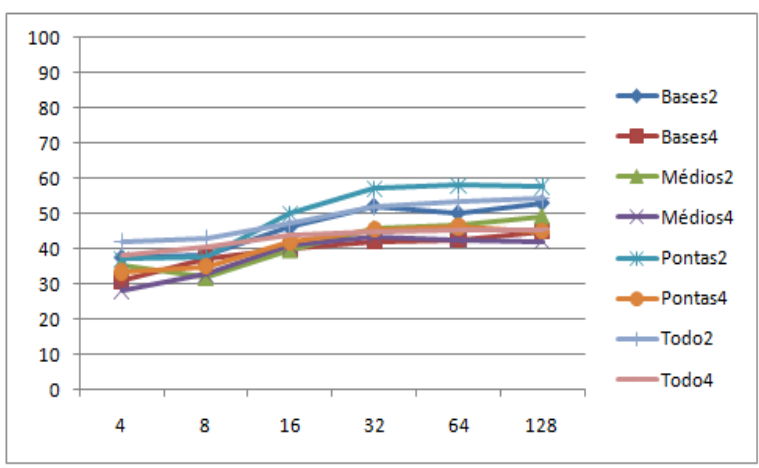

(c)

Figura 7.10: Acerto (eixo Y) para cada número de cores (eixo X), (a) Acerto para coleta 1 usando KNN, (b) Acerto para coleta 2 usando KNN e (c) Acerto para coleta 3 usando $\mathrm{KNN}$

resultados sem diferença significativa aos obtidos com k-vizinhos mais próximos.

- Border/Interior Classification

Os resultados do uso de BIC como extrator de características são apresentados nas tabelas 7.4, 7.5 e 7.6 com acertos globais de $44.688 \%$ na classe Pontas2 para a Coleta1, $46.896 \%$ na base de imagens Todo2 para a Coleta2 e $44.167 \%$ na base de imagens Todo2 para a Coleta3. BIC precisa assim como o método anterior de redução do número de cores para torna-lo viável, com a diferença que o número de descritores depende diretamente do número de cores usada. No método anterior sempre eram extraídas as mesmas medidas estatísticas quaisquer que seja o tamanho do histograma gerado. 


\begin{tabular}{|c|c|c|c|c|c|c|}
\hline Base de Imagens & $\begin{array}{c}\text { Nro. de } \\
\text { Descritores }\end{array}$ & $\begin{array}{l}\text { Nro. de Imagens } \\
\text { Corretamente } \\
\text { Classificadas }\end{array}$ & $\begin{array}{l}\text { Probabilidade de } \\
\text { Acerto Global (\%) }\end{array}$ & Kappa & $\begin{array}{l}\text { Desvio padrão } \\
\text { do acerto (\%) }\end{array}$ & $\begin{array}{c}\text { Confiança } \\
\text { Acertos }\end{array}$ \\
\hline Bases2 & 16 & 608 & 38.000 & 0.339 & 0.474 & 98.129 \\
\hline Bases4 & 16 & 677 & 42.313 & 0.385 & 0.587 & 98.283 \\
\hline Médios2 & 16 & 677 & 42.313 & 0.385 & 0.585 & 98.227 \\
\hline Médios4 & 16 & 589 & 36.813 & 0.326 & 0.457 & 98.246 \\
\hline Pontas2 & 16 & 715 & 44.688 & 0.410 & 0.757 & 98.162 \\
\hline Pontas4 & 16 & 636 & 39.750 & 0.357 & 0.492 & 98.226 \\
\hline Todo2 & 16 & 1893 & 39.438 & 0.354 & 0.490 & 99.356 \\
\hline Todo4 & 16 & 1745 & 36.354 & 0.321 & 0.468 & 99.320 \\
\hline
\end{tabular}

Tabela 7.4: Sumário da classificação usando o método BIC para a Coleta 1 usando KNN para classificar os dados, O melhor resultado foi obtido com 8 cores.

\begin{tabular}{|c|c|c|c|c|c|c|}
\hline Base de Imagens & $\begin{array}{c}\text { Nro. de } \\
\text { Descritores }\end{array}$ & $\begin{array}{l}\text { Nro. de Imagens } \\
\text { Corretamente } \\
\text { Classificadas }\end{array}$ & $\begin{array}{l}\text { Probabilidade de } \\
\text { Acerto Global (\%) }\end{array}$ & Kappa & $\begin{array}{l}\text { Desvio padrão } \\
\text { do acerto (\%) }\end{array}$ & $\begin{array}{l}\text { Confiança } \\
\text { Acertos }\end{array}$ \\
\hline Bases2 & 16 & 599 & 37.438 & 0.333 & 0.469 & 98.200 \\
\hline Bases4 & 16 & 457 & 28.563 & 0.238 & 0.286 & 98.038 \\
\hline Médios2 & 16 & 556 & 34.750 & 0.304 & 0.353 & 98.200 \\
\hline Médios4 & 16 & 437 & 27.313 & 0.225 & 0.274 & 97.365 \\
\hline Pontas2 & 16 & 561 & 35.063 & 0.307 & 0.431 & 97.562 \\
\hline Pontas 4 & 16 & 458 & 28.625 & 0.239 & 0.301 & 97.237 \\
\hline Todo2 & 16 & 2251 & 46.896 & 0.434 & 0.830 & 99.199 \\
\hline Todo4 & 16 & 1906 & 39.708 & 0.357 & 0.649 & 98.815 \\
\hline
\end{tabular}

Tabela 7.5: Sumário da classificação usando o método BIC para a Coleta 2 usando KNN para classificar os dados, O melhor resultado foi obtido com 8 cores.

\begin{tabular}{cccccc}
\hline Base de Imagens & $\begin{array}{c}\text { Nro. de } \\
\text { Descritores }\end{array}$ & $\begin{array}{c}\text { Nro. de Imagens } \\
\text { Corretamente } \\
\text { Classificadas }\end{array}$ & $\begin{array}{c}\text { Probabilidade de } \\
\text { Acerto Global (\%) }\end{array}$ & Kappa & $\begin{array}{c}\text { Desvio padrão } \\
\text { do acerto (\%) }\end{array}$ \\
\hline Bases2 & 16 & 629 & 39.313 & 0.353 & 0.454 \\
Confiança \\
Acertos
\end{tabular}

Tabela 7.6: Sumário da classificação usando o método BIC para a Coleta 3 usando KNN para classificar os dados, O melhor resultado foi obtido com 8 cores.

O índice Kappa indica uma moderada cooncordância dos acertos com a distribuição das classes. Os resultados com todas as variações do número de cores é apresentado no gráfico 7.11.

- Momentos invariantes de cor 


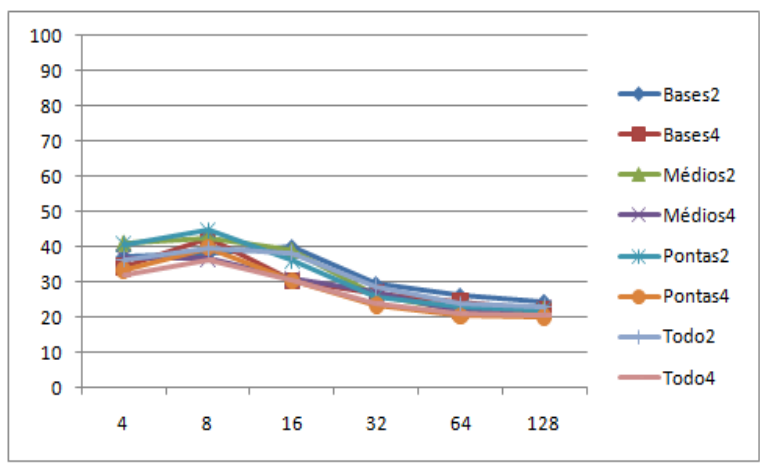

(a)

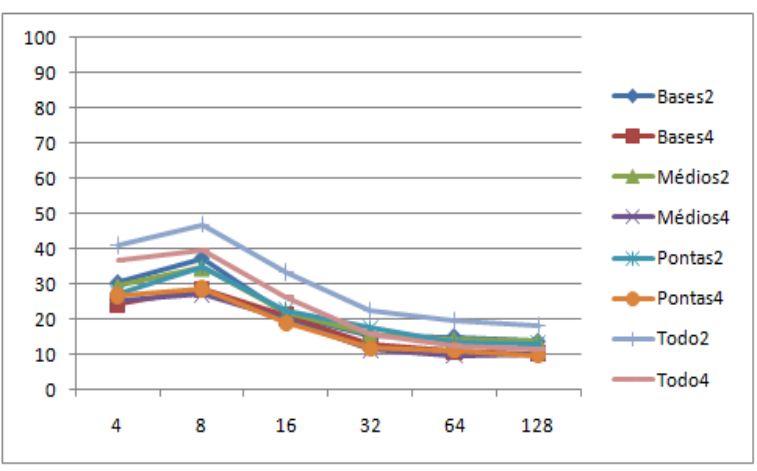

(b)

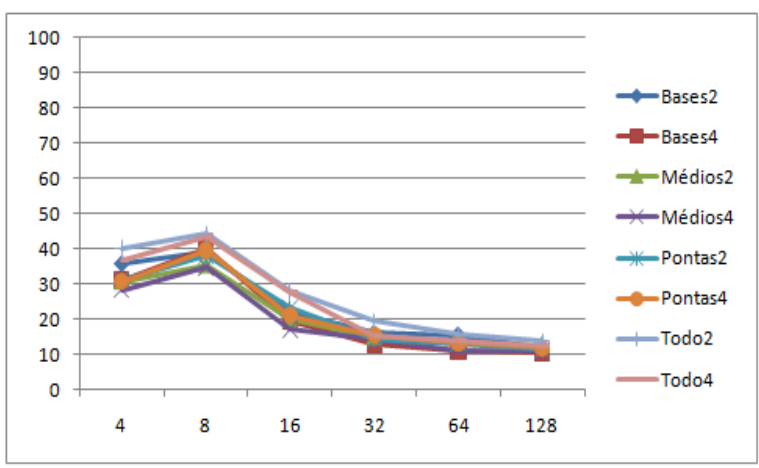

(c)

Figura 7.11: Acerto (eixo $\mathrm{Y}$ ) para cada número de cores (eixo X) na coleta 1, (a) classificação usando KNN, (b) classificação usando Naive Bayes e (c) Classificação usando SVM

Os resultados apresentados pelo método nas tabelas 7.7, 7.8 e 7.9 mostram uma melhora no acerto global e índice kappa com quase o dobro de descritores que o método anterior, para a coleta 1 o melhor acerto global obtido é 62.250 na base Bases4, para a coleta 2 o melhor acerto obtido é 56.042 na base Todo2 e finalmente para a coleta 3 o melhor acerto é 51.500 na base Bases2. A diferença dos métodos anteriores momentos invariantes não precisam de redução de cores porem só um experimento é realizado por base. Os resultados obtidos com os momentos PSO não são apresentados por ter gerado resultados muito baixos. A coleta 1 usa classificador SVM para obter os melhores resultados, a coleta 2 e 3 obtiveram seus melhores resultados com o uso de KNN.

- Momentos de cromaticidade 


\begin{tabular}{|c|c|c|c|c|c|c|}
\hline Base de Imagens & $\begin{array}{c}\text { Nro. de } \\
\text { Descritores }\end{array}$ & $\begin{array}{l}\text { Nro. de Imagens } \\
\text { Corretamente } \\
\text { Classificadas }\end{array}$ & $\begin{array}{l}\text { Probabilidade de } \\
\text { Acerto Global (\%) }\end{array}$ & Kappa & $\begin{array}{l}\text { Desvio padrão } \\
\text { do acerto (\%) }\end{array}$ & $\begin{array}{l}\text { Confiança } \\
\text { Acertos }\end{array}$ \\
\hline Bases2 & 30 & 904 & 56.500 & 0.536 & 1.075 & 12.478 \\
\hline Bases4 & 30 & 996 & 62.250 & 0.597 & 1.110 & 12.483 \\
\hline Médios2 & 30 & 956 & 59.750 & 0.571 & 1.103 & 12.489 \\
\hline Médios4 & 30 & 992 & 62.000 & 0.595 & 1.115 & 12.471 \\
\hline Pontas2 & 30 & 940 & 58.750 & 0.560 & 1.098 & 12.485 \\
\hline Pontas4 & 30 & 907 & 56.688 & 0.538 & 1.038 & 12.481 \\
\hline Todo2 & 30 & 2720 & 56.667 & 0.538 & 1.078 & 12.487 \\
\hline Todo4 & 30 & 2651 & 55.229 & 0.522 & 1.030 & 12.486 \\
\hline
\end{tabular}

Tabela 7.7: Sumário da classificação usando o método momentos invariantes para a Coleta 1 usando SVM para classificar os dados.

\begin{tabular}{|c|c|c|c|c|c|c|}
\hline Base de Imagens & $\begin{array}{c}\text { Nro. de } \\
\text { Descritores }\end{array}$ & $\begin{array}{l}\text { Nro. de Imagens } \\
\text { Corretamente } \\
\text { Classificadas }\end{array}$ & $\begin{array}{l}\text { Probabilidade de } \\
\text { Acerto Global (\%) }\end{array}$ & Kappa & $\begin{array}{l}\text { Desvio padrão } \\
\text { do acerto (\%) }\end{array}$ & $\begin{array}{c}\text { Confiança } \\
\text { Acertos }\end{array}$ \\
\hline Bases2 & 30 & 735 & 45.938 & 0.423 & 1.065 & 98.200 \\
\hline Bases4 & 30 & 534 & 33.375 & 0.289 & 1.263 & 98.200 \\
\hline Médios2 & 30 & 738 & 46.125 & 0.425 & 1.027 & 98.200 \\
\hline Médios4 & 30 & 509 & 31.813 & 0.273 & 1.279 & 98.200 \\
\hline Pontas2 & 30 & 826 & 51.625 & 0.484 & 0.872 & 98.200 \\
\hline Pontas4 & 30 & 597 & 37.313 & 0.331 & 1.180 & 98.200 \\
\hline Todo2 & 30 & 2690 & 56.042 & 0.531 & 0.973 & 99.416 \\
\hline Todo4 & 30 & 2063 & 42.979 & 0.392 & 1.001 & 99.412 \\
\hline
\end{tabular}

Tabela 7.8: Sumário da classificação usando o método momentos invariantes para a Coleta 2 usando KNN para classificar os dados.

\begin{tabular}{cccccr}
\hline Base de Imagens & $\begin{array}{c}\text { Nro. de } \\
\text { Descritores }\end{array}$ & $\begin{array}{c}\text { Nro. de Imagens } \\
\text { Corretamente } \\
\text { Classificadas }\end{array}$ & $\begin{array}{c}\text { Probabilidade de } \\
\text { Acerto Global (\%) }\end{array}$ & Kappa & $\begin{array}{c}\text { Desvio padrão } \\
\text { do acerto (\%) }\end{array}$ \\
\hline Bases2 & 30 & 824 & 51.500 & 0.483 & 1.027 \\
Confiança \\
Acertos
\end{tabular}

Tabela 7.9: Sumário da classificação usando o método momentos invariantes para a Coleta 3 usando KNN para classificar os dados.

A análise usando momentos de cromaticidade indica um acerto global máximo de 51.875 na base de imagens Pontas2 para a coleta1, 50.375 na base de imagens Pontas2 para a coleta2, 47.229 na base de imagens Todo4 para a coleta3 indicado pelos valores das tabelas 7.10, 7.11 e 7.12. Os valores dos índices kappa e o nível de confiança do acerto são similares aos resultados obtidos pelos métodos anteriores.

O método foi testado com 4,8,16,32,64,128 cores. O acerto global para 


\begin{tabular}{|c|c|c|c|c|c|c|}
\hline Base de Imagens & $\begin{array}{c}\text { Nro. de } \\
\text { Descritores }\end{array}$ & $\begin{array}{l}\text { Nro. de Imagens } \\
\text { Corretamente } \\
\text { Classificadas }\end{array}$ & $\begin{array}{l}\text { Probabilidade de } \\
\text { Acerto Global (\%) }\end{array}$ & Kappa & $\begin{array}{l}\text { Desvio padrão } \\
\text { do acerto (\%) }\end{array}$ & $\begin{array}{c}\text { Confiança } \\
\text { Acertos }\end{array}$ \\
\hline Bases2 & 10 & 733 & 45.813 & 0.422 & 0.861 & 98.121 \\
\hline Bases4 & 10 & 760 & 47.500 & 0.440 & 0.847 & 98.289 \\
\hline Médios2 & 10 & 773 & 48.313 & 0.449 & 0.852 & 98.172 \\
\hline Médios4 & 10 & 652 & 40.750 & 0.368 & 0.831 & 98.275 \\
\hline Pontas2 & 10 & 830 & 51.875 & 0.487 & 0.820 & 98.184 \\
\hline Pontas 4 & 10 & 729 & 45.563 & 0.419 & 0.844 & 98.265 \\
\hline Todo2 & 10 & 2323 & 48.396 & 0.450 & 0.810 & 99.368 \\
\hline Todo4 & 10 & 2076 & 43.250 & 0.395 & 0.866 & 99.380 \\
\hline
\end{tabular}

Tabela 7.10: Sumário da classificação usando o método momentos cromaticidade para a Coleta 1 usando KNN para classificar os dados.

\begin{tabular}{|c|c|c|c|c|c|c|}
\hline Base de Imagens & $\begin{array}{c}\text { Nro. de } \\
\text { Descritores }\end{array}$ & $\begin{array}{l}\text { Nro. de Imagens } \\
\text { Corretamente } \\
\text { Classificadas }\end{array}$ & $\begin{array}{l}\text { Probabilidade de } \\
\text { Acerto Global (\%) }\end{array}$ & Kappa & $\begin{array}{l}\text { Desvio padrão } \\
\text { do acerto (\%) }\end{array}$ & $\begin{array}{c}\text { Confiança } \\
\text { Acertos }\end{array}$ \\
\hline Bases2 & 10 & 653 & 40.813 & 0.369 & 0.751 & 97.902 \\
\hline Bases4 & 10 & 508 & 31.750 & 0.272 & 0.731 & 98.202 \\
\hline Médios2 & 10 & 604 & 37.750 & 0.336 & 0.750 & 98.200 \\
\hline Médios4 & 10 & 440 & 27.500 & 0.227 & 0.708 & 98.200 \\
\hline Pontas2 & 10 & 659 & 41.188 & 0.373 & 0.782 & 98.200 \\
\hline Pontas4 & 10 & 542 & 33.875 & 0.295 & 0.746 & 98.217 \\
\hline Todo2 & 10 & 2418 & 50.375 & 0.471 & 0.788 & 99.257 \\
\hline Todo4 & 10 & 1966 & 40.958 & 0.370 & 0.774 & 99.377 \\
\hline
\end{tabular}

Tabela 7.11: Sumário da classificação usando o método momentos cromaticidade para a Coleta 2 usando KNN para classificar os dados.

\begin{tabular}{|c|c|c|c|c|c|c|}
\hline Base de Imagens & $\begin{array}{c}\text { Nro. de } \\
\text { Descritores }\end{array}$ & $\begin{array}{l}\text { Nro. de Imagens } \\
\text { Corretamente } \\
\text { Classificadas }\end{array}$ & $\begin{array}{l}\text { Probabilidade de } \\
\text { Acerto Global (\%) }\end{array}$ & Kappa & $\begin{array}{l}\text { Desvio padrão } \\
\text { do acerto (\%) }\end{array}$ & $\begin{array}{c}\text { Confiança } \\
\text { Acertos }\end{array}$ \\
\hline Bases2 & 10 & 583 & 36.438 & 0.322 & 0.720 & 98.067 \\
\hline Bases4 & 10 & 615 & 38.438 & 0.343 & 0.753 & 98.283 \\
\hline Médios2 & 10 & 533 & 33.313 & 0.289 & 0.738 & 97.914 \\
\hline Médios4 & 10 & 531 & 33.188 & 0.287 & 0.732 & 98.322 \\
\hline Pontas2 & 10 & 564 & 35.250 & 0.309 & 0.747 & 98.027 \\
\hline Pontas4 & 10 & 666 & 41.625 & 0.377 & 0.709 & 98.107 \\
\hline Todo2 & 10 & 2034 & 42.375 & 0.385 & 0.698 & 99.153 \\
\hline Todo4 & 10 & 2267 & 47.229 & 0.437 & 0.641 & 99.384 \\
\hline
\end{tabular}

Tabela 7.12: Sumário da classificação usando o método momentos cromaticidade para a Coleta 3 usando KNN para classificar os dados.

todos os métodos e todos os números de cores usados é amostrado na Figura 7.12.

Todos os experimentos de cor mostram resultados muito similares o melhor acerto obtido 62.250, a maioria dos resultados encontra-se entre $40 \mathrm{e}$ $50 \%$ de acerto o que é considerado muito baixo para o número de classes usado (16 por cada coleta). Os resultados mostram que as folhas de tipo 2 fornecem informações mais importantes em quase todas as tabelas o 


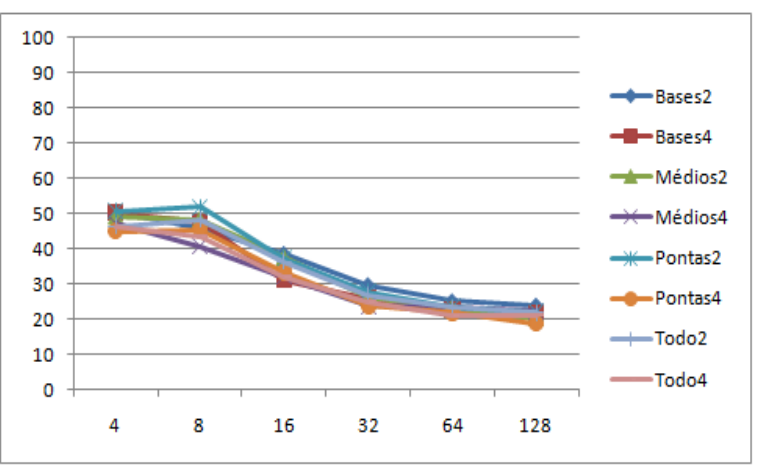

(a)

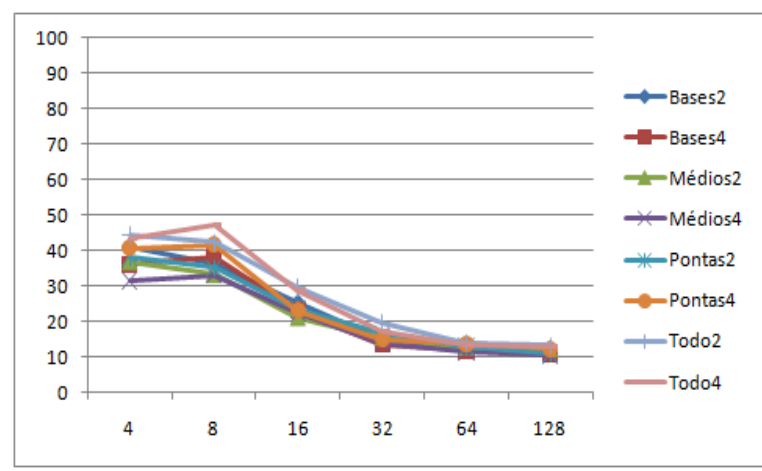

(b)

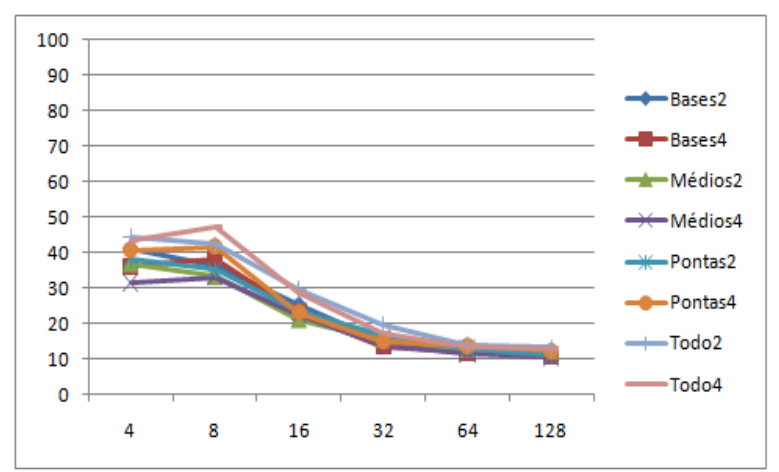

(c)

Figura 7.12: Acerto (eixo Y) para cada número de cores (eixo X) na coleta 1, (a) classificação usando KNN, (b) classificação usando Naive Bayes e (c) Classificação usando SVM

que se traduz em melhores resultados nas bases de imagens Bases2, Médios2 e Pontas2. A conclusão dos experimentos de cor é que descritores puros de cor não fornecem informações suficientes para a diferenciação entre as deficiências. É importante determinar o impacto da cor na classificação porque no planejamento inicial poderia se entender que o problema poderia ser resolvido com uma aproximação baseada unicamente em cor. Outra conclusão importante dos resultados até agora apresentados é que a coleta 1 obtém os melhores resultados de classificação para todos os experimentos, sendo a coleta 2 a segunda mais dificil de classificar e a coleta 3 a mais difícil. Isto indica que ainda que os resultados encontram-se muito abaixo do necessário é possível uma detecção num estágio inicial de crescimento (coleta 1) de deficiências nutricionais. 
A continuação são apresentadas as matrizes de confusão para os métodos que obtiveram o melhor resultado para cada coleta. Para a coleta 1 7.13 o método Momentos invariantes obteve um acerto global de $62,25 \%$ na base Bases4, para a coleta 27.14 o método Histograma colorido obteve um acerto global de $57,25 \%$ na base Pontas2, finalmente para a coleta 3 7.15 o método Histograma colorido obteve um acerto global de $57,81 \%$ na base Pontas2

$\begin{array}{ccccccccccccccccc}\mathrm{a} & \mathrm{b} & \mathrm{c} & \mathrm{d} & \mathrm{e} & \mathrm{f} & \mathrm{g} & \mathrm{h} & \mathrm{i} & \mathrm{j} & \mathrm{k} & \mathrm{l} & \mathrm{m} & \mathrm{n} & \mathrm{o} & \mathrm{p} & \mathrm{a}=\text { T1-Cálcio } \\ 86 & 0 & 1 & 0 & 2 & 0 & 5 & 0 & 0 & 0 & 0 & 0 & 6 & 0 & 0 & 0 & \mathrm{~b}=\text { T1-Enxofre } \\ 0 & 88 & 0 & 0 & 0 & 8 & 0 & 0 & 0 & 0 & 4 & 0 & 0 & 0 & 0 & 0 & \mathrm{c}=\text { T1-Magnésio } \\ 0 & 1 & 93 & 5 & 1 & 0 & 0 & 0 & 0 & 0 & 0 & 0 & 0 & 0 & 0 & 0 & \mathrm{c} \\ 0 & 1 & 1 & 98 & 0 & 0 & 0 & 0 & 0 & 0 & 0 & 0 & 0 & 0 & 0 & 0 & \mathrm{~d}=\text { T1-Nitrogênio } \\ 0 & 2 & 0 & 0 & 82 & 0 & 0 & 1 & 4 & 10 & 0 & 0 & 1 & 0 & 0 & 0 & \mathrm{e}=\text { T1-Potássio } \\ 0 & 13 & 0 & 0 & 0 & 50 & 0 & 11 & 0 & 0 & 0 & 18 & 8 & 0 & 0 & 0 & \mathrm{f}=\text { T2-Cálcio } \\ 2 & 0 & 0 & 0 & 0 & 0 & 88 & 0 & 0 & 0 & 10 & 0 & 0 & 0 & 0 & 0 & \mathrm{~g}=\text { T2-Enxofre } \\ 0 & 1 & 0 & 0 & 0 & 0 & 18 & 39 & 0 & 0 & 0 & 25 & 17 & 0 & 0 & 0 & \mathrm{~h}=\text { T2-Magnésio } \\ 0 & 2 & 0 & 0 & 11 & 0 & 0 & 0 & 56 & 6 & 0 & 1 & 0 & 3 & 19 & 2 & \mathrm{i}=\text { T2-Nitrogênio } \\ 0 & 0 & 0 & 0 & 11 & 0 & 0 & 3 & 1 & 54 & 0 & 2 & 0 & 3 & 8 & 18 & \mathrm{j}=\text { T2-Potássio } \\ 0 & 8 & 0 & 0 & 0 & 0 & 16 & 26 & 0 & 0 & 39 & 0 & 10 & 0 & 0 & 1 & \mathrm{k}=\text { T3-Cálcio } \\ 3 & 0 & 0 & 0 & 0 & 38 & 0 & 0 & 0 & 0 & 0 & 59 & 0 & 0 & 0 & 0 & 1=\text { T3-Enxofre } \\ 0 & 9 & 0 & 0 & 0 & 0 & 17 & 21 & 0 & 0 & 0 & 19 & 34 & 0 & 0 & 0 & \mathrm{~m}=\text { T3-Magnésio } \\ 0 & 0 & 1 & 0 & 8 & 0 & 1 & 1 & 22 & 38 & 0 & 5 & 0 & 7 & 11 & 6 & \mathrm{n}=\text { T3-Nitrogênio } \\ 0 & 0 & 0 & 0 & 1 & 0 & 0 & 0 & 20 & 8 & 0 & 0 & 0 & 2 & 49 & 20 & \mathrm{o}=\text { T3-Potássio } \\ 0 & 0 & 0 & 0 & 0 & 0 & 0 & 0 & 1 & 8 & 0 & 4 & 0 & 1 & 12 & 74 & \mathrm{p}=\text { T4 }\end{array}$

Tabela 7.13: Matriz de confusão para a coleta 1 com o método momentos invariantes.

$\begin{array}{ccccccccccccccccc}\mathrm{a} & \mathrm{b} & \mathrm{c} & \mathrm{d} & \mathrm{e} & \mathrm{f} & \mathrm{g} & \mathrm{h} & \mathrm{i} & \mathrm{j} & \mathrm{k} & 1 & \mathrm{~m} & \mathrm{n} & \mathrm{o} & \mathrm{p} & \mathrm{a}=\text { T1-Cálcio } \\ 30 & 10 & 0 & 8 & 0 & 14 & 9 & 0 & 0 & 0 & 13 & 13 & 3 & 0 & 0 & 0 & \mathrm{~b}=\text { T1-Enxofre } \\ 7 & 52 & 0 & 2 & 0 & 1 & 1 & 13 & 2 & 0 & 6 & 9 & 6 & 0 & 0 & 1 & \mathrm{c}=\text { T1-Magnésio } \\ 0 & 0 & 100 & 0 & 0 & 0 & 0 & 0 & 0 & 0 & 0 & 0 & 0 & 0 & 0 & 0 & \mathrm{~d} \\ 1 & 8 & 0 & 61 & 0 & 0 & 17 & 2 & 0 & 0 & 2 & 9 & 0 & 0 & 0 & 0 & \mathrm{~d}=\text { T1-Nitrogênio } \\ 0 & 0 & 0 & 0 & 74 & 0 & 0 & 0 & 0 & 22 & 0 & 0 & 0 & 0 & 4 & 0 & \mathrm{e}=\text { T1-Potássio } \\ 1 & 7 & 0 & 14 & 0 & 59 & 1 & 1 & 0 & 0 & 10 & 6 & 1 & 0 & 0 & 0 & \mathrm{f}=\mathrm{T} 2-\text { Cálcio } \\ 3 & 11 & 0 & 1 & 0 & 1 & 54 & 0 & 1 & 0 & 13 & 14 & 2 & 0 & 0 & 0 & \mathrm{~g}=\text { T2-Enxofre } \\ 7 & 1 & 0 & 1 & 0 & 4 & 7 & 31 & 7 & 0 & 0 & 4 & 37 & 0 & 0 & 1 & \mathrm{~h}=\mathrm{T} 2-\text { Magnésio } \\ 2 & 0 & 0 & 0 & 0 & 2 & 0 & 4 & 82 & 0 & 0 & 1 & 7 & 1 & 0 & 1 & \mathrm{i}=\text { T2-Nitrogênio } \\ 0 & 0 & 0 & 0 & 23 & 0 & 0 & 0 & 0 & 44 & 0 & 0 & 0 & 0 & 33 & 0 & \mathrm{j}=\mathrm{T} 2 \text {-Potássio } \\ 4 & 7 & 0 & 12 & 0 & 11 & 6 & 5 & 1 & 0 & 41 & 10 & 1 & 0 & 0 & 2 & \mathrm{k}=\text { T3-Cálcio } \\ 4 & 4 & 0 & 2 & 0 & 10 & 12 & 0 & 0 & 0 & 8 & 58 & 0 & 0 & 0 & 2 & 1=\text { T3-Enxofre } \\ 2 & 3 & 0 & 0 & 0 & 2 & 0 & 31 & 13 & 0 & 0 & 1 & 46 & 0 & 0 & 2 & \mathrm{~m}=\text { T3-Magnésio } \\ 0 & 0 & 0 & 0 & 0 & 0 & 0 & 0 & 0 & 0 & 0 & 2 & 0 & 69 & 0 & 29 & \mathrm{n}=\text { T3-Nitrogênio } \\ 0 & 0 & 0 & 0 & 4 & 0 & 0 & 0 & 0 & 36 & 0 & 0 & 0 & 0 & 60 & 0 & \mathrm{o}=\text { T3-Potássio } \\ 0 & 0 & 0 & 0 & 0 & 2 & 0 & 4 & 1 & 0 & 0 & 0 & 5 & 33 & 0 & 55 & \text { p = T4 }\end{array}$

Tabela 7.14: Matriz de confusão para a coleta 2 com o método histograma colorido.

Observa-se na matriz de confusão da coleta 1 que os nutrientes T1, T2 e T4 possuem um acerto global aceitável enquanto os nutrientes em nível T3 possuem os acertos mais baixos sendo T3-Nitrogênio a classe com maior erro na classificação com $7 \%$ corretamente classificadas. Outro dado importante que pode se observar é que a média de acerto dos nutrientes com nivel T1 é de 89,4\% indicando que as classes T1 (deficiência 


\begin{tabular}{|c|c|c|c|c|c|c|c|c|c|c|c|c|c|c|c|c|}
\hline $\mathrm{a}$ & $\mathrm{b}$ & $\mathrm{c}$ & $\mathrm{d}$ & $\mathrm{e}$ & $\mathrm{f}$ & $\mathrm{g}$ & $\mathrm{h}$ & $\mathrm{i}$ & $\mathrm{j}$ & $\mathrm{k}$ & 1 & $\mathrm{~m}$ & $\mathrm{n}$ & o & $\mathrm{p}$ & \\
\hline 89 & 4 & 0 & 0 & 0 & 0 & 3 & 0 & 1 & 0 & 0 & 3 & 0 & 0 & 0 & 0 & $\mathrm{~b}=\mathrm{T} 1$-Cálcio \\
\hline 7 & 53 & 4 & 1 & 2 & 2 & 4 & 3 & 2 & 0 & 3 & 4 & 2 & 10 & 1 & 2 & $\mathrm{a}=\mathrm{T}$ l-Enxofre \\
\hline 3 & 0 & 84 & 12 & 0 & 0 & 0 & 0 & 0 & 0 & 1 & 0 & 0 & 0 & 0 & 0 & $\mathrm{c}=\mathrm{Tl}-$ Magnésio \\
\hline 0 & 0 & 15 & 85 & 0 & 0 & 0 & 0 & 0 & 0 & 0 & 0 & 0 & 0 & 0 & 0 & d = T1-Nitrogênio \\
\hline 0 & 0 & 0 & 0 & 70 & 0 & 0 & 2 & 0 & 12 & 0 & 0 & 7 & 1 & 2 & 6 & e = T1-Potássio \\
\hline 3 & 1 & 0 & 0 & 0 & 52 & 8 & 3 & 1 & 0 & 0 & 22 & 10 & 0 & 0 & 0 & $\mathrm{~g}=\mathrm{T} 2$-Cálcio \\
\hline 1 & 1 & 0 & 0 & 0 & 7 & 51 & 0 & 14 & 1 & 2 & 2 & 13 & 0 & 8 & 0 & $\mathrm{f}=\mathrm{T} 2$-Enxofre \\
\hline 3 & 0 & 0 & 0 & 4 & 1 & 3 & 26 & 0 & 1 & 0 & 3 & 32 & 5 & 11 & 11 & $\mathrm{~h}=\mathrm{T} 2$-Magnésio \\
\hline 2 & 0 & 0 & 0 & 0 & 13 & 1 & 0 & 39 & 13 & 0 & 1 & 3 & 0 & 27 & 1 & $\mathrm{i}=\mathrm{T} 2$-Nitrogênio \\
\hline 0 & 0 & 0 & 0 & 12 & 1 & 0 & 0 & 9 & 49 & 0 & 0 & 3 & 0 & 11 & 15 & $\mathrm{j}=\mathrm{T} 2$-Potássio \\
\hline 7 & 2 & 0 & 0 & 0 & 1 & 21 & 5 & 0 & 0 & 56 & 0 & 5 & 1 & 1 & 1 & 1 = T3-Cálcio \\
\hline 1 & 1 & 1 & 0 & 0 & 2 & 0 & 0 & 0 & 2 & 0 & 89 & 1 & 0 & 3 & 0 & k = T3-Enxofre \\
\hline 4 & 0 & 0 & 0 & 3 & 12 & 7 & 19 & 3 & 3 & 0 & 1 & 36 & 0 & 5 & 7 & $\mathrm{~m}=\mathrm{T} 3$-Magnésio \\
\hline 8 & 0 & 0 & 0 & 1 & 0 & 0 & 3 & 0 & 0 & 0 & 0 & 0 & 78 & 0 & 10 & $\mathrm{n}=\mathrm{T} 3$-Nitrogênio \\
\hline 0 & 0 & 0 & 0 & 2 & 9 & 0 & 8 & 23 & 11 & 4 & 1 & 3 & 0 & 33 & 6 & o = T3-Potássio \\
\hline 4 & 0 & 0 & 0 & 7 & 0 & 0 & 15 & 3 & 11 & 0 & 1 & 7 & 7 & 10 & 35 & $\mathrm{p}=\mathrm{T} 4$ \\
\hline
\end{tabular}

Tabela 7.15: Matriz de confusão para a coleta 3 com o método histograma colorido.

severa) são as mais fáceis de classificar e as T3 com uma média de 37,6\% são as mais difíceis de classificar, isto pode ser explicado porque um organismo vivo não pode ser completamente parametrizado num conjunto de condições de alimentação, estas podem reagir de forma distinta as condições que são submetidas, uma planta pode ter parâmetros de crescimento quase normais com uma dose perto da ideal e as mudanças não serem tão significativas na superfície da folha podendo em alguns casos crescer como plantas normais ou em outros pode transformar outros nutrientes ou combinações de nutrientes para suprir a necessidade faltante do nutriente em questão. No caso especifico da coleta 1 a maioria das imagens da classe T3 são classificadas como deficiências misturadas das classes T2, indicando que provavelmente existiu uma absorção de outros nutrientes ou simplesmente o padrão gerado pela transformação de nutrientes não é corretamente reconhecido è classificado erroneamente. Entretanto, estas conclusões devem levar em conta que o nível de acerto global encontra-se longe do ideal para obter conclusões definitivas. Para a coleta 2 existe uma mudança no conjunto de classes com o maior erro de classificação, sendo as classes T2 com a média de acerto global de $54 \%$ seguido de perto pelas classes T3 com $54.8 \%$, nesta coleta as classes T1 se mantém com as mais fáceis de classificar com um acerto médio de $64 \%$. A coleta 3 confirma as observações da tendência das classes T2 ser as mais difíceis de classificar, com uma média de $43,4 \%$ para T2. As coletas refletem os estágios de crescimento da planta num período, os resultados observados nas matrizes de confusão para as 3 coletas in- 
dicam que inicialmente as classes T3 são as mais difíceis de classificar mudando gradualmente conforme a planta cresce, sendo as classes T2 as mais dificeis de classificar para a coleta2 e 3 .

- Matrizes de Coocorrência

O uso de textura em escala de cinza nos experimentos representa possibilidade de reconhecimento baseado unicamente em textura. As tabelas 7.16, 7.17 e 7.18 mostra um acerto global máximo de $47.625 \%$ para a coleta $1 \mathrm{em}$ Bases 4, 45.896\% para a coleta $2 \mathrm{em}$ Todo 2 e $48.563 \%$ para a coleta 3 em Pontas 2 obtido com 32 cores, os erros máximos apresentados em diversas classes indica que a técnica não é robusta nem adequada para a análise das imagens.

\begin{tabular}{|c|c|c|c|c|c|c|}
\hline Base de Imagens & $\begin{array}{c}\text { Nro. de } \\
\text { Descritores }\end{array}$ & $\begin{array}{l}\text { Nro. de Imagens } \\
\text { Corretamente } \\
\text { Classificadas }\end{array}$ & $\begin{array}{c}\text { Probabilidade de } \\
\text { Acerto Global (\%) }\end{array}$ & Kappa & $\begin{array}{l}\text { Desvio padrão } \\
\text { do acerto (\%) }\end{array}$ & $\begin{array}{c}\text { Confiança } \\
\text { Acertos }\end{array}$ \\
\hline Bases2 & 24 & 678 & 42.375 & 0.385 & 0.127 & 12.471 \\
\hline Bases4 & 24 & 762 & 47.625 & 0.441 & 0.193 & 12.481 \\
\hline Médios2 & 24 & 746 & 46.625 & 0.431 & 0.166 & 12.486 \\
\hline Médios4 & 24 & 717 & 44.813 & 0.411 & 0.153 & 12.485 \\
\hline Pontas2 & 24 & 726 & 45.375 & 0.417 & 0.162 & 12.488 \\
\hline Pontas 4 & 24 & 621 & 38.813 & 0.347 & 0.284 & 12.470 \\
\hline Todo2 & 24 & 2067 & 43.063 & 0.393 & 0.142 & 12.487 \\
\hline Todo4 & 24 & 1937 & 40.354 & 0.364 & 0.202 & 12.488 \\
\hline
\end{tabular}

Tabela 7.16: Sumário da classificação usando o método matrizes de coocorrência para a Coleta 1 usando SVM para classificar os dados.

\begin{tabular}{|c|c|c|c|c|c|c|}
\hline Base de Imagens & $\begin{array}{c}\text { Nro. de } \\
\text { Descritores }\end{array}$ & $\begin{array}{l}\text { Nro. de Imagens } \\
\text { Corretamente } \\
\text { Classificadas }\end{array}$ & $\begin{array}{l}\text { Probabilidade de } \\
\text { Acerto Global (\%) }\end{array}$ & Kappa & $\begin{array}{l}\text { Desvio padrão } \\
\text { do acerto (\%) }\end{array}$ & $\begin{array}{c}\text { Confiança } \\
\text { Acertos }\end{array}$ \\
\hline Bases2 & 24 & 720 & 45.000 & 0.413 & 0.160 & 12.475 \\
\hline Bases4 & 24 & 560 & 35.000 & 0.307 & 0.238 & 12.473 \\
\hline Médios2 & 24 & 701 & 43.813 & 0.401 & 0.153 & 12.482 \\
\hline Médios4 & 24 & 564 & 35.250 & 0.309 & 0.221 & 12.462 \\
\hline Pontas2 & 24 & 716 & 44.750 & 0.411 & 0.157 & 12.487 \\
\hline Pontas4 & 24 & 585 & 36.563 & 0.323 & 0.282 & 12.478 \\
\hline Todo2 & 24 & 2203 & 45.896 & 0.423 & 0.173 & 12.482 \\
\hline Todo4 & 24 & 1754 & 36.542 & 0.323 & 0.266 & 12.453 \\
\hline
\end{tabular}

Tabela 7.17: Sumário da classificação usando o método matrizes de coocorrência para a Coleta 2 usando SVM para classificar os dados.

A Figura 7.13 mostra o acerto para as variantes do experimento com 8 16 e 32 cores, é importante notar que os gráficos indicam uma melhora do acerto com o uso de uma maior quantidade de cores quantizados, 


\begin{tabular}{|c|c|c|c|c|c|c|}
\hline Base de Imagens & $\begin{array}{c}\text { Nro. de } \\
\text { Descritores }\end{array}$ & $\begin{array}{l}\text { Nro. de Imagens } \\
\text { Corretamente } \\
\text { Classificadas }\end{array}$ & $\begin{array}{l}\text { Probabilidade de } \\
\text { Acerto Global (\%) }\end{array}$ & Kappa & $\begin{array}{l}\text { Desvio padrão } \\
\text { do acerto (\%) }\end{array}$ & $\begin{array}{c}\text { Confiança } \\
\text { Acertos }\end{array}$ \\
\hline Bases2 & 24 & 766 & 47.875 & 0.444 & 0.132 & 12.476 \\
\hline Bases4 & 24 & 567 & 35.438 & 0.311 & 0.296 & 12.479 \\
\hline Médios2 & 24 & 656 & 41.000 & 0.371 & 0.183 & 12.482 \\
\hline Médios4 & 24 & 609 & 38.063 & 0.339 & 0.222 & 12.471 \\
\hline Pontas2 & 24 & 777 & 48.563 & 0.451 & 0.128 & 12.482 \\
\hline Pontas4 & 24 & 605 & 37.813 & 0.337 & 0.245 & 12.479 \\
\hline Todo2 & 24 & 2061 & 42.938 & 0.391 & 0.170 & 12.482 \\
\hline Todo4 & 24 & 1668 & 34.750 & 0.304 & 0.301 & 12.475 \\
\hline
\end{tabular}

Tabela 7.18: Sumário da classificação usando o método matrizes de coocorrência para a Coleta 3 usando SVM para classificar os dados.

entretanto, o uso de 64 ou 128 cores deixou o processo com um custo computacional muito elevado para ser considerado computacionalmente aceitável.

Outro tipo de combinações de extratores de características não fornecem resultados melhores validando os resultados obtidos pelo trabalho de (Clausi e Deng, 2005).

- Wavelets de Gabor

O método de wavelets de Gabor é o mais comummente usado para extrair informações de textura em imagens. Pelas conclusões geradas no trabalho de (Casanova, 2008) não são usadas distintas configurações de intervalos de freqüência para os filtros por ter um impacto pouco significativo nos resultados finais.

Observamos nos resultados apresentados nas tabelas 7.19, 7.20 e 7.21 que o maior acerto para a coleta 1 é de $49.125 \%$ na base Médios4, 49.938\% para a coleta 2 na base Bases 2 e $49.875 \%$ para a coleta 3 na base Bases2. Observa-se nos resultados que o maior acerto não supera o $50 \%$ de acerto com uma das técnicas mais ampliamente usadas na literatura, isto indica a dificuldade de classificação e a grande variabilidade que apresentam as texturas entre distintos tipos de deficiências. Analisando os gráficos da Figura 7.14 observamos que os melhores resultados foram alcançados com 6 escalas e 4 orientações e nas outras configurações sempre são obtidos melhores resultados quando se usa um maior número de escalas. Entretanto para a escolha do melhor resultado não é usado o acerto glo- 


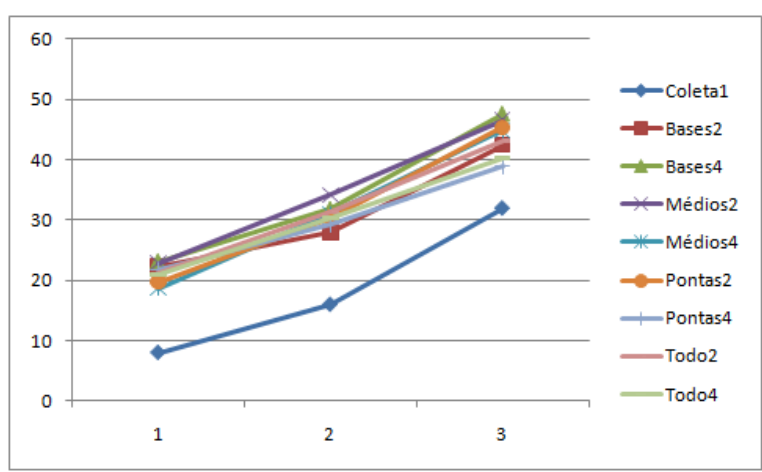

(a)

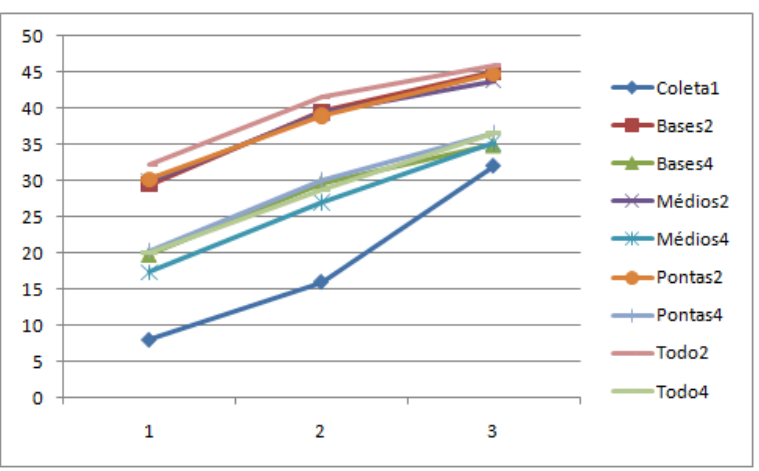

(b)

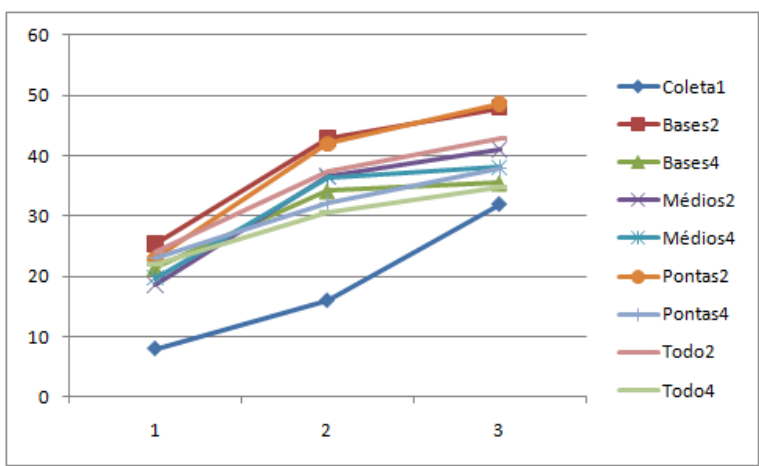

(c)

Figura 7.13: Acerto (eixo Y) para cada número de cores (eixo X) na coleta 1, (a) Acerto para coleta 1 usando SVM, (b) Acerto para coleta 2 usando SVM e (c) Acerto para coleta 3 usando SVM

bal unicamente senão também o número de descritores gerados para manter o custo computacional num limite aceitável.

\begin{tabular}{|c|c|c|c|c|c|c|}
\hline Base de Imagens & $\begin{array}{c}\text { Nro. de } \\
\text { Descritores }\end{array}$ & $\begin{array}{l}\text { Nro. de Imagens } \\
\text { Corretamente } \\
\text { Classificadas }\end{array}$ & $\begin{array}{l}\text { Probabilidade de } \\
\text { Acerto Global (\%) }\end{array}$ & Kappa & $\begin{array}{l}\text { Desvio padrão } \\
\text { do acerto (\%) }\end{array}$ & $\begin{array}{c}\text { Confiança } \\
\text { Acertos }\end{array}$ \\
\hline Bases2 & 24 & 699 & 43.688 & 0.399 & 0.599 & 12.481 \\
\hline Bases4 & 24 & 748 & 46.750 & 0.432 & 0.582 & 12.474 \\
\hline Médios2 & 24 & 744 & 46.500 & 0.429 & 0.584 & 12.473 \\
\hline Médios4 & 24 & 786 & 49.125 & 0.457 & 0.532 & 12.486 \\
\hline Pontas2 & 24 & 773 & 48.313 & 0.449 & 0.557 & 12.477 \\
\hline Pontas 4 & 24 & 623 & 38.938 & 0.349 & 0.653 & 12.465 \\
\hline Todo2 & 24 & 2213 & 46.104 & 0.425 & 0.592 & 12.480 \\
\hline Todo4 & 24 & 1956 & 40.750 & 0.368 & 0.642 & 12.484 \\
\hline
\end{tabular}

Tabela 7.19: Sumário da classificação usando o método wavelets de Gabor para a Coleta 1 usando SVM para classificar os dados.

- Wavelets de Gabor e outros extratores 


\begin{tabular}{|c|c|c|c|c|c|c|}
\hline Base de Imagens & $\begin{array}{c}\text { Nro. de } \\
\text { Descritores }\end{array}$ & $\begin{array}{l}\text { Nro. de Imagens } \\
\text { Corretamente } \\
\text { Classificadas }\end{array}$ & $\begin{array}{l}\text { Probabilidade de } \\
\text { Acerto Global (\%) }\end{array}$ & Kappa & $\begin{array}{l}\text { Desvio padrão } \\
\text { do acerto (\%) }\end{array}$ & $\begin{array}{c}\text { Confiança } \\
\text { Acertos }\end{array}$ \\
\hline Bases2 & 24 & 799 & 49.938 & 0.466 & 0.544 & 12.484 \\
\hline Bases4 & 24 & 564 & 35.250 & 0.309 & 0.720 & 12.472 \\
\hline Médios2 & 24 & 781 & 48.813 & 0.454 & 0.533 & 12.495 \\
\hline Médios4 & 24 & 526 & 32.875 & 0.284 & 0.777 & 12.473 \\
\hline Pontas2 & 24 & 755 & 47.188 & 0.437 & 0.529 & 12.496 \\
\hline Pontas4 & 24 & 580 & 36.250 & 0.320 & 0.713 & 12.483 \\
\hline Todo2 & 24 & 2306 & 48.042 & 0.446 & 0.528 & 12.490 \\
\hline Todo4 & 24 & 1696 & 35.333 & 0.310 & 0.717 & 12.475 \\
\hline
\end{tabular}

Tabela 7.20: Sumário da classificação usando o método wavelets de Gabor para a Coleta 2 usando SVM para classificar os dados.

\begin{tabular}{cccccr}
\hline Base de Imagens & $\begin{array}{c}\text { Nro. de } \\
\text { Descritores }\end{array}$ & $\begin{array}{c}\text { Nro. de Imagens } \\
\text { Corretamente } \\
\text { Classificadas }\end{array}$ & $\begin{array}{c}\text { Probabilidade de } \\
\text { Acerto Global (\%) }\end{array}$ & $\begin{array}{c}\text { Kappa } \\
\text { Desvio padrão } \\
\text { do acerto (\%) }\end{array}$ \\
\hline Bases2 & 24 & 798 & 49.875 & 0.465 & 0.355 \\
Acertos
\end{tabular}

Tabela 7.21: Sumário da classificação usando o método wavelets de Gabor para a Coleta 3 usando SVM para classificar os dados.

Para manter o número de tabelas ao mínimo possível unicamente são mostradas as tabelas da técnica que obteve os melhores resultados globais para todas as coletas, assim, as aproximações baseadas em variância e percentíl foram as que tiveram pior desempenho conseguindo resultados apenas acima dos resultados do processo de wavelets de Gabor normal, a técnica de wavelets de Gabor e co-variância foi a que fico como segunda melhor técnica, entretanto, o melhor desempenho foi obtido pela técnica de LBP, gerando os melhores resultados entre o conjunto. As tabelas 7.22, 7.23 e 7.24 mostram os resultados obtidos pela técnica. Para a coleta 1 o melhor resultado foi $54.250 \%$ na base Pontas2, para a coleta 2 o melhor resultado obtido é $51.500 \%$ na base Pontas 2 e na coleta 3 o melhor resultado obtido foi $50.375 \%$ na base Pontas2, tudo isto com 4 escalas e 6 orientações. Para todas as coletas os resultados obtidos superam amplamente aos resultados obtidos pelo processo de wavelets de Gabor normal. Para simplicidade da análise são omitidos o resto de tabelas de resultados e as gráficas de acerto para as combinações de 


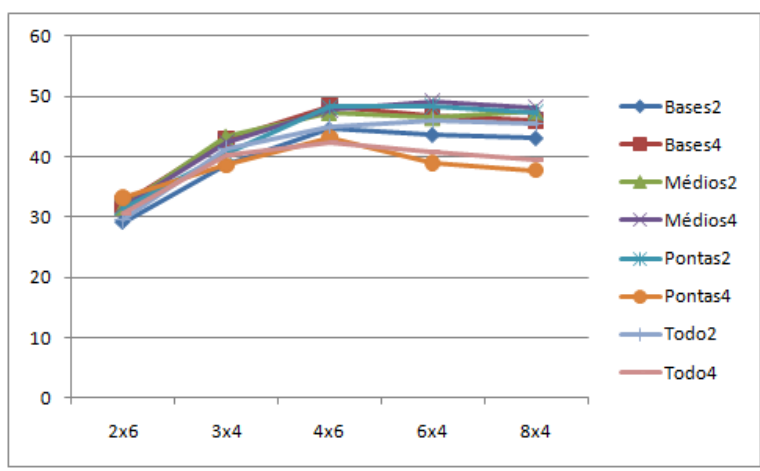

(a)

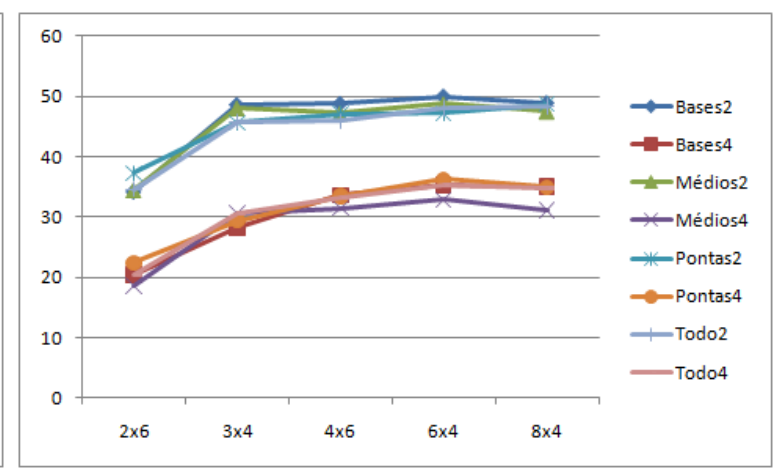

(b)

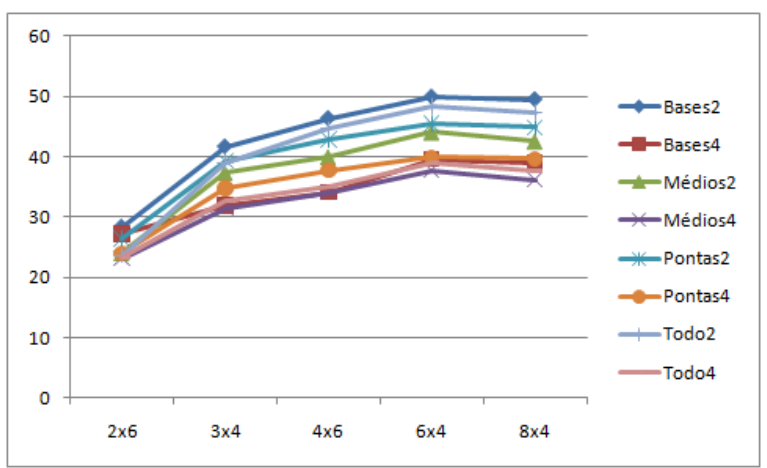

(c)

Figura 7.14: Acerto (eixo Y) para cada combinação de escalas e orientaçoes (eixo X), (a) Acerto para coleta 1 usando SVM, (b) Acerto para coleta 2 usando SVM e (c) Acerto para coleta 3 usando SVM

experimentos geradas.

\begin{tabular}{|c|c|c|c|c|c|c|}
\hline Base de Imagens & $\begin{array}{c}\text { Nro. de } \\
\text { Descritores }\end{array}$ & $\begin{array}{l}\text { Nro. de Imagens } \\
\text { Corretamente } \\
\text { Classificadas }\end{array}$ & $\begin{array}{l}\text { Probabilidade de } \\
\text { Acerto Global (\%) }\end{array}$ & Kappa & $\begin{array}{l}\text { Desvio padrão } \\
\text { do acerto (\%) }\end{array}$ & $\begin{array}{c}\text { Confiança } \\
\text { Acertos }\end{array}$ \\
\hline Bases2 & 6120 & 846 & 52.875 & 0.497 & 1.207 & 12.465 \\
\hline Bases4 & 6120 & 845 & 52.813 & 0.497 & 1.213 & 12.476 \\
\hline Médios2 & 6120 & 859 & 53.688 & 0.506 & 1.344 & 12.458 \\
\hline Médios4 & 6120 & 808 & 50.500 & 0.472 & 1.179 & 12.454 \\
\hline Pontas2 & 6120 & 868 & 54.250 & 0.512 & 1.372 & 12.473 \\
\hline Pontas4 & 6120 & 709 & 44.313 & 0.406 & 0.733 & 12.458 \\
\hline
\end{tabular}

Tabela 7.22: Sumário da classificação usando o método wavelets de Gabor e LBP para a Coleta 1 usando SVM para classificar os dados.

- Dimensão fractal volumétrica

O uso de fractais na análise de textura natural é uma técnica nova apresentada em (Backes et al., 2009) que mostra uma ampla vantagem sobre 


\begin{tabular}{|c|c|c|c|c|c|c|}
\hline Base de Imagens & $\begin{array}{c}\text { Nro. de } \\
\text { Descritores }\end{array}$ & $\begin{array}{l}\text { Nro. de Imagens } \\
\text { Corretamente } \\
\text { Classificadas }\end{array}$ & $\begin{array}{l}\text { Probabilidade de } \\
\text { Acerto Global (\%) }\end{array}$ & Kappa & $\begin{array}{l}\text { Desvio padrão } \\
\text { do acerto (\%) }\end{array}$ & $\begin{array}{c}\text { Confiança } \\
\text { Acertos }\end{array}$ \\
\hline Bases2 & 6120 & 795 & 49.688 & 0.463 & 1.048 & 12.471 \\
\hline Bases4 & 6120 & 596 & 37.250 & 0.331 & 0.934 & 12.447 \\
\hline Médios2 & 6120 & 807 & 50.438 & 0.471 & 1.228 & 12.464 \\
\hline Médios4 & 6120 & 567 & 35.438 & 0.311 & 0.694 & 12.409 \\
\hline Pontas2 & 6120 & 824 & 51.500 & 0.483 & 1.340 & 12.463 \\
\hline Pontas4 & 6120 & 609 & 38.063 & 0.339 & 0.756 & 12.433 \\
\hline
\end{tabular}

Tabela 7.23: Sumário da classificação usando o método wavelets de Gabor e LBP para a Coleta 2 usando SVM para classificar os dados.

\begin{tabular}{cccccc}
\hline Base de Imagens & $\begin{array}{c}\text { Nro. de } \\
\text { Descritores }\end{array}$ & $\begin{array}{c}\text { Nro. de Imagens } \\
\text { Corretamente } \\
\text { Classificadas }\end{array}$ & $\begin{array}{c}\text { Probabilidade de } \\
\text { Acerto Global (\%) }\end{array}$ & $\begin{array}{c}\text { Kappa } \\
\text { Confiança } \\
\text { Acertos }\end{array}$ & $\begin{array}{c}\text { Desvio padrão } \\
\text { do acerto (\%) }\end{array}$ \\
\hline Bases2 & 6120 & 789 & 49.313 & 0.459 & 1.008 \\
Bases4 & 6120 & 663 & 41.438 & 0.375 & 0.963 \\
Médios2 & 6120 & 725 & 35.313 & 0.417 & 12.462 \\
Médios4 & 6120 & 572 & 50.750 & 0.315 & 0.640 \\
Pontas2 & 6120 & 806 & 43.688 & 0.471 & 1.289 \\
Pontas4 & 6120 & 699 & 0.399 & 12.456 \\
\hline
\end{tabular}

Tabela 7.24: Sumário da classificação usando o método wavelets de Gabor e LBP para a Coleta 3 usando SVM para classificar os dados.

outras técnicas tradicionais quando são analisadas texturas naturais. Os resultados obtidos nas tabelas $7.25,7.26$ e 7.27 nos experimentos mostra esta vantagem na maioria das bases testadas, para a coleta 1 o melhor resultado obtido foi $57.500 \%$ na bases Bases 4 , na coleta 2 o melhor resultado obtido foi $50.188 \%$ na base Bases2 e na coleta 3 o melhor resultado obtido foi $55.063 \%$ na base Bases2. A técnica de dimensão fractal volumétrica basea-se no uso de assinaturas para descrever a textura analisada, assim, estas assinaturas podem variar o resultado final dependendo do raio usado para a análise, neste experimento foram testadas 10 tipos de assinaturas com raios crescentes de 2 até 20, pode-se observar os resultados da classificação para os 10 experimentos na Figura 7.15 o melhor acerto é obtido com um raio de expansão de 16 para todos os experimentos.

- Wavelets de Gabor e Fractais

Uma das técnicas propostas neste trabalho de mestrado é o uso de dimensão fractal volumétrica sob o espaço de convolução de Gabor. Os resultados em texturas artificiais apresentados em (Zuniga e Bruno, 2010) 


\begin{tabular}{cccccr}
\hline Base de Imagens & $\begin{array}{c}\text { Nro. de } \\
\text { Descritores }\end{array}$ & $\begin{array}{c}\text { Nro. de Imagens } \\
\text { Corretamente } \\
\text { Classificadas }\end{array}$ & $\begin{array}{c}\text { Probabilidade de } \\
\text { Acerto Global (\%) }\end{array}$ & $\begin{array}{c}\text { Kappa } \\
\text { Desvio padrão } \\
\text { do acerto (\%) }\end{array}$ \\
\hline Bases2 & & & & & \\
Bases4 & 334 & 826 & 51.625 & 0.484 & 0.625 \\
Acertos
\end{tabular}

Tabela 7.25: Sumário da classificação usando o método dimensão fractal volumétrica para a Coleta 1 usando SVM para classificar os dados.

\begin{tabular}{|c|c|c|c|c|c|c|}
\hline Base de Imagens & $\begin{array}{c}\text { Nro. de } \\
\text { Descritores }\end{array}$ & $\begin{array}{l}\text { Nro. de Imagens } \\
\text { Corretamente } \\
\text { Classificadas }\end{array}$ & $\begin{array}{l}\text { Probabilidade de } \\
\text { Acerto Global (\%) }\end{array}$ & Kappa & $\begin{array}{l}\text { Desvio padrão } \\
\text { do acerto (\%) }\end{array}$ & $\begin{array}{c}\text { Confiança } \\
\text { Acertos }\end{array}$ \\
\hline Bases2 & 334 & 803 & 50.188 & 0.469 & 0.705 & 12.467 \\
\hline Bases4 & 334 & 650 & 40.625 & 0.367 & 1.204 & 12.434 \\
\hline Médios2 & 334 & 758 & 47.375 & 0.439 & 0.930 & 12.458 \\
\hline Médios4 & 334 & 650 & 40.625 & 0.367 & 0.241 & 12.437 \\
\hline Pontas2 & 334 & 829 & 51.813 & 0.486 & 0.698 & 12.477 \\
\hline Pontas4 & 334 & 736 & 46.000 & 0.424 & 0.948 & 12.461 \\
\hline Todo2 & 334 & 2321 & 48.354 & 0.449 & 0.927 & 12.449 \\
\hline Todo4 & 334 & 1886 & 39.292 & 0.352 & 1.306 & 12.441 \\
\hline
\end{tabular}

Tabela 7.26: Sumário da classificação usando o método dimensão fractal volumétrica para a Coleta 2 usando SVM para classificar os dados.

\begin{tabular}{|c|c|c|c|c|c|c|}
\hline Base de Imagens & $\begin{array}{c}\text { Nro. de } \\
\text { Descritores }\end{array}$ & $\begin{array}{l}\text { Nro. de Imagens } \\
\text { Corretamente } \\
\text { Classificadas }\end{array}$ & $\begin{array}{l}\text { Probabilidade de } \\
\text { Acerto Global (\%) }\end{array}$ & Kappa & $\begin{array}{l}\text { Desvio padrão } \\
\text { do acerto (\%) }\end{array}$ & $\begin{array}{c}\text { Confiança } \\
\text { Acertos }\end{array}$ \\
\hline Bases2 & 334 & 881 & 55.063 & 0.521 & 0.592 & 12.474 \\
\hline Bases4 & 334 & 769 & 48.063 & 0.446 & 0.945 & 12.484 \\
\hline Médios2 & 334 & 838 & 52.375 & 0.492 & 0.912 & 12.468 \\
\hline Médios4 & 334 & 782 & 48.875 & 0.455 & 0.998 & 12.476 \\
\hline Pontas2 & 334 & 861 & 53.813 & 0.507 & 0.109 & 12.457 \\
\hline Pontas4 & 334 & 799 & 49.938 & 0.466 & 0.102 & 12.470 \\
\hline Todo2 & 334 & 2561 & 53.354 & 0.502 & 0.128 & 12.483 \\
\hline Todo4 & 334 & 2339 & 48.729 & 0.453 & 0.993 & 12.482 \\
\hline
\end{tabular}

Tabela 7.27: Sumário da classificação usando o método dimensão fractal volumétrica para a Coleta 3 usando SVM para classificar os dados.

mostram que o método é robusto e obtém melhor diferenciação de texturas que os métodos mais comummente usados e do estado da arte. Os resultados apresentados nas tabelas $7.28,7.29$ e 7.30 mostram um acerto global máximo de $59.500 \%$ para a coleta 1 na base Pontas 2 sendo o melhor resultado obtido para a coleta 1 com todas as técnicas de análise de textura em escala de cinza usadas. Observa-se também que os acertos para a maioria das bases de cada coleta o melhor resultado é obtido por 


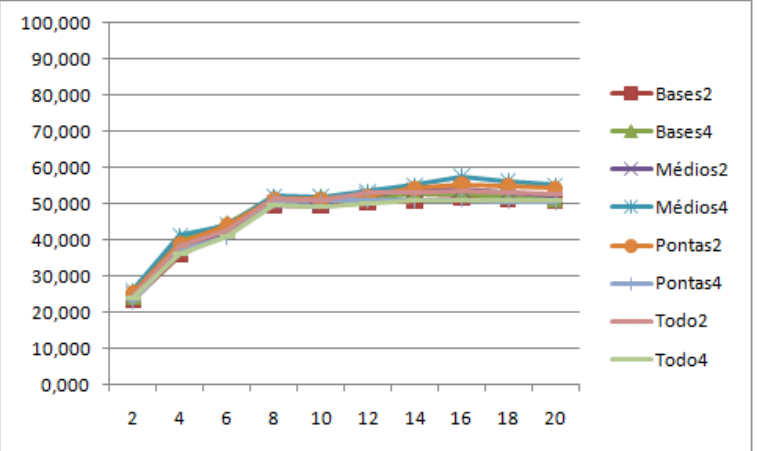

(a)

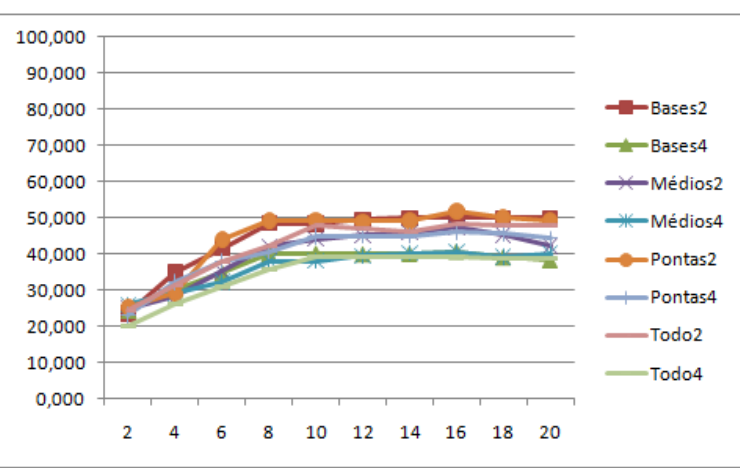

(b)

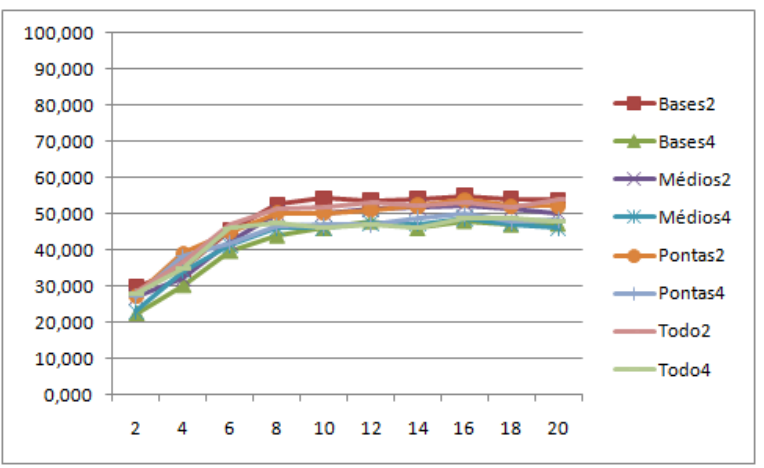

(c)

Figura 7.15: Acerto (eixo Y) para cada raio de expansão (eixo X), (a) Acerto para coleta 1 usando SVM, (b) Acerto para coleta 2 usando SVM e (c) Acerto para coleta 3 usando SVM

esta técnica. Na coleta 2 o melhor acerto global obtido é $53.813 \%$ na base Bases 2 sendo também o melhor acerto para todos os métodos em escala de cinza. Finalmente a coleta 3 o melhor resultado obtido é $55.063 \%$ na base Todo2. Os resultados mostram-se robustos para todas as coletas sendo esta a melhor técnica testada. Os resultados apresentados nas tabelas são com a configuração de 4 escalas e 6 orientações, para algumas bases a configuração 8 escalas x 4 orientações fornece resultados um pouco melhores mas o uso de 32 imagens convoluidas ao invés de 24 da configuração $4 \times 6$ resulta num processo computacionalmente mais custoso. A Figura 7.16 mostra o acerto para distinto número de raios de expansão usados para reduzir a assinatura. O número de descritores Fourier usados é extraido do trabalho de (Zuniga e Bruno, 2010) è fixo para todos os experimentos 


\begin{tabular}{|c|c|c|c|c|c|c|}
\hline Base de Imagens & $\begin{array}{c}\text { Nro. de } \\
\text { Descritores }\end{array}$ & $\begin{array}{l}\text { Nro. de Imagens } \\
\text { Corretamente } \\
\text { Classificadas }\end{array}$ & $\begin{array}{l}\text { Probabilidade de } \\
\text { Acerto Global (\%) }\end{array}$ & Kappa & $\begin{array}{l}\text { Desvio padrão } \\
\text { do acerto (\%) }\end{array}$ & $\begin{array}{c}\text { Confiança } \\
\text { Acertos }\end{array}$ \\
\hline Bases2 & 240 & 881 & 55.063 & 0.521 & 0.187 & 12.417 \\
\hline Bases4 & 240 & 875 & 54.688 & 0.517 & 0.182 & 12.408 \\
\hline Médios2 & 240 & 929 & 58.063 & 0.553 & 0.165 & 12.426 \\
\hline Médios4 & 240 & 855 & 53.438 & 0.503 & 0.172 & 12.429 \\
\hline Pontas2 & 240 & 952 & 59.500 & 0.568 & 0.153 & 12.444 \\
\hline Pontas 4 & 240 & 815 & 50.938 & 0.477 & 0.193 & 12.404 \\
\hline Todo2 & 240 & 2657 & 55.354 & 0.524 & 0.177 & 12.420 \\
\hline Todo4 & 240 & 2437 & 50.771 & 0.482 & 0.198 & 12.400 \\
\hline
\end{tabular}

Tabela 7.28: Sumário da classificação usando o método wavelets de Gabor e fractais para a Coleta 1 usando SVM para classificar os dados.

\begin{tabular}{|c|c|c|c|c|c|c|}
\hline Base de Imagens & $\begin{array}{c}\text { Nro. de } \\
\text { Descritores }\end{array}$ & $\begin{array}{l}\text { Nro. de Imagens } \\
\text { Corretamente } \\
\text { Classificadas }\end{array}$ & $\begin{array}{l}\text { Probabilidade de } \\
\text { Acerto Global (\%) }\end{array}$ & Kappa & $\begin{array}{l}\text { Desvio padrão } \\
\text { do acerto (\%) }\end{array}$ & $\begin{array}{c}\text { Confiança } \\
\text { Acertos }\end{array}$ \\
\hline Bases2 & 240 & 861 & 53.813 & 0.507 & 0.171 & 12.426 \\
\hline Bases4 & 240 & 639 & 39.938 & 0.359 & 0.436 & 12.350 \\
\hline Médios2 & 240 & 850 & 53.125 & 0.500 & 0.179 & 12.403 \\
\hline Médios4 & 240 & 590 & 36.875 & 0.327 & 0.522 & 12.327 \\
\hline Pontas2 & 240 & 850 & 53.125 & 0.500 & 0.169 & 12.409 \\
\hline Pontas4 & 240 & 610 & 38.125 & 0.340 & 0.485 & 12.324 \\
\hline Todo2 & 240 & 2540 & 52.927 & 0.491 & 0.153 & 12.270 \\
\hline Todo4 & 240 & 1890 & 39.375 & 0.346 & 0.461 & 12.322 \\
\hline
\end{tabular}

Tabela 7.29: Sumário da classificação usando o método wavelets de Gabor e fractais para a Coleta 2 usando SVM para classificar os dados.

\begin{tabular}{|c|c|c|c|c|c|c|}
\hline Base de Imagens & $\begin{array}{c}\text { Nro. de } \\
\text { Descritores }\end{array}$ & $\begin{array}{l}\text { Nro. de Imagens } \\
\text { Corretamente } \\
\text { Classificadas }\end{array}$ & $\begin{array}{l}\text { Probabilidade de } \\
\text { Acerto Global (\%) }\end{array}$ & Kappa & $\begin{array}{l}\text { Desvio padrão } \\
\text { do acerto (\%) }\end{array}$ & $\begin{array}{c}\text { Confiança } \\
\text { Acertos }\end{array}$ \\
\hline Bases2 & 334 & 873 & 54.563 & 0.543 & 0.184 & 12.474 \\
\hline Bases4 & 334 & 802 & 50.125 & 0.472 & 0.138 & 12.412 \\
\hline Médios2 & 334 & 838 & 52.375 & 0.492 & 0.147 & 12.468 \\
\hline Médios4 & 334 & 821 & 51.316 & 0.455 & 0.139 & 12.476 \\
\hline Pontas2 & 334 & 886 & 54.875 & 0.521 & 0.122 & 12.432 \\
\hline Pontas4 & 334 & 811 & 50.687 & 0.476 & 0.135 & 12.472 \\
\hline Todo2 & 334 & 2643 & 55.063 & 0.527 & 0.163 & 12.496 \\
\hline Todo4 & 334 & 2426 & 50.541 & 0.471 & 0.128 & 12.478 \\
\hline
\end{tabular}

Tabela 7.30: Sumário da classificação usando o método wavelets de Gabor e fractais para a Coleta 1 usando SVM para classificar os dados.

- Padrões locais binários

Padrões locais binários representam uma das novas e mais bem sucedias técnicas de extração de características de textura em imagens, a análise é baseado num operador que mede a relação entre pixels dentro de uma vizinhança. As tabelas 7.31, 7.32 e 7.33 mostram o resultado usando o método. As melhoras na taxa de acerto global são importantes chegando para $65.00 \%$ na base Pontas2 para a coleta 1, 61.646\% na base Todo2 para 


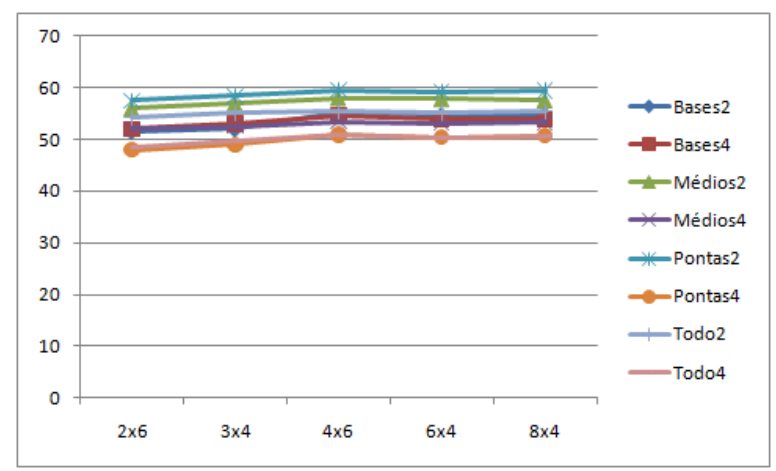

(a)

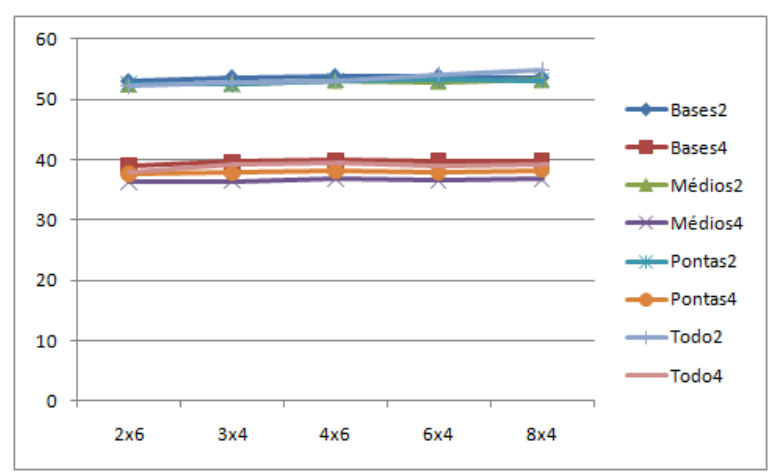

(b)

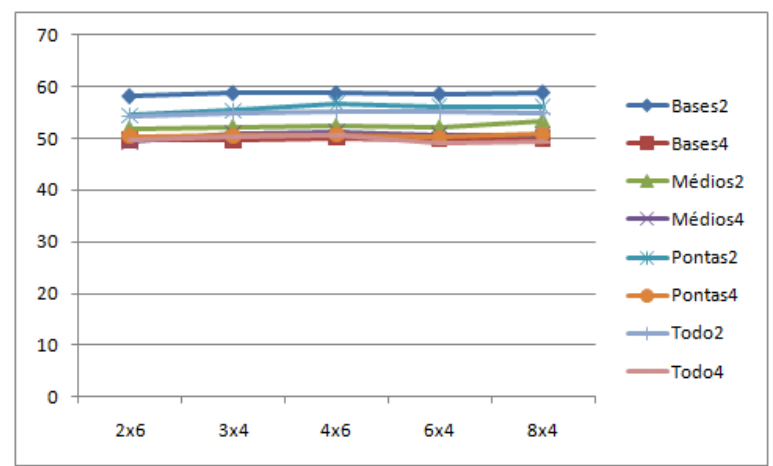

(c)

Figura 7.16: Acerto (eixo Y) para cada número de raio de expansão(eixo X) (a) Acerto para coleta 1 usando SVM, (b) Acerto para coleta 2 usando SVM e (c) Acerto para coleta 3 usando SVM

a coleta 2 e $55.021 \%$ na base Todo2 para a coleta 3 . É importante notar que o melhor acerto foi obtido com uma vizinhança de 4 gerando um vetor de características de 16 atributos. Observa-se também que é o tipo de folha 2 que obtém os melhores resultados para todas as coletas.

- Padrões locais binários Invariantes

A aplicação de invariância à rotação e escalamento é uma característica importante para toda técnica de extração de características e define como o extrator vai reagir fazendo as mudanças não produzir um impacto significativo no vetor de características final. As tabelas 7.34, 7.35 e 7.36 indicam que para as bases de imagens usadas esta propriedade não tem nenhuma importância, pelo fato de todas as imagens ser orientadas e apresentar as mesmas dimensões os resultados ficam mais baixos do 


\begin{tabular}{|c|c|c|c|c|c|c|}
\hline Base de Imagens & $\begin{array}{c}\text { Nro. de } \\
\text { Descritores }\end{array}$ & $\begin{array}{l}\text { Nro. de Imagens } \\
\text { Corretamente } \\
\text { Classificadas }\end{array}$ & $\begin{array}{l}\text { Probabilidade de } \\
\text { Acerto Global (\%) }\end{array}$ & Kappa & $\begin{array}{l}\text { Desvio padrão } \\
\text { do acerto (\%) }\end{array}$ & $\begin{array}{c}\text { Confiança } \\
\text { Acertos }\end{array}$ \\
\hline Bases2 & 16 & 724 & 45.250 & 0.416 & 2.003 & 12.470 \\
\hline Bases4 & 16 & 829 & 51.813 & 0.486 & 2.126 & 12.489 \\
\hline Médios2 & 16 & 827 & 51.688 & 0.485 & 2.201 & 12.486 \\
\hline Médios4 & 16 & 794 & 49.625 & 0.463 & 2.989 & 12.483 \\
\hline Pontas2 & 16 & 890 & 55.625 & 0.527 & 2.720 & 12.487 \\
\hline Pontas 4 & 16 & 665 & 41.563 & 0.377 & 2.474 & 12.474 \\
\hline Todo2 & 16 & 2356 & 49.083 & 0.457 & 2.897 & 12.485 \\
\hline Todo4 & 16 & 2088 & 43.500 & 0.397 & 2.427 & 12.485 \\
\hline
\end{tabular}

Tabela 7.31: Sumário da classificação usando o método padrões locais binarios para a Coleta 1 usando SVM para classificar os dados.

\begin{tabular}{|c|c|c|c|c|c|c|}
\hline Base de Imagens & $\begin{array}{c}\text { Nro. de } \\
\text { Descritores }\end{array}$ & $\begin{array}{l}\text { Nro. de Imagens } \\
\text { Corretamente } \\
\text { Classificadas }\end{array}$ & $\begin{array}{l}\text { Probabilidade de } \\
\text { Acerto Global (\%) }\end{array}$ & Kappa & $\begin{array}{l}\text { Desvio padrão } \\
\text { do acerto (\%) }\end{array}$ & $\begin{array}{c}\text { Confiança } \\
\text { Acertos }\end{array}$ \\
\hline Bases2 & 16 & 846 & 52.875 & 0.497 & 2.185 & 12.482 \\
\hline Bases4 & 16 & 580 & 36.250 & 0.320 & 3.183 & 12.471 \\
\hline Médios2 & 16 & 844 & 52.750 & 0.496 & 2.124 & 12.480 \\
\hline Médios4 & 16 & 582 & 36.375 & 0.321 & 3.421 & 12.472 \\
\hline Pontas2 & 16 & 828 & 51.750 & 0.485 & 2.220 & 12.479 \\
\hline Pontas 4 & 16 & 625 & 39.063 & 0.350 & 3.291 & 12.467 \\
\hline Todo2 & 16 & 2549 & 53.104 & 0.500 & 2.373 & 12.483 \\
\hline Todo4 & 16 & 1809 & 37.688 & 0.335 & 3.196 & 12.474 \\
\hline
\end{tabular}

Tabela 7.32: Sumário da classificação usando o método padrões locais binarios para a Coleta 2 usando SVM para classificar os dados.

\begin{tabular}{|c|c|c|c|c|c|c|}
\hline Base de Imagens & $\begin{array}{c}\text { Nro. de } \\
\text { Descritores }\end{array}$ & $\begin{array}{l}\text { Nro. de Imagens } \\
\text { Corretamente } \\
\text { Classificadas }\end{array}$ & $\begin{array}{l}\text { Probabilidade de } \\
\text { Acerto Global (\%) }\end{array}$ & Kappa & $\begin{array}{l}\text { Desvio padrão } \\
\text { do acerto (\%) }\end{array}$ & $\begin{array}{c}\text { Confiança } \\
\text { Acertos }\end{array}$ \\
\hline Bases2 & 16 & 831 & 51.938 & 0.487 & 2.167 & 12.492 \\
\hline Bases4 & 16 & 691 & 43.188 & 0.394 & 2.432 & 12.480 \\
\hline Médios2 & 16 & 739 & 46.188 & 0.426 & 2.102 & 12.486 \\
\hline Médios4 & 16 & 643 & 40.188 & 0.362 & 2.452 & 12.484 \\
\hline Pontas2 & 16 & 786 & 49.125 & 0.457 & 2.024 & 12.485 \\
\hline Pontas4 & 16 & 661 & 41.313 & 0.374 & 2.791 & 12.469 \\
\hline Todo2 & 16 & 2414 & 50.292 & 0.470 & 2.163 & 12.486 \\
\hline Todo4 & 16 & 1920 & 40.000 & 0.360 & 2.971 & 12.485 \\
\hline
\end{tabular}

Tabela 7.33: Sumário da classificação usando o método padrões locais binarios para a Coleta 3 usando SVM para classificar os dados.

que o processo LBP normal. Para a coleta 1 o maior acerto global obtido foi $45.250 \%$ na base Bases 4 , para a coleta $250.125 \%$ na base Bases2 e para a coleta $346.125 \%$ na base Bases2.

A Figura 7.17 mostra o acerto para as três variantes do experimento, $1 x 8$, $2 x 16$ e $3 x 24$ onde o primeiro parametro é a distancia do pixel analisado a os vizinhos e segundo parametro é a totalidade de vizinhos considerados no operador. Os resultados indicam que o melhor acerto é obtido numa 


\begin{tabular}{|c|c|c|c|c|c|c|}
\hline Base de Imagens & $\begin{array}{c}\text { Nro. de } \\
\text { Descritores }\end{array}$ & $\begin{array}{l}\text { Nro. de Imagens } \\
\text { Corretamente } \\
\text { Classificadas }\end{array}$ & $\begin{array}{l}\text { Probabilidade de } \\
\text { Acerto Global (\%) }\end{array}$ & Kappa & $\begin{array}{l}\text { Desvio padrão } \\
\text { do acerto (\%) }\end{array}$ & $\begin{array}{l}\text { Confiança } \\
\text { Acertos }\end{array}$ \\
\hline Bases2 & 26 & 633 & 39.563 & 0.355 & 0.893 & 12.482 \\
\hline Bases4 & 26 & 724 & 45.250 & 0.416 & 1.279 & 12.487 \\
\hline Médios2 & 26 & 647 & 40.438 & 0.365 & 0.932 & 12.489 \\
\hline Médios4 & 26 & 652 & 40.750 & 0.368 & 0.986 & 12.480 \\
\hline Pontas2 & 26 & 708 & 44.250 & 0.405 & 1.125 & 12.485 \\
\hline Pontas4 & 26 & 664 & 41.500 & 0.376 & 0.85 & 12.475 \\
\hline Todo2 & 26 & 1935 & 40.313 & 0.363 & 0.813 & 12.477 \\
\hline Todo4 & 26 & 1799 & 37.479 & 0.333 & 0.778 & 12.480 \\
\hline
\end{tabular}

Tabela 7.34: Sumário da classificação usando o método padrões locais binários invariantes para a Coleta 1 usando SVM para classificar os dados.

\begin{tabular}{|c|c|c|c|c|c|c|}
\hline Base de Imagens & $\begin{array}{c}\text { Nro. de } \\
\text { Descritores }\end{array}$ & $\begin{array}{l}\text { Nro. de Imagens } \\
\text { Corretamente } \\
\text { Classificadas }\end{array}$ & $\begin{array}{l}\text { Probabilidade de } \\
\text { Acerto Global (\%) }\end{array}$ & Kappa & $\begin{array}{l}\text { Desvio padrão } \\
\text { do acerto (\%) }\end{array}$ & $\begin{array}{l}\text { Confiança } \\
\text { Acertos }\end{array}$ \\
\hline Bases2 & 26 & 802 & 50.125 & 0.468 & 1.471 & 12.483 \\
\hline Bases4 & 26 & 583 & 36.438 & 0.322 & 0.697 & 12.463 \\
\hline Médios2 & 26 & 786 & 49.125 & 0.457 & 1.527 & 12.493 \\
\hline Médios4 & 26 & 544 & 34.000 & 0.296 & 0.599 & 12.458 \\
\hline Pontas2 & 26 & 746 & 46.625 & 0.431 & 1.422 & 12.486 \\
\hline Pontas4 & 26 & 586 & 36.625 & 0.324 & 0.670 & 12.474 \\
\hline Todo2 & 26 & 2335 & 48.646 & 0.452 & 1.429 & 12.490 \\
\hline Todo4 & 26 & 1673 & 34.854 & 0.305 & 0.608 & 12.469 \\
\hline
\end{tabular}

Tabela 7.35: Sumário da classificação usando o método padrões locais binários invariantes para a Coleta 1 usando SVM para classificar os dados.

\begin{tabular}{cccccc}
\hline Base de Imagens & $\begin{array}{c}\text { Nro. de } \\
\text { Descritores }\end{array}$ & $\begin{array}{c}\text { Nro. de Imagens } \\
\text { Corretamente } \\
\text { Classificadas }\end{array}$ & $\begin{array}{c}\text { Probabilidade de } \\
\text { Acerto Global (\%) }\end{array}$ & Kappa & $\begin{array}{c}\text { Desvio padrão } \\
\text { do acerto (\%) }\end{array}$ \\
\hline Bases2 & 26 & 738 & 46.125 & 0.425 & 1.233 \\
Confiança \\
Acertos
\end{tabular}

Tabela 7.36: Sumário da classificação usando o método padrões locais binários invariantes para a Coleta 1 usando SVM para classificar os dados.

vizinhança de 3 com 24 vizinhos analisados.

A continuação são apresentadas as matrizes de confusão para os métodos que obtiveram o melhor resultado para cada coleta com os métodos de extração de características de textura em escala de cinza. Para a coleta 17.37 o método wavelets de Gabor e fractais obteve um acerto global de $59.50 \%$ na base Pontas2, para a coleta 27.38 o método wavelets de Gabor e fractais obteve um acerto global de $53.813 \%$ na base Bases22, 


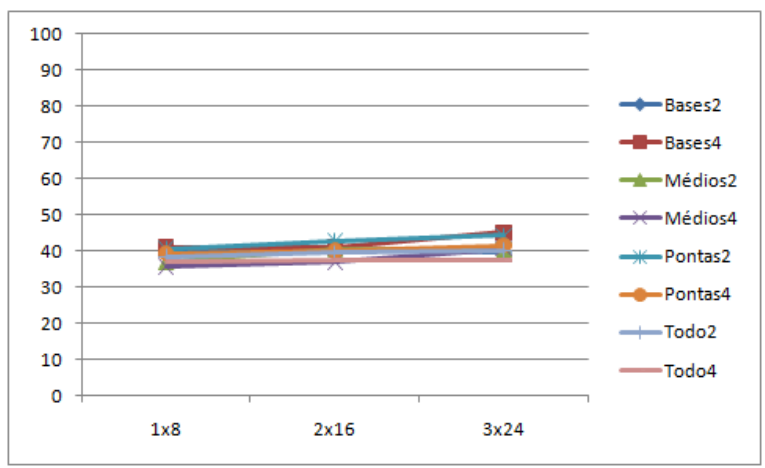

(a)

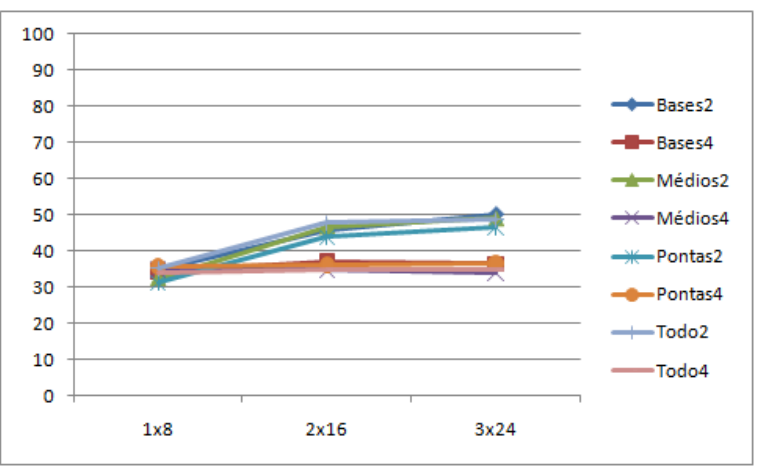

(b)

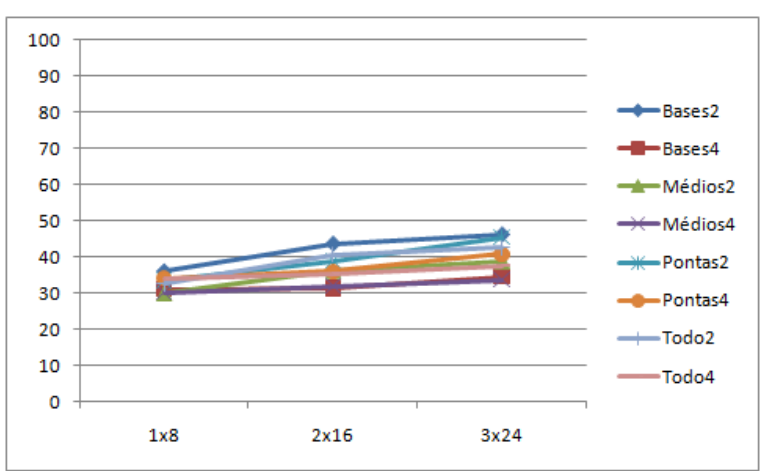

(c)

Figura 7.17: Acerto (eixo Y) para cada experimento (eixo X), (a) Acerto para coleta 1 usando SVM, (b) Acerto para coleta 2 usando SVM e (c) Acerto para coleta 3 usando SVM

finalmente para a coleta 37.39 o método Dimensão fractal volumétrica obteve um acerto global de $55.063 \%$ na base Bases 2

$\begin{array}{ccccccccccccccccc}\mathrm{a} & \mathrm{b} & \mathrm{c} & \mathrm{d} & \mathrm{e} & \mathrm{f} & \mathrm{g} & \mathrm{h} & \mathrm{i} & \mathrm{j} & \mathrm{k} & 1 & \mathrm{~m} & \mathrm{n} & \mathrm{o} & \mathrm{p} & \mathrm{a}=\text { T1-Cálcio } \\ 77 & 0 & 5 & 0 & 0 & 0 & 5 & 8 & 0 & 0 & 0 & 1 & 3 & 0 & 0 & 1 & \mathrm{~b}=\text { T1-Enxofre } \\ 0 & 100 & 0 & 0 & 0 & 0 & 0 & 0 & 0 & 0 & 0 & 0 & 0 & 0 & 0 & 0 & \mathrm{c}=\text { T1-Magnésio } \\ 0 & 5 & 54 & 14 & 0 & 0 & 2 & 15 & 0 & 0 & 0 & 4 & 5 & 1 & 0 & 0 & \mathrm{~d}=\text { T1-Nitrogênio } \\ 0 & 0 & 14 & 79 & 0 & 0 & 0 & 1 & 0 & 0 & 0 & 0 & 6 & 0 & 0 & 0 & \mathrm{~d}=\text { T1-Potássio } \\ 0 & 3 & 0 & 0 & 43 & 0 & 1 & 2 & 3 & 15 & 0 & 0 & 0 & 0 & 22 & 11 & \mathrm{e} \\ 0 & 12 & 0 & 0 & 0 & 87 & 0 & 0 & 0 & 0 & 0 & 1 & 0 & 0 & 0 & 0 & \mathrm{f}=\mathrm{T} 2-\text { Cálcio } \\ 0 & 0 & 0 & 0 & 0 & 0 & 66 & 0 & 0 & 0 & 34 & 0 & 0 & 0 & 0 & 0 & \mathrm{~g}=\text { T2-Enxofre } \\ 0 & 5 & 16 & 2 & 1 & 0 & 2 & 40 & 10 & 1 & 0 & 4 & 8 & 7 & 0 & 4 & \mathrm{~h}=\text { T2-Magnésio } \\ 0 & 1 & 4 & 0 & 1 & 0 & 0 & 14 & 45 & 0 & 0 & 1 & 10 & 23 & 0 & 1 & \mathrm{i}=\text { T2-Nitrogênio } \\ 0 & 0 & 0 & 0 & 15 & 0 & 1 & 0 & 0 & 57 & 0 & 0 & 0 & 0 & 15 & 12 & \mathrm{j}=\text { T2-Potássio } \\ 0 & 1 & 3 & 0 & 0 & 0 & 0 & 1 & 1 & 0 & 94 & 0 & 0 & 0 & 0 & 0 & \mathrm{k}=\text { T3-Cálcio } \\ 2 & 0 & 0 & 0 & 0 & 28 & 0 & 0 & 0 & 0 & 0 & 68 & 0 & 0 & 0 & 2 & 1=\text { T3-Enxofre } \\ 0 & 8 & 11 & 8 & 1 & 0 & 0 & 5 & 9 & 0 & 0 & 0 & 50 & 8 & 0 & 0 & \mathrm{~m}=\text { T3-Magnésio } \\ 0 & 1 & 10 & 2 & 1 & 0 & 0 & 9 & 33 & 0 & 0 & 0 & 5 & 38 & 0 & 1 & \text { n }=\text { T3-Nitrogênio } \\ 0 & 0 & 0 & 0 & 33 & 0 & 0 & 0 & 0 & 23 & 0 & 0 & 0 & 0 & 22 & 22 & \text { o = T3-Potássio } \\ 0 & 2 & 0 & 0 & 19 & 3 & 0 & 8 & 3 & 11 & 5 & 0 & 1 & 0 & 16 & 32 & \text { p T T }\end{array}$

Tabela 7.37: Matriz de confusão para a coleta 1 com o método wavelets de Gabor e fractais 


\begin{tabular}{|c|c|c|c|c|c|c|c|c|c|c|c|c|c|c|c|c|}
\hline a & $\mathrm{b}$ & $\mathrm{c}$ & $\mathrm{d}$ & e & $\mathrm{f}$ & g & $\mathrm{h}$ & $\mathrm{i}$ & $\mathrm{j}$ & $\mathrm{k}$ & 1 & $\mathrm{~m}$ & $\mathrm{n}$ & o & $\mathrm{p}$ & \\
\hline 83 & 3 & 0 & 0 & 6 & 0 & 2 & 2 & 0 & 2 & 0 & 0 & 2 & 0 & 1 & 0 & $\mathrm{a}=\mathrm{T} 1$-Cálcio \\
\hline 0 & 83 & 0 & 0 & 0 & 1 & 3 & 4 & 0 & 0 & 0 & 0 & 8 & 0 & 0 & 1 & $\mathrm{~b}=\mathrm{T} 1$-Enxofre \\
\hline 1 & 0 & 96 & 0 & 0 & 0 & 2 & 0 & 0 & 0 & 0 & 0 & 0 & 0 & 0 & 1 & $\mathrm{c}=\mathrm{T} 1-$ Magnésio \\
\hline 0 & 3 & 0 & 82 & 0 & 4 & 5 & 4 & 0 & 0 & 2 & 0 & 0 & 0 & 0 & 0 & $\mathrm{~d}=\mathrm{T} 1$-Nitrogênio \\
\hline 0 & 2 & 0 & 1 & 64 & 0 & 1 & 0 & 0 & 21 & 0 & 0 & 2 & 0 & 9 & 0 & e = T1-Potássio \\
\hline 2 & 3 & 1 & 11 & 1 & 23 & 10 & 7 & 0 & 1 & 17 & 17 & 3 & 0 & 0 & 4 & $\mathrm{f}=\mathrm{T} 2$-Cálcio \\
\hline 1 & 1 & 0 & 11 & 0 & 11 & 45 & 3 & 0 & 0 & 17 & 7 & 2 & 0 & 0 & 2 & $g=T 2$-Enxofre \\
\hline 6 & 3 & 0 & 8 & 2 & 8 & 12 & 23 & 0 & 1 & 8 & 7 & 8 & 0 & 0 & 14 & $\mathrm{~h}=\mathrm{T} 2$-Magnésio \\
\hline 0 & 0 & 0 & 0 & 0 & 0 & 0 & 0 & 70 & 0 & 0 & 0 & 0 & 28 & 0 & 2 & $\mathrm{i}=\mathrm{T} 2$-Nitrogênio \\
\hline 1 & 2 & 0 & 0 & 27 & 0 & 1 & 0 & 0 & 45 & 0 & 0 & 0 & 0 & 24 & 0 & $\mathrm{j}$ = T2-Potássio \\
\hline 1 & 3 & 0 & 4 & 0 & 9 & 27 & 5 & 0 & 0 & 38 & 7 & 0 & 0 & 0 & 6 & $\mathrm{k}=$ T3-Cálcio \\
\hline 1 & 0 & 0 & 3 & 0 & 23 & 13 & 9 & 0 & 0 & 12 & 32 & 4 & 0 & 0 & 3 & $1=\mathrm{T} 3$-Enxofre \\
\hline 6 & 0 & 1 & 1 & 0 & 3 & 8 & 10 & 0 & 0 & 3 & 4 & 43 & 0 & 0 & 21 & $\mathrm{~m}=\mathrm{T} 3$-Magnésio \\
\hline 0 & 0 & 0 & 0 & 0 & 0 & 0 & 0 & 35 & 0 & 0 & 0 & 0 & 63 & 0 & 2 & $\mathrm{n}=\mathrm{T} 3$-Nitrogênio \\
\hline 0 & 2 & 0 & 0 & 16 & 0 & 0 & 1 & 0 & 34 & 0 & 1 & 0 & 0 & 46 & 0 & $\mathrm{o}=\mathrm{T} 3$-Potássio \\
\hline 5 & 0 & 0 & 2 & 0 & 5 & 4 & 16 & 7 & 0 & 1 & 6 & 23 & 6 & 0 & 25 & $\mathrm{p}=\mathrm{T} 4$ \\
\hline
\end{tabular}

Tabela 7.38: Matriz de confusão para a coleta 2 com o método wavelets de Gabor e fractais

$\begin{array}{ccccccccccccccccc}\mathrm{a} & \mathrm{b} & \mathrm{c} & \mathrm{d} & \mathrm{e} & \mathrm{f} & \mathrm{g} & \mathrm{h} & \mathrm{i} & \mathrm{j} & \mathrm{k} & 1 & \mathrm{~m} & \mathrm{n} & \mathrm{o} & \mathrm{p} & \mathrm{a}=\text { T1-Cálcio } \\ 69 & 2 & 1 & 3 & 0 & 0 & 3 & 13 & 0 & 0 & 1 & 5 & 0 & 1 & 0 & 2 & \mathrm{~b}=\text { T1-Enxofre } \\ 1 & 76 & 0 & 8 & 0 & 0 & 0 & 2 & 0 & 0 & 0 & 0 & 0 & 13 & 0 & 0 & \mathrm{c}=\text { T1-Magnésio } \\ 0 & 2 & 75 & 1 & 0 & 0 & 11 & 3 & 0 & 0 & 0 & 8 & 0 & 0 & 0 & 0 & \mathrm{c} \\ 7 & 0 & 0 & 91 & 0 & 0 & 1 & 0 & 0 & 0 & 0 & 0 & 0 & 1 & 0 & 0 & \mathrm{~d}=\text { T1-Nitrogênio } \\ 0 & 0 & 0 & 0 & 59 & 0 & 0 & 0 & 4 & 15 & 0 & 0 & 1 & 0 & 21 & 0 & \mathrm{e}=\mathrm{T} 1-\text { Potássio } \\ 0 & 7 & 15 & 6 & 0 & 38 & 0 & 4 & 0 & 0 & 0 & 30 & 0 & 0 & 0 & 0 & \mathrm{f}=\mathrm{T} 2-\text { Cálcio } \\ 0 & 0 & 1 & 0 & 0 & 0 & 42 & 0 & 3 & 0 & 47 & 0 & 2 & 3 & 0 & 2 & \mathrm{~g}=\text { T2-Enxofre } \\ 2 & 18 & 0 & 1 & 0 & 0 & 6 & 48 & 0 & 0 & 0 & 0 & 6 & 19 & 0 & 0 & \mathrm{~h}=\text { T2-Magnésio } \\ 0 & 0 & 0 & 0 & 2 & 1 & 0 & 0 & 82 & 1 & 5 & 0 & 5 & 0 & 0 & 4 & \mathrm{i}=\text { T2-Nitrogênio } \\ 0 & 0 & 0 & 0 & 10 & 0 & 0 & 0 & 6 & 70 & 0 & 0 & 3 & 0 & 10 & 1 & \mathrm{j}=\mathrm{T} 2 \text {-Potássio } \\ 0 & 22 & 18 & 3 & 0 & 1 & 26 & 1 & 0 & 0 & 29 & 0 & 0 & 0 & 0 & 0 & \mathrm{k}=\text { T3-Cálcio } \\ 1 & 0 & 0 & 0 & 0 & 32 & 0 & 0 & 9 & 0 & 0 & 54 & 1 & 2 & 0 & 1 & 1=\text { T3-Enxofre } \\ 1 & 4 & 0 & 0 & 2 & 5 & 3 & 29 & 12 & 11 & 4 & 0 & 14 & 6 & 5 & 4 & \mathrm{~m}=\text { T3-Magnésio } \\ 11 & 1 & 1 & 1 & 0 & 0 & 3 & 9 & 0 & 0 & 0 & 0 & 0 & 74 & 0 & 0 & \mathrm{n}=\text { T3-Nitrogênio } \\ 0 & 0 & 0 & 0 & 30 & 0 & 0 & 0 & 1 & 10 & 0 & 0 & 0 & 0 & 58 & 1 & \mathrm{o}=\text { T3-Potássio } \\ 4 & 6 & 0 & 2 & 7 & 2 & 1 & 21 & 22 & 8 & 2 & 0 & 5 & 15 & 3 & 2 & \mathrm{p}=\text { T4 }\end{array}$

Tabela 7.39: Matriz de confusão para a coleta 3 com o método Dimensão fractal volumétrica

A primeira conclusão obtida é que a textura em escala de cinza Possui menos informação relevante para a classificação que a informação de cor, os resultados para todas as coletas em comparação com as coletas dos experimentos de cor são menores. Observa-se também na matriz de confusão da coleta 1 o mesmo padrão observado nos experimentos de cor, as classes T3 são as mais difíceis de classificar com uma média de $54,4 \%$, as classes T1 são as mais fáceis de classificar com um margem mais reduzida que nos experimentos de cor, $70,6 \%$ de média de acerto. O resto de matrizes de confusão seguem um padrão de acertos similar ao das matrizes de confusão dos experimentos de cor. Uma conclusão importante dos experimentos de textura é que ainda as técnicas do estado da arte de classificação de textura não fornecem resultados aceitáveis o que indica 
a dificuldade de classificação das amostras e a grande similaridade entre deficiências de distintas classes desde o ponto de vista de mudança textural da superfície da folha.

\section{- Dimensão fractal volumétrica multiespectral}

Um dos métodos mais bem sucedidos em análise de texturas naturais coloridas é o método de dimensão fractal volumétrica multiespectral (Backes e Bruno, 2008), o método aproveita as propriedades fractais das superfícies naturais para extrair uma assinatura que reflete as relações entre os pixels dos canais de cor de uma imagem colorida. As tabelas 7.40, 7.41 e 7.42 mostram os resultados para este método com um acerto global máximo de $60.188 \%$ para a coleta 1 na base Médios4, $56.813 \%$ para a coleta 2 na base Pontas 2 e $58.438 \%$ para a coleta 3 na base Pontas4, os resultados indicam uma melhora significativa no acerto em comparação com o mesmo método para escala de cinza mas ainda os resultados são inaceitáveis para a resolução do problema. Foram testadas distintas configurações de raio de expansão obtendo um padrão de acerto similar ao método de escala de cinza. Os resultados das tabelas foram obtidos com um raio de expansão de 18, número similar ao obtido no método de escala de cinza (16) considerando um raio máximo de análise de 20. A desição de usar raios pequenos radica na pouca efetividade de raios maiores e o custo computacional elevado do calculo.

\begin{tabular}{cccccc}
\hline Base de Imagens & $\begin{array}{c}\text { Nro. de } \\
\text { Descritores }\end{array}$ & $\begin{array}{c}\text { Nro. de Imagens } \\
\text { Corretamente } \\
\text { Classificadas }\end{array}$ & $\begin{array}{c}\text { Probabilidade de } \\
\text { Acerto Global (\%) }\end{array}$ & $\begin{array}{c}\text { Kappa } \\
\text { Desvio padrão } \\
\text { do acerto (\%) }\end{array}$ & $\begin{array}{c}\text { Confiança } \\
\text { Acertos }\end{array}$ \\
\hline Bases2 & 334 & 840 & 52.500 & 0.493 & 0.148 \\
Bases4 & 334 & 963 & 60.188 & 0.575 & 12.464 \\
Médios2 & 334 & 920 & 57.500 & 0.547 & 0.098 \\
Médios4 & 334 & 963 & 511 & 0.575 & 0.074 \\
Pontas2 & 334 & 877 & 54.938 & 0.541 & 0.083 \\
Pontas4 & 334 & 2256 & 47.000 & 0.518 & 0.092 \\
Todo2 & 251 & 2064 & 43.000 & 0.422 & 0.112 \\
Todo4 & 251 & & 0.378 & 12.478 \\
\hline
\end{tabular}

Tabela 7.40: Sumário da classificação usando o método Dimensão fractal volumétrica multiespectral para a Coleta 1 usando SVM para classificar os dados.

- Dimensão fractal volumétrica multiespectral usando análise canônica 


\begin{tabular}{cccccc}
\hline Base de Imagens & $\begin{array}{c}\text { Nro. de } \\
\text { Descritores }\end{array}$ & $\begin{array}{c}\text { Nro. de Imagens } \\
\text { Corretamente } \\
\text { Classificadas }\end{array}$ & $\begin{array}{c}\text { Probabilidade de } \\
\text { Acerto Global (\%) }\end{array}$ & $\begin{array}{c}\text { Kappa } \\
\text { Cesvio padrão } \\
\text { do acerto (\%) } \\
\text { Acertos }\end{array}$ \\
\hline Bases2 & 334 & 867 & 54.188 & 0.511 & 0.089 \\
Bases4 & 334 & 727 & 55.438 & 0.418 & 0.127 \\
Médios2 & 334 & 835 & 43.188 & 0.490 & 0.098 \\
Médios4 & 334 & 691 & 56.813 & 0.394 & 0.119 \\
Pontas2 & 334 & 909 & 48.500 & 0.539 & 0.079 \\
Pontas4 & 334 & 776 & 43.188 & 0.451 & 12.472 \\
Todo2 & 251 & 2073 & 0.380 & 0.102 \\
Todo4 & 251 & 2052 & 42.750 & 0.376 & 12.467 \\
\hline
\end{tabular}

Tabela 7.41: Sumário da classificação usando o método Dimensão fractal volumétrica multiespectral para a Coleta 2 usando SVM para classificar os dados.

\begin{tabular}{cccccc}
\hline Base de Imagens & $\begin{array}{c}\text { Nro. de } \\
\text { Descritores }\end{array}$ & $\begin{array}{c}\text { Nro. de Imagens } \\
\text { Corretamente } \\
\text { Classificadas }\end{array}$ & $\begin{array}{c}\text { Probabilidade de } \\
\text { Acerto Global (\%) }\end{array}$ & $\begin{array}{c}\text { Kappa } \\
\text { Confiança } \\
\text { Acertos }\end{array}$ \\
\hline Bases2 & 334 & 941 & 58.813 & 0.561 & 0.065 \\
Bases4 & 334 & 855 & 52.438 & 0.503 & 0.076 \\
Médios2 & 334 & 836 & 48.125 & 0.491 & 0.098 \\
Médios4 & 334 & 770 & 57.625 & 0.447 & 0.100 \\
Pontas2 & 334 & 922 & 58.438 & 0.548 & 0.069 \\
Pontas4 & 334 & 935 & 44.271 & 0.557 & 0.067 \\
Todo2 & 251 & 2125 & 42.271 & 0.392 & 12.473 \\
Todo4 & 251 & 2029 & 0.370 & 12.455 \\
\hline
\end{tabular}

Tabela 7.42: Sumário da classificação usando o método Dimensão fractal volumétrica multiespectral para a Coleta 3 usando SVM para classificar os dados.

A análise canônica apresentada como parte do método de wavelets de Gabor com fractais é uma técnica ideal para decorrealacionar atributos de uma assinatura e reduzir dimensionalidade, neste método é usada a análise canônica para a redução de dimensionalidade das assinaturas geradas pelo método de dimensão fractal volumétrica multiespectral usando um número de variáveis que contenham o 99, 99\% da informação da assinatura, é definido 10 como número de descritores usado com sucesso em (Rossatto et al., 2011). O incremento na taxa de acerto global é significativo para algumas bases, as tabelas 7.43, 7.44 e 7.45 mostram o acerto para cada coleta, o melhor acerto para coleta 1 é de $60.938 \%$ na base Pontas2, para a coleta 2 o melhor acerto é de $58.188 \%$ na baseBases 2 e na coleta 3 o melhor acerto é de $55.438 \%$ resultando numa melhora para a coleta 1 e 2 com respeito ao método sem uso de análise canônica. Entretanto, percebe-se que o problema encontra-se além da capacidade do método de diferenciar as texturas até um ponto aceitável. 


\begin{tabular}{|c|c|c|c|c|c|c|}
\hline Base de Imagens & $\begin{array}{c}\text { Nro. de } \\
\text { Descritores }\end{array}$ & $\begin{array}{l}\text { Nro. de Imagens } \\
\text { Corretamente } \\
\text { Classificadas }\end{array}$ & $\begin{array}{l}\text { Probabilidade de } \\
\text { Acerto Global (\%) }\end{array}$ & Kappa & $\begin{array}{l}\text { Desvio padrão } \\
\text { do acerto (\%) }\end{array}$ & $\begin{array}{c}\text { Confiança } \\
\text { Acertos }\end{array}$ \\
\hline Bases2 & 9 & 890 & 55.625 & 0.527 & 0.217 & 12.493 \\
\hline Bases4 & 9 & 967 & 60.438 & 0.578 & 0.736 & 12.493 \\
\hline Médios2 & 9 & 849 & 53.063 & 0.499 & 0.432 & 12.487 \\
\hline Médios4 & 9 & 889 & 55.563 & 0.526 & 0.761 & 12.487 \\
\hline Pontas2 & 9 & 975 & 60.938 & 0.583 & 0.839 & 12.488 \\
\hline Pontas 4 & 9 & 831 & 51.938 & 0.487 & 0.538 & 12.487 \\
\hline Todo2 & 9 & 2451 & 51.063 & 0.466 & 0.542 & 16.680 \\
\hline Todo 4 & 9 & 2039 & 42.479 & 0.373 & 0.228 & 16.659 \\
\hline
\end{tabular}

Tabela 7.43: Sumário da classificação usando o método Dimensão fractal volumétrica multiespectral usando análise canônica para a Coleta 1 usando SVM para classificar os dados.

\begin{tabular}{|c|c|c|c|c|c|c|}
\hline Base de Imagens & $\begin{array}{c}\text { Nro. de } \\
\text { Descritores }\end{array}$ & $\begin{array}{l}\text { Nro. de Imagens } \\
\text { Corretamente } \\
\text { Classificadas }\end{array}$ & $\begin{array}{l}\text { Probabilidade de } \\
\text { Acerto Global (\%) }\end{array}$ & Kappa & $\begin{array}{l}\text { Desvio padrão } \\
\text { do acerto (\%) }\end{array}$ & $\begin{array}{c}\text { Confiança } \\
\text { Acertos }\end{array}$ \\
\hline Bases2 & 9 & 931 & 58.188 & 0.554 & 0.721 & 12.489 \\
\hline Bases4 & 9 & 702 & 43.875 & 0.401 & 0.233 & 12.492 \\
\hline Médios2 & 9 & 871 & 54.438 & 0.514 & 0.564 & 12.485 \\
\hline Médios4 & 9 & 710 & 44.375 & 0.407 & 0.191 & 12.475 \\
\hline Pontas2 & 9 & 857 & 53.563 & 0.505 & 0.560 & 12.480 \\
\hline Pontas4 & 9 & 757 & 47.313 & 0.438 & 0.243 & 12.471 \\
\hline Todo2 & 9 & 2089 & 43.521 & 0.384 & 0.171 & 16.666 \\
\hline Todo4 & 9 & 2058 & 42.875 & 0.377 & 0.382 & 16.662 \\
\hline
\end{tabular}

Tabela 7.44: Sumário da classificação usando o método Dimensão fractal volumétrica multiespectral usando análise canônica para a Coleta 2 usando SVM para classificar os dados.

\begin{tabular}{|c|c|c|c|c|c|c|}
\hline Base de Imagens & $\begin{array}{c}\text { Nro. de } \\
\text { Descritores }\end{array}$ & $\begin{array}{l}\text { Nro. de Imagens } \\
\text { Corretamente } \\
\text { Classificadas }\end{array}$ & $\begin{array}{l}\text { Probabilidade de } \\
\text { Acerto Global (\%) }\end{array}$ & Kappa & $\begin{array}{l}\text { Desvio padrão } \\
\text { do acerto (\%) }\end{array}$ & $\begin{array}{c}\text { Confiança } \\
\text { Acertos }\end{array}$ \\
\hline Bases2 & 9 & 866 & 54.125 & 0.511 & 0.628 & 12.480 \\
\hline Bases4 & 9 & 869 & 54.313 & 0.513 & 0.633 & 12.485 \\
\hline Médios2 & 9 & 852 & 53.250 & 0.501 & 0.598 & 12.479 \\
\hline Médios4 & 9 & 766 & 47.875 & 0.444 & 0.289 & 12.486 \\
\hline Pontas2 & 9 & 863 & 53.938 & 0.509 & 0.602 & 12.477 \\
\hline Pontas 4 & 9 & 887 & 55.438 & 0.525 & 0.591 & 12.486 \\
\hline Todo2 & 9 & 2013 & 41.938 & 0.367 & 0.240 & 16.667 \\
\hline Todo4 & 9 & 2075 & 43.229 & 0.381 & 0.196 & 16.651 \\
\hline
\end{tabular}

Tabela 7.45: Sumário da classificação usando o método Dimensão fractal volumétrica multiespectral usando análise canônica para a Coleta 3 usando SVM para classificar os dados.

- Wavelets de Gabor multiespectrais

Uma das técnicas mais promisorias na análise de texturas coloridas é as wavelets de Gabor multiespectrais, o uso deste método representa não unicamente uma fonte consistente de informação discriminante de textu- 
ras coloridas se não também o ponto de partida do método de wavelets de gabor multiespectral e fractais. Para determinar com maior exatitude a influencia das escalas e orientações foram geradas 12 experimentos com escalas variando de 2 ate 8 e orientações de 2 até 6 . o melhor resultado foi escolhido considerando 3 fatores importantes o número de descritores usados, o acerto máximo para cada coleta e a meia dos acertos de todas as outras bases de cada coleta. O experimento que obteve os melhores resultados foi usando 6 escalas e 4 orientações. As tabelas 7.46, $7.47 \mathrm{e}$ 7.48 mostram os resultados obtidos, para a coleta 1 o melhor acerto global obtido foi $72.750 \%$ na base Pontas2 para a coleta 2 o melhor resultado é $68.063 \%$ na base Bases2 e para a coleta 3 o melhor resultado foi $66.000 \%$ na base Todo2. Os resultados mostram um incremento significativo do acerto sendo os primeiro resultados que conseguem se aproximar a um nível aceitável de classificação entre as amostras. A Figura 7.18 mostra os resultados para todos os experimentos, observa-se que para os experimentos $4 x 2,4 x 4,4 x 6,6 x 2,6 x 4,6 x 6,8 x 2,8 x 4,8 x 6$ os resultados mantém-se quase constantes e para todos os experimentos quando o número de escalas e maior ao número de orientações os resultados são melhores.

\begin{tabular}{|c|c|c|c|c|c|c|}
\hline Base de Imagens & $\begin{array}{c}\text { Nro. de } \\
\text { Descritores }\end{array}$ & $\begin{array}{l}\text { Nro. de Imagens } \\
\text { Corretamente } \\
\text { Classificadas }\end{array}$ & $\begin{array}{l}\text { Probabilidade de } \\
\text { Acerto Global (\%) }\end{array}$ & Kappa & $\begin{array}{l}\text { Desvio padrão } \\
\text { do acerto (\%) }\end{array}$ & $\begin{array}{c}\text { Confiança } \\
\text { Acertos }\end{array}$ \\
\hline Bases2 & 72 & 1056 & 66.000 & 0.637 & 0.662 & 12.465 \\
\hline Bases4 & 72 & 1094 & 68.375 & 0.663 & 0.714 & 12.471 \\
\hline Médios2 & 72 & 1140 & 71.250 & 0.693 & 0.818 & 12.461 \\
\hline Médios4 & 72 & 1061 & 66.313 & 0.641 & 0.671 & 12.461 \\
\hline Pontas2 & 72 & 1164 & 72.750 & 0.709 & 0.838 & 12.467 \\
\hline Pontas4 & 72 & 1014 & 63.375 & 0.609 & 0.562 & 12.447 \\
\hline Todo2 & 72 & 3357 & 69.938 & 0.679 & 0.669 & 12.464 \\
\hline Todo4 & 72 & 2983 & 62.146 & 0.596 & 0.564 & 12.449 \\
\hline
\end{tabular}

Tabela 7.46: Sumário da classificação usando o wavelets de Gabor multiespectral para a Coleta 1 usando SVM para classificar os dados.

- Wavelets de Gabor multiespectral e fractais

O método faz uso da melhor combinação de wavelets de Gabor multiespectrais para aplicar análise fractal sob as imagens convoluidas. Nos experimentos anteriores determina-se que a melhor combinação de resultados é dada pelo experimento $6 \times 4,6$ escalas e 4 orientações, e o melhor raio de expansão para o método de dimensão fractal volumétrica multi- 


\begin{tabular}{|c|c|c|c|c|c|c|}
\hline Base de Imagens & $\begin{array}{c}\text { Nro. de } \\
\text { Descritores }\end{array}$ & $\begin{array}{l}\text { Nro. de Imagens } \\
\text { Corretamente } \\
\text { Classificadas }\end{array}$ & $\begin{array}{l}\text { Probabilidade de } \\
\text { Acerto Global (\%) }\end{array}$ & Kappa & $\begin{array}{c}\text { Desvio padrão } \\
\text { do acerto (\%) }\end{array}$ & $\begin{array}{c}\text { Confiança } \\
\text { Acertos }\end{array}$ \\
\hline Bases2 & 72 & 1089 & 68.063 & 0.659 & 0.762 & 12.459 \\
\hline Bases4 & 72 & 748 & 46.750 & 0.432 & 0.439 & 12.426 \\
\hline Médios2 & 72 & 1072 & 67.000 & 0.648 & 0.786 & 12.467 \\
\hline Médios4 & 72 & 749 & 46.813 & 0.433 & 0.444 & 12.413 \\
\hline Pontas2 & 72 & 961 & 60.063 & 0.574 & 0.639 & 12.453 \\
\hline Pontas4 & 72 & 802 & 50.125 & 0.468 & 0.490 & 12.421 \\
\hline Todo2 & 72 & 3122 & 65.042 & 0.627 & 0.798 & 12.480 \\
\hline Todo4 & 72 & 2609 & 54.354 & 0.513 & 0.561 & 12.431 \\
\hline
\end{tabular}

Tabela 7.47: Sumário da classificação usando o wavelets de Gabor multiespectral para a Coleta 2 usando SVM para classificar os dados.

\begin{tabular}{|c|c|c|c|c|c|c|}
\hline Base de Imagens & $\begin{array}{c}\text { Nro. de } \\
\text { Descritores }\end{array}$ & $\begin{array}{l}\text { Nro. de Imagens } \\
\text { Corretamente } \\
\text { Classificadas }\end{array}$ & $\begin{array}{l}\text { Probabilidade de } \\
\text { Acerto Global (\%) }\end{array}$ & Kappa & $\begin{array}{l}\text { Desvio padrão } \\
\text { do acerto (\%) }\end{array}$ & $\begin{array}{c}\text { Confiança } \\
\text { Acertos }\end{array}$ \\
\hline Bases2 & 72 & 1039 & 64.938 & 0.626 & 0.892 & 12.463 \\
\hline Bases4 & 72 & 1016 & 63.500 & 0.611 & 0.715 & 12.445 \\
\hline Médios2 & 72 & 1027 & 64.188 & 0.618 & 0.784 & 12.470 \\
\hline Médios4 & 72 & 863 & 53.938 & 0.509 & 0.582 & 12.437 \\
\hline Pontas2 & 72 & 981 & 61.313 & 0.587 & 0.699 & 12.451 \\
\hline Pontas4 & 72 & 954 & 59.625 & 0.569 & 0.720 & 12.439 \\
\hline Todo2 & 72 & 3168 & 66.000 & 0.637 & 0.642 & 12.463 \\
\hline Todo4 & 72 & 2980 & 62.083 & 0.596 & 0.841 & 12.452 \\
\hline
\end{tabular}

Tabela 7.48: Sumário da classificação usando o wavelets de Gabor multiespectral para a Coleta 3 usando SVM para classificar os dados.

espectral é de 18. Com esta concepção realiza-se os experimentos deste método. As tabelas 7.49, 7.50 e 7.51 mostram os resultados do método, o melhor acerto obtido na coleta 1 é de $81.125 \%$ na base Pontas2, para a coleta 2 o melhor resultado é $71.563 \%$ no método Pontas 2 e na coleta 3 o melhor resultado é $71.563 \%$ na base Bases 2 . a melhora dos resultados é clara obtendo um acerto de $81.125 \%$ para a coleta 1 sendo o melhor acerto obtido para a coleta 1 por todos os métodos testados. Da mesma maneira os resultados para a coleta 2 e coleta 3 são os melhores resultados obtidos para qualquer método.

A Figura 7.19 mostra o acerto global para diferentes quantidades de variáveis canônicas $(2,4,6,8,10)$.

A continuação são apresentadas as matrizes de confusão para os experimentos de textura colorida. As tabelas 7.52, 7.53 e 7.54 mostram os resultados para as 3 coletas, as tabelas representam os melhores resultados obtidos e pertencem ao método de wavelets de Gabor multiespectrais 


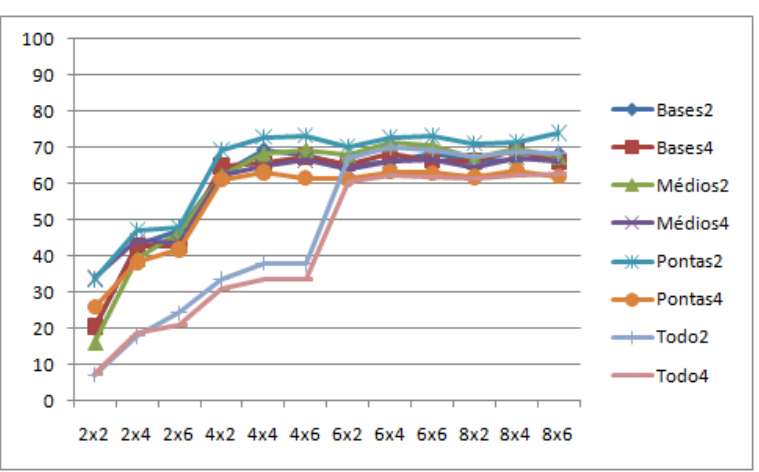

(a)

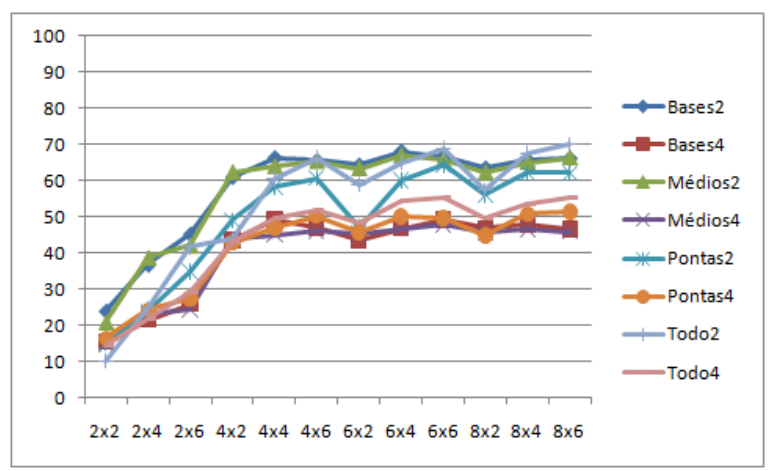

(b)

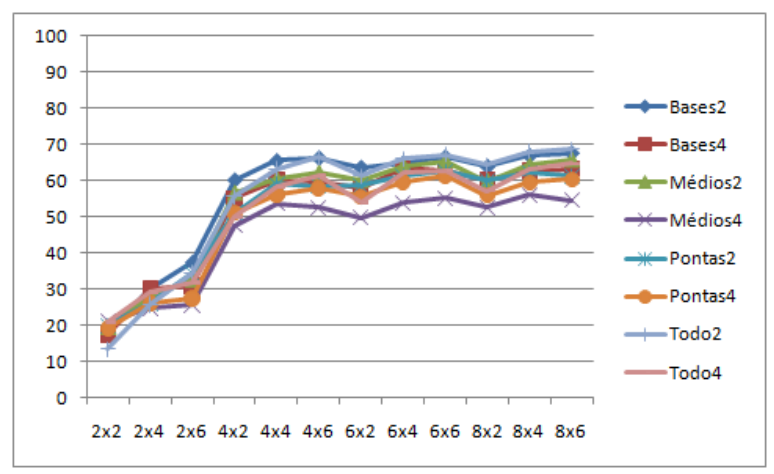

(c)

Figura 7.18: Acerto (eixo Y) para cada combinação de escalas e orientações (eixo X) (a) Acerto para coleta 1 usando SVM, (b) Acerto para coleta 2 usando SVM e (c) Acerto para coleta 3 usando SVM

\begin{tabular}{|c|c|c|c|c|c|c|}
\hline Base de Imagens & $\begin{array}{c}\text { Nro. de } \\
\text { Descritores }\end{array}$ & $\begin{array}{l}\text { Nro. de Imagens } \\
\text { Corretamente } \\
\text { Classificadas }\end{array}$ & $\begin{array}{l}\text { Probabilidade de } \\
\text { Acerto Global (\%) }\end{array}$ & Kappa & $\begin{array}{l}\text { Desvio padrão } \\
\text { do acerto (\%) }\end{array}$ & $\begin{array}{c}\text { Confiança } \\
\text { Acertos }\end{array}$ \\
\hline Bases2 & 720 & 1192 & 74.500 & 0.728 & 0.237 & 12.498 \\
\hline Bases4 & 720 & 1174 & 73.375 & 0.716 & 0.213 & 12.498 \\
\hline Médios2 & 720 & 1225 & 76.563 & 0.750 & 0.252 & 12.496 \\
\hline Médios4 & 720 & 1111 & 69.438 & 0.674 & 0.182 & 12.496 \\
\hline Pontas2 & 720 & 1298 & 81.125 & 0.779 & 0.308 & 12.499 \\
\hline Pontas4 & 720 & 1086 & 67.875 & 0.657 & 0.198 & 12.495 \\
\hline Todo2 & 720 & 3816 & 78.875 & 0.719 & 0.260 & 12.495 \\
\hline Todo4 & 720 & 3532 & 73.583 & 0.698 & 0.199 & 12.495 \\
\hline
\end{tabular}

Tabela 7.49: Sumário da classificação usando o método wavelets de Gabor multiespectral e fractais para a Coleta 1 usando SVM para classificar os dados.

e fractais.

Analisando os resultados finais observa-se que o menor acerto foi a classe T4, isto quer dizer que pode existir um alto número de falsos positivos 


\begin{tabular}{|c|c|c|c|c|c|c|}
\hline Base de Imagens & $\begin{array}{c}\text { Nro. de } \\
\text { Descritores }\end{array}$ & $\begin{array}{l}\text { Nro. de Imagens } \\
\text { Corretamente } \\
\text { Classificadas }\end{array}$ & $\begin{array}{c}\text { Probabilidade de } \\
\text { Acerto Global (\%) }\end{array}$ & Kappa & $\begin{array}{l}\text { Desvio padrão } \\
\text { do acerto (\%) }\end{array}$ & $\begin{array}{c}\text { Confiança } \\
\text { Acertos }\end{array}$ \\
\hline Bases2 & 720 & 1130 & 70.625 & 0.687 & 0.189 & 12.496 \\
\hline Bases4 & 720 & 828 & 51.750 & 0.485 & 0.063 & 12.497 \\
\hline Médios2 & 720 & 1111 & 69.438 & 0.674 & 0.196 & 12.499 \\
\hline Médios4 & 720 & 788 & 49.250 & 0.459 & 0.052 & 12.490 \\
\hline Pontas2 & 720 & 1145 & 71.563 & 0.697 & 0.207 & 12.497 \\
\hline Pontas4 & 720 & 894 & 55.875 & 0.529 & 0.092 & 12.490 \\
\hline Todo2 & 720 & 3282 & 68.375 & 0.670 & 0.160 & 12.495 \\
\hline Todo4 & 720 & 2709 & 56.438 & 0.544 & 0.099 & 12.495 \\
\hline
\end{tabular}

Tabela 7.50: Sumário da classificação usando o método wavelets de Gabor multiespectral e fractais para a Coleta 2 usando SVM para classificar os dados.

\begin{tabular}{cccccc}
\hline Base de Imagens & $\begin{array}{c}\text { Nro. de } \\
\text { Descritores }\end{array}$ & $\begin{array}{c}\text { Nro. de Imagens } \\
\text { Corretamente } \\
\text { Classificadas }\end{array}$ & $\begin{array}{c}\text { Probabilidade de } \\
\text { Acerto Global (\%) }\end{array}$ & Kappa & $\begin{array}{c}\text { Desvio padrão } \\
\text { do acerto (\%) }\end{array}$ \\
\hline Bases2 & 720 & 1145 & 71.563 & 0.697 & 0.179 \\
Coses4 & 720 & 1106 & 69.125 & 0.671 & 0.136 \\
Acertos
\end{tabular}

Tabela 7.51: Sumário da classificação usando o método wavelets de Gabor multiespectral e fractais para a Coleta 3 usando SVM para classificar os dados.

\begin{tabular}{|c|c|c|c|c|c|c|c|c|c|c|c|c|c|c|c|c|}
\hline $\mathrm{a}$ & b & c & $\mathrm{d}$ & $\mathrm{e}$ & $\mathrm{f}$ & $\mathrm{g}$ & $\mathrm{h}$ & i & $\mathrm{j}$ & $\mathrm{k}$ & 1 & $\mathrm{~m}$ & $\mathrm{n}$ & o & $\mathrm{p}$ & \\
\hline 88 & 0 & 5 & 0 & 0 & 0 & 0 & 2 & 1 & 0 & 0 & 0 & 4 & 0 & 0 & 0 & $\mathrm{~b}=\mathrm{T} 1$-Cálcio \\
\hline 0 & 100 & 0 & 0 & 0 & 0 & 0 & 0 & 0 & 0 & 0 & 0 & 0 & 0 & 0 & 0 & $\mathrm{a}=\mathrm{T} 1$-Enxofre \\
\hline 1 & 1 & 94 & 0 & 0 & 0 & 0 & 2 & 0 & 0 & 0 & 0 & 2 & 0 & 0 & 0 & $\mathrm{c}=\mathrm{T} 1-$ Magnésio \\
\hline 0 & 0 & 8 & 91 & 0 & 0 & 0 & 0 & 0 & 0 & 0 & 0 & 0 & 1 & 0 & 0 & $\mathrm{~d}=\mathrm{T} 1$-Nitrogênio \\
\hline 0 & 7 & 1 & 0 & 75 & 1 & 0 & 3 & 1 & 6 & 0 & 0 & 1 & 1 & 3 & 1 & $\mathrm{e}=\mathrm{T}$ 1-Potássio \\
\hline 0 & 1 & 0 & 0 & 0 & 96 & 0 & 0 & 3 & 0 & 0 & 0 & 0 & 0 & 0 & 0 & $\mathrm{~g}=\mathrm{T} 2$-Cálcio \\
\hline 0 & 0 & 0 & 0 & 0 & 0 & 83 & 0 & 0 & 0 & 17 & 0 & 0 & 0 & 0 & 0 & $\mathrm{f}=\mathrm{T} 2$-Enxofre \\
\hline 0 & 11 & 5 & 0 & 0 & 1 & 1 & 67 & 6 & 0 & 0 & 2 & 5 & 2 & 0 & 0 & $\mathrm{~h}=\mathrm{T} 2$-Magnésio \\
\hline 0 & 3 & 0 & 0 & 0 & 0 & 0 & 3 & 74 & 0 & 0 & 0 & 5 & 15 & 0 & 0 & $\mathrm{i}=\mathrm{T} 2$-Nitrogênio \\
\hline 0 & 0 & 1 & 0 & 3 & 0 & 0 & 0 & 0 & 70 & 0 & 0 & 0 & 0 & 19 & 7 & $\mathrm{j}=\mathrm{T} 2$-Potássio \\
\hline 0 & 1 & 1 & 0 & 0 & 0 & 1 & 1 & 0 & 0 & 96 & 0 & 0 & 0 & 0 & 0 & 1 = T3-Cálcio \\
\hline 0 & 0 & 0 & 0 & 0 & 13 & 0 & 0 & 0 & 0 & 0 & 87 & 0 & 0 & 0 & 0 & $\mathrm{k}=\mathrm{T} 3$-Enxofre \\
\hline 0 & 3 & 2 & 0 & 0 & 0 & 0 & 5 & 2 & 0 & 0 & 0 & 88 & 0 & 0 & 0 & $\mathrm{~m}=\mathrm{T} 3-$ Magnésio \\
\hline 0 & 1 & 0 & 0 & 0 & 0 & 0 & 1 & 9 & 0 & 0 & 0 & 1 & 88 & 0 & 0 & $\mathrm{n}=\mathrm{T} 3$-Nitrogênio \\
\hline 0 & 0 & 1 & 0 & 10 & 0 & 0 & 0 & 0 & 14 & 0 & 0 & 0 & 0 & 65 & 10 & $\mathrm{o}=\mathrm{T} 3$-Potássio \\
\hline 0 & 2 & 0 & 0 & 8 & 3 & 0 & 6 & 3 & 10 & 5 & 0 & 0 & 1 & 26 & 36 & $\mathrm{p}=\mathrm{T} 4$ \\
\hline
\end{tabular}

Tabela 7.52: Matriz de confusão para a coleta 1 com o método wavelets de Gabor multiespectrais e fractais

enquanto ao sistema determinar se existe alguma deficiência ou a folha analisada é normal. Isto é devido a que as folhas T4 da coletal possuem um padrão muito similar ao das deficiências. O melhor $81.125 \%$ resultado é obtido na coleta 1 indicando que é possível uma detecção de deficiências num estágio incial de crescimento. Ainda que os valores de acerto 


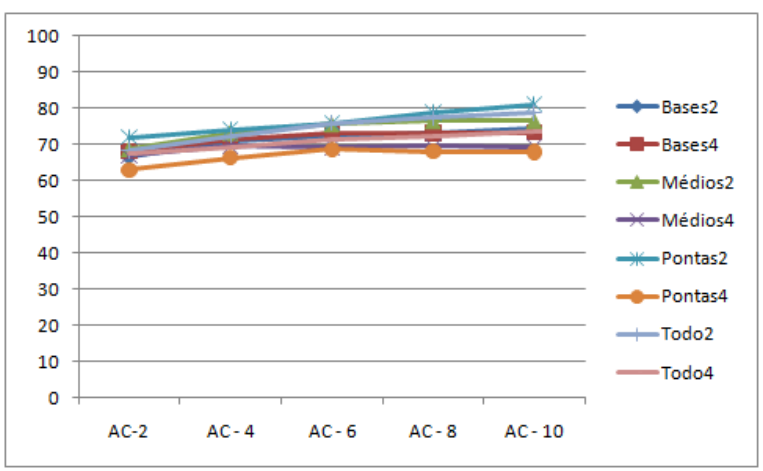

(a)

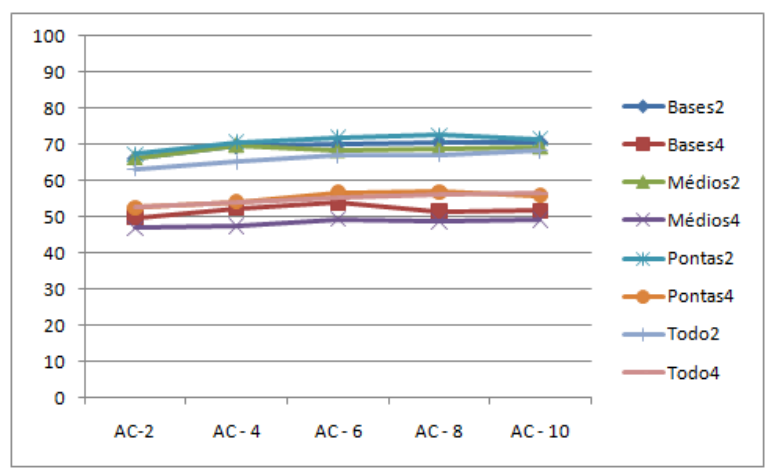

(b)

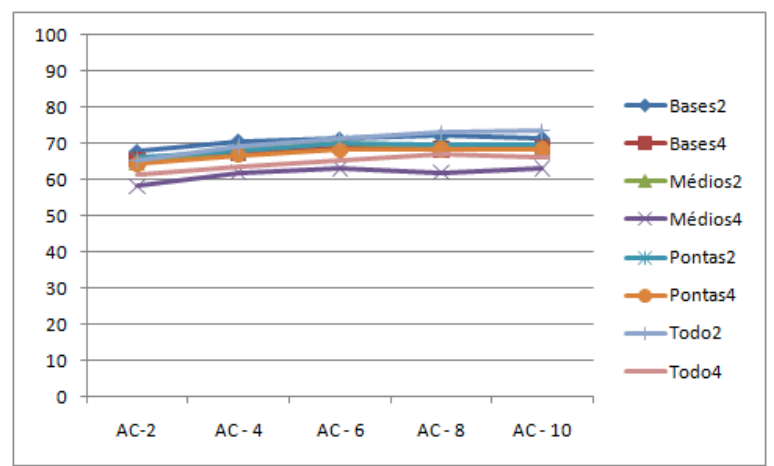

(c)

Figura 7.19: Acerto (eixo Y) para cada conjunto de variáveis canônicas (eixo X) (a) Acerto para coleta 1 usando SVM, (b) Acerto para coleta 2 usando SVM e (c) Acerto para coleta 3 usando SVM

$\begin{array}{cccc}\mathrm{a} & \mathrm{b} & \mathrm{c} & \mathrm{d} \\ 88 & 0 & 1 & 0 \\ 0 & 93 & 2 & 0 \\ 0 & 1 & 99 & 0 \\ 0 & 0 & 0 & 100 \\ 0 & 1 & 0 & 0 \\ 0 & 7 & 0 & 0 \\ 0 & 12 & 0 & 0 \\ 1 & 2 & 0 & 0 \\ 0 & 0 & 0 & 0 \\ 0 & 0 & 0 & 0 \\ 1 & 7 & 0 & 0 \\ 0 & 3 & 2 & 0 \\ 3 & 0 & 0 & 0 \\ 0 & 0 & 2 & 0 \\ 0 & 0 & 1 & 0 \\ 0 & 0 & 0 & 0\end{array}$

$\begin{array}{ccc} & \mathrm{f} & \mathrm{g} \\ 0 & 0 & 0 \\ 0 & 2 & 1 \\ 0 & 0 & 0 \\ 0 & 0 & 0 \\ 1 & 0 & 0 \\ 0 & 54 & 4 \\ 0 & 12 & 40 \\ 0 & 1 & 0 \\ 0 & 0 & 0 \\ 4 & 0 & 0 \\ 0 & 28 & 5 \\ 0 & 12 & 1 \\ 0 & 3 & 0 \\ 0 & 0 & 0 \\ 0 & 0 & 0 \\ 1 & 0 & 0\end{array}$

$\mathrm{h}$
10
1
0
0
1
1
0
70
0
0
0
0
15
0
0
18

$\mathrm{j}$
0
0
0
0
14
0
0
3
0
60
0
0
0
0
0
31
0

0

$\begin{array}{lc}\text { k } & 1 \\ 0 & 0 \\ 1 & 0 \\ 0 & 0 \\ 0 & 0 \\ 0 & 0 \\ 1 & 7 \\ 1 & 23 \\ 0 & 1 \\ 0 & 0 \\ 0 & 0 \\ 46 & 6 \\ 2 & 62 \\ 0 & 3 \\ 0 & 0 \\ 0 & 0 \\ 0 & 0\end{array}$

$\mathrm{m}$
1
0
0
0
0
6
2
21
0
0
7
3
76
0
0
0

$\begin{array}{ccc} & \text { o } & \text { p } \\ 0 & 0 & 0 \\ 0 & 0 & 0 \\ 0 & 0 & 0 \\ 0 & 0 & 0 \\ 0 & 3 & 0 \\ 0 & 0 & 0 \\ 0 & 0 & 0 \\ 0 & 0 & 1 \\ 6 & 0 & 3 \\ & 35 & 0 \\ 0 & 0 & 0 \\ 0 & 0 & 0 \\ 0 & 0 & 0 \\ 4 & 0 & 11 \\ 0 & 68 & 0 \\ 16 & 0 & 53\end{array}$

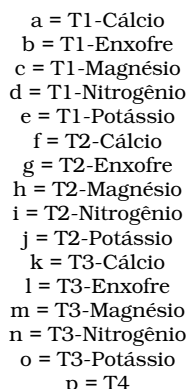

Tabela 7.53: Matriz de confusão para a coleta 2 com o método wavelets de Gabor multiespectrais e fractais

global mostram-se baixos para determinar com certeza que o sistema consegue identificar com sucesso as deficiências observa-se um dado cu- 
Tabela 7.54: Matriz de confusão para a coleta 3 com o método wavelets de Gabor multiespectrais e fractais

rioso nas matrizes de confusão, uma porção significativa das imagens incorretamente classificadas foram classificadas como outro nível de deficiência do mesmo nutriente. Por exemplo, a classe com o maior erro da coleta 1 é T3-Potássio, mas observa-se que a maior porção das imagens incorretamente classificadas desta classe (14) foram classificadas como deficiência T2-Potássio, mais ainda a segunda maior quantidade de imagens incorretamente classificadas desta classe (10) foi classificada como T1-Potássio. Este padrão de erro de classificação repete-se para quase todas as classes de todas as coletas. Lembrando que os níveis de deficiência T1,T2 e T3 foram criados para obter distintos níveis de resposta da deficiência. Os resultados indicam que existe uma forte correlação entre os distintos níveis de cada nutriente fortalecendo a conclusão que realmente existe uma mudança na superfície da folha que pode ser facilmente relacionada a um conjunto de niveis de deficiência de um nutriente. Esta conclusão nos leva a pensar que o sucesso do sistema vá além dos resultados globais para cada classe. Pode-se criar uma correlação entre os níveis de deficiência dos nutrientes para obter resultados muito mais significativos. Uma outra conclusão importante observada nos experimentos de cor e textura em escala de cinza é que as classes T1 são as mais fáceis de classificar para todas as coletas. 


\subsubsection{Sintese dos resultados}

A partir dos dados apresentados na experimentação podem ser concluídos alguns pontos importantes a respeito dos descritores usados.

- O uso de cor e textura em escala de cinza por separado não fornece resultados adequados para a identificação das deficiências, só nas técnicas de textura colorida que os melhores resultados são obtidos.

- As classes T1 dos experimentos mostram-se como as mais fáceis de classificar sendo as classes T3 as mas dificultosas, isto devido à resposta biológica das plantas ao ter um valor de nutriente perto do normal.

- Os resultados dos experimentos com textura colorida indicam que é possível uma correta identificação de deficiências nutricionais num estágio inicial de crescimento com um acerto global máximo de $81.125 \%$.

- Analisando as matrizes de confusão pode-se observar que a maioria das amostras incorretamente classificadas foram colocadas num outro nível de deficiência do mesmo nutriente, isto indica que existe uma forte correlação entre as amostras de distintos níveis de deficiência para cada nutriente.

- As coletas 2 e 3 foram as mais dificeis de classificar com um acerto global máximo de $71.563 \%$ para a coleta 2 e $71.563 \%$ mas mantendo o padrão de erro mencionado no ítem anterior.

- Um dos pontos mais resaltantes para quase os experimentos e a importância de cada base testada, sendo que a base de Pontas2 é a melhor base que pode ser usada na coleta 1, as bases Bases2 e Pontas 2 mostram resultados similares para a análise das amostras da coleta 2 , finalmente a base Bases2 é a melhor para imagens da coleta 3. Isto indica que para amostras desconhecidas que esperam uma predição de deficiência deve tomar-se em conta a coleta da imagem (dado conhecido antes do processamento da amostra) para saber qual parte da folha é mais importante para cada coleta. 
Em resumo verifica-se que é possível uma detecção de deficiências nutricionais num estágio inicial de crescimento mantendo resultados aceitáveis para o resto de estágios. 



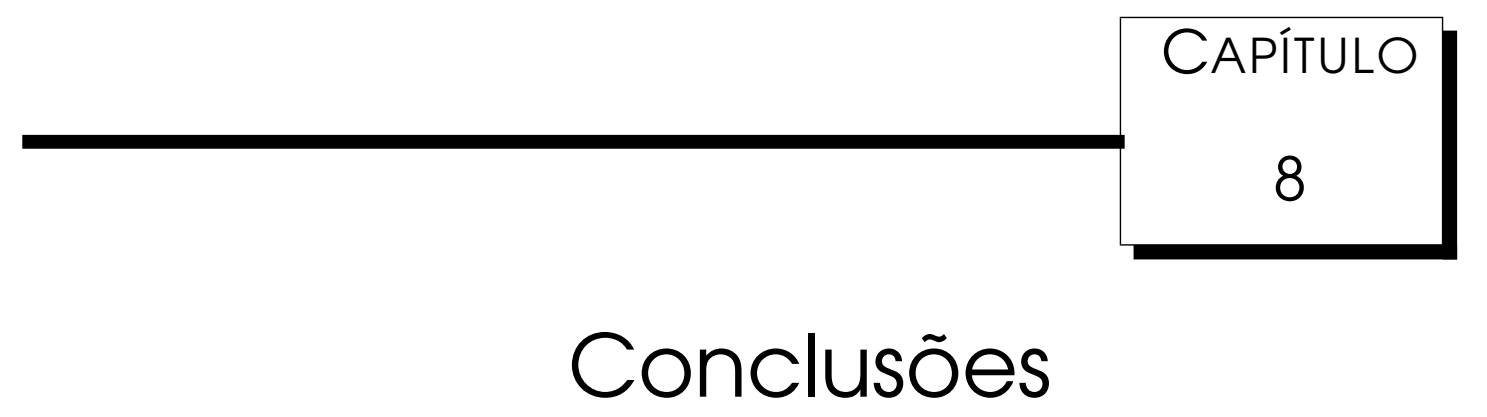

A identificação de deficiências nutricionais é uma importante e difícil tarefa, principalmente devido à grande variedade de sintomas que as plantas podem apresentar frente a uma deficiência e a variação que estes sintomas podem ter devido ao nível de deficiência que a planta apresenta. O processo de analise visual para a determinação da deficiência por um profissional na área exige muito esforço e carrega um erro introduzido por mistura de deficiências, distintos níveis de deficiência e a limitação de deficiências que um observador humano poderia identificar. Além destes problemas, a grande necessidade de identificar deficiências num estagio de crescimento onde ainda possam ser tomadas medidas corretivas é uma necessidade na indústria. Até antes do trabalho desenvolvido, não existiam métodos para obter uma predição de deficiência imediata devido a que os analises químicos são demorados e tem um custo elevado.

Neste contexto, esta pesquisa apresentou métodos computacionais válidos para análise de deficiências nutricionais em especial análise de textura colorida podendo identificar deficiências nutricionais num estagio inicial de crescimento das plantas. Este trabalho apresentou contribuições na área de visão computacional e em agricultura. Do ponto de vista tecnológico gerou uma patente nacional registrada pelos pesquisadores deste projeto. Esta pesquisa 
tem potencialidade para promover benefícios econômicos para a agricultura e incrementar a produção de grãos nas culturas no Brasil. O levantamento realizado da literatura em patentes sinalizou que a abordagem realizada neste trabalho de mestrado foi inédita.

Analisando os resultados pode ser concluído que tanto a informação de cor como de textura é necessária para alcançar melhores resultados frente ao uso destes atributos separadamente. Cabe ressaltar que os métodos propostos neste mestrado obtiveram os melhores resultados quando comparados com outras técnicas do estado da arte de análise de textura. Estes algoritmos caracterizam uma importante contribuição metodológica do mestrado. Além de serem mais adequadas à aplicação desenvolvidas neste trabalho, os métodos apresentados nas Seções 3.5.7, 7.2 podem ser extendidos com sucesso para diversas aplicações e problemas relacionados a análise de textura e textura cromática.

Guanto aos métodos de reconhecimento de padrões utilizados pode-se observar que:

- Para as técnicas cromáticas, pela sua simplicidade e natureza dos seus descritores, que a técnica de K-vizinhos mais próximos é a mais adequada para obter os melhores resultados;

- Para a análise de textura e textura colorida a utilização de SVM foi a mais adequada. O uso de métodos mais sofisticados de aprendizado de máquina permite ao sistema ter uma flexibilidade na identificação de novas amostras, treinadas com um conjunto significativo de imagens. As amostras desconhecidas podem ter variações em algumas características apresentadas e ainda serem identificadas pelo sistema. Este foi o fator principal para a escolha de métodos de aprendizado de máquina para a resolução do problema.

O desenvolvimento do sistema envolveu pesquisa biológica, visão computacional, aprendizado de maquina, processamento de sinais entre outras. As folhas foram submetidas a diversas técnicas de processamento de imagens desde o processo de aquisição, segmentação, reorientação, seleção e classificação o que torna este trabalho diversificado e robusto favorecendo o desenvolvimento de um sistema de visão computacional funcional e bem sucedido. 


\subsubsection{Principais contribuições}

Este trabalho de mestrado originou artigos apresentados em congressos e um pedido de depósito de patente. Entre os benefícios diretos derivados deste trabalho encontram-se a contribuição a área de extração de características de imagens e a contribuição na melhoria da produtividade e redução de custos da agricultura no Brasil.

As principais contribuições alcançadas ao longo do desenvolvimento do projeto são:

- Foi desenvolvido um sistema de detecção de deficiências nutricionais, implementado desde a aquisição de imagens até a classificação. A metodologia obteve ótimos resultados mostrando-se eficaz para a detecção de distintos níveis de deficiências nutricionais para os macronutrientes do milho.

- Desenvolvimento do método de wavelets de Gabor e fractais para análise de textura em escala de cinza. O método mostrou-se eficaz na extração de características de textura e na adequada diferenciação superando todos os métodos de extração de características testados, entre eles alguns métodos tradicionais da literatura e métodos do estado da arte.

- Desenvolvimento do método de wavelets de Gabor multiespectral e fractais para analise de textura colorida. O método superou outros métodos encontrados na literatura, obtendo melhoras de até $10 \%$ na taxa de acerto global de classificação para algumas bases.

- Identificação de mudanças de padrões de texturas na superfície das folhas. Foi observado que é única para cada tipo de deficiência e varia de acordo com o nível da deficiência, estabelecendo fundações teóricas para identificação de deficiências nutricionais baseado unicamente na mudança da textura foliar.

- Identificação de deficiências nutricionais num estagio inicial de crescimento das plantas permitindo medidas corretivas de adubação antes da produtividade da cultura ser comprometida. 


\subsubsection{Trabalhos Futuros}

Espera-se que em base ao protótipo desenvolvido possa-se gerar um sistema que seja capaz de gerar resultados com imagens de campo acrescentando uma maior quantidade de nutrientes. Outra possibilidade não estudada neste projeto é o uso de deficiências simultâneas de nutrientes o que poderia ser o próximo passo desta pesquisa, a mistura de deficiências pode gerar sintomas novos e não estudados.

Deve-se estudar outros sintomas que poderiam fornecer informação importante da deficiência na planta (mudanças no tamanho da folha, do talho, mudança na forma e tamanho das raízes, etc).

Um outro aspecto importante para contribuir na melhora de resultados e a massificação do uso do sistema, seria o estudo de outras possibilidades de aquisição de imagens (câmeras, sensores, etc) para reduzir o trabalho que implica escanear folhas separadamente. 


\section{Referências Bibliográficas}

Ahonen, T., Hadid, A., e Pietikainen, M. (2004). Face recognition with local binary patterns. Computer Vision - ECCV 2004, páginas 469-481. Citado na página 41.

Ali, A., Karmakar, G., e Dooley, L. (2004). Fuzzy image segmentation using suppressed fuzzy c-means clustering. Int. J. Advanced Networking and Applications. Citado na página 19.

Amaral Filho, J. P. R. d., Fornasieri Filho, D., Farinelli, R., e Barbosa, J. C. (2005). Espaçamento, densidade populacional e adubação nitrogenada na cultura do milho. Revista Brasileira de Ciência do Solo, 29:467 - 473. Citado na página 6.

Argenta, G., Silva, P. R. F. d., Mielniczuk, J. A., e Bortolini, C. G. (2002). Parâmetros de planta como indicadores do nível de nitrogênio na cultura do milho. Pesquisa Agropecuária Brasileira, 37:519 - 527. Citado na página 6.

Argenti, F., Alparone, L., e Benelli, G. (1990). Fast algorithm for texture analysis using co-occurrence matrices. IEEE Proc Part F: Radar Signal Proc, (8):137-443. Citado na página 61.

Backes, A. R. (2006). Implementação e comparação de métodos de estimativa de dimensão fractal e sua aplicação à análise e processamento de imagens. Citado nas páginas xi e 33. 
Backes, A. R. e Bruno, O. M. (2008). Fractal and multi-scale fractal dimension analysis: A comparative study of bouligand-minkowski method. INFOCOMP Journal of Computer Science, 7(2):74-83. Citado nas páginas xii, 34, 35, 42, e 119 .

Backes, A. R., D, C., e Bruno, O. M. (2009). Plant leaf identification based on volumetric fractal dimension. International Journal of Pattern Recognition and Artificial Intelligence, 23:1145-1160. Citado nas páginas 36, 37, 65, 68, e 109.

Bandzi, P., O. M. P. J. (2007). New statistics for texture classification based on gabor filters, intl. radioengineering j. IEEE Transactions on Image Processing, 16:133-137. Citado nas páginas 32 e 64.

BATAGLIA, O. C. e. a. (1983). Método de análises química de plantas. Campinas: Instituto Agronômico,, página 48. Citado na página 75.

Casanova, D. (2008). Identificação de espécies vegetais através da análise de textura foliar. Dissertação de mestrado - Biblioteca Digital de Teses e Dissertações da USP. Citado nas páginas 15, 16, 17, 55, 56, e 106.

Chen, C. H., Pau, L. F., e Wang, P. S. P. (1998). The Handbook of Pattern Recognition and Computer Vision (2nd Edition). World Scientific Publishing Co. Citado na página 26.

Clausi, D. e Deng, H. (2005). Fusion of gabor filter and co-occurrence probability features for texture recognition. IEEE Transactions on Image Processing, 14:925-936. Citado nas páginas 61 e 106.

Coelho, A. M. e Alves, V. M. C. (2004). Adubação fosfatada na cultura do milho,. Fósforo na agricultura brasileira, Potafos, páginas 243-283. Citado na página 6.

Coelho, A. M.; França, G. E. (1995). Seja o doutor do seu milho: nutrição e adubação. Piracicaba: POTAFOS, (2):1-9. Citado nas páginas 8, 9, e 10.

Cohen, A. J. (1960). coeficient agreement for nominal classes. Educational and Phsycological Measurement, 20:37-46. Citado na página 83. 
Conab (2010). Acompanhamento da safra brasileira: grãos, quarto levantamento, janeiro 2010. Companhia Nacional de Abastecimento, página 39. Citado na página 5.

Costa, L. d. F. D. e Cesar, Jr., R. M. (2000). Shape Analysis and Classification: Theory and Practice. CRC Press, Inc., Boca Raton, FL, USA. Citado na página 35.

Da Silva, F. d. F. (2011). Sistema de visão artificial para a identificação da nutrição de milho submetido a níveis de cálcio, magnésio e enxofre. Dissertação de mestrado - Biblioteca Digital de Teses e Dissertações da USP. Citado nas páginas $6,10,11,12,72,74$, e 75 .

Daugman, J. (1980). Two-dimensional spectral analysis of cortical receptive field profiles. Vision Research, 20:847-856. Citado na página 30.

Daugman, J. (1985). Uncertainty relation for resolution in space, spatial frequency and orientation optimised by two-dimensional visual cortical filters. Journal of the Optical Society of America, (2):1160-1169. Citado na página 27.

Duda, R. O., H. P. (2000). Pattern classification. página 654. Citado na página 85.

Emprapa (2006). Cultivo do milho: Economia da produção. Empresa Brasileira de Pesquisa Agropecuária - Milho e sorgo. Citado na página 6.

Fabbri, R., Luciano, Torelli, J. C., e Bruno, O. M. (2008). 2d euclidean distance transform algorithms: A comparative survey. ACM Comput. Surv., 40(1):144. Citado na página 34 .

FANCELLI, A. (1986). Alimentícias: guia para aula, estudos e discussão. página 131. Citado na página 76 .

Gabor, D. (1946). Theory of communication. Proceedings of the Institute of Electrical Engineers, 26(93):429-457. Citado na página 30.

Gonzalez, R. C. e Woods, R. E. (2006). Digital Image Processing (3rd Edition). Prentice-Hall, Inc., Upper Saddle River, NJ, USA. Citado na página 18. 
Gonzalez, R. C., Woods, R. E., e Eddins, S. L. (2003). Digital Image Processing Using MATLAB. Prentice-Hall, Inc., Upper Saddle River, NJ, USA. Citado na página 13.

Grigorescu, S. E., Petkov, N., e Kruizinga, P. (2002). Comparison of texture features based on gabor filters. IEEE Transactions on Image processing, 11(10):1160-1167. Citado na página 32.

Guanghui, T. e Changying, L. (2003). Development of non-contact measurement on plant growth in greenhouses using machine vision. ASABE Annual Meeting. Citado na página 15.

Hai-peng, Y., Yi-xing, L., e Zhen-bo, L. (2005). Auto detection of wood texture orientation by radon transform. Journal of Forestry Research, 16:1-4. 10.1007/BF02856843. Citado nas páginas 53 e 54.

Haralick, R. M. (1979). Statistical and structural approaches to texture. Proceedings of the IEEE, 5(67):786-804. Citado nas páginas 27, 28, e 61.

Hu, M. (1962). Visual pattern recognition by moment invariants. páginas 179-187. Citado nas páginas 23 e 60.

Laine, A. e Fan, J. (1993). Texture classification by wavelet packet signatures. IEEE Trans. Pattern Analysis and Machine Intelligence, 11(15):1186-1191. Citado na página 27.

Lei, Z., L. S. H. R. P. M. L. S. (2008). Gabor volume based local binary pattern for face representation and recognition. 8th IEEE Intl. Conference on Automatic Face and Gesture Recognition, páginas 1-6. Citado na página 32.

Malavolta, E. (2006). Manual de nutrição de plantas. São Paulo: Agronômica Ceres, página 638. Citado nas páginas 1, 8, 9, e 11 .

Mallat, S. (1989). Multifrequency channel decomposition of images and wavelet models. IEEE Trans. Acoustic, Speech and Signal Processing, 12(37):2091-2110. Citado na página 27.

Manjunath, B. S. e Ma, W. Y. (1996). Texture features for browsing and retrieval of image data. IEEE Trans. Pattern Anal. Mach. Intell., 18(8):837-842. Citado nas páginas 30 e 31 . 
Materka, A. e Strzelecki, M. (1998). Texture analysis methods - a review. Technical University of Lodz - Institute of Electronics. Citado nas páginas 28 e 61 .

McCarthy, C., Hancock, N., e Raine, S. R. (2008). On-the-go machine vision sensing of cotton plant geometric parameters: first results. in: Billingsley, john and bradbeer, robin, (eds.) mechatronics and machine vision in practice: first results. Billingsley, John and Bradbeer, Robin, (eds.) Mechatronics and machine vision in practice. Citado na página 15.

Mindru, F., Tuytelaars, T., Gool, L. V., e Moons, T. (2004). Moment invariants for recognition under changing viewpoint and illumination. Comput. Vis. Imag Underst, 94:3-27. Citado nas páginas 24 e 60.

Mosaic (2010). Deficiencias nutricionais em plantas de milho. Microessentials knowledge database. Citado nas páginas 9, 10, e 12.

Muneeswaran, k., Ganesan, 1., Arumugam, s., e harinarayan, p. (2005). A novel approach combining gabor wavelet and moments for texture segmentation. Intl. J. of Wavelets, Multiresolution and Information Processing, 3(4):559-572. Citado na página 32.

Niblack, W. (1985). An introduction to digital image processing. Strandberg Publishing Company, Birkeroed, Denmark, Denmark. Citado na página 13.

Nogueira-Júnior, S., Nogueira, E. A., e Tsunechiro, A. (1987). Considerações sobre a agroindústria do milho. São Paulo: Instituto de Economia Agrícola, página 18. Citado nas páginas 1 e 5.

Ojala, T., Pietikäinen, M., e Mäenpää, T. (2002). Multiresolution gray-scale and rotation invariant texture classification with local binary patterns. Pattern Analysis and Machine Intelligence, 7(24):971-987. Citado nas páginas 40 e 67.

Padmavathi, G., Subashini, P., e Sumi, A. (2010). Empirical evaluation of suitable segmentation algorithms for ir images. IJCSI International Journal of Computer Science Issues, 7(2):4. Citado nas páginas 18, 19, e 50. 
Paschos, G. (2000). Fast color texture recognition using chromaticity moments. Pattern Recogn. Lett., 21(8):837-841. Citado nas páginas xi, 24, 26, e 60 .

Pazoti, M. (2005). Citrusvis - um sistema de visão computacional para a identificação do fungo guignardia citricarpa, causador da mancha preta em citros. Dissertação de mestrado - Biblioteca Digital de Teses e Dissertações da USP. Citado na página 17.

Plotze, R. d. O. (2004). Identificação de espécies vegetais através da análise da forma interna de órgãos foliares. Citado na página 15.

Prado, R. (2008). Manual de nutrição de plantas forrageiras. FUNEP, página 500. Citado na página 7 .

Ramos, M. J. M., Monnerat, P. H., Carvalho, A. J. C. d., Pinto, J. L. d. A., e Silva, J. A. d. (2009). Sintomas visuais de deficiência de macronutrientes e de boro em abacaxizeiro 'imperial'. Revista Brasileira de Fruticultura, 31:252 - 256. Citado na página 7.

Rosenfeld, A. e Weszka, J. (1980). Picture recognition. Digital Pattern Recognition, páginas 135-166. Citado na página 27.

Rossatto, D., Casanova, D., Kolb, R., e Bruno, O. (2011). Fractal analysis of leaf-texture properties as a tool for taxonomic and identification purposes: a case study with species from neotropical melastomataceae (miconieae tribe). Plant Systematics and Evolution, 291:103-116. Citado nas páginas 45, 86, e 120.

Runtz, K. (1991). Electronic recognition of plant species for machine vision sprayer control systems. WESCANEX 91 IEEE Western Canada Conference on Computer, Power and Communications Systems in a Rural Environment. Citado na página 15.

Sá Junior, J. J. d. M. (2008). Identificação de espécies vegetais por meio de análise de imagens microscópicas de folhas. Citado na página 15.

Sawyer, J. (2004). Nutrient deficiencies and application injuries in field crops. IPM - Iowa state university, (42). Citado na página 11. 
Sharma, N., Rawat, P., e Singh, J. (2001). Efficient cbir using color histogram processing. Signal and Image Processing : An International Journal(SIPIJ), 2(1). Citado na página 21.

Siggelko, S. (2002). Feature histograms for content-based image retrieval. Ph.D. thesis, University of Freiburg, Institute for Computer Science, Freiburg, Germany. Citado na página 21.

Stehling, R. O., Nascimento, M. A., e Falcão, A. X. (2002). A compact and efficient image retrieval approach based on border/interior pixel classification. páginas 102-109. Citado nas páginas xi, 22, 23, e 59.

Timmermans, A. (1998). Computer vision system for on-line sorting of pot plants based on learning techniques. Acta Hort ISHS, (421). Citado na página 15.

Tou, J., Tay, Y., e Lau, P. (2007). Gabor filters and grey-level cooccurrence matrices in texture classification. MMU International Symposium on Information and Communications Technologies,. Citado na página 64.

Tricot, C. (1995). Curves and fractal dimension. Citado na página 33.

Weszka, J. S. e Rosenfeld, A. (1976). A comparative study of texture measures for terrain classification. IEE Trans. System, Man and Cybernetics, 6:269285. Citado na página 27.

Wu, J., Kankanhalli, M., Lim, J., e Hong, D. (2002). Color feature extraction. 9:49-67. Citado na página 20.

Wu, J., Wang, D., C.J. Rosen, C., e Bauer, M. (2007). Comparison of petiole nitrate concentrations, spad chlorophyll readings, and quickbird satellite imagery in detecting nitrogen status of potato canopies. Field Crops Research, 101(1):96-103. Citado na página 6.

Z. Guo, L. Z. e Zhang, D. (2010). Rotation invariant texture classification using lbp variance (lbpv) with global matching. Pattern Recognition, 43:706-719. Citado na página 67. 
Zhang, W., Shan, S., Gao, W., Chen, X., e Zhang, H. (2005). Local gabor binary pattern histogram sequence (lgbphs): A novel non-statistical model for face representation and recognition. Tenth IEEE ICCV, 1(10):786-791. Citado nas páginas 32 e 64.

Zhao, G. e Pietikainen, M. (2007). Dynamic texture recognition using local binary patterns with an application to facial expressions. IEEE Trans. Pattern Anal. Mach. Intell., 29(6):915-928. Citado na página 41.

Zuniga, A. G. e Bruno, O. M. (2010). Enhancing gabor wavelets using volumetric fractal dimension. In Proceedings of the 15th Iberoamerican congress conference on Progress in pattern recognition, image analysis, computer vision, and applications, CIARP'10, páginas 362-369, Berlin, Heidelberg. Springer-Verlag. Citado nas páginas xi, 32, 38, 43, 110, e 112. 